\title{
PóS-GRADUAÇÃO EM SAÚdE PÚBLICA: ANÁLISE DE DISSERTAÇÕES DE MESTRADO E TESES DE DOUTORADO
}

(1990-1994)

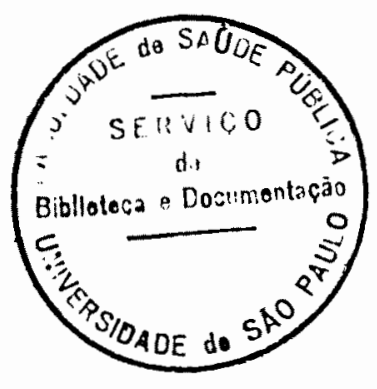

\section{DAISY PIRES NORONHA}

TESE DE DOUTORADO APRESENTADA À FACULDADE dE SAÚde PÚblica da UNIVERSIDAdE dE SÃo PAULO PARA OBTENÇÃO DO GRAU DE DOUTOR.

ORIENTADOR: Profa. MARIA STELLA FERREIRA LEVY

SĀO PAULO

1996 
"Quem quer fazer uma tese deve fazer uma tese que esteja à altura de fazer"

\section{U.Eco}


A meus pais (em memória) e irmãos,

por tudo que representam em minha vida

A Maria Dilma de Oliveira Gonçalves,

Maria Antonieta Ferraz (em memória),

Maria Teresinha Dias de Andrade,

pelo muito que representam em minha profissão.

\section{AGRADECIMENTOS}

Chegar ao final deste trabalho só foi possivel graças ao incentivo e apoio recebidos de várias pessoas que, acreditando em mim, ajudaram-se, de uma ou de outra forma, a realizar uma travessia como esta. São pessoas especiais que não preciso indicar seus nomes pois elas sabem quem são. 
NORONHA, Daisy Pires. Pós-graduação em saúde pública: análise de dissertações de Mestrado e teses de Doutorado (1990-1994). São Paulo, 1996. /Tese de Doutorado - Faculdade de Saúde Pública da Universidade de São Paulo/

\section{RESUMO}

Foi realizada uma análise descritiva das dissertações de mestrado e teses de doutorado defendidas nos cursos de pós-graduação em saúde pública da Escola Nacional de Saúde da Fundação Oswaldo Cruz, Faculdade de Saúde Pública da Universidade de São Paulo e Instituto de Medicina Social da Universidade Estadual do Rio de Janeiro, no periodo de 1990-1994. O estudo teve como objetivo detectar aspectos referentes a: temática das dissertaçōes/teses e natureza da pesquisa, nivel de divulgação e características dos documentos citados, como subsídios para estabelecimento de indicadores necessários à avaliação da produtividade científica brasileira no campo da saúde pública. O universo constituiu-se de 266 dissertações de mestrado e 84 teses de doutorado. A análise temática revelou uma diversificação acentuada nos temas estudados, com uma descontinuidade temporal no período estudado. Os temas desenvolvidos mostraram evidente direcionamento para a pesquisa aplicada (76,3\% na produção dos mestrados e $80,6 \%$ na dos Doutorados). Quanto à análise da divulgação foi constatado que $83,1 \%$ das disseraçōes/teses encontravam-se indexadas (no formato original) em bases de dados bibliográficos especializadas, e, $27,1 \%$ delas foram publicadas, em outros formatos, após a sua aprovação. O conjunto das citações amostrada (6.019) revelou que: os artigos de periódicos contribuíram com maior número de citações $(46,7 \%)$, principalmente para os trabalhos de natureza aplicada; o percentual de livros citados foi mais representativo para as teses de doutorado; a maior concentração dos documentos citados encontra-se no conjunto publicado de 6 a 10 anos da defesa da dissertação/tese; o idioma português predominou nas citações $(49,3 \%)$; para os artigos de periódicos predominou o idioma inglês; a maioria das citações correspondeu a documentos de autoria única $(46,8 \%)$; os alunos valeram-se mais de dissertações/teses de outras instituições do que das escolas que freqüentaram. Conclui-se, entre outros aspectos, que as dissertações/teses não devem ser consideradas apenas como um trabalho de ascensão acadêmica, mas, para isso, precisam ser conhecidas para serem reconhecidas. 
NORONHA, Daisy Pires. Public health graduation courses: dissertations and theses analysis (1990-1994). São Paulo, 1996. /Doctoral Theses - Faculdade de Saúde Pública. Universidade de São Paulo/

\section{SUMMARY}

This study analyses master dissertations and doctoral theses presented at public health graduation courses, from 1990 to 1994, in three different Institutes: "Escola Nacional de Saúde Pública da Fundação Oswaldo Cruz" (ENSP/FIOCRUZ), "Faculdade de Saúde Pública da Universidade de São Paulo" (FSP/USP) and "Instituto de Medicina Social da Universidade do Estado do Rio de Janeiro" (IMS/UERJ). The aim was to point out some characteristics of the dissertations/theses such as: subject matter focused, type of research, the level of their dissemination, and citation analysis, in order to contribute to stablish a Brazilian scientific productivity pattern in the field of public health. 266 master dissertations and 85 doctoral theses were analysed, and the results were: diversified subjects were focused with a discontinuous occurrence in the studied period; trend towards applied research; $83.1 \%$ of the dissertations and theses were indexed in the field data bases; only $27.1 \%$ of them were published in other formats (journal articles, books, etc.). Citation analysis was made with a sample of 6.019 bibliographic references and showed that in general, there were more references to scientific journal articles $(46.7 \%)$, particularly in applied studies; doctoral theses cited more books than master dissertations; there was a concentration of references made to publications between 6 to 10 years old; publications in Portuguese were responsible for $49.3 \%$ of the citations; most of the cited articles were in English language; $46,8 \%$ of the cited documents were of single authorship; dissertations and theses from other institutions were more cited than those of the authors' School. At the end, some suggestions are made to improve the dissemination of this literature, once besides being considered as an academic work, dissertations and theses must be considered an important information source for the development of actions in the public health field. 


\section{ÍNDICE}

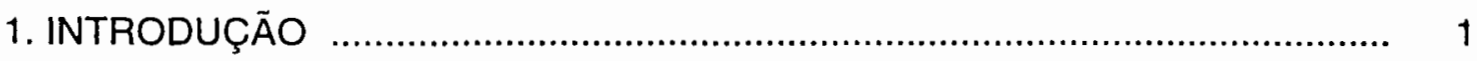

1.1. A pesquisa científica e sua tipologia ..................................................... 3

1.2. A universidade e a pesquisa científica ................................................... 5

1.3. Cursos de pós-graduação em saúde pública ............................................. 7

1.4. Produção científica na pós-graduação: Dissertações e Teses.................... 10

1.4.1. A temática das pesquisas acadêmicas......................................... 12

1.4.2. A divulgação da produção científica acadêmica............................ 13

1.5. Avaliação da produção científica .............................................................. 21

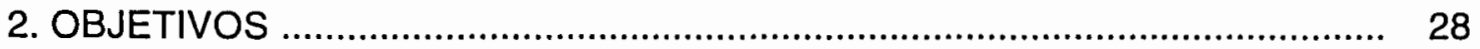

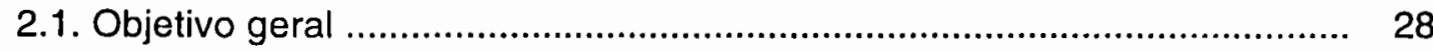

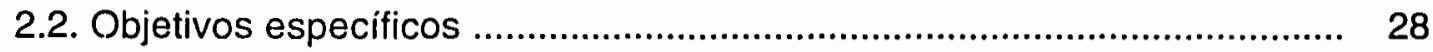

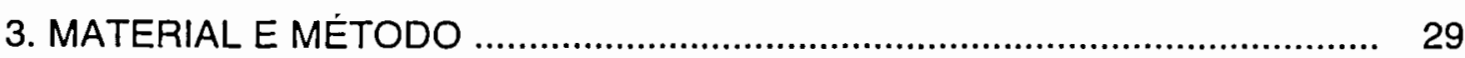

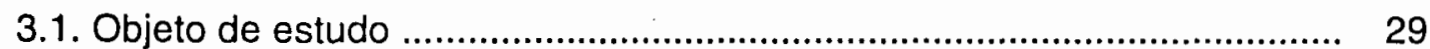

3.2. Caracteristicas dos Cursos de Pós-graduação em Saúde Pública.......... 29

3.2.1. Escola Nacional de Saúde Pública da Fundação Oswaldo Cruz (ENSP/FIOCRUZ) …................................................. 30

3.2.2. Faculdade de Saúde Pública da Universidade de São Paulo (FSP/USP)

3.2.3. Instituto de Medicina Social da Universidade Estadual do Rio de Janeiro (IMS/UERJ)

3.3. Periodo de estudo .......................................................................... 36

3.4. Levantamento dos dados .............................................................. 36

3.5. Universo de estudo ................................................................ 38 


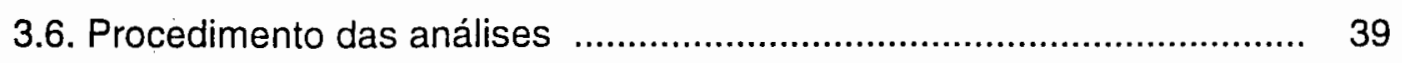

3.6.1. Caracterização das dissertações/teses .................................... 39

3.6.1.1. Natureza da pesquisa ........................................... 40

3.6.1.2. Análise temática .................................................. 41

3.6.2. Análise da divulgação....................................................... 42

3.6.2.1. Indexação em bases de dados bibliográficos ................. 43

3.6.2.2. Divulgação em outros formatos .................................. 45

3.6.3. Análise das citações bibliográficas ........................................ 45

3.6.3.1. Amostragem ........................................................ 46

3.6.3.2. Tipos dos documentos citados ................................ 47

3.6.3.3. Temporalidade dos documentos citados ...................... 49

3.6.3.4. Idioma dos documentos citados ................................... 49

3.6.3.5. Procedência geográfica dos documentos citados ........... 49

3.6.3.6. Tipos de autoria dos documentos citados ................... 50

3.6.3.7. Núcleo dos títulos dos periódicos citados....................... 50

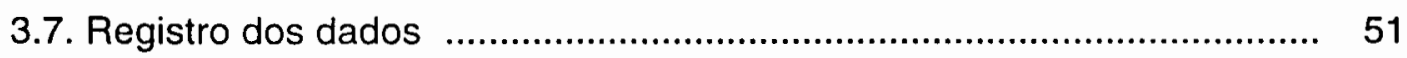

4. RESULTADOS E DISCUSSÃO …..................................................... 52

4.1. Caracterização das Dissertações e Teses .......................................... 52

4.1.1. Natureza da pesquisa ................................................... 55

4.1.2. Análise temática .......................................................... 59

4.2. Divulgação das Dissertações e Teses ............................................ 76

4.2.1. Divulgação em bases de dados bibliográficos automatizadas....... 77

4.2.2. Divulgação em outros formatos .............................................. 82

4.3. Análise das citações bibliográficas nas Dissertações e Teses ............... 88

4.3.1. Tipos de documentos citados ................................................ 89

4.3.2. Temporalidade dos documentos citados ................................ 99 
4.3.3. Idioma dos documentos citados 105

4.3.4. Procedência geográfica dos documentos citados ....................... 110

4.3.5. Caracterização da autoria das citações bibliográficas ................ 116

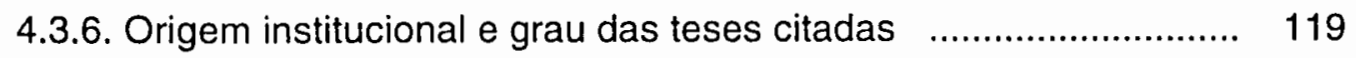

4.3.7. Núcleo dos títulos dos periódicos citados ............................... 122

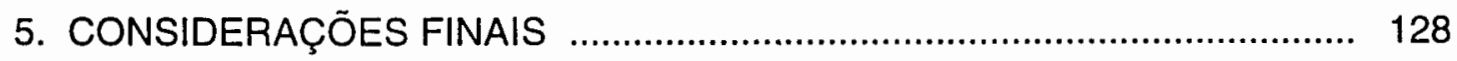

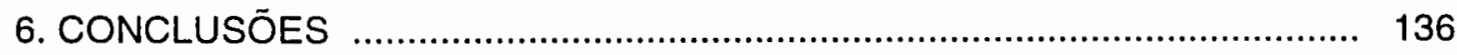

REFERÊNCIAS BIBLIOGRÁFICAS ................................................... 141

ANEXOS:

Anexo 1 - Relação das Dissertações de Mestrado e Teses de Doutorado defendidas nos cursos de Pós-Graduação em Saúde Pública da ENSP/FIOCRUZ, FSP/USP E IMS/UERJ.

Anexo 2 - Lista hierárquica das categorias principais dos Descritores de Saúde (DeCS)

Anexo 3 - Modelo de planilhas para o registro dos dados das Dissertações

e Teses.

Anexo 4 - Quadro da evolução temporal dos assuntos das Dissertações de Mestrado e Teses de Doutorado (1990-1994)

Anexo 5 - Gráfico para a determinação das citações em zonas de frequência (Lei de Bradford)

Anexo 6 - Listagem alfabética dos títulos de periódicos citados nas Dissertações de Mestrado e Teses de Doutorado. 


\section{INTRODUÇÃO}

A saúde pública, como campo de atuação, envolve atividades que visam principalmente propiciar melhores condiçōes de saúde à população. Os problemas de agravo à saúde das pessoas são sistematizados em três categorias, físico-química, biológica e social, que se inter-relacionam (FORATTINI, 1995) ${ }^{29}$. Assim sendo, as pesquisas em saúde pública se interagem com vários ramos do conhecimento humano, - que a torna um campo inter e multidisciplinar, voltados à solução de problemas da população humana, concernentes à saúde.

A situação de saúde da população brasileira é bastante similar a dos demais paises do Terceiro Mundo, passando por surtos de males típicos das mais pobres regiōes, ocasionados por ausência de cuidados elementares de higiene. Quase que diariamente são notificados pelos jornais casos de cólera (que atingiu a mais de 10.000 pessoas no país, nos dois primeiros meses de 1994), leptospirose, meningite, leishmaniose, dengue, entre outros, que se disseminam principalmente em meio à população de baixa renda devido às condições precárias de vida e falta de infraestrutura sanitária. O caso mais recente do escândalo das mortes ocorridas em uma região do nordeste brasileiro, devido à intoxicação causada pela água contaminada em tratamento de hemodiálise, mostra apenas um recorte da situação em que vive a maioria do povo brasileiro. Na regiăo Amazônica, também como exemplo, ainda se constata a primazia de causas de mortalidade por doenças como a malária, já tida anteriormente como controlada.

Todo esse quadro se repete, mesmo em regiões consideradas mais desenvolvidas, como por exemplo o Estado de São Paulo, onde casos de leptospirose, leishmaniose e de raiva são notificados com frequência. Nesses centros, representados pelos Estados do sul e sudeste, estão aumentando as causas de mortalidade por 
doenças crônicas e degenerativas (cardiovasculares, neoplásicas, etc.), por acidentes, entre outras, a exemplo do que ocorre nos países mais avançados. São novas doenças que surgem de uma realidade cada vez mais urbana, e problemas de saúde de interesse mundial, com acentuado agravante no que diz respeito à sua proliferação e controle, como o caso da AIDS e dos males causados pelo uso de drogas.

Na 8a. Conferência Nacional de Saúde ${ }^{20}$ (p.30), em 1986, o então presidente Sarney, em seu discurso, dizia: "O Brasil não pode continuar sendo uma nação de vários Brasís: um Brasil menor, de cidadãos de primeira e abastada classe; e um Brasil imenso, de um povo de segunda e necessitada classe". Essa fala, todavia, ainda continua em curso, com agravantes maiores que parecem ser do desconhecimento ou do descaso de governantes, nas diferentes hierarquias de poder, não levando em conta o que reza no Art.196 da Constituição Federal" de 1988: "saúde é um direito de todos e um dever do Estado..." (p.88). Este artigo reflete os novos rumos propostos pelo Sistema Nacional de Saúde, apontados nas conclusões daquele evento, considerando a saúde em uma dimensão muito maior do que simplesmente questão de mortalidade, hospitalização, medicamento, etc.

Para atingir esse dimensionamento e para reverter ou, no mínimo, minimizar o quadro da má situação de saúde da população brasileira, são realizadas as mais variadas formas de ação, que vão desde criação de comissões de estudo e pesquisa, com a contribuição de trabalhos individuais de pesquisadores, profissionais e/ou acadèmicos da área, até atos governamentais, institucionalizados em casos e períodos específicos.

Assim, todas as atividades exercidas pelo homem com o objetivo de "incrementar o acervo de conhecimentos que the permita sobreviver cada vez mais, tanto em quantidade como em qualidade" (ANDRADE, 1992, p.1) ${ }^{6}$ estão relacionadas ao desenvolvimento da pesquisa científica no campo da saúde pública. São trabalhos que procuram criar e aprimorar a busca de caminhos, procedimentos, métodos, visando principalmente ao bem-estar da coletividade. 


\subsection{A PESQUISA CIENTÍFICA E SUA TIPOLOGIA}

A pesquisa consiste em trabalho criativo, com métodos próprios e técnicas específicas, elaborado em base sistemática e que tem por meta aumentar o conhecimento do homem, da cultura e da sociedade, com propostas de novas aplicações desses conhecimentos. A pesquisa é "atividade básica das ciências na sua indagação e descoberta da realidade" (MINAYO ${ }^{62}, 1992$, p.23); seu campo é infinito abrangendo as ciências exatas, biológicas e humanas. Desta forma, a pesquisa implica a atuação da comunidade de modo concreto, procurando criar e aprimorar caminhos que permitam ao homem sobreviver cada vez mais, tanto em quantidade como em qualidade.

A busca de uma verdade, de um fato que contribua ao aumento do conhecimento pode ser feita sob diferentes aspectos de dimensão e profundidade especificas, que são identificados conforme o objeto de estudo, os objetivos propostos e a metodologia utilizada em sua investigação.

As diferentes formas de procedimento na realização de uma investigação propiciam categorias diferentes de tipos de trabalho de pesquisa nas diferentes áreas do conhecimento. Todavia, é bastante acentuada a divergência na categorização da natureza de uma pesquisa, conforme se verifica na literatura.

A categorização mais abrangente, segundo a literatura disponivel, é aquela que agrupa os trabalhos de todos os ramos das ciências, desenvolvidos de forma BÁSICA e APLICADA, sempre voltados ao aumento do conhecimento.

Enquanto a BÁSICA visa o avanço científico através do desenvolvimento de novos conhecimentos e conceitos, aperfeiçoamento de metodologias para seu embasamento teórico, a APLICADA é voltada a solucionar problemas práticos, com sugestões de melhoria e aperfeiçoamento dos conhecimentos existentes. 
Os motivos que levam a essa diferenciação são apresentados de forma distinta pelos estudiosos. Assim, a pesquisa pode ser baseada no desejo de conhecer pela simples satisfação de conhecer (básica) ou quando baseada no desejo de conhecer para agir (prática) (GIL, 1989, p.43) ${ }^{39}$.

Para Bulmer, citado por MINAYO ${ }^{62}$ (1992, p.25), a divisão Básica e Aplicada é falsa, na medida em que pesquisas teóricas podem ter importantes consequências práticas e pesquisas aplicada certamente têm implicações e contribuições teóricas. A pesquisa básica não tem finalidade prática embora suas descobertas possam influenciar e subsidiar outras decisões nos avanços no campo da ciência.

Segundo FORATTINI ${ }^{29}$ (1995) toda pesquisa científica em saúde pública "é precipuamente básica" desde que ela se constitua em fonte de conhecimentos que poderão vir a ser aplicados na solução dos problemas que se relacionam à qualidade de vida do homem. Para esse autor "a pesquisa aplicada pode ser encarada como etapa no desenvolvimento da pesquisa básica" a qual identificou os fatos fundamentais da problemática focalizada.

ROCHE ${ }^{82}$ (1988, p.114) enfatiza que "toda pesquisa científica bem feita se aplica um dia ou outro". De qualquer modo duas perguntas se impõem quando se trata de pesquisa: para que? e para quem? e que são respondidas tanto pela Básica como pela Aplicada.

Para se traçar um perfil do desenvolvimento científico no campo da saúde têm sido realizados trabalhos que procuram classificar a produção científica nas diferentes categorias de pesquisa. Destacam-se, como exemplo, os achados de CORDEIRO e col. $^{23}$ (1990), em "paper" apresentado no Encontro sobre Pesquisa em Saúde no Brasil, promovido pela "Commission on Health Research for Development", na Fundação Oswaldo Cruz, onde classificam os projetos do Programa de Saúde Coletiva em níveis de atuação, definindo em pesquisa Básica os "projetos que têm como compromisso principal a produção de conhecimento", e, em pesquisa Aplicada, os "projetos que têm a finalidade de produzir resultados imediatamente aplicáveis nas práticas de saúde", e 
pesquisa Operacional, os "projetos desenvolvidos no âmbito dos serviços, atividades ou tecnologias"(p.23). Com base nesse documento e em trabalho de Velho, na área da agricultura, ANDRADE ${ }^{6}$ (1992), adota a mesma classificação em análise da produção de artigos de periódicos da comunidade acadêmica brasileira, representada por docentes dos cursos de pós-graduação em saúde pública. Já COSTA LIMA e col. ${ }^{24}$ (1985) adotaram os termos "básicos"e "aplicados" para diferenciar o conteúdo de artigos sobre doenças endêmicas, classificando como "aplicados" aqueles relacionados diretamente ao homem ou à população humana.

A literatura mostra que a categorização da produção científica, de diferentes áreas, segundo a natureza da pesquisa, é bastante complexa e polêmica, entrando até no mérito da facilidade maior ou menor em se realizar trabalhos de uma ou de outra natureza. Para BORGES ${ }^{10}$ (1994), no entanto, "não existe trabalho fácil ou difícil: existe trabalho bom e trabalho ruim" (p.274). A opinião dos especialistas é bastante diversificada e algumas vezes radicais nas suas conceituações. É necessário que se considerem, além da contribuição da classificação aos seus objetivos, as limitações que possam ocorrer em qualquer uma das categorizações adotadas.

Essa discussão, no entanto, foge aos objetivos do presente trabalho. Para melhor sistematização das variáveis estudadas nas dissertações e teses em saúde pública, se propõe apenas a classificar os documentos estudados em Básicos e Aplicados, categorias essas que são mais abrangentes e comuns nas diferentes tipologias apresentadas.

\subsection{A UNIVERSIDADE E A PESQUISA CIENTÍFICA}

A pesquisa faz parte da universidade brasileira desde o seu surgimento em 1930. "A criação da Universidade de São Paulo em 1934, constitui a primeira iniciativa bem sucedida de instaurar atividades de pesquisa na universidade" (GRANJA, 1995, 
p.5) ${ }^{42}$. No entanto, apenas em 1968, com a Reforma Universitária, ela é tida como um dos componentes da tríade função da universidade, ao lado do ensino e da prestação de serviços à comunidade.

Os cursos de pós-graduação, institucionalizados com a Lei 5.540 , conhecida como a da "Reforma Universitária", deram impulso decisivo para a modernalização da universidade brasileira e transformando-a, segundo relatório do MEC/SEC, em um "centro criador de ciências, de cultura e de novas técnicas" (VIACAVA e col., 1991, p.24) ${ }^{100}$, favorecendo, as condições para a realização das atividades de pesquisa. Mas, foi somente a partir do II Plano Nacional de Pós-Graduação, de 1982, quando foi enfatizada a pós-graduação "strictu sensu" para "a formação de pesquisadores (ou docentes-pesquisadores) para a área científica e tecnológica" (RIBEIRO, 1986, p.32) ${ }^{80}$. A preocupação da pós-graduação, até então, pelo I Plano de 1975, era a titulação de docentes qualificados para o ensino superior principalmente para a graduação.

As primeiras pesquisas em saúde no Brasil, desenvolvidas em institutos de pesquisa e departamentos nacionais de saúde, datam do final do século 19 , com interesses voltados às áreas de bacteriologia e parasitologia, e, posteriormente, às áreas da engenharia e ciências exatas. A formação dos novos cientistas era realizada através de "cursos de aperfeiçoamento" sendo pioneiros o Instituto Agronômico de Campinas (1887), o Instituto Butantan (1899) e o Instituto Oswaldo Cruz (1900) (GRANJA, 1995, p.4) ${ }^{42}$. A partir da década de 30, com a criação da primeira universidade brasileira e do Ministério de Educação e Cultura (MEC), a pesquisa em saúde volta seu interesse para o desenvolvimento das áreas básicas e clínicas devido à demanda decorrente da expansão dos setores urbanos e industriais. É somente a partir da década de 50 que as pesquisas são dirigidas aos serviços de saúde pela "necessidade de racionalizar o setor saúde pressionado pela diminuição dos gastos estatais em saúde" (VIACAVA e col.1991, p.11) ${ }^{100}$.

A pesquisa científica também é realizada em entidades privadas, desde que ela "vislumbre interesse lucrativo nos possiveis resultados" (FORATTINI, 1995, 
p.84) ${ }^{29}$, como acontece, com maior frequência no Japão e Suiça. Este não é o quadro da situação do Brasil, onde, segundo SCHWARTZMAN e CASTRO ${ }^{86}$ (1986), a ciência está fortemente concentrada na universidade, onde $90 \%$ das pesquisas do país são realizadas (MARTINS e QUEIROZ, 1987) " “É no ambiente universitário que a pesquisa científica, em seu caráter básico e aplicado, tem de encontrar abrigo" (FORATTINI $^{29}, 1995$, p.84). Assim, o papel da universidade é voltado ao avanço da sociedade na medida em que envolve açōes voltadas à pesquisa científica.

No entanto, as universidades não têm capacidade para sustentar a totalidade das pesquisas realizadas, ficando estas na dependência de recursos externos. A falta de recursos influi no sucesso da produção do conhecimento, sendo motivo de baixa produtividade da pesquisa, principalmente em países periféricos como o Brasil.

\subsection{CURSOS DE PÓS-GRADUAÇĀO EM SAÚDE PÚBLICA}

A demanda aos cursos de pós-graduação é caracterizada principalmente pelos docentes das faculdade que necessitam de titulação para progredir na carreira universitária (muitas vezes sem a vocação para pesquisa que é feita apenas como exigência legal da carreira) e de alunos que, sem vínculos empregaticios com faculdades ou instituições de ensino superior, visam aprimorar ou investir na sua capacitação profissional para a concorrência do mercado de trabalho.

A partir dos anos 70 a expansão da pós-graduação é marcante, medida pela multiplicação desses cursos em faculdades e escolas vinculadas ou não (faculdades isoladas) a universidades federais, estaduais ou particulares. Este desenvolvimento também é decorrente da criação de agências de fomento voltadas ao desenvolvimento das atividades de pesquisa e à formação de pesquisadores, entre elas, a CAPES 
(Coordenação de Aperfeiçoamento de Pessoal de Nível Superior), criada em 1951 e reestruturada em 1974, como órgão auxiliar do MEC e com a "responsabilidade de introduzir modificações no modelo universitário brasileiro no contexto da modernização e desenvolvimento da sociedade, dando ênfase na formação de recursos humanos e na capacitação de profissionais para a investigação" (VIACAVA e col., 1991, p.13) ${ }^{100}$. Graças às agências de fomento "a ciência brasileira amadureceu, ganhou corpo e uma certa estabilidade" (CASTRO, 1994) ${ }^{18}$.

Em 1966 existiam cerca de 50 cursos de pós-graduação no Brasil, em todas as áreas do conhecimento, chegando, segundo dados do MEC/CAPES, a 1.200 cursos (829 de Mestrado e 381 de Doutorado) em 1986. Destes, 403 cursos eram da área da saúde em geral (VIACAVA e col., 1991, p.26) ${ }^{100}$.

$\mathrm{Na}$ avaliação dos cursos de pós-graduação no Brasil, realizada pela CAPES, foram levantados 1.588 cursos, sendo 1.061 Mestrados e 527 Doutorados, com dados de 1992 e 1993 (PINTO, 1995) ${ }^{71}$. Os resultados dessa avaliação, elaborada em 1993, (CAPES, p.45) ${ }^{22}$, revelam um total de 16 cursos de pós-graduação de Mestrado e Doutorado em Saúde Coletiva, sub-área da Medicina, com início que variou desde a implantação da Reforma Universitária em 1970, aos mais recentemente implantados na década de 90. Esses cursos são ministrados por nove instituições, a saber:

a) FUNDAÇÃO OSWALDO CRUZ. ESCOLA NACIONAL DE SAÚDE PÚBLICA (ENSP/FIOCRUZ)

Mestrado em Saúde Pública (início em 1977)

Doutorado em Saúde Pública (início em 1980)

Mestrado em Saúde da Criança (início em 1988)

b) UNIVERSIDADE ESTADUAL DE CAMPINAS. FACULDADE DE

CIÊNCIAS MÉDICAS. DEPARTAMENTO DE MEDICINA PREVENTIVA E SOCIAL (UNICAMP)

Mestrado em Saúde Coletiva (início em 1991) 
c) UNIVERSIDADE ESTADUAL DO RIO DE JANEIRO. INSTITUTO DE MEDICINA SOCIAL (IMS/UERJ)

Mestrado em Saúde Coletiva (início em 1974)

Doutorado em Saúde Coletiva (início em 1990)

d) UNIVERSIDADE FEDERAL DA BAHIA. FACULDADE DE MEDICINA (FM/UFBa)

Mestrado em Saúde Comunitária (início em 1974)

Doutorado em Saúde Pública (início em 1989)

e) UNIVERSIDADE FEDERAL DE PELOTAS. FACULDADE DE MEDICINA.

DEPARTAMENTO DE MEDICINA SOCIAL (FM/UFPel)

Mestrado em Epidemiologia (início em 1991)

f) UNIVERSIDADE FEDERAL DE SÃO PAULO (Escola Paulista de

Medicina). DEPARTAMENTO DE MEDICINA PREVENTIVA E SOCIAL

(UNIFESP)

Mestrado em Epidemiologia (início em 1988)

g) UNIVERSIDADE DE SÃO PAULO. FACULDADE DE MEDICINA.

DEPARTAMENTO DE MEDICINA PREVENTIVA (FM/USP)

Mestrado em Medicina Preventiva (início em 1973)

Doutorado em Medicina Preventiva (início em 1973)

h) UNIVERSIDADE DE SÃo PAULO. FACULDADE DE MEDICINA DE RIBEIRÃO PRETO. DEPARTAMENTO DE MEDICINA SOCIAL (FMRP/USP)

Mestrado em Medicina Preventiva (início em 1971)

Doutorado em Medicina Preventiva (início em 1971)

i) UNIVERSIDADE DE SÃO PAULO. FACULDADE DE SAÚDE PÚBLICA (FSP/USP)

Mestrado em Saúde Pública (início em 1970)

Doutorado em Saúde Pública (início em 1970) 
Destes cursos, 10 já perduram por mais de 13 anos, com credenciamento pela CAPES, sendo seis de Mestrado e quatro de Doutorado, sob a responsabilidade de seis instituições universitárias (ENSP/FIOCRUZ, FM/UFBa, FM/USP, FMRP/USP, FSP/USP e IMS/UERJ). Três dessas instituições (FM/UFBa, FM/USP e FMRP/USP) mantêm cursos sob a responsabilidade de Departamentos; os demais cursos são oferecidos por instituições dedicadas ao ensino e pesquisa em saúde pública. Todos esses cursos são considerados de pós-graduação "strictu sensu" e envolvem, para a realização das pesquisas, docentes, orientadores e alunos.

A clientela da maioria desses cursos é multiprofissional, envolvendo pessoal graduado da área da saúde (medicina, enfermagem, nutrição, odontologia, farmácia, veterinária, etc.) e de áreas afins (ciências sociais, antropologia, economia, psicologia, serviço social, estatística, biologia, etc.) com a devida aprovação dos respectivos colegiados. No entanto, existem cursos destinados a profissionais de área específica como os de Mestrado e Doutorado em Medicina Preventiva, cuja clientela é caracterizada pelo médico, com residência completa.

\subsection{PRODUÇÃO CIENTÍFICA NA PÓS-GRADUAÇÃO: DISSERTAÇŌES E TESES}

Nos cursos de pós-graduação são realizados trabalhos de pesquisas envolvendo estudos dos mais variados temas, dada a característica multidisciplinar da saúde pública, dos quais participam o corpo docente, pesquisadores, e corpo discente.

Os alunos dos cursos de pós-graduação - mestrandos e doutorandos - em cumprimento aos dispositivos obrigatórios existentes, são avaliados mediante a elaboração de um trabalho escrito, que, para sua aprovação, passa pelo crivo de uma banca examinadora composta por especialistas da área, que, segundo BORGES $(1994)^{10}$, deve ser constituída "pela competência e não pela amizade" (p.272). 
Para o curso de nivel Mestrado são apresentadas, como produto de capacitação dos alunos na investigação científica, as chamadas "Dissertação de Mestrado", para as quais se exige um trabalho de investigação, sem que haja necessariamente contribuição original para a ciência. Já o curso de pós-graduação, nível Doutorado, exige como produto final na formação do aluno, a "Tese de Doutorado", que deve apresentar resultados de uma investigação mais profunda e original de um tema (FRANÇA e col. ${ }^{31}$, 1990; SEVERINO $\left.{ }^{87}, 1992\right)$, e onde a criatividade é fundamental. Para tanto, "é indispensável que o pós-graduando "ponha a mão na massa", isto é, obtenha seus próprios resultados" (BORGES, 1994, p.273) ${ }^{10}$.

Pelos regimentos dos cursos de pós-graduação, tanto o mestrando como o doutorando, desde sua matrícula, deverá ter definido um professor-orientador, na área escolhida, que deverá assumir o compromisso de acompanhá-lo durante o curso e orientá-lo em todas as fases na evolução do projeto de pesquisa, sobretudo para o Mestrado.

O trabalho monográfico, como produto final do curso de pós-graduação dissertaçāo/tese - no entanto, pode ser substituído, em alguns casos, por coletâneas de trabalhos originais publicados durante o curso, como parte do processo formal de obtenção do grau acadêmico, a exemplo do que ocorre no sistema britânico da pósgraduação (London School of Hygiene \& Tropical Medicine, 1992, p.42) ${ }^{58}$. Esta opção de avaliação já vem sendo considerada no Brasil, como se verifica na Escola Nacional de Saúde Pública da FIOCRUZ, conforme o seu "Regimento Interno dos Cursos de Pós-Graduação "strictu sensu" em Saúde Pública"36, de 1996. Por esse regimento consta que o Doutorado pode ser concluido através de um "trabalho original de alta qualificação e complexidade científica", apresentado em uma das seguintes formas: tese no formato tradicional; coletânea de artigos publicados em periódicos indexados; e livro como produto de investigação [p.10]. Este critério já havia sido sugerido também por ANDRADE ${ }^{6}$ (1992) em seu doutorado, na Apresentação de sua tese (p.xxiv). 
Pressupõe-se, então, que o produto dos cursos de pós-graduação, através de seus Mestrados e Doutorados, possa constituir-se em componente importante para o avanço científico em todos os campos do conhecimento, envolvendo temas de interesse para a melhoria das condições de vida da população.

\subsubsection{A TEMÁTICA DAS PESQUISAS ACADÊMICAS}

As dissertações e teses produzidas nos cursos de pós-graduação em saúde pública, a exemplo de outros tipos de documentos, refletem a formação acadêmica e profissional dos autores-pesquisadores, influindo na escolha e na diversificação da especialização dos temas abordados, devido, particularmente, ao caráter multidisciplinar desse campo.

A escolha do tema, no entanto, não está condicionada unicamente à formação profissional ou acadêmica do aluno de pós-graduação. Segundo SEVERINO ${ }^{87}$ (1992), a temática das teses deve estar voltada à uma problemática vivenciada pelo aluno, deve Ihe dizer respeito, não em nivel sentimental, mas "a nível da avaliação, da relevância e da significação dos problemas abordados para o próprio pesquisador, a vista de sua relação com o universo que o envolve" (p.109). A escolha e a realização de um tema de pesquisa deve ser de relevância não só acadêmica, mas sobretudo social e "deve cada vez mais ser criativo" (p.111).

Em qualquer das circunstâncias, a escolha do tema de uma pesquisa, para WITTER e col. ${ }^{104}$ (1992), é voltado ao que já se sabe de uma determinada área e o que há por se saber, sofrendo o "impacto de variáveis ambientais que vão desde os modismos até as necessidades reais de se solucionar problemas e da realidade em que atua o pesquisador" (p.7).

Umberto $\operatorname{ECO}^{26}$ (1995) aponta as quatro regras que devem ser consideradas quando da escolha do tema para uma tese: a) que o tema responda aos interesses do 
candidato; b) que as fontes de consulta sejam acessiveis (alcance material do candidato); c) que as fontes de consulta sejam manejáveis (alcance cultural do candidato); d) que o quadro metodológico da pesquisa esteja ao alcance da experiência do candidato. Enfim, "quem quer fazer uma tese deve fazer uma tese que esteja à altura de fazer "(p.6). De qualquer forma, a maior vantagem para o estudante ao realizar um projeto de tese é a oportunidade de se aprofundar no estudo de um tópico de seu interesse e trabalhar com problemas "reais" em organizações "reais" (SAYERS e WOOD, 1991) ${ }^{85}$.

O orientador pode também exercer influência quanto à escolha do tema da pesquisa a ser desenvolvido pelos alunos de pós-graduação. SAYERS e WOOD ${ }^{85}$ (1991) em trabalho sobre o uso de dissertações na área da ciência da informaçāo, ao entrevistarem os seus autores, verificaram que $44 \%$ deles escolheram os temas de suas dissertações por sugestão dos orientadores, $23 \%$ por eles próprios e $30 \%$ por sugestāo de organizações externas.

Um dos fatores determinantes que levaram orientadores de cursos de pósgraduação em saúde pública à escolha do tema de suas pesquisas e que poderia também ser preponderante para os mestrandos e doutorandos desse campo, foi a solução de problemas nacionais, com práticas de saúde voltadas para interesses locais (ANDRADE, 1992) ${ }^{6}$.

Assim, aglutinando os diferentes temas, FRENK e col. ${ }^{32}$ (1986) consideraram que a pesquisa em saúde pública pode ser sobre a saúde quando objetiva o avanço do conhecimento e para a saúde quando voltada à solução de problemas da saúde.

\subsubsection{A DIVULGAÇÃO DA PRODUÇÃO CIENTÍFICA ACADÊMICA}


O crescimento da ciência e tecnologia e consequente aumento da produção científica, constitui-se em verdadeiro desafio aos pesquisadores para o controle e seleção dos suportes utilizados, para a divulgação dos resultados de seus achados. 0 volume de informação oriunda dos novos fatos, novos achados, novas idéias, descobertos pela ciência, vem aumentando em uma progressão geométrica durante os dois últimos séculos (ANDERLA, 1979) ${ }^{4}$, contribuindo para o crescimento e diversificação dos veículos utilizados para atingir a comunidade interessada.

Dentre esses veículos, os que mais se destacam são aqueles utilizados na comunicação formal, cujos suportes de registro da informação variam entre os artigos de periódicos, trabalhos apresentados em eventos científicos, livros, dissertações, teses, relatórios, entre outros.

Aliado a esses meios formais para a divulgação da ciência, tem obtido espaço cada vez mais marcante, a comunicação informal entre os pesquisadores, como palestras, consultorias, correspondência, etc. Com a novas tecnologias, esse contato entre pesquisadores ampliou-se consideravelmente, com a utilização de redes eletrônicas de comunicação, que permitem a utilização de uma gama de recursos e serviços.

Segundo ROCHE (1994) ${ }^{83}$, "agora há mais comunicação de pessoa a pessoa que de artigo a artigo" (p.5), embora, segundo o autor, o que se comunica por esse processo são "detaihes triviais" e não a essência do que realmente se quer revelar. A comunicação pessoal entre os pares é tida tão importante quanto o suporte bibliográfico para o desenvolvimento das pesquisas (FERREIRA e SOUZA, 1987) ${ }^{28}$.

A comunicação escrita, em nosso meio, ainda é o principal veículo para a divulgação das pesquisas, tida com maior utilização e considerada a mais segura, uma vez que ela garante ao pesquisador propriedade científica de seus achados e a possibilidade de seu reconhecimento pelos pares (POBLACIÓN e DUARTE, 1989) ${ }^{73}$. Essa comunicação é feita através de documentos considerados convencionais (livros, 
artigos de periódicos) e naqueles tidos como não-convencionais (teses, dissertações, anais de eventos, relatórios), definidos posteriormente.

A recuperação da informação gravada nos diferentes tipos de documentos, até há pouco tempo feita, unicamente, de modo manual, vem sendo obtida eletronicamente pelo sistema "on-line", com consulta direta aos grandes bancos e bases de dados bibliográficos e, posteriormente, pelas bases de dados em CD-ROM (Compact Disk Read Only Memory). Mais recentemente, o acesso a bancos e bases de dados bibliográficos está sendo feito através de redes, locais (da própria instituição) e internacionais (possibilitado com a Internet), oferecendo a informação com mais rapidez. Os resultados das investigações, quando divulgados pelos canais formais, podem ser considerados "velhos" em termos de velocidade na dinâmina social, se comparados às informaçōes disseminadas informalmente (POBLACIÓN e DUARTE, 1989) ${ }^{73}$.

Nos dias de hoje, verifica-se uma proliferação acentuada dessas fontes, já preconizado por GARVEY ${ }^{38}$ (p.7), em estudos realizados em 1979, quando menciona que a taxa de crescimento dos artigos científicos torna-se 10 vezes maior a cada 50 anos, desde 1750; a dos serviços de indexação e resumos, a cada 30 anos desde 1860; e, a dos bancos de dados, a cada 10 anos, desde 1949. O número de bases de dados bibliográficos internacionais somam mais de 3.500 , hospedadas em mais de 40 grande bancos, como o DIALOG, QUESTEL, ORBIT, entre outros. SIGULEM ${ }^{88}$ (1992), em trabalho sobre informática na medicina, aponta a existência de cerca de 4.000 bases de dados eletrônicas, sendo 400 em CD-ROM, destinadas ao acervo bibliográfico disponivel ao profissional da saúde. No Brasil, o CD-ROM foi introduzido pela BIREME (Centro Latino-Americano e do Caribe de Informação em Ciências da Saúde), em 1987. para compor a base de dados LILACS (Literatura Latino-Americana em Ciências da Saúde).

As bases de dados bibliográficos especializadas têm procurado, atualmente, arrolar os diferentes tipos de documentos, não só os considerados convencionais, como também, e principalmente, aqueles chamados não-convencionais, ou de 
"literatura cinzenta", caracterizados por não terem compromisso comercial, com limitada divulgação e de difícil acesso (POBLACIÓN, 1992) ${ }^{74}$. Por outro lado essa literatura flui com rapidez entre os pares, principalmente, pela facilidade de elaboração uma vez que independe da formalização exigida na apresentação da chamada "literatura branca" (POBLACIÓN e NORONHA, 1996) ${ }^{75}$.

Uma dimensão, ainda pouco conhecida, na divulgação da produção científica, é se as teses e dissertações atingem à comunidade científica de forma satisfatória e se efetivamente contribuem para o desenvolvimento da ciência.

Em um primeiro momento, têm-se em conta, baseado em observações, que o destino das teses e dissertações são as estantes das bibliotecas e que os usuários não as consultam a não ser para complementar levantamentos bibliográficos que estejam realizando ou tomá-las como "modelo" para a montagem de seus trabalhos. Além disso, cada dia mais as teses e dissertações "assustam" aos usuários das bibliotecas pela sua aparência na espessura - o número de páginas desses documentos, principalmente as teses de doutorado, vêm aumentando consideravelmente - afastando a consulta a seu conteúdo. Tudo isso, aliado ao fato apontado por $\operatorname{ALVES}^{3}$ (1992), de alguns desses documentos serem considerados mal escritos, sem expressão ou meramente discursivos em linguagem rebuscada, com textos repetitivos, desnecessariamente longos ou vazios, que "afastam rapidamente o leitor não cativo, por mais que os assunto the interesse" (p.58).

Considerando-se então que as teses e dissertações, de características de documentos nāo-convencionais, são trabalhos que representam pesquisas que discutem idéias, comprovam pressupostos dos mais variados temas, levam anos para serem elaboradas, com ou sem ajuda financeira de agências de fomento e que, ainda, para sua aprovação, passam, na sua defesa, por um crivo de especialistas e profissionais comprovadamente reconhecidos na área, ficam aqui algumas questões: as dissertações e teses apresentadas nos cursos de pós-graduação em saúde pública envolvem temas voltados para solucionar ou minimizar os problemas de saúde em nível 
local, regional, nacional? São temas de interesse da comunidade científica? Estão os mesmos voltadas à solução prática de problemas de saúde da população? Que características possui a literatura utilizada para a sua elaboração?

Além disso, questiona-se também como os pesquisadores ou iniciantes na pesquisa tomam conhecimento das dissertações/teses defendidas nas diversas instituições e como o seu conteúdo pode atingir de maneira mais abrangente aos pares. O que se tem em conta, com certeza, é que esses documentos são lidos, pelo menos, pelos membros da banca examinadora.

Na verdade, pouco se sabe sobre o uso e o valor das teses em geral, isto é, de que forma e extensão os seus achados são usados e assimilados por outros especialistas no campo, dado que "o destino de grande maioria das teses e dissertações é mofar nas prateleiras das bibliotecas universitárias" (ALVES, 1992, p.58) ${ }^{3}$. Que esta situação permaneça ou demore a se modificar, não implica em não se criar mecanismos para que o conteúdo desses documentos chegue ao conhecimento da comunidade científica.

No parecer de BREIMER e BREIMER ${ }^{13}$ (1995), as teses mesmo consideradas grandes fontes de referência com dados atualizados, com revisão imparcial da literatura, "paradoxalmente são virtualmente inacessiveis" (p.175). Não é difícil constatar que a maioria das informações nelas divulgadas não seja utilizada pelos pares, e isto devido, em grande parte, pelo próprio desconhecimento de sua existência. São fontes pouco divulgadas, só estando disponiveis nas bibliotecas das instituições em que foram defendidas (é o mínimo esperado...) e muitas vezes fora do acesso do usuário.

Na maioria dos países a produção de teses é baseada em pequeno número de exemplares que é estipulado pelos próprios regulamentos dos cursos de pósgraduação. Esses regulamentos variam entre os países, entre as universidades e até mesmo entre as próprias unidades acadêmicas. Mas, no minimo, como já exposto, é feito um exemplar para a Biblioteca, outro para o orientador e membros da banca examinadora. Em alguns países, como a Holanda e Suécia, são solicitadas, no mínimo, 
75 cópias de cada tese para ser distribuida às bibliotecas universitárias e instituições da área (BREIMER e BREIMER, 1995) ${ }^{13}$. Este, no entanto, é um sistema caro, pelo gasto na impressão, distribuição e armazenagem.

Uma maneira de reverter o quadro, isto é, oferecer maior divulgação com pouco custo, é fazer com que esses documentos, após sua defesa e aprovação, sejam, divulgados, em seu formato original em fontes de dados bibliográficos, impressas ou automatizadas, e editados, posteriormente à sua defesa, em outros formatos, como publicação de livros, capítulos, artigos de periódicos, comunicações em anais de eventos, etc.

Uma maior divulgação das dissertações/teses, na sua forma original, está na dependência das atividades das bibliotecas das Unidades, que respondem pelo processamento e divulgação das mesmas em edições impressas de "boletins bibliográficos", "catálogos de teses", entre outras fontes de alerta, além de colaborar na alimentação de bases de dados automatizadas.

No caso especifico de teses brasileiras, além das bibliotecas, a CAPES, como entidade coordenadora dos cursos de pós-graduação no Brasil, após as notificações recebidas dos respectivos cursos de pós-graduação, colabora na manutenção de bases de dados desse material em nivel nacional. Para tanto, junto com o IBICT (Instituto Brasileiro de Informação em Ciência e Tecnologia) desenvolvem a base de dados "TESES", cujo acesso é feito, via "on-line", pela Rede Antares (Rede de Serviços de Informação em Ciência e Tecnologia), e em edições em CD-ROM . Encontra-se em fase de implantação o programa "Prossiga", na Internet, que conta com o projeto "Prossiga/Site" (Sistema de Informação sobre Teses) que trata da criação de bases de dados de dissertações/teses, executado pelo IBICT em parceria com a CAPES e com as principais universidades do país, que deverá estar disponível, na rede, no início de 1997 (CHASTINET ${ }^{19}$, 1996?). Outras bases de dados existem e que atendem à demanda de dissertações/teses brasileiras, como UNIBIBLI (reúne acervo das universidades paulistas USP, UNICAMP e UNESP), DEDALUS (acervo da USP), 
LILACS e REPIDISCA (acervo de bibliotecas da rede BIREME), disseminadas em CDROM, microfichas e com acesso "on-line".

Em nivel internacional o serviço mais abrangente na divulgação das dissertações/teses é feito pela empresa americana "University Microfilms International", com a edição (impressa e em CD-ROM) do "Dissertation Abstracts International"14, publicada em três seções (Seção A-"Humanities and Social Sciences"; Seção B"Physical Sciences and Engineering"; Seção C-"Abstracts of European Dissertations").

Este mesmo serviço permite o acesso "on-line" nos bancos de dados bibliográficos "DIALOG Information Retrieval Services", ORBIT ("On-line" Retrieval of Bibliography Information Time Shared") e BRS (Bibliographic Retrieval Service).

Uma proposta apresentada por BREIMER e BREIMER ${ }^{13}$ (1995), é criar uma base internacional acessivel pela Internet, estruturada de duas formas: uma, denominada "Microthesia", divulgando os resumos (aproximadamente 500 palavras) das dissertações/teses, semelhante à base MEDLINE, base de dados bibliográficos da área biomédica, e na qual cientistas de todo o mundo poderiam consultar e selecionar as teses de seu interesse; e outra forma, para o seu acesso, denominada "Macrothesia", que divulgaria o texto na íntegra, com possibilidade de ser gravada em disquete ou impressa em papel. Uma terceira parte desse sistema de acesso à informação sobre teses, proposta por esses autores, é denominada de "Inquisitor" que possibilitaria o contato internacional entre os doutorandos e os demais pesquisadores, com troca de informações sobre o trabalho. Este sistema proposto beneficiaria, principalmente, aos pesquisadores dos países menos favorecidos, pela limitação de acesso às publicações científicas.

Há que se considerar, também, até que ponto esses modernos formatos de divulgação da informação (bases de dados, redes, CD-ROM, etc.) são do conhecimento e utilizados pelos alunos dos cursos de pós-graduação na identificação de documentos de seu interesse. Em trabalho sobre a comunicação científica de professores pesquisadores da área médica de uma universidade brasileira, OLIVEIRA e ARAGÃO ${ }^{69}$ 
(1995) detectaram um baixo índice de utilização das bases LILACS/MEDLINE, questionando a sua pouca utilização, seja pela falta de conhecimento da fonte, da importância da informação divulgada, seja pelo hábito arraigado de consulta a documentos convencionais impressos (indices, "abstracts" publicados).

Além da divulgação das teses, na integra, para que os conhecimentos aí registrados sejam mais amplamente disseminados e mais facilmente acessados, é necessário que as dissertaçōes/teses, como documentos não-convencionais, venham a se transformar em documentos convencionais, que, pelas suas características, possuem maiores oportunidades para atingir a maioria da comunidade cientifica.

Nas áreas das ciências biológicas e tecnológicas, o instrumento que vem sendo mais utilizado para divulgar as informações registradas nas dissertações/teses, é o artigo de periódico, diferindo das ciências humanas, onde, por tradição, as teses são publicadas sob forma de livro, após a sua defesa. Outra forma utilizada para a divulgação dos achados desses documentos é através de comunicações em eventos técnico-científicos, atingindo simultaneamente a uma grande massa de interessados nos temas desenvolvidos.

Segundo BORGES ${ }^{10}$ (1994), a produção de uma tese é considerada irrelevante se não puder gerar trabalhos para serem publicados, principalmente em periódicos cujos artigos são indexados em fontes bibliográficas internacionais como o "Index Medicus" na área biomédica, e/ou nas publicaçōes produzidas pelo ISI (Institute for Scientific Information). Para GRANOVSKY e col. ${ }^{43}$ (1992), dentre os vários atributos para avaliar a qualidade de uma tese, é apontado, como prioritário, o número de publicações em revistas científicas.

Divulgar as dissertaçōes/teses, após a sua defesa, em outros formatos, além de abrir fronteiras para seu conhecimento, tem também a vantagem de complementar a formação do aluno como treinamento para a redação de trabalho científico. 


\subsection{AVALIAÇÃO DA PRODUÇÃO CIENTÍFICA}

A avaliação como processo de medida de valor, reconhecimento, apreciação é parte integrante da vida profissional e acadêmica de um pesquisador. Ele é avaliado ao ingressar na universidade, é avaliado para "sair" da universidade e continuamente avaliado no decorrer de suas atividades. Não é só o que ele faz, mas também o que deixou de fazer, que está na mira dos processos avaliatórios.

O produto das atividades científicas, medida através da publicação, é periodicamente avaliado nos dias de hoje. É através do conhecimento da produtividade científica e acadêmica, em qualquer suporte utilizado para sua disseminação, que se pode conhecer o que vem sendo pesquisado e como o produto dessas pesquisas divulgadas podem influenciar o meio científico.

A mensuração da produção de trabalhos de pesquisa de um estudioso não é fácil e objetiva, "continuará a ser um problema para o qual nunca haverá uma solução simples" (DIAMOND, 1990, p.50) ${ }^{25}$. Implica no conhecimento de fatores que interferem no desenvolvimento das pesquisas determinando até que ponto as mesmas vêm atendendo a seus objetivos, ou seja, às necessidades do público-alvo. Esses fatores podem também contribuir para o estabelecimento de subsídios para tomadas de decisões administrativas, definição de política científica, bem como da criação de padrões para medir a atividade científica.

Para Velho (1987), citada por ANDRADE ${ }^{6},(1992$, p.11) a avaliação da atividade científica é um processo "contínuo e sistemático, analítico e interpretativo que busca estabelecer relações entre os produtos das atividades da universidade e os objetivos a que se propõe". A avaliação pode ser feita antes, durante e após a elaboração de um projeto de pesquisa, em vários níveis, e por métodos diversificados.

A pesquisa pode ser avaliada por um conjunto de indicadores de desempenho que se referem às medidas de "in put" e de "out put" . O "in put" considera as 
caracteristicas dos pesquisadores, os recursos financeiros, as condições de realização das pesquisas, etc. O "out put" visa medir o resultado das investigações através da divulgação de seu produto pelos canais formais, como a publicação de artigos, teses, dissertações, e contagem do número de citações feitas aos trabalhos publicados. Essas medidas objetivam avaliar, principalmente, o desempenho da atividade científica, e não o pesquisador ou a instituição (VELHO, 1989) ${ }^{98}$.

A avaliação da produtividade científica ("out put") é do dominio da Bibliometria que, já em 1969, foi designada para utilização de métodos quantitativos para "investigar o processo de comunicação científica pela medida e análise dos vários aspectos do

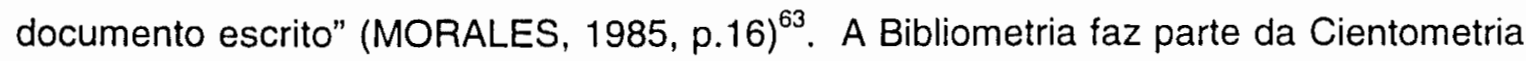
(quantificação da ciência) definida como "área que compreende todos os tipos de análises quantitativas da ciência que se baseiam em fontes de arquivo, sem observação direta da atividade da pesquisa, e que são devotados aos produtos ou resultados dos processos científicos"(VELHO, 1989, p.958)

A literatura tem mostrado que os estudos cientométricos e bibliométricos vêm se desenvolvendo nos países avançados, principalmente nos Estados Unidos, após a década de 60, com o Institute for Scientific Information (ISI), que criou bancos de dados, como o "Science Citation Index"(SCI) e "Social Science Citation Index"(SSCl), entre outros, destinados a avaliar qualitativamente a produção científica medida através das citação pelos pares em artigos dos principais títulos de periódicos científicos do mundo. O parâmetro não é apenas quantitativo (número de artigos) mas de relevância, isto é, cada vez que um artigo é usado, ganha pontos de qualidade. Assim, a qualidade de um trabalho científico, publicado em um dos periódicos indexados por essas obras elaboradas pelo ISI, pode ser medida pelo número de citações que o mesmo recebe da comunidade cientifica. No entanto, deve-se considerar, também, que "a audiência do público mais depende do interesse imediato por parte deste do que propriamente da qualidade intrínseca do artigo" (FORATTINI ${ }^{30}, 1996$, p.7). 
O conjunto de referências bibliográficas (citações) utilizadas na elaboração de um documento "evidencia elos entre indivíduos, instituições e áreas de pesquisa, visto que mostram o relacionamento de uma publicação com outra"(RODRIGUES, 1982, p.36) ${ }^{84}$. Assim, as referências bibliográficas citadas em um documento mostram o relacionamento entre o documento citado e o citante, e, a sua análise contribui para o reconhecimento de um cientista em particular entre seus pares e para avaliar a informação coletada pelo tipo de literatura utilizada, além de dirigir o leitor para outras fontes de informação sobre o assunto.

Para a aplicação desse indicador nos países do Terceiro Mundo existem alguns "senões" que devem ser considerados, principalmente se a avaliação for baseada em dados obtidos do $\mathrm{SCl}$ ou $\mathrm{SSCl}$, que são tendenciosos em alguns casos, subestimando resultados (VELHO, 1989) ${ }^{98}$. Estudos de Velho e Moravcsik, mostram que "os dados de publicação e citação obtidos dentro de um determinado país periférico não podem ser comparados com aqueles obtidos para o mesmo país a partir do SCl" (VELHO, 1989, p.962) $)^{98}$, delineando um quadro diferenciado para a ciência. Para essa autora, transplantar os indicadores científicos gerados nos países avançados "para uso em países cientificamente periféricos como o Brasil, como tem sido feito até hoje, é buscar mais problemas que soluções" (p.958). Uma saida está em se estabelecer nossos próprios indicadores científicos, obtidos através de estudos sobre medidas de quantificação de publicações e citações.

A avaliação da produção científica só é válida se os dados contados puderem ser comparados com outros. Segundo CASTRO $^{17}$ (1985) o valor absoluto por si só nada diz, "só tem sentido em termos comparativos" (p.167), em diferentes locais, em campos específicos da ciência e de periodos distintos, como os resultados atuais comparados com os do passado.

O uso conjunto de diferentes análises ou métodos asseguram maiores índices de qualidade de uma publicação cientifica. Na avaliação da produção científica, 
FORATTINI $^{30}$ (1996) considera a indexação de artigos nos bancos de dados do ISI ( $\mathrm{SCl}, \mathrm{SSCl}$ e de outras áreas) parte da "tríade da publicação científica" para medir a qualidade do periódico. Essa triade é formada pela "competição" (no sentido de somar e não disputar - quanto mais citado maior a visibilidade), pelo "impacto" (com o enriquecimento do acervo do conhecimento) e pela "internacionalidade" (atingir à comunidade científica de outros paises, facilitado pela indexação de seus artigos em bases de dados regionais e internacionais).

Os estudos sobre a produção científica, quando comparados, têm propiciado o estabelecimento de alguns indicadores que descrevem aspectos quantitativos e qualitativos da pesquisa. Mesmo assim, esses indicadores são analisados na literatura com registros de controvérsias sobre a sua validade, principalmente quando utilizados indiscriminadamente, em diferentes áreas e em países de diferentes níveis de desenvolvimento.

Neste sentido, a análise de citação, como uma das técnicas cientométricas, que vem sendo aplicada em crescente progressão na avaliação de trabalhos de pesquisa,nas diferentes áreas, é descrita em várias maneiras na literatura. Junto a essa técnica, outras medidas de "in put" e "out put" da produção científica, são mostradas como produtos de pesquisa de pós-graduação, em dissertações de mestrado e teses de doutorado, como as seguintes: CARVALHO ${ }^{15}, 1976$, em ciências biológicas; RODRIGUES ${ }^{84}, 1982$, em ciência da informação; $\operatorname{ANDRADE}^{5}, 1984$, em epidemiologia; TERADA $^{92}, 1984$, em energia nuclear; Velho (1985), citada por ANDRADE $^{6}$, área da agricultura; POBLACIÓN ${ }^{72}, 1986$, área da saúde; NORONHA ${ }^{65}, 1987$, em saúde pública; FRICK ${ }^{33}, 1991$, em economia; ANDRADE ${ }^{6}, 1992$, em saúde pública; OLIVEIRA ${ }^{68}, 1992$, em enfermagem obstétrica; LIMA ${ }^{54}, 1993$, na área agrícola; REJOWSKi ${ }^{78}, 1993$, em turismo; GRANJA ${ }^{42}, 1995$, em psicologia; SOUZA ${ }^{91}$ (1995) em saúde coletiva(").

\footnotetext{
(*) Não se pôde contar com a consulta a esta dissertação, pois a solicitação de cópia da mesma, feita há 39 dias do fechamento da edição do presente trabalho, não havia sido ainda atendida. deixando, assim. de serem consideradas informações que, com certeza, seriam relevantes a esta tese. Este "pequeno", porém frustrante detalhe, ilustra a precariedade dos serviços de intercâmbio e diliculdades existentes no atendimento a pedidos desta natureza.
} 
Outros trabalhos exemplificam pesquisas realizadas envolvendo processos de avaliação sem ter por meta a obtenção de grau acadêmico, como os de ALENCAR e col. $^{2}$ (1989); WITTER e col. $^{103}$ (1989); PUERARI e PEREIRA ${ }^{77}$ (1992); OLIVEIRA e ARAGÃO ${ }^{69},(1995)$; entre vários outros.

Todos esses trabalhos mencionados fazem parte de uma amostra da literatura que trata da avaliação da produção da comunidade técnico-científica e acadêmica brasileira que, somada à literatura produzida em outros países, forma uma vasta bibliografia sobre o assunto que se mantém estável por muitos anos. Apenas a título de ilustração, a seguir são mencionados alguns trabalhos estrangeiros realizados sobre o assunto, com enfoques diferenciados quanto aos tipos de documentos estudados e em diferentes áreas.

HEINZKILL ${ }^{47}$ (1980) analisa as citações em notas de rodapé de artigos de diferentes revistas especializadas em literatura inglesa, para firmar alguns padrões de consenso nesta área, como a maior utilização de livros do que revistas, a maior importância do uso de publicações antigas, além de verificar a dispersão de trabalhos em grande número de revistas que são citadas. Uma das conclusões apontadas por esse autor é que, quanto mais estudos de citação forem feitos e quanto mais conhecimentos adquirimos para interpretá-los, melhor serão identificadas as diferenças nos padrões no uso de bibliotecas especializadas em ciências médicas, ciências sociais e humanidades.

LANCASTER e col. ${ }^{53}$ (1992), avaliam a produção de pesquisadores em ciências puras e aplicadas de seis países do leste europeu, componentes do Pacto de Varsóvia, mostrando que essa produção não apresenta, segundo as fontes citadas nos artigos publicados, uma tendência ideológica devido à proximidade da União Soviética, conforme era suposto. Outros fatores exerceram maior influência nas fontes citadas nos artigos estudados, como o local de publicação e o grau de familiaridade com um idioma específico. 
WALCOTT ${ }^{101}$ (1992), apresenta um estudo em que se propõe a investigar os padrões de citação nas teses de doutorado produzidas nos Estados Unidos no campo da geociência no periodo de 1981 a 1985, comparando os seus achados com outros determinados em investigações anteriores na mesma área em outros tipos de fontes. Destaca a importância do acervo das bibliotecas especializadas em cobrir a demanda e o acesso à informação necessária ao desenvolvimento das teses.

GODIN e col. ${ }^{40}$ (1995), fazem um levantamento da produção de pesquisadores da província de Québec (Canadá) de 1980 a 1990, procurando mostrar que a produção científica das universidades está decaindo enquanto a produzida em outros setores como a indústria, hospital e governo, está aumentando (o aumento da produção das universidades nos 10 anos foi de $45,0 \%$, enquanto que na indústria somou a $49,2 \%$ e nos laboratórios do governo chegou a 115\%). No entanto, conclui que, pela baixa produtividade desses setores, e contando com a estagnação da produção das universidades, "levará décadas ... para que publicaçōes do governo e da indústria alcancem o nivel de produção de trabalhos nas universidades" (p.10).

HAIQI $^{44}$ (1995), faz a análise de citações em artigos publicados em revistas de biblioteconomia médica, publicadas na China, Japão e Estados Unidos, para medir a tendência de cada pais nas pesquisas em biblioteconomia, relacionada a tipos de fontes citadas, frequência de citação de periódicos, bem como número de páginas e de referências dos artigos analisados nos periódicos selecionados.

Mesmo com toda literatura existente, os estudos de avaliação da quantificação e caracterização da produção cientifica, ainda sofrem críticas e são considerados insuficientemente desenvolvidos, em nosso meio, para serem objeto de uma abordagem qualitativa.

Embora sejam apontadas limitações no seu uso, grande número de pesquisadores concluiu que a frequência de citação pode servir como indicador de qualidade percebida. Levando-se em conta a opinião de BRAGA $^{12}$ (1974), existe uma correlação positiva entre as medidas qualitativas e quantitativas, embora diferentes, 
provocada pelo principio da "vantagem cumulativa"(Efeito Mateus) onde "o sucesso qualitativo de um documento provoca subsequentes publicações de outros documentos; a ausência de sucesso tende a provocar o término da produtividade" (p.165). E isto leva a se considerar que, quanto mais citado um documento sinal de melhor qualidade, 0 que é bastante discutivel, conforme indica a literatura.

Enfim, enquanto as análises qualitativas são difíceis de serem estabelecidas e interpretadas, até pelo aspecto da subjetividade, as análises quantitativas não devem ser desconsideradas dado que o seu sucesso depende do que se propõe da avaliação feita. Nos países periféricos essas avaliações necessitam ser trabalhadas e incrementadas para que sejam identificadas tendências, lacunas, deficiências e necessidades para o desenvolvimento científico, procurando estabelecer seus próprios indicadores científicos, o que, de certa forma, minimizaria a marca desses países serem considerados atrasados e improdutivos (ANDRADE, 1992) ${ }^{6}$.

Mas é necessário considerar também que, independente dos métodos usados, da forma de processar os resultados, toda a avaliação deve ser "um processo continuado em que os resultados já alcançados em uma etapa permitam readaptar as idéias do planejamento para geração de novas estratégias que facilitem atingir as metas pretendidas"(LIMA, 1986, p.132) ${ }^{57}$.

Assim, a proposta do presente trabalho é contribuir para a ampliação do universo de estudos sobre a avaliação da produtividade cientifica brasileira, com dados que caracterizem a produção das dissertações de mestrado e teses de doutorado em saúde pública, medida quanto à natureza do trabalho e direção tomada nos temas desenvolvidos, à amplitude de sua divulgação na comunidade e à utilização de documentos para sua efetivação.

\footnotetext{
"Princípio que sucesso atrai sucesso ou fracasso atrai fracasso, expresso no Evangelho MT 25,29:-"a quem muito tem muito será dado, a quem, nada tem até o pouco, que parece que tem, será tirado" (LIMA e FIGUEIREDO ${ }^{\text {s6 }}, 1984$, p.142)
} 


\section{OBJETIVOS}

\subsection{OBJETIVO GERAL}

Analisar as dissertações de Mestrado e teses de Doutorado, geradas em cursos de pós-graduação em saúde pública, no Brasil, para conhecer o desempenho da pesquisa nessa área e contribuir com subsídios para o estabelecimento de indicadores adequados para avaliação do desempenho da atividade científica no campo da saúde pública.

\subsection{OBJETIVOS ESPECÍFICOS:}

- Identificar os tipos de pesquisa desenvolvidos nas dissertações de Mestrado e teses de Doutorado, definidos segundo a natureza Básica e Aplicada.

- Identificar a temática em que se classificam as dissertações de Mestrado e teses de Doutorado, no campo da saúde pública.

- Verificar como se apresenta a disseminação das dissertações de Mestrado e teses de Doutorado, no seu formato original, em bases de dados bibliográficos automatizadas.

- Verificar como se apresenta a divulgação das dissertaçōes de Mestrado e teses de Doutorado em outros formatos de publicação.

- Verificar as características e modalidades das publicações citadas nas dissertações de Mestrado e teses de Doutorado. 


\section{MATERIAL E MÉTODO}

\subsection{OBJETO DE ESTUDO}

O objeto de estudo é constituído de Dissertações de Mestrado e Teses de Doutorado defendidas, de 1990 a 1994, nos cursos de pós-graduação em saúde pública, das instituições: Escola Nacional de Saúde Pública da Fundação Oswaldo Cruz (ENSP/FIOCRUZ), Faculdade de Saúde Pública da Universidade de São Paulo (FSP/USP) e Instituto de Medicina Social da Universidade do Estado do Rio de Janeiro (IMS/UERJ) (Anexo 1).

\subsection{CARACTERISTICAS DOS CURSOS DE PÓS-GRADUAÇÃO EM SAÚDE PÚBLICA}

Conforme já exposto, existem no Brasil 16 cursos de pós-graduacão em saúde pública/coletiva - niveis Mestrado e Doutorado - (CAPES, p.45) ${ }^{22}$, ministrados em nove instituições. Desse universo foram selecionadas três instituiçōes (ENSP/FIOCRUZ, FSP/USP e IMS/UERJ) por apresentarem algumas características comuns. Assim, são instituições dedicadas com exclusividade ao campo da saúde pública/coletiva há mais de 15 anos, desenvolvendo atividades de ensino, pesquisa e prestação de serviços à comunidade. Seus cursos de pós-graduaçào "strictu sensu", devidamente credenciados pela CAPES, são de nivel Mestrado e Doutorado. Tais cursos são abertos a uma clientela variada, de diferentes formações, envolvendo atividades próprias de equipe multiprofissional, utilizando-se de orientação, metodologia e técnicas comuns ou específicas de cada área, segundo o regimento das respectivas instituições. Formam, sobretudo, docentes e pesquisadores para exercerem atividades que visam à saúde e ao bem-estar da coletividade dentro de uma ampla gama de áreas em que atuam, como administração e planejamento de serviços de saúde, epidemiologia, educação em saúde, enfermagem, odontologia, saúde ambiental, entre outras. Como produto desses 
cursos, são desenvolvidas as dissertações e teses que arrolam temas de importância para o desenvolvimento da saúde pública no Brasil.

\subsubsection{ESCOLA NACIONAL DE SAUDE PÚBLICA DA FUNDAÇÃO OSWALDO CRUZ (ENSP/FIOCRUZ)}

Criada em 1954, tem suas origens no Curso Especial de Higiene e Saúde Pública, anexo à Faculdade de Medicina do Rio de Janeiro, criado pelo Decreto n.16.682-A de 13 de janeiro de 1925 e sob a responsabilidade administrativa, técnica e didática do Instituto Oswaldo Cruz. Pelo Decreto n. 43.926, de 26 de junho de 1958, a ENSP foi integrada ao Ministério da Saúde. O curso de pós-graduação ("strictu sensu") foi credenciado em 1977, dentro das normas estabelecidas pela Lei 5.540/68, com a retomada do curso de Mestrado (realizados anteriormente 3 cursos em 1967 e 1968 dentro de um regime especial e com currículos próprios para atender às necessidades do país). Em janeiro de 1980 foi aberto o curso em nivel Doutorado.

CURSOS: Mestrado em Saúde Pública (início em 1977)

Doutorado em Saúde Pública (início em 1980)

OBJETIVO DOS CURSOS: O curso de Mestrado tem por objetivo a formação de docentes, pesquisadores e capacitação de técnicos, nas diferentes sub-áreas específicas do campo da saúde pública. O objetivo do Doutorado é a formação de profissionais capazes de criar, orientar e dirigir linhas de investigação e docência, com originalidade e independência, na área de concentração em saúde pública.

ÁREAS DE CONCENTRAÇÃO: Planejamento em Saúde; Epidemologia Geral e das Grandes Endemias; Saúde e Sociedade; Saneamento Ambiental; Saúde do Trabalhador; Toxicologia Ocupacional. 
CLIENTELA: Profissionais de nivel universitário (algumas das grandes sub-áreas têm exigências particulares de formação profissional).

FORMA DE SELEÇÃOIINGRESSO: Condicionada a uma prova escrita sobre temas gerais da saúde pública e da sub-área de concentração e, prova escrita de compreensão de texto em inglês (eliminatórias). Em uma segunda etapa é feita avaliação da proposta de trabalho para a dissertação, avaliação do currículo e entrevista (caráter classificatório).

A seleção para o doutorado, em etapa eliminatória, é feita pela análise de documento contendo a apresentação do objeto de investigação para a tese, do currículo, do histórico escolar e das cartas de referência, pelo Orientador e Comissāo de Seleção.

REGIME E DURAÇĀO: Regime em tempo integral. O programa de Mestrado é previsto para durar no máximo dois anos e conclui-se com a dissertação. Para completar - Mestrado o aluno terá que cumprir um total de 48 créditos (30 de atividades acadêmicas e 18 relativos à dissertação). Dado o caráter interdisciplinar do campo da saúde pública, o mestrando poderá contar com a colaboração de mais dois orientadores, além do orientador principal. O doutorado completa-se no máximo em 4 anos em um total de 96 créditos,sendo 60 créditos acadêmicos e 36 para elaboração da tese.

QUALIFICAÇĀO: a qualificação para o Mestrado consiste na defesa do projeto da dissertação, perante uma banca examinadora designada pela CPG, de três professores doutores, sendo, no minimo, um externo à ENSP.Para o Doutorado, o aluno deverá ser submetido a um Exame de Qualificação até o final do 2. ano do curso, que compreende 2 partes: apresentação do projeto da tese e um artigo 
científico, dentro da área da saúde pública, publicado durante a vigência do doutorado ou a ser publicado.

O trabalho final de Doutorado consiste em um trabalho original, de alta qualificação, que pode ter uma das seguintes formas: tese no formato original; coletânea de artigos publicados sobre o tema escolhido para o aprofundamento do doutorado; livro sobre o tema estudado. A defesa da tese, far-se-á perante uma banca composta por cinco membros, com título de doutor ou equivalente, sendo dois externos à instituição.

\subsubsection{FACULDADE DE SAÚDE PÚBLICA DA UNIVERSIDADE DE SÃO PAULO (FSP/USP)}

Sua origem remonta a 1918, com o chamado "Laboratório de Higiene", uma cátedra da Faculdade de Medicina. Em 1925 deixa de ser dependência direta da Faculdade de Medicina, passando a denominar-se "Instituto de Higiene de São Paulo". Em 1931 o Instituto foi reconhecido como Escola de Higiene e Saúde Pública, e incorporado à Universidade de São Paulo em 1938, como uma de suas instituições complementares subordinada à Cadeira de Higiene da Faculdade de Medicina. Tornase uma instituição autônoma de ensino superior da USP em 1945 (Decreto lei n. 14.857, de 10 de julho de 1945), sob a denominação de Faculdade de Higiene e Saúde Pública. Em 1969, a Faculdade de Higiene e Saúde Pública passou a denominar-se Faculdade de Saúde Pública, constituindo-se hoje em uma das 33 unidades de ensino superior que compõem a Universidade de São Paulo. Pelo Parecer n.77/69 do C.E.Su., foram estabelecidos os requisitos para os cursos de pós-graduação "strictu sensu" - Mestrado e Doutorado - passando a ministrá-los a partir de 1970.

CURSOS: Mestrado em Saúde Pública (início em 1970)

Doutorado em Saúde Pública (início em 1970)

\footnotetext{
- Informaçōes extraídas dos catálogos da ABRASCO9 (1992) e da FSP/USP ${ }^{94.95}$ (1989, 1990).
} 
OBJETIVO DOS CURSOS: Formar docentes e/ou pesquisadores que exerçam ou venham a exercer atividades na(s) área(s) acadêmica e/ou de pesquisa e/ou de prestação de serviço.

ÁREAS DE CONCENTRAÇÃO: Administração Hospitalar; Epidemiologia; Nutrição; Saúde Ambiental e Serviços de Saúde Pública.

CLIENTELA: docentes, pesquisadores e profissionais graduados que apresentem os requisitos exigidos.

FORMA DE SELEÇÃO/INGRESSO: condicionada a um exame de habilitação eliminatório (proficiência em idioma estrangeiro) e prova escrita para avaliar capacidade de interpretação, sintese, expressão e análise de textos sob a responsabilidade da Comissão de Pós-Graduação (CPG) e uma seleção a cargo do Departamento onde se situam as áreas de conhecimento de escolha do candidato. É facultado a ele inscrever-se em duas áreas de conhecimento, estabelecendo qual é a prioritária.

REGIME E DURAÇĀO: Regime em tempo integral. Os candidatos a Mestrado devem completar mínimo de 120 unidades de crédito, distribuídas entres disciplinas (mínimo 90 créditos) e preparo da dissertação (30 créditos). O programa de Mestrado compreende a apresentação da respectiva dissertação e não poderá ser concluido em prazo inferior a um ano e superior a cinco anos. Os candidatos a Doutorado devem completar 240 unidades de crédito, sendo 120 correspondentes aquelas exigidas para o curso de nível Mestrado e as demais distribuidas entre aulas formais, trabalhos de laboratório e estágio (mínimo 40 créditos) e pesquisa e preparo da tese (80 créditos). 0 programa de Doutorado compreende a apresentação da respectiva tese e não poderá ser concluido em prazo inferior a dois anos e superior a cinco anos. 
QUALIFICAÇĀO: O projeto de pesquisa com vista à Dissertação e à Tese, deve ser aprovado em Exame Geral de Qualificação, perante uma Comissão Julgadora constituída por três membros sendo um externo ao Departamento e da qual o orientador é membro nato e seu presidente. Defesa da Dissertação e Tese: antes da defesa final, as dissertações e teses são apresentadas em forma de minuta para os membros titulares da banca emitirem parecer escrito sobre as mesmas, após entrevista (individual ou coletiva) com o candidato. Após esta pré-banca, no prazo de 60 dias, o candidato deverá apresentar cópia de sua dissertação ou tese, na forma definitiva, para ser marcada a sessão pública de arguição e julgamento. As Dissertações e Teses serão defendidas frente a uma comissão julgadora constituida de 3 e 5 membros, respectivamente, portadores no mínimo do título de Doutor, sendo membro nato o orientador do candidato. No caso de Mestrado, um dos membros e respectivo suplente deve ser estranho ao Departamento e no Doutorado, no mínimo dois membros e respectivos suplentes (p.29)

\subsubsection{INSTITUTO DE MEDICINA SOCIAL DA UNIVERSIDADE ESTAUAL DO RIO DE JANEIRO (IMS/UERJ)}

O Instituto de Medicina Social da Universidade Estadual do Rio de Janeiro, assume sua identidade, com objetivos delineados, em 1974, com o início das atividades do Mestrado em Medicina Social (até então ligado à Faculdade de Ciências Médicas). O primeiro credenciamento obtido do Curso de Mestrado junto ao CFE foi em 1982. Este curso passou por mudanças inovadoras, dentre as quais se destaca a sua abertura para outras categorias profissionais do setor saúde e das ciências sociais, com sua transformação no Mestrado em Saúde Coletiva por ocasião de seu recredenciamento

\footnotetext{
"Informaçōes extraídas dos catálogos da ABRASCO9" (1992) e do IMS/UERJ'", (1996).
} 
em 1987. Em 1991 inicia as atividades do curso de Doutorado em Saúde Coletiva.

CURSO: Mestrado em Saúde Coletiva (início em 1974)

Doutorado em Saúde Coletiva (início em 1991)

OBJETIVO: Formar pessoal capacitado a desenvolver pesquisa, ensino e prestação de serviço no campo da Saúde Coletiva; desenvolver instrumentos de reflexão sobre a medicina como prática social, analisando a gênese e desenvolvimento do conhecimento e das práticas de saúde, bem como suas dimensões técnicas, econômicas e político-ideológicas

ÁREAS DE CONCENTRAÇÃO: Ciências Humanas em Saúde; Epidemiologia;Política, Planejamento e Administração de Saúde

CLIENTELA: Graduados em ciências humanas ou profissionais de nivel universitário com especialização em saúde coletiva e áreas afins.

FORMA DE SELEÇÄO/INGRESSO: Subordinada a uma prova de língua estrangeira; prova escrita sobre temas de escolha do candidato; entrevista e avaliação do currículo. Todas essas etapas são eliminatórias.

REGIME E DURAÇÃO: Regime em tempo integral. A duração mínima para o Mestrado é de 18 meses e máxima de 36 meses, perfazendo um total de 120 unidades de crédito. O curso de Doutorado, com duração mínima de 2 e máxima de 4 anos, compreende 240 unidades de crédito, sendo 120 correspondentes aos créditos do curso de nivel de Mestrado e 120 distribuídos em atividades acadêmicas do Programa de Pós-Graduação (40 créditos) e 80 créditos para pesquisa e preparação de tese. 
QUALIFICAÇÃO: Tanto para o Mestrado como para o Doutorado, o aluno deverá ser submetido à defesa de sua dissertação ou tese, perante uma comissão julgadora composta por 3 e 5 docentes, respectivamente, sendo, no mínimo, um externo à instituição. Os projetos da dissertação e da tese são aprovados previamente em Exame de Qualificação.

\subsection{PERÍODO DE ESTUDO}

O período selecionado para constituir o universo das teses estudadas foi de 5 anos - 1990 a 1994 - o mais recente, de maior interesse, e detentor de $41,0 \%$ do total das dissertações/teses defendidas nas escolas selecionadas. Este período, com o início dos anos 90, serve como marco inicial para posteriores estudos sobre dissertações e teses no campo da saúde pública.

\subsection{LEVANTAMENTO DOS DADOS}

As dissertações e teses, objeto de estudo do presente trabalho, foram identificadas através de listas fornecidas pelas seções de pós-graduação, das respectivas Unidades, onde as mesmas foram apresentadas e também por listas impressas diretamente de bases de dados automatizadas, confrontadas com catálogos publicados (ENSP/FIOCRUZ ${ }^{34}, 1994 ;$ FSP/USP $\left.^{96}, 1993\right)$.

Para a obtenção dos dados que deveriam ser analisados, as Bibliotecas das Unidades estudadas prestaram sua colaboração fornecendo fotocópias das folhas de rosto, dos resumos e das listagens das referências bibliográficas das Dissertações e Teses defendidas de 1990 a 1994. Considerou-se, na identificaçāo, o ano de sua defesa e não o ano de sua apresentação impressa, indicado na folha de rosto das mesmas. Conforme previamente estipulado, a data limite para o recebimento dessas cópias foi o final do mês de julho de 1995. A definição desta data levou em conta questões de ordem prática, com o prazo máximo de sete meses, para que todas as dissertações e teses estivessem disponiveis no acervo das Bibliotecas. Alguns fatores 
impediram que a totalidade do universo desses documentos pudesse ser analisado, conforme relato a seguir.

Após a sua defesa, as dissertações e teses são encaminhadas às bibliotecas das unidades estudadas para preservação da memória documental das mesmas, onde são processadas e dispostas para o acesso dos usuários. O período dispendido nesse preparo técnico é bastante variado, sendo, em média, de um mês, segundo informações de técnicos especializados que trabalham no setor.

Excepcionalmente, pode ocorrer que algumas dissertações e teses, após a sua defesa, devam passar por algumas correçōes ou alterações, pelos seus autores, sugeridas pelos membros da banca examinadora, antes de se tornarem disponiveis para o acesso do público. Quando isso ocorre, não se sabe ao certo o período de tempo que o aluno dispōe para re-preparar a tese para sua liberação definitiva. Segundo informações obtidas das Bibliotecas, pode levar até mais de um ano para que o documento corrigido chegue à biblioteca para poder ser devidamente processado e disseminado. Mesmo com reclamações efetuadas, o que na verdade se verifica é a não existência de um controle mais rígido por parte dos responsáveis no cumprimento dos prazos para a entrega das dissertações ou teses nas bibliotecas das unidades. Segundo o "Regimento Interno dos Cursos de Pós-Graduação "strictu sensu" em Saúde Pública" da ENSP/FIOCRUZ ${ }^{36}$ (1996), os pós-graduandos têm três meses para realizar as modificaçōes sugeridas, por escrito, pela banca examinadora, no caso da tese ter sido "aprovada com restriçōes".

Estes fatos, aliados às ocorrências de perdas e desvios desse material bibliográfico das estantes das bibliotecas, contribuíram para a não realização da análise da totalidades das dissertações e teses defendidas nas unidades dentro do período estipulado. 


\subsection{UNIVERSO DE ESTUDO}

O universo de estudo foi constituído por 350 documentos, sendo 266 dissertações de mestrado e 84 teses de doutorado, equivalente a $90,9 \%$ do total defendido no periodo. Este universo agrupado pelas Unidades apresentou a seguinte distribuição: $86,6 \%$ da ENSP/FIOCRUZ, $100 \%$ da FSP/USP e $66,7 \%$ do IMS/UERJ (Gráfico 1).

GRÁFICO 1 - Proporção das Dissertaçōes de Mestrado e Teses de Doutorado Defendidas e Analisadas (1990-1994)

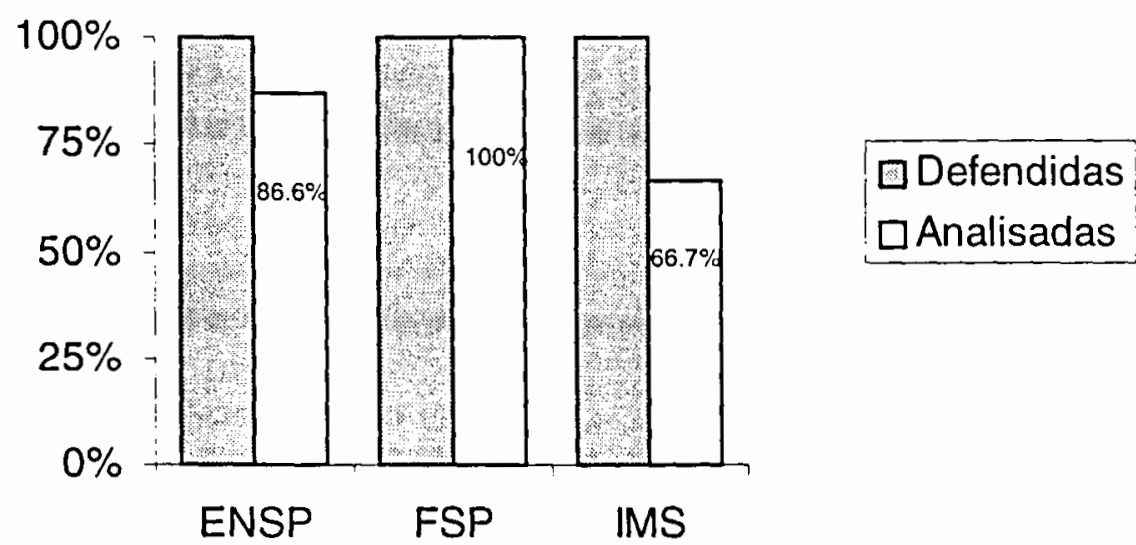

Deve-se esclarecer que o IMS, com menor representatividade (66,7\%), deveria participar com mais seis dissertações (defendidas, uma em 1992 e cinco em 1994), que, no entanto, não puderam ser consideradas para o presente estudo pelo fato das informações terem chegado após o prazo estipulado e a presente pesquisa já se encontrar em andamento. Além disso, não constou desta análise a única tese de doutorado defendida nessa Unidade, até então, por não estar disponivel no acervo da Biblioteca, na ocasião do fornecimento dos dados. 


\subsection{PROCEDIMENTO DAS ANÁLISES}

O universo de estudo, formado por 350 unidades, foi analisado considerando-se as seguintes categorias: análise das dissertações/teses pela natureza da pesquisa e pela temática, análise da divulgação e análise das citações.

Os dados referentes a cada uma dessas análises foram registrados em planilhas desenhadas (modelos em Anexo 3) e ingressados em bases de dados criadas em computador (ver item 3.7-Registro dos Dados), gerados especificamente para esta finalidade.

\subsubsection{CARACTERIZAÇĀO DAS DISSERTAÇÕES/TESES}

As Dissertaçōes de Mestrado e Teses de Doutorado foram analisadas segundo a natureza da pesquisa realizada, nas categorias denominadas pesquisas Básica e Aplicada, e a temática conforme o vocabulário DeCS (Descritores em Ciências da Saúde), elaborado pela BIREME.

Pela impossibilidade de acesso ao original das 350 dissertações e teses, a identificaçäo da natureza da pesquisa e da temática foi feita pela análise das informações contidas nas cópias dos resumos recebidos.

Para a classificação do universo de estudo, nessas duas características, contou-se, respectivamente, com a colaboração de profissionais docentes da área de metodologia da pesquisa e de técnicos especializados na indexação de documentos em bases de dados especializadas na área.

A maioria dos resumos permitiu a identificação dos objetos e objetivos dos estudos, bem como a metodologia utilizada e os principais resultados e conclusões obtidos. Em alguns deles os objetivos não estavam claros, confundindo-se com o objeto de estudo. Isto, de certa forma, dificultou a classificação dos tipos de pesquisa, e, também a dos assuntos. 


\subsubsection{NATUREZÁ DA PESQUISA}

As dissertações/teses, foram agrupadas segundo a natureza da pesquisa em "Básica" e "Aplicada". Essa tipologia foi estabelecida a partir da análise dos objetivos, principais resultados e conclusões constantes dos resumos analisados. Com base na literatura consultada foram estipulados os seguintes critérios para a classificação dos tipos de pesquisa:

- Para os trabalhos categorizados como pesquisa BÁSICA, levou-se em conta o objetivo voltado ao conhecimento do tema estudado sem indicação explícita à aplicação dos resultados em solução de problemas práticos. Assim, os trabalhos deveriam enquadrar-se nos seguintes critérios: reflexões em torno de um tema, baseado ou não em revisão bibliográfica; trabalho experimental sem vista de aplicação específica; análise de dados, de fatos, para formulação de teorias, leis, hipóteses, aperfeiçoamento de metodologias existentes. Esses critérios foram operacionalizados em trabalhos que abrangeram, sobretudo, estudos taxonômicos; estudos de microorganismos, descrição ou identificação de novas espécies de agente infeccioso, estabelecimento de padrões, sempre quando não identificada sua aplicação prática.

- Na categoria APLICADA foram incluídos trabalhos que se enquadravam nos critérios: manipulação de dados para composição de novos grupos, novos modelos, com determinação de possíveis usos de descobertas; definição de novos métodos ou maneiras para se alcançar certos objetivos; sugestões de melhorias de serviços com aperfeiçoamento de dados existentes; enfim, trabalhos que visavam a solucionar problemas práticos e tomada de decisões também voltados a serviços. Esses critérios foram identificados em estudos exploratórios e descritivos onde são relatados características de uma população ou amostra, de instituiçōes; estudos de diagnósticos; estudos de hábitos alimentares; conhecimentos, atitudes e práticas; desenvolvimento de ações educativas; ecologia de vetores com medidas preventivas; dentre outros. Tais temas, sempre voltados à solução de problemas de saúde da população, foram 
abordados a partir de sua identificação, justificativa do porquê de sua ocorrência, e apresentação de medidas para a melhoria das condições de saúde da população e do atendimento dos serviços e ela prestados.

\subsubsection{ANÁLISE TEMÁTICA}

A análise temática das dissertações/teses foi feita com base nos descritores extraídos do vocabulário DeCS. Este foi criado para classificar os documentos que sustentam as bases de dados bibliográficos da BIREME (a hierarquização dos grandes assuntos desse Vocabulário é mostrada no Anexo 2). O DeCS é composto por 16 categorias de assuntos principais que, por sua vez, subdividem-se em outras subcategorias. Desde 1987, quando em sua primeira edição, este vocabulário vem sendo periodicamente atualizado, incorporando às suas categorias e respectivas subcategorias de assuntos, novos descritores que frequentemente aparecem na literatura latino-americana.

Das 16 categorias do DeCS, uma é dedicada ao campo da Saúde Pública (SP) que está representada por seis sub-categorias, a saber:

SP-1 Administração e Planejamento de Saúde

SP-2 Cuidados de Saúde

SP-3 Demografia

SP-4 Saúde Ambiental

SP-5 Epidemiologia e Estatística

SP-6 Nutrição

A classificação temática das dissertaçōes/teses analisadas deu-se nessa categoria (SP) e respectivas sub-categorias. Quando os assuntos não se enquadravam nas subcategorias da SP-Saúde Pública, "Outras” categorias foram incluídas.

Para cada dissertação/tese foi identificado um único descritor (termo que expressa conceitos) considerado o principal, que poderia ou não vir acompanhado de 
seu qualificador (termo que, acrescido aos assuntos, permite definir aspectos particulares dos mesmos).

Desta forma, a abordagem temática foi focalizada nos aspectos geral e específico nas áreas da categoria SP (Saúde pública) e demais categorias agrupadas em "outras áreas".

Com esta análise temática objetiva-se detectar a tendência das dissertações/teses, isto é, a que assuntos estão mais voltados os interesses das. pesquisas dos alunos dos cursos de pós-graduação em saúde pública, e o grau de continuidade temporal dos mesmos, isto é, se o interesse por determinados temas mantém-se estável no periodo estudado ou sofre uma queda na produção em um periodo, revitalizando-se posteriormente em outros. Além disso, pretende-se conhecer se os temas abordados nestes recentes cinco anos (1990-1994) estão evidenciando a preocupação com novos problemas emergentes de saúde e/ou reafirmando a outros existentes, desde o ínicio dos anos 90.

\subsubsection{ANÁLISE DA DIVULGAÇÃO}

Para se conhecer o alcance de divulgação das dissertações/teses, após a sua defesa e aprovação, foi verificada a sua indexação, no formato original, em bases de dados bibliográficos especializadas e a sua eventual publicação por processos convencionais em outros formatos (livros, artigos, etc.). Para a consulta às bases de dados foi considerado um período de 9 meses de carência, ou seja, de tempo entre a apresentação e indexação nas fontes bibliográficas. Assim, ficou estabelecido a consulta às bases de dados em setembro de 1995. Para o conhecimento da divulgação em outro formato foi determinado o período de 13 meses (fevereiro de 1996), entre a aprovação da dissertação/tese, e sua eventual reformulação em outro formato para fins 
de publicação. Para a coleta dessa informação foram utilizadas as bases de dados bibliográficos, além das informações obtidas diretamente dos professores-orientadores.

\subsubsection{INDEXAÇÃO EM BASES DE DADOS BIBLIOGRÁFICOS}

Esta análise foi direcionada para identificar a divulgação das dissertações e teses, em formato original, nas bases de dados bibliográficos automatizadas.

Foram selecionadas as principais bases bibliográficas, nacionais e latinoamericanas, disponíveis em CD-ROM, em setembro de 1995, e que apresentassem características em comum, quanto a sua abrangência na cobertura dos temas da saúde pública no período de 1990 a 1994 , e que fossem de fácil acesso para a comunidade acadêmica. Não foram considerados as bibliografias e os catálogos impressos na área, por não se apresentarem atualizados no periodo estudado.

As bases de dados selecionadas, cujo levantamento foi feito pelo sobrenome dos autores, foram as seguintes:

- LILACS (Literatura Latino-Americana em Ciências da Saúde) - produzida pela BIREME (Sistema Latino-Americano e do Caribe de Informação em Ciências da Saúde). Reúne referências bibliográficas e resumos de livros, artigos de periódicos, teses, relatórios técnicos, documentos governamentais, comunicações em eventos, entre outros documentos produzidos na América Latina e no Caribe, retrospectivos a 1982, na área das ciências da saúde. É alimentada com informações bibliográficas fornecidas pelas bibliotecas que fazem parte da rede BIREME. A consulta foi feita na base LILACS/CD-ROM , 22a. ed., maio de 1995.

\footnotetext{
"Esclarece-se que o LILACS/CD-ROM inclui, além da base de dados LILACS, outras, dentre as quais, REPIDISCA e AD-SAÚDE., objeto de análise do presente trabalho.
} 
- REPIDISCA (Rede Pan-Americana de Informação e Documentação em Engenharia Sanitaria e Ciências do Ambiente) - Coordenada pelo CEPIS (Centro Panamericano de Ingenieria Sanitaria y Ciencias del Ambiente), de Lima, Peru, e alimentada pelos Centros Cooperantes da rede. Arrola referências bibliográficas e resumos de documentos convencionais e nãoconvencionais sobre engenharia sanitaria e ciências ambientais, produzidas na América Latina e no Caribe, desde 1980, além do acervo do CEPIS. Consulta em base LILACS/CD-ROM, na 22a. ed., maio de 1995.

- AD-SAUDE - Base nacional cooperativa, inclui documentos publicados por autores brasileiros no campo da administração de serviços de saúde. Coordenada pela Biblioteca da FSP/USP, recebe contribuições de sete Centros Cooperantes brasileiros da área, com informações produzidas desde 1986. A pesquisa foi feita "on-line" em rede local, com dados ingressados na base até 15 de setembro de1995 (mais atualizados que a edição em CDROM).

- TESES - Base de dados do IBICT (Instituto Brasileiro de Informação em Ciência e Tecnologia), reúne referências bibliográficas de teses e dissertações defendidas no Brasil ou por brasileiros no exterior, nas áreas de Ciência e Tecnologia, provenientes de bases de dados dos sistemas IBICT, BIBLIODATAVALCO da FGV, do SABI (Sistema de Automação de Bibliotecas) da UFRGS, do SIBI (Sistema Integrado de Bibliotecas) da USP, e da CAPES. A consulta foi feita na base em CD-ROM, edição de 1993 e complementada por acesso "on-line", na rede Antares do IBICT, em setembro de 1995. 


\subsubsection{DIVULGAÇÃO EM OUTROS FORMATOS}

Para complementar as informações sobre a divulgação das dissertações/teses, procurou-se conhecer se as mesmas, após a sua defesa e aprovação, foram divulgadas em forma de documento convencional (livros, capitulos de livro, artigos de periódico,e mesmo como comunicações em eventos). Para isso foram consultadas as mesmas edições das bases de dados bibliográficas especializadas: LILACS, REPIDISCA e ADSAUDE. Foi solicitada também a colaboração dos respectivos professores-orientadores, a partir de um quadro onde estavam relacionadas as dissertações/teses sob sua orientação, para informar se era ou não de seu conhecimento a publicação do respectivo material e em que formatos: livro, capítulo, artigos de periódico ou outra forma (a especificar). Esta consulta foi realizada nos meses de janeiro e fevereiro de 1996.

\subsubsection{ANÁLISE DAS CITAÇÕES BIBLIOGRÁFICAS}

A citação bibliográfica, conforme já mencionado por RODRIGUES ${ }^{84}$ (1982, p.36), refere-se ao "conjunto de uma ou mais referências bibliográficas, que incluídas em uma publicação, evidenciam elos entre indivíduos, instituições e áreas de pesquisa, visto que mostram o relacionamento de uma publicação com outra".

A presente análise previu a categorização das referências bibliográficas incluídas nas dissertações e teses identificando-as segundo os diferentes tipos de documentos utilizados, sua temporalidade, idioma e procedência geográfica. Além disso, foram identificados os tipos de autoria e o núcleo dos títulos de periódicos mais citados.

O número de referências bibliográficas identificadas nas 350 dissertações e teses analisadas foi bastante volumoso, perfazendo um total de 35.505 citações (média 
de 101 citações/documento), sendo 24.098 para as 266 Dissertações de Mestrado e 11.407 referências mencionadas nas 84 Teses de Doutorado. Não foram computadas neste total, 299 citações referentes a "citação de citação", isto é, quando o mesmo documento era citado mais de uma vez na listagem das referências bibliográficas com indicação da parte citada pela expressão "apud" (citado por).

Para a presente análise, tendo em vista o tamanho deste universo, as referências bibliográficas foram selecionadas através de processo de amostragem.

\subsubsection{AMOSTRAGEM}

Na determinação da amostra, os trabalhos foram separados em cinco estratos definidos segundo instituição e grau (mestrado e doutorado). Do total de citações existentes em cada estrato $(\mathrm{Nh})$ foram sorteadas $\mathrm{Nh}$ citaçōes pelo processo de amostragem sistemática. Cada tamanho $\mathrm{Nh}$ foi definido proporcionalmente ao número de citações Nh, adotando-se intervalo de sorteio igual para os cinco estratos (KALTON, $1983)^{49}$. O tamanho da amostra em cada estrato foi definido de forma a assegurar erro amostral para as frequências relativas estimadas nas tabelas referidas não superiores a 0,07. O tamanho total da amostra foi estabelecido em 6.019 citações.

Para o sorteio da amostra das citações, os documentos foram agrupados alfabeticamente pelos sobrenomes dos autores, segundo o grau (Mestrado e Doutorado) e o ano da defesa (1990-1994) para cada uma das três instituiçōes (ENSP, FSP e IMS). As referências bibliográficas foram numeradas sequencialmente.

As citações sorteadas, segundo o critério de amostragem adotado, foram assinaladas nas listagens das referências bibliográficas. Os elementos de identificação que compõem essas citações, sorteadas como amostra, foram transportados diretamente para uma base de dados especialmente criada para esta finalidade (ver "Registro de Dados" - item 3.7). 
Cada referência bibliográfica sorteada foi classificada quanto à tipologia do documento, temporalidade, idioma, origem geográfica, tipo de autoria e núcleo dos periódicos mais citados.

\subsubsection{TIPOS DOS DOCUMENTOS CITADOS}

Os documentos citados foram classificados nos seguintes tipos:

a) LIVROS E CAPITULOS DE LIVROS - São considerados como livros as publicaçōes que desenvolvem informaçōes de um ou vários temas congêneres, agrupados em capitulos, ou em vários volumes, de um ou com a colaboração de vários autores (individuais ou institucionais). Em Conferência da Unesco, em 1964, o livro foi definido como a publicação impressa não-periódica com pelo menos 49 páginas sem se considerar as capas (HARROD, 1984) ${ }^{46}$.

b) ARTIGOS DE PERIÓDICOS - contribuição escrita de uma ou várias pessoas publicada em um periódico que se caracteriza como publicação editada em fascículos, com o mesmo título, em intervalos regulares ou não, durante período não definido $\left(\right.$ HARROD, 1984) ${ }^{46}$.

c) DISSERTAÇÕES E TESES - segundo definiçōes da $A_{B N T^{8}}$ (1984, p.2) Dissertação é o "documento que representa o resultado de um trabalho experimental ou exposiçāo de um estudo científico recapitulativo, de tema único e bem delimitado em sua extensão, com o objetivo de reunir, analisar e interpretar informações. Deve evidenciar o conhecimento de literatura existente sobre o assunto e a capacidade de sistematização do candidato. É feito sob orientação de um pesquisador, visando a obtenção do título de Mestre"; e Tese é o "documento que representa o resultado de um 
trabalho experimental de tema especifico e bem delimitado. Deve ser elaborado com base em investigação original, constituindo-se em real contribuição para a especialidade em questão. Visa a obtenção do título de Doutor ou Livre-Docente". Nesta categoria estão incluídas as dissertações e teses defendidas nas diversas instituições de ensino e pesquisa, nacionais e estrangeiras, classificadas segundo o grau em: Mestrado, Doutorado, Livre-docência, Cátedra e "outro". As duas primeiras, conforme mencionado, são defendidas por alunos como produto final de cursos de pós-graduação, níveis mestrado e doutorado; a Livre-docência é uma tese apresentada nas universidades pelo docente que desejar ascender na carreira acadêmica, após o doutorado, não estando mais vinculada a cursos de pós-graduação. A tese de Cátedra, extinta em 1968 com a reforma universitária, era elaborada para a obtenção do grau acadêmico mais elevado da carreira docente.Quando o grau não estava mencionado, as teses foram classificadas na categoria "outro".

Além do grau, as dissertaçōes e teses citadas foram categorizadas segundo sua institução de origem em: ENSP, FSP, IMS, Outras instituições nacionais e Instituições do exterior.

d) COMUNICAÇÕES EM EVENTOS - nesta categoria incluem-se os artigos ou trabalhos apresentados em eventos técnico-científicos (conferências, seminários, congressos, jornadas, etc.), divulgados ou não nos Anais (registro publicado de encontros de sociedades e instituições, frequentemente acompanhado dos trabalhos na integra ou em forma de resumo (HARROD, 1984) ${ }^{46}$. Foram também considerados neste item, os Anais dos eventos quando citados no seu todo, isto é, sem destacar nenhum trabalho.

e) RELATÓRIOS TÉCNICOS - documentos que divulgam formalmente os resultados ou os progressos de pesquisas através de relatos elaborados por indivíduos ou grupos de especalistas. (CAMPELLO, 1982) 
f) OUTRAS PUBLICAÇÕES - foram incluídos nesta categoria todos os documentos, convencionais ou não convencionais, que não se enquadraram nas categorias anteriormente citadas, tais como legislação, dados estatísticos, dicionários, folhetos, enciclopédias, documentos internos, entre outros.

\subsubsection{TEMPORALIDADE DOS DOCUMENTOS CITADOS}

A temporalidade do documento citado foi medida em relação ao ano da defesa da tese e agrupada nas categorias: até 2 anos; de 3 a 5 anos; de 6 a 10 anos; de 11 a 20 anos; com mais de 20 anos. Quando o ano da publicação citada não foi identificado, a mesma foi agrupada no item "sem data".

\subsubsection{IDIOMA DOS DOCUMENTOS CITADOS}

As citações foram classificadas segundo o idioma da publicação em: português; inglês; espanhol; francês; italiano; alemão; "outros". No caso de publicação bilingue foi considerado o idioma de maior divulgação internacional.

\subsubsection{PROCEDÉNCIA GEOGRÁFICA DOS DOCUMENTOS CITADOS}

Nesta categoria foi considerado o país (ou região) de origem onde foi editado o documento citado, como: Brasil; América Latina ; Estados Unidos da América; Inglaterra; França ; Itália; Alemanha; "Outros" países/regiões. Para a identificação dos locais não mencionados nas citações, nos casos de artigos de periódicos, foram consultados: guia internacional de periódicos ("Ulrich's International Periodicals Directory"), listagem dos títulos indexados no Index Medicus e Excerpta Medica, bases de dados SeCS (Seriados em Ciências da Saúde) da BIREME, CCN-Catálogo Coletivo Nacional, do IBICT, e UNIBIBLI (catálogo coletivo - livros, teses, periódicos - das três universidades paulistas: USP, UNICAMP e UNESP). 


\subsubsection{TIPO DE AUTORIA DOS DOCUMENTOS CITADOS}

Os documentos foram classificados segundo o tipo de autoria em: única (documentos produzidos sob a responsabilidade intelectual de um só autor); múltipla (documentos produzidos sob a responsabilidade intelectual de dois ou mais autores); institucional (documentos produzidos em nome de uma institutição); e, "sem autoria" (quando não mencionada ou não identificada).

\subsubsection{NÚCLEO DOS TÍTULOS DOS PERIÓDICOS CITADOS}

No caso de citação de artigo de periódicos, o título do mesmo foi transcrito visando identificar o núcleo de periódicos mais citados nos trabalhos analisados. 0 registro foi feito pelo título completo e por extenso, sem a indicação de preposições e artigos. Como a maioria das citações apresentava os títulos de forma abreviada, foram consultadas as mesmas fontes utilizadas na identificação da localização geográfica dos periódicos.

Para a análise dos dados das citações dos periódicos foi adotada a metodologia de Bradford (BRADFORD, 1961)" que, embora tenha sido estabelecida em 1934, para avaliar a dispersão de artigos de periódicos, é usada também na avaliação do uso de periódicos (consulta, empréstimo), na avaliação de artigos indexados em fontes secundárias e em análises de citação. Assim, essa metodologia permite que os dados agrupados, segundo a ordem de frequência de sua utilização, determinem os títulos de maior ou menor demanda de uso (frequência de citação). 


\subsection{REGISTRO DOS DADOS}

Os dados coletados foram armazenados em duas bases de dados criadas em dBASE IV: uma para registro das caracteristicas formais das teses, utilizada para as análises de sua caracterização (item 3.6.1) e de divulgação (item 3.6.2), e outra específica para a análise das citações (item 3.6.3).

Para a análise conjunta dos dados foi utilizado o "software" SPSS (Statistical Package for Social Sciences) através do qual os dados estudados foram trabalhados e representados em tabelas e gráficos. Este programa permitiu também a elaboração de listagens dos títulos de periódicos citados nos trabalhos, além dos assuntos específicos das dissertações e teses estudadas. 


\section{RESULTADOS E DISCUSSÃO}

A tabulação dos dados levantados referentes às propostas do presente trabalho, apresentou o seguinte resultado:

\subsection{CARACTERIZAÇÃO DAS DISSERTAÇÕES E TESES}

A análise dos 350 documentos foi realizada considerando-se as características da produção, segundo o grau acadêmico: 266 dissertações de mestrado (76,0\%) e 84 teses de doutorado $(24,0 \%)$.

A Tabela 1 mostra a distribuição das dissertações e teses segundo a instituição onde foram apresentadas e o ano de sua defesa (1990 a 1994).

Verifica-se que as dissertações de mestrado defendidas nas três instituições, mantêm equilíbrio entre a FSP (45,9\%) e ENSP (42,1\%), totalizando, ambas, 88,0\% da produção total no período. Já para os doutorados nota-se predomínio da FSP com $86,9 \%$; as demais foram defendidas na ENSP (13,1\%). No IMS não figura nenhuma tese de doutorado. Embora o curso de doutorado nesse Instituto tenha iniciado em 1991, foi defendida uma tese nesse periodo que, no entanto, não foi objeto de estudo desta pesquisa, conforme mencionado (item 3.5).

A análise cronológica mostra um aumento da produção de dissertações/teses, principalmente comparando $1990 \mathrm{com} 1991$ (+63,0\% de aumento no total geral, com predomínio para os mestrados). Após uma queda em $1992(-10,7 \%)$, foi retomado o crescimento, com maior acréscimo de 1993 para 1994 (+28,2\%) por influência da FSP, com maior número de documentos. O maior crescimento da produção na ENSP deu-se de 1992 para 1993. Já o IMS,de 1991 para 1992, teve um aumento bastante alto $(85,1 \%)$ comparado ao total dos dois anos anteriores, mostrando uma queda nos anos seguintes. Este resultado talvez seja reflexo da mudança ocorrida no curso de pós- 
graduação desse Instituto, ocorrida em 1987, quando seu curso de mestrado em Medicina Social se transforma em Saúde Coletiva ${ }^{93}$ (p.7).

Tomando-se como referencial os anos de 1990 e 1994, houve um aumento da produção total de mestrados da ordem de $91,0 \%$ e de $115,4 \%$ para os doutorados. Este dado, baseado na produção de teses, sugere estar havendo uma demanda maior para os cursos de doutorado, que apresentou um aumento, nos últimos dois anos (1993 e 1994), de $33,3 \%$ na ENSP e de $100,0 \%$ na FSP, percentagens essas maiores do que as verificadas no aumento dos mestrados ( $10,7 \%$ para a ENSP e $52,6 \%$ para a FSP). O IMS deteve 40,6\% de sua produção no ano de 1992, declinando a partir de então.

De modo geral, as instituições estudadas mantêm uma certa instabilidade quanto ao número de teses defendidas, com totais variados nos cinco anos. 
Tabela 1 - Dissertações de Mestrado (M) e Teses de Doutorado (D) analisadas, segundo as Instituiçōes e Ano de Defesa.

\begin{tabular}{|c|c|c|c|c|c|c|c|c|c|c|c|c|c|c|c|c|}
\hline \multirow{3}{*}{ Ano/Defesa } & \multicolumn{4}{|c|}{ ENSP } & \multicolumn{4}{|c|}{ FSP } & \multirow{2}{*}{\multicolumn{2}{|c|}{$\frac{\text { IMS }}{M}$}} & \multicolumn{4}{|c|}{ TOTAL } & \multicolumn{2}{|c|}{ TOTAL GERAL } \\
\hline & \multirow[t]{2}{*}{$M$} & \multirow[t]{2}{*}{$D$} & \multicolumn{2}{|c|}{ Total } & \multirow[t]{2}{*}{$M$} & \multirow[t]{2}{*}{$D$} & \multicolumn{2}{|c|}{ Total } & & & \multicolumn{2}{|c|}{$M$} & \multicolumn{2}{|c|}{ D } & \multirow[b]{2}{*}{$N$} & \multirow[b]{2}{*}{$\%$} \\
\hline & & & $N$ & $\%$ & & & $N$ & $\%$ & $N$. & $\%$ & N. & $\%$ & $N$. & $\%$ & & \\
\hline 1990 & 10 & - & 10 & 8.1 & 18 & 13 & 31 & 15.9 & 5 & 15.6 & 33 & 12.4 & 13 & 15,5 & 46 & 13.1 \\
\hline 1991 & 29 & 4 & 33 & 26.8 & 32 & 8 & 40 & 20,5 & 2 & 6.3 & 63 & 23,7 & 12 & 14,3 & 75 & 21,4 \\
\hline 1992 & 14 & - & 14 & 11,4 & 24 & 16 & 40 & 20,5 & 13 & 40,6 & 51 & 19,2 & 16 & 19,0 & 67 & 19,1 \\
\hline 1993 & 28 & 3 & 31 & 25,2 & 19 & 12 & 31 & 15,9 & 9 & 28,1 & 56 & 21,0 & 15 & 17,9 & 71 & 20,3 \\
\hline 1994 & 31 & 4 & 35 & 28,5 & 29 & 24 & 53 & 27,2 & 3 & 9.4 & 63 & 23.7 & 28 & 33,3 & 91 & 26,0 \\
\hline TOTAL & $\begin{array}{c}112 \\
(42,1) \\
\end{array}$ & $\begin{array}{c}11 \\
(13,1) \\
\end{array}$ & 123 & 100 & $\begin{array}{r}122 \\
(45,9) \\
\end{array}$ & $\begin{array}{r}73 \\
(86,9) \\
\end{array}$ & 195 & 100 & $\begin{array}{c}32 \\
(12,0) \\
\end{array}$ & 100,0 & $\begin{array}{l}266 \\
176,0 \\
\end{array}$ & $\begin{array}{l}100,0 \\
\% \\
\end{array}$ & $\begin{array}{l}84 \\
(24,0 \\
\end{array}$ & $\begin{array}{l}100,0 \\
\end{array}$ & $\begin{array}{c}350 \\
(100,0)\end{array}$ & 100,0 \\
\hline
\end{tabular}




\subsubsection{NATUREZA DA PESQUISA}

A distribuição das dissertações e teses, considerada segundo a natureza da pesquisa - Básica e Aplicada - pode ser vista na Tabela 2. Assim, pelos resultados obtidos verifica-se que a pesquisa Aplicada predomina $(77,4 \%)$, tanto na produção das dissertações de mestrado $(76,3 \%)$ como na de teses de doutorado $(80,6 \%)$ defendidas nas três Unidades de ensino selecionadas. O percentual de pesquisas Básicas é de $22,6 \%$, embora os Mestrados (23,7\%) apresentem uma pequena superioridade em relação aos Doutorados $(19,4 \%)$.

A análise por Instituição mostra tendências diferenciadas de acordo com os niveis de Mestrado e Doutorado, mas com o predominio de pesquisas Aplicadas. Considerando-se as Unidades em separado, na ENSP destacam-se os Doutorados, com predominância para a pesquisa Básica $(63,6 \%)$ e os Mestrados a Aplicada $(67,9 \%)$. Na FSP o predomínio é das pesquisas Aplicadas, tanto para os Mestrados $(88,5 \%)$ como para os Doutorados $(87,7 \%)$; mantém a mesma tendência para o desenvolvimento da pesquisa Básica (aproximadamente 12,0\%) em relação às Aplicadas (aproximadamente $88,0 \%$ ), tanto no nivel mestrado como doutorado.

Por outro lado, a ENSP mostra tendências opostas para as linhas de mestrado (32,1\% para Básica e 67,9\% para Aplicadas) em comparação com as de doutorado (63,6\% para Básica e 36,4\% para Aplicada). O curso do IMS em nível de mestrado, apresenta uma diferença menor entre as pesquisas Básicas $(40,6 \%)$ e Aplicadas $(59,4 \%)$. Estes dados, no seu conjunto, confirmam a tendência da área para as pesquisas Aplicadas. 
Tabela 2 - Dissertações de Mestrado e Teses de Doutorado analisadas, segundo Categorias de Pesquisa

\begin{tabular}{|c|c|c|c|c|c|c|c|c|c|c|c|c|c|c|}
\hline \multirow{3}{*}{ Categorias Pesquisa } & \multicolumn{4}{|c|}{ ENSP } & \multicolumn{4}{|c|}{ FSP } & \multicolumn{2}{|c|}{ IMS } & \multicolumn{2}{|c|}{ TOTAL } & \multicolumn{2}{|c|}{ TOTAL GERAL } \\
\hline & \multirow[t]{2}{*}{$M$} & \multirow[t]{2}{*}{ D } & \multicolumn{2}{|c|}{ Total } & \multirow[t]{2}{*}{ M } & \multirow[t]{2}{*}{$D$} & \multicolumn{2}{|c|}{ Total } & \multicolumn{2}{|c|}{$M$} & \multirow[t]{2}{*}{ M } & \multirow[t]{2}{*}{$\mathrm{D}$} & \multirow[t]{2}{*}{$\mathrm{N}$} & \multirow[t]{2}{*}{$\%$} \\
\hline & & & N. & $\%$ & & & N. & $\%$ & 1 & $\%$ & & & & \\
\hline Básica & $\begin{array}{c}36 \\
(32,1)\end{array}$ & $\begin{array}{c}7 \\
(63,6)\end{array}$ & 43 & 35,0 & $\begin{array}{c}14 \\
(11,5)\end{array}$ & $\begin{array}{c}9 \\
(12,3)\end{array}$ & 23 & 11,8 & 13 & 40,6 & $\begin{array}{c}63 \\
(23,7)\end{array}$ & $\begin{array}{c}16 \\
(19,4)\end{array}$ & 79 & 22,6 \\
\hline Aplicada & $\begin{array}{c}76 \\
(67,9)\end{array}$ & $\begin{array}{c}4 \\
(36,4)\end{array}$ & 80 & 65,0 & $\begin{array}{c}108 \\
(88,5)\end{array}$ & $\begin{array}{c}64 \\
(87,7)\end{array}$ & 172 & 88,2 & 19 & 59,4 & $\begin{array}{c}203 \\
(76,3)\end{array}$ & $\begin{array}{c}68 \\
(80,6)\end{array}$ & 271 & 77,4 \\
\hline TOTAL & $\begin{array}{c}112 \\
(100,0)\end{array}$ & $\begin{array}{c}11 \\
(100,0)\end{array}$ & 123 & 100 & $\begin{array}{c}122 \\
(100,0)\end{array}$ & $\begin{array}{c}73 \\
(100,0)\end{array}$ & 195 & 100,0 & 32 & 100,0 & $\begin{array}{c}266 \\
(100,0)\end{array}$ & $\begin{array}{c}84 \\
(100,0)\end{array}$ & 350 & 100,0 \\
\hline
\end{tabular}


A Tabela 3 mostra a distribuição cronológica segundo as categorias de pesquisa, com certo equilíbrio na produção anual, permitindo, no entanto, verificar que o percentual das pesquisas Básicas, em confronto com as Aplicadas, tende a crescer no período, ficando entre $19,6 \%$ e $24,2 \%$ da produção anual total; as pesquisas Aplicadas detêm entre $80,4 \%$ e $76,0 \%$ dessa produção.

Ao se considerar o ano de defesa das dissertaçōes/teses (Tabela 3) verifica-se um aumento de 29,4\% para as pesquisas Básicas nos últimos dois anos (1993 e 1994), e de $27,8 \%$ para as pesquisas Aplicadas. As pesquisas Básicas, mesmo em menor número, vêm aumentando proporcionalmente a cada ano.

Tabela 3 - Categorias de Pesquisa das Dissertaçōes de Mestrado e Teses de Doutorado analisadas, segundo o Ano de Defesa

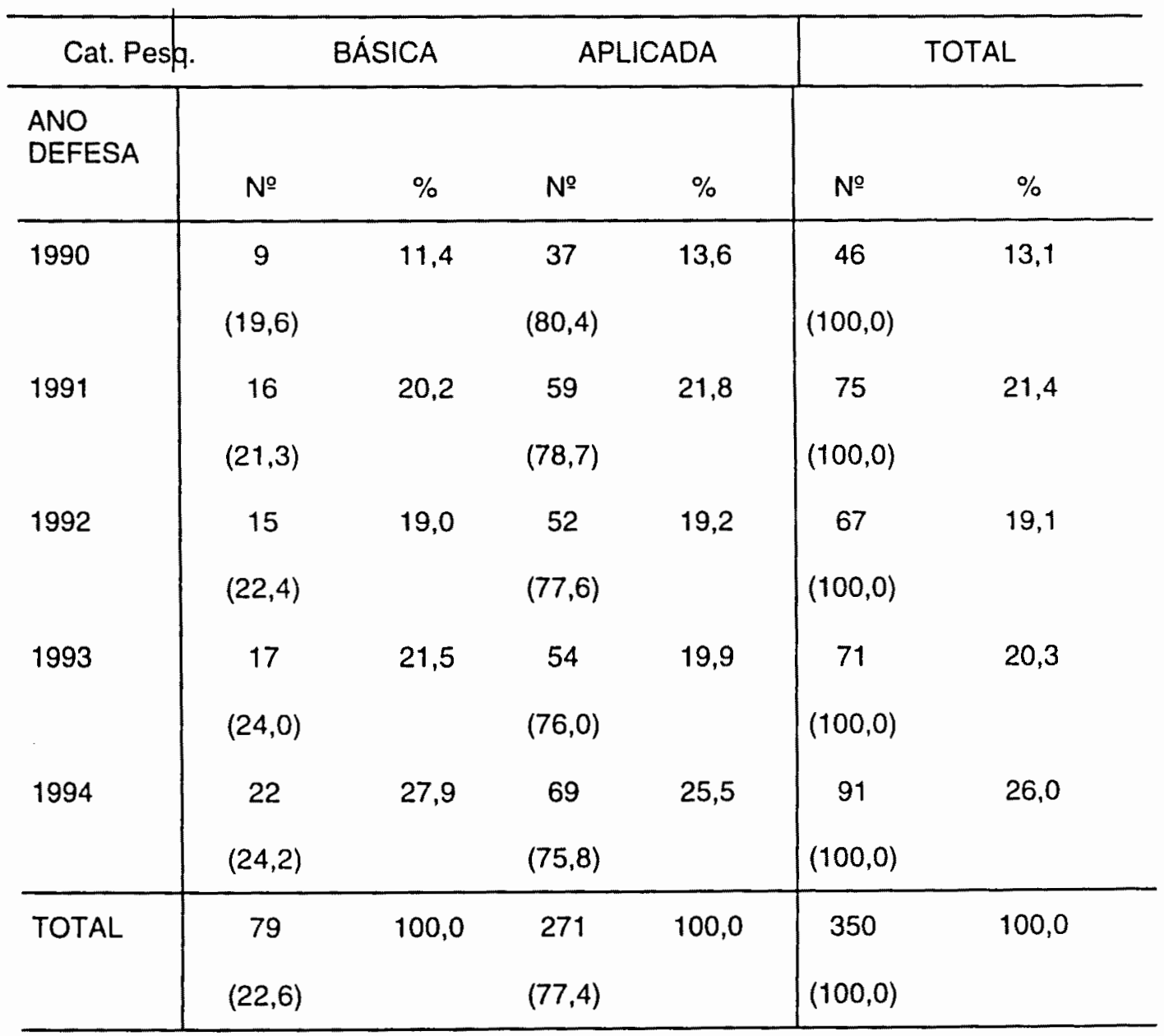

Resultados semelhantes aos do presente trabalho foram encontrados por $\operatorname{ANDRADE}^{6}$ (1992), mediante a análise da produtividade de docentes de cursos de pós- 
graduação em saúde pública, onde predominaram os artigos de pesquisa Aplicada e Operacional no total de $81,9 \%$. Apenas 18,1\% dos artigos eram de natureza Básica.

Outros resultados semelhantes foram encontrados em trabalhos que procuraram caracterizar a produção bibliográfica na área da saúde divulgada em diferentes formatos. A relação a seguir (Quadro 1) mostra alguns trabalhos realizados que agruparam a produtividade científica e acadêmica em saúde, segundo a natureza da pesquisa.

Quadro 1 - Trabalhos que caracterizam a produção científica e acadêmica em saúde, segundo a natureza da pesquisa.

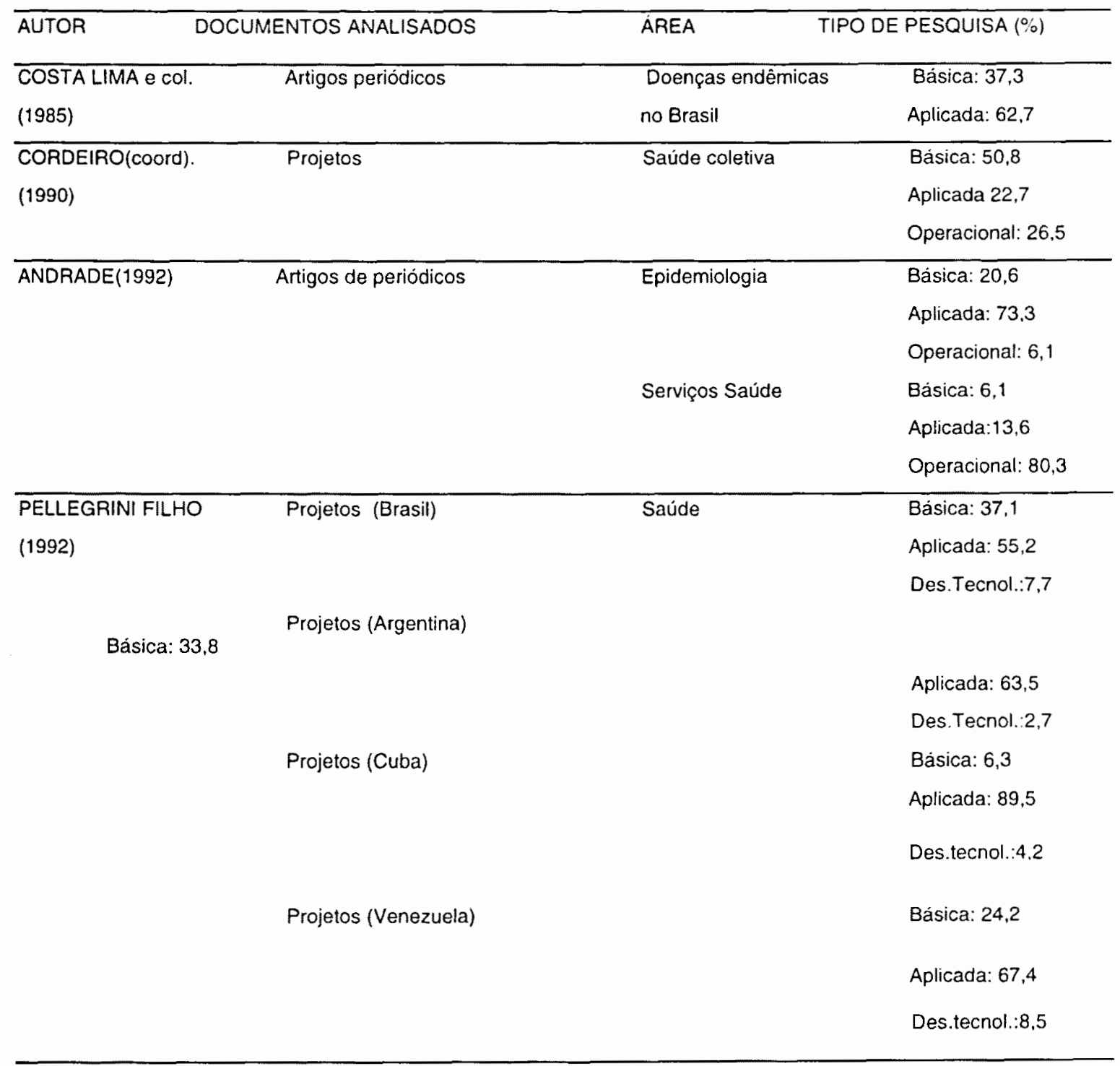


Por esses trabalhos verifica-se que tanto os artigos publicados como os projetos de pesquisa, no campo da saúde pública/coletiva, tendem à pesquisa Aplicada, com exceção do levantamento feito por CORDEIRO e col. ${ }^{23}$ (1990) que mostra 50,8\% dos projetos de pesquisa de natureza Básica.

Esta tendência pode ser explicada na colocação apresentada por RIBEIRO ${ }^{80}$ (1986), de que a escassez de recursos humanos e econômicos dos países subdesenvolvidos favorece a "ênfase na pesquisa aplicada como forma de economizar recursos e atingir resultados práticos a curto prazo" (p.27), conferindo-lhe prioridade enquanto "condicionante imediato do desenvolvimento" (p.27). Esta situação vem, de certa forma, ao encontro dos achados de $\mathrm{KUNSCH}^{52}$ (1992, p.46) onde a maioria das pesquisas realizadas em 29 universidades brasileiras estudadas, era dirigida à solução de problemas práticos (62,07\% de pesquisas Aplicadas).

\subsubsection{ANÁLISE TEMÁTICA}

Conforme já mencionado, o campo da Saúde Pública está representado na categoria "SP" do vocabulário DeCS que, por sua vez, subdivide-se em seis subcategorias e, nas quais, as dissertações e teses foram classificadas. Quando o assunto não se enquadrava em nenhuma das sub-categorias, as respectivas dissertações/teses eram agrupadas em um único tópico denominado "Outras áreas"

A distribuição das dissertações e teses segundo sua classificação por assunto, nas sub-categorias componentes da categoria SP-Saúde Pública, denominadas doravante de "áreas DeCS", pode ser vista na Tabela 4.

Predominam nas dissertações e teses $(52,5 \%)$ os assuntos relacionados a duas áreas: Epidemiologia e Estatística $(29,1 \%)$ e a Cuidados de Saúde $(23,4 \%)$. Este quadro 
permanece quando se analisa comparativamente o total dos trabalhos segundo o grau: $53,4 \%$ dos mestrados e $50,0 \%$ dos doutorados são voltados a essas duas áreas.

Nas demais áreas, para os mestrados e para os doutorados, a ordem de prioridade é a seguinte: Saúde Ambiental (14,3\%); Administração e Planejamento em Saúde $(12,0 \%)$ e Nutrição $(6,6 \%)$. Chama a atenção o fato de que a sub-categoria SP3-Demografia está representada por apenas quatro mestrados, equivalentes a $1,1 \%$ do total dos documentos, ou, $1,5 \%$ das dissertaçōes estudadas. $O$ número é bastante reduzido, o que parece estar relacionado, entre outros, ao fato de poder não ter sido considerado como assunto principal aspectos sobre fecundidade, mortalidade geral ou infantil, relacionados à "dinâmica populacional", como parte desta sub-categoria.

Os trabalhos agrupados em "Outras áreas" somam 47 documentos $(13,4 \%)$, distribuidos, de acordo com o grau, em 31 mestrados $(11,6 \%)$ e 16 doutorados $(19.0 \%)$. Esses resultados estão refletindo não só a multidisciplinaridade da saúde pública que, arrolando uma gama variada de temas que não se enquadram totalmente na categoria SP-Saúde Pública, mas, sobretudo, sugere que essa categoria do DeCS pode não estar atendendo, a contento, a temática desenvolvida nos trabalhos desse campo. Este é um fator de grande importância, e merece reavaliações, uma vez que a recuperação dos trabalhos nas bases de dados especializadas, de maior alcance aos profissionais da saúde em nivel nacional (LILACS, REPIDISCA, AD-SAÚDE), é feita mediante estratégias de busca com descritores desse vocabulário. 
Tabela 4 - Dissertaçōes de Mestrado e Teses de Doutorado analisadas, segundo as Áreas de Assuntos do DeCS.

\begin{tabular}{|c|c|c|c|c|c|c|c|c|c|c|c|c|c|c|c|c|}
\hline \multirow{2}{*}{ Áreas - DeCS } & \multicolumn{4}{|c|}{ ENSP } & \multicolumn{4}{|c|}{ FSP } & \multicolumn{2}{|c|}{ IMS } & \multicolumn{4}{|c|}{ TOTAL } & \multicolumn{2}{|c|}{ TOTAL GERAL } \\
\hline & $M$ & $D$ & \multicolumn{2}{|c|}{$\mathrm{N} .{ }^{\text {Total }} \%$} & $M$ & $D$ & \multicolumn{2}{|c|}{ Total } & \multicolumn{2}{|c|}{$M$} & \multicolumn{2}{|c|}{$M$} & \multicolumn{2}{|c|}{ D. } & $N$ & $\%$ \\
\hline SP-1 & 24 & 2 & 26 & 21,1 & 6 & 6 & 12 & 6,2 & 4 & 12,5 & $\begin{array}{l}34 \\
(81,0)\end{array}$ & 12,8 & $\begin{array}{c}8 \\
(19,0)\end{array}$ & 9,5 & $\begin{array}{c}42 \\
(100,0)\end{array}$ & 12,0 \\
\hline$S P \cdot 2$ & 23 & 2 & 25 & 20,3 & 31 & 17 & 48 & 24,6 & 9 & 28,1 & $\begin{array}{l}63 \\
(76,8)\end{array}$ & 23,7 & $\begin{array}{c}19 \\
(23,2)\end{array}$ & 22,6 & $\begin{array}{c}82 \\
(100,0)\end{array}$ & $23, .4$ \\
\hline SP-3 & $\cdot$ & - & $\cdot$ & & 1 & $\cdot$ & 1 & 0,5 & 3 & 9.4 & $\stackrel{4}{(100,0)}$ & 1,5 & & - & $\begin{array}{c}4 \\
(100,0)\end{array}$ & 1,1 \\
\hline SP-4 & 12 & 1 & 13 & 10,6 & 23 & 11 & 34 & 17,4 & 3 & 9,4 & $\begin{array}{l}38 \\
(76,0)\end{array}$ & 14,3 & $\begin{array}{c}12 \\
(24,0)\end{array}$ & 14,3 & $\begin{array}{c}50 \\
(100,0)\end{array}$ & 14,3 \\
\hline SP-5 & 42 & 3 & 45 & 36,6 & 31 & 20 & 51 & 26,2 & 6 & 18.7 & $\begin{array}{l}79 \\
(77,5)\end{array}$ & 29,7 & $\begin{array}{l}23 \\
(22,5)\end{array}$ & 27,4 & $\begin{array}{c}102 \\
(100,0)\end{array}$ & 29,1 \\
\hline SP.6 & 4 & - & 4 & 3.3 & 12 & 6 & 18 & 9,2 & 1 & 3,1 & $\begin{array}{l}17 \\
(73,9)\end{array}$ & 6,4 & $\begin{array}{l}6 \\
(26,1)\end{array}$ & 7,2 & $\begin{array}{c}23 \\
(100.0)\end{array}$ & 6,6 \\
\hline OUTRAS & 7 & 3 & 10 & 8.1 & 18 & 13 & 31 & 15,9 & 6 & 18,8 & $\begin{array}{l}31 \\
(66,0)\end{array}$ & 11,6 & $\begin{array}{l}16 \\
(34,0)\end{array}$ & 19,0 & $\begin{array}{c}47 \\
(100,0)\end{array}$ & 13,4 \\
\hline TOTAL & 112 & 11 & 123 & 100 & 122 & 73 & 195 & 100. & 32 & 100,0 & 266 & 100,0 & 84 & 100,0 & 350 & 100,0 \\
\hline
\end{tabular}

SP-1 - Administração e Planejamento em Saúde

SP-2 - Cuidados de Saúde

SP-3 - Demografia

SP.4 - Saúde Ambiental

SP-5 - Epidemiologia e Estatística

SP.6 - Nutrição

"Outras" áreas 
Nesse mesmo sistema, cruzando a temática com a natureza da pesquisa (Básica e Aplicada), a Tabela 5 confirma o predomínio de trabalhos de natureza Aplicada com percentuais acima de $80 \%$ na maioria das áreas. As exceções são encontradas em: Demografia (SP-3), com uma única dissertação de natureza Aplicada (25,0\%); na área de Administração e Planejamento em Saúde (SP-1) que mantém um equilíbrio $(50,0 \%)$ entre ambas; e no conjunto das "Outras" áreas onde a categoria Aplicada corresponde a $66,0 \%$. Por outro lado, as sub-categorias que mais contribuiram para as pesquisas Aplicadas foram, em primeiro lugar a SP-5-Epidemiologia e Estatística (32,5\%) seguida da SP-2-Cuidados de Saúde $(24,3 \%)$.

O predomínio da pesquisa Aplicada em mais de $80 \%$ para os trabalhos nas subcategorias SP-2, SP-4, SP-5 e SP-6 vem confirmar que essas são áreas de ação, isto é, as dissertaçōes e teses ai classificadas tendem a temas de utilização mais imediata dos resultados.

Os trabalhos de natureza Básica são mais representados na sub-categoria SP-1Administração e Planejamento em Saúde $(26,6 \%)$, com maior destaque para os da ENSP. Seguem-se as sub-categorias "Cuidados de Saúde" (SP-2) e as "Outras" áreas com o mesmo percentual de $20,25 \%$. Os trabalhos dessa natureza nessas áreas têm por meta o aumento do conhecimento na área, mas cuja aplicação não é imediata, requerendo, talvez, maior número de investigações sobre os temas estudados, para posterior aplicação. Em princípio, todas as pesquisas básicas, um dia, deverão ser aplicadas, ou, como já mencionado por FORATTINI ${ }^{29}$ (1995) "toda pesquisa científica é, precipuamente de natureza básica" (p.82).

Os trabalhos de natureza Básica e classificados em "Outras áreas" somam 16 documentos $(20,3 \%$ do total das pesquisas básicas $)$, percentualmente superior aos 31 documentos de natureza Aplicada ( $11,4 \%$ do total das pesquisas aplicadas), o que vem 
mais uma vez mostrar que os documentos classificados nos assuntos da categoria SPSaúde Pública são mais voltados a trabalhos visando aplicação de seus achados.

Conforme mencionado, a cada Dissertação e Tese, foi dado um único assunto específico, identificado por descritores componentes das sub-categorias do sistema DeCS, considerado como principal ou aquele que se revelasse mais representativo ao seu conteúdo. Para alguns casos foram agregados aos assuntos, termos (qualificadores) que permitiram melhor determinar a temática desses documentos. É o caso de trabalhos referentes a aspectos epidemiológicos de doenças que foram classificados na sub-categoria SP-5 (Epidemiologia e Estatística), porém, quando tratavam do aspecto do diagnóstico das doenças foram colocados em "Outras áreas".

Os Quadros 2 a 8 mostram os 210 descritores que determinaram os conteúdos das 350 dissertações/teses analisadas, agrupadas de acordo com as categorias mais abrangentes. Verifica-se, então, a existência de uma variedade bastante acentuada de assuntos, correspondendo a 1,7 trabalhos por descritor. A sub-categoria SP-5 (Epidemiologia e Estatística) mostrou maior concentração de teses por descritor $(1,9)$ evidenciando menor variedade de temas. As 47 dissertações/teses agrupadas em "outras áreas" foram classificadas em 40 assuntos diferentes, ou seja, 1,1 trabalho/descritor, mostrando grande diversidade temática, consequência, talvez, das diferentes formaçōes profissionais dos autores. 
Tabela 5 - Categorias de Pesquisa das Dissertações de Mestrado e Teses de Doutorado analisadas, segundo as Àreas de Assuntos do DeCS.

\begin{tabular}{|c|c|c|c|c|c|c|c|c|c|c|}
\hline \multirow{2}{*}{$\begin{array}{l}\text { Cat. Pesq. } \\
\text { Areas DeCS }\end{array}$} & \multicolumn{2}{|c|}{ ENSP (M-D) } & \multicolumn{2}{|c|}{ FSP $(M-D)$} & \multicolumn{2}{|c|}{$\operatorname{IMS}(M)$} & \multicolumn{2}{|c|}{ TOTAL } & \multicolumn{2}{|c|}{ TOTAL GERAL } \\
\hline & Básica & Aplicada & Básica & Aplicada & Básica & Aplicada & Básica & Aplicada & $N$ & $\%$ \\
\hline SP-1 & 16 & 10 & 2 & 10 & 3 & 1 & ${ }_{(50,0)}^{21} 26,6$ & $\begin{array}{l}21 \quad 7,8 \\
(50,0)\end{array}$ & $\begin{array}{c}42 \\
(100,0)\end{array}$ & 12,0 \\
\hline SP-2 & 10 & 15 & 3 & 45 & 3 & 6 & ${ }_{(19,5)}^{16} 20,2$ & $\begin{array}{l}66 \quad 24,3 \\
(80,5)\end{array}$ & $\begin{array}{c}82 \\
(100,0)\end{array}$ & 23,4 \\
\hline SP-3 & - & - & - & 1 & 3 & - & $\begin{array}{c}3 \\
(75,0)\end{array}$ & $\begin{array}{l}1 \quad 0,4 \\
(25,0)\end{array}$ & $\begin{array}{c}4 \\
(100,0)\end{array}$ & 1,1 \\
\hline SP-4 & 3 & 10 & 3 & 31 & - & 3 & $\begin{array}{cc}6 & 7,6 \\
(12,0) & \end{array}$ & $\begin{array}{l}44 \quad 16,2 \\
(88,0)\end{array}$ & $\begin{array}{c}50 \\
(100,0)\end{array}$ & 14,3 \\
\hline$S P-5$ & 8 & 37 & 5 & 46 & 1 & 5 & $\begin{array}{l}1417,7 \\
(13,7)\end{array}$ & $\begin{array}{l}88 \quad 32,5 \\
(86,3)\end{array}$ & $\begin{array}{c}102 \\
(100,)\end{array}$ & 29,1 \\
\hline SP-6 & 2 & 2 & 1 & 17 & - & 1 & $\underset{(13,0)}{3} 3,8$ & $\begin{array}{l}207,4 \\
(87,0)\end{array}$ & $\begin{array}{c}23 \\
(100,0)\end{array}$ & 6,6 \\
\hline OUTRAS & 4 & 6 & 9 & 22 & 3 & 3 & $\begin{array}{l}16 \quad 20,3 \\
(34,0) \\
\end{array}$ & $\begin{array}{l}31 \quad 11,4 \\
(66,0) \\
\end{array}$ & $\begin{array}{c}47 \\
(100,0) \\
\end{array}$ & 13,4 \\
\hline TOTAL & $\begin{array}{c}43 \\
(54,4)\end{array}$ & $\begin{array}{c}80 \\
(29,5)\end{array}$ & $\begin{array}{c}23 \\
(29,1)\end{array}$ & $\begin{array}{c}172 \\
(63,5) \\
\end{array}$ & $\begin{array}{c}13 \\
(16,5)\end{array}$ & $\begin{array}{c}19 \\
(7,0)\end{array}$ & $\begin{array}{l}79 \quad 100,0 \\
(22,6)\end{array}$ & $\begin{array}{l}271100,0 \\
(77,4)\end{array}$ & $\begin{array}{c}350 \\
(100,0) \\
\end{array}$ & 100,0 \\
\hline
\end{tabular}

SP-1 - Administração e Planejamento em Saúde

SP-2 - Cuidados de Saúde

SP-3 - Demografia

SP-4 - Saúde Ambiental

SP-5 - Epidemiologia e Estatística

SP-6 - Nutrição

"Outras" áreas 
As sub-categorias DeCS estão resumidas, a seguir, destacando-se os aspectos que caracterizam as pesquisas a nivel mestrado e doutorado.

a) SP-1 - a área da "Administração e Planejamento em Saúde" (Quadro 2) incluiu 42 trabalhos, sendo a grande maioria $(81,0 \%)$ constituída pelos mestrados. Esta área arrola trabalhos que se referem a conceitos relacionados com a efetividade, a suficiência e a eficiência dos serviços de saúde. O assunto "Política de saúde" (nove no total) foi o mais desenvolvido nesta área, principalmente nas dissertações, onde a preocupação da pesquisa está voltada a mostrar a necessidade dos governos levarem adiante a tarefa de melhorar a saúde da população com medidas e decisões através de uma política sanitária nacional.

\begin{tabular}{|c|c|c|c|}
\hline SP-1 ADMINISTRAÇÃO E PLANEJAMENTO EM SAÚDE & $M$ & $\mathrm{D}$ & TOTAL \\
\hline $\begin{array}{l}\text { ADMINISTRAÇÃO FARMACÊUTICA } \\
\text { Uso de Medicamentos }\end{array}$ & 2 & - & 2 \\
\hline $\begin{array}{l}\text { ADMINISTRAÇĀO FINANCEIRA } \\
\text { Administraçăo Financeira de Hospitais } \\
\text { Orçamento }\end{array}$ & $\begin{array}{l}1 \\
1\end{array}$ & $\begin{array}{l}- \\
-\end{array}$ & $\begin{array}{l}1 \\
1\end{array}$ \\
\hline $\begin{array}{l}\text { DIREITOS HUMANOS } \\
\text { Direito à Saúde } \\
\text { Direito dos Deficientes }\end{array}$ & $\begin{array}{l}1 \\
1\end{array}$ & - & $\begin{array}{l}1 \\
1\end{array}$ \\
\hline $\begin{array}{l}\text { PLANEJAMENTO EM SAÚDE } \\
\text { Conselhos de Planejamento em Saúde } \\
\text { Prioridades em Saúde }\end{array}$ & $\begin{array}{l}3 \\
1 \\
-\end{array}$ & - & $\begin{array}{l}3 \\
1 \\
1\end{array}$ \\
\hline $\begin{array}{l}\text { PRÁTICA PROFISSIONAL } \\
\text { Ética } \\
\text { Ética Médica }\end{array}$ & $\begin{array}{l}3 \\
-\end{array}$ & $\dot{1}$ & $\begin{array}{l}3 \\
1 \\
1\end{array}$ \\
\hline $\begin{array}{l}\text { POLITICAS DE SAÚDE } \\
\text { Política Habitacional }\end{array}$ & $\begin{array}{l}7 \\
1\end{array}$ & $\begin{array}{l}1 \\
-\end{array}$ & $\begin{array}{l}8 \\
1\end{array}$ \\
\hline REFORMA SANITÁRIA & 1 & - & 1 \\
\hline $\begin{array}{l}\text { RELAÇÕES TRABALHISTAS } \\
\text { Sindicatos }\end{array}$ & 1 & - & 1 \\
\hline SISTEMAS DE SAÚDE & - & 1 & 1 \\
\hline SISTEMAS DE INFORMAÇĀO & 1 & - & 1 \\
\hline SISTEMAS LOCAIS DE SAÚDE & 6 & 1 & 7 \\
\hline $\begin{array}{l}\text { TÉCNICAS DE PLANEJAMENTO } \\
\text { Planejamento Estratégico } \\
\text { Planejamento Participativo }\end{array}$ & $\begin{array}{l}1 \\
2\end{array}$ & $\dot{1}$ & $\begin{array}{l}1 \\
3 \\
1\end{array}$ \\
\hline VIGILÂNCIA SANITÁRIA & 1 & - & 1 \\
\hline TOTAL ... & 34 & 8 & 42 \\
\hline
\end{tabular}


Outro tema que despertou interesse dos mestrandos (seis), nessa área, foi o desenvolvimento de pesquisas sobre "Sistemas Locais de Saúde" que abarca um conjunto de elementos que, inter-relacionados, contribuem para a saúde da população em locais determinados. Destacam-se ainda nesta área, os trabalhos desenvolvidos sobre "Planejamento em Saúde" que, junto aqueles voltados às "Técnicas de Planejamento" (participativo e estratégico), somam sete mestrados e três doutorados. O assunto "Práticas Profissionais" foi um dos escolhidos por três mestrandos e dois doutorandos. Outros demais assuntos foram abordados uma ou duas vezes pelas dissertações/teses, no periodo.

b) SP-2 - esta sub-categoria "Cuidados de Saúde" (Quadro 3), que se refere à promoção da saúde de modo geral, foi de interesse para o desenvolvimento de 63 mestrados e 19 doutorados. São trabalhos de temas sobre a promoção e manutenção da saúde física e mental da população, para grupos específicos como à saúde da mulher, escolar, infantil, para idosos, entre outros. Inclui ainda os serviços voltados à saúde comunitária como a educação do paciente, participações da comunidade e do paciente. Nestes assuntos, "Serviços de Saúde"e "Serviços de Saúde Comunitária", foram defendidas 26 dissertações e 8 teses. Além desses, são abordados temas sobre recursos institucionais (seis documentos relativos a centros de reabilitação, hospitais, centros de saúde) e recursos humanos em saúde, com nove documentos voltados às áreas hospitalar, farmacêutica, de enfermagem, etc. Destacam-se também, 12 trabalhos sobre cuidados especificos de saúde: como saúde bucal, ocular, saúde da mulher e do idoso, entre outros. Temas sobre "administração de serviços de saúde" foram tratados em oito mestrados e um doutorado. A "vacinação" como "Administração Jos Cuidados ao Paciente" foi estudada em quatro mestrados. 
QUADRO 3- Assuntos das Dissertações de Mestrado e Teses de Doutorado, da Categoria SP-2 - Cuidados de Saúde (DeCS)

\begin{tabular}{|c|c|c|c|}
\hline SP-2 - CUIDADOS DE SAÚDE & $M$ & $\mathrm{D}$ & TOTAL \\
\hline \multicolumn{4}{|l|}{ ADMINISTRAÇĀO CUIDADOS DO PACIENTE } \\
\hline Campanhas de Vacinação /Sarampo/ & 1 & - & 1 \\
\hline Vacina antivariólica & 1 & - & 1 \\
\hline Vacinaçāo & 2 & $\cdot$ & 2 \\
\hline \multicolumn{4}{|l|}{ ADMINISTRAÇĀO DE SERVICOS DE SAÚDE } \\
\hline Acesso aos Serviços de Saúde & 1 & - & 1 \\
\hline Administraçâo Hospitalar & 3 & - & 3 \\
\hline Necessidades e Demandas Serviços de Saúde & 3 & 1 & 4 \\
\hline Serviço de Limpeza & 1 & - & 1 \\
\hline \multicolumn{4}{|l|}{ CUIDADOS DE ENFERMAGEM } \\
\hline Enfermagem de Centro Cirúrgico & - & 1 & 1 \\
\hline Enfermagem de Saúde Pública & 1 & 2 & 3 \\
\hline Enfermagem Ocupacional & 1 & $\cdot$ & 1 \\
\hline Enfermagem Psiquiatrics & 1 & - & 1 \\
\hline \multicolumn{4}{|l|}{ CUIDADOS DE SAÚDE } \\
\hline Qualidade dos Cuidados de Saúde & 3 & - & 3 \\
\hline Saúde Bucal & 2 & 1 & 3 \\
\hline Saúde da Mulher & 1 & - & 1 \\
\hline Saúde do ldoso & - & 1 & 1 \\
\hline Saúde Ocular & 1 & $\cdot$ & 1 \\
\hline Avaliação de Processos de Resultados & & 2 & 3 \\
\hline RECURSOS HUMANOS EM SAU்DE & • & 1 & 1 \\
\hline Auxiliares de Enfermagem & 2 & - & 2 \\
\hline Farmacêuticos & 1 & $\cdot$ & 1 \\
\hline Nutricionistas & 1 & - & 1 \\
\hline Ocupaçōes em Saúde (Educação) & 1 & - & 1 \\
\hline Recursos Humanos em Entermagem & 1 & $\cdot$ & 1 \\
\hline Recursos Humanos em Hospitais & 1 & - & 1 \\
\hline Recursos Humanos em Odontologia & 1 & - & 1 \\
\hline \multicolumn{4}{|l|}{ RECURSOS EM SAÚDE - INSTITUICCÕES } \\
\hline Centros de Reabilitação & - & 1 & 1 \\
\hline Centros de Saúde & 1 & - & 1 \\
\hline Hospitais Psiquiátricos & 1 & - & 1 \\
\hline Instituiçōes de Saúde & 1 & - & 1 \\
\hline Laboratórios Hospitalares & - & 1 & 1 \\
\hline Ocupaçōes de Leitos & 1 & $\cdot$ & 1 \\
\hline SAÚDE PÚBLICA & 1 & $\cdot$ & 1 \\
\hline SEGURO SAÚDE & 1 & - & 1 \\
\hline SERVIÇOS DE SAU்DE & 7 & - & 7 \\
\hline Assistência à Saúde /Deficientes/ & 1 & - & 1 \\
\hline Cuidado Pré-Natal & 1 & $\cdot$ & 1 \\
\hline Serviços Emergência Psiquiátrica & 1 & - & 1 \\
\hline Serviços Saúde Bucal & - & 1 & 1 \\
\hline Serviços Saúde Escolar & 1 & - & 1 \\
\hline Serviços Saúde da Mulher & 1 & . & 1 \\
\hline Serviços Saúde Infantil & 1 & 1 & 2 \\
\hline Serviços Saúde Mental & 1 & - & 1 \\
\hline Serviços Saúde Ocupacional & 2 & - & 2 \\
\hline Serviços Saúde dos Idosos & - & 1 & 1 \\
\hline Unidade Hospitalar de Odontologia & 1 & - & 1 \\
\hline \multicolumn{4}{|l|}{ SERVIÇOS DE SAU்DE COMUNITÁRIA } \\
\hline Conhecimentos, Atitudes, Práticas & 2 & 3 & 5 \\
\hline Educação do Paciente & 1 & - & 1 \\
\hline Educação em Saúde & 4 & - & 4 \\
\hline Participação Comunitária & - & 1 & 1 \\
\hline Participaçāo do Paciente & 1 & - & 1 \\
\hline Atitude frente à Saúde & 1 & 1 & 2 \\
\hline TOTAL..... & 63 & 19 & 82 \\
\hline
\end{tabular}


c) SP-3 - O grupo de descritores que caracterizam os trabalhos da área "Demografia" (Quadro 4) refere-se a análise e descrição da população sob o ponto de vista de sua distribuição, suas características e seu controle. Três descritores identificaram as quatro dissertações que desenvolveram temas nessa área: duas sobre anticoncepção relacionadas aos métodos e planejamento familiar e duas voltadas ao estudo da características da população - trabalho feminino e trabalhadores idosos, com sua história de vida e memórias do trabalho.

QUADRO 4 - Assuntos das Dissertaçōes de Mestrado e Teses de Doutorado, da Categoria SP-3 - Demografia (DeCS)

\begin{tabular}{llll}
\hline SP-3 DEMOGRAFIA & $M$ & D & TOTAL \\
\hline & & & \\
PLANEJAMENTO FAMILIAR & 2 & - & 2 \\
Anticoncepção & & & \\
$\begin{array}{l}\text { FORÇAS DE TRABALHO } \\
\text { Trabalhadores Idosos } \\
\text { Trabalho Feminino }\end{array}$ & 1 & - & 1 \\
\hline \multicolumn{1}{c}{ TOTAL ...... } & 1 & - & 1 \\
\hline
\end{tabular}

d) SP-4 - Os estudos que envolvem a temática "Saúde Ambiental" (Quadro 5) são aqueles voltados ao equilibrio ecológico que deve existir entre o homem e o meio ambiente para o seu completo bem-estar fisico, mental e social. Foram 38 mestrados e 12 doutorados que abordaram temas sobre: "Abastecimento de água"(análise, consumo, qualidade); Saneamento (tratamento e disposição de águas residuárias, residuos sólidos); Saúde Ocupacional, voltados a condiçōes e Segurança do Trabalho; Meio Ambiente, enfocando planejamento ambiental, ecologia de vetores e poluição ambiental. $O$ interesse dos mestrandos em assuntos desta área está mais voltado ao estudo de "Saneamento"(13 dissertaçōes e um doutorado) enquanto os doutorandos voltaram-se mais para desenvolver trabalhos sobre qualidade e consumo da água (cinco teses e uma dissertação). 
QUADRO 5 - Assuntos das Dissertações de Mestrado e Teses de Doutorado, da Categoria SP-4 - Saúde Ambiental (DeCS)

\begin{tabular}{|c|c|c|c|}
\hline SP-4 SAÚDE AMBIENTAL & $M$ & $\mathrm{D}$ & TOTAL \\
\hline $\begin{array}{l}\text { ABASTECIMENTO DE ÁGUA } \\
\text { Consumo de Água } \\
\text { Qualidade da Água } \\
\text { Análise da Água /Represa/ }\end{array}$ & $\dot{-}$ & $\begin{array}{l}1 \\
1 \\
3 \\
-\end{array}$ & $\begin{array}{l}1 \\
1 \\
3 \\
1\end{array}$ \\
\hline $\begin{array}{l}\text { CONDIÇŌES DE TRABALHO } \\
\text { Ambiente de Trabalho } \\
\text { Trabalhos em Turnos }\end{array}$ & $\begin{array}{l}1 \\
1 \\
2\end{array}$ & $\dot{-}$ & $\begin{array}{l}1 \\
1 \\
2\end{array}$ \\
\hline $\begin{array}{l}\text { MEDICINA OCUPACIONAL } \\
\text { Doenças Ocupacionais }\end{array}$ & 2 & - & 2 \\
\hline $\begin{array}{l}\text { MEIO AMBIENTE } \\
\text { Planejamento Ambiental } \\
\text { Saúde Ambiental } \\
\text { Ecologia de Vetores }\end{array}$ & $\begin{array}{l}1 \\
5 \\
1 \\
2\end{array}$ & $\begin{array}{l}1 \\
- \\
-\end{array}$ & $\begin{array}{l}2 \\
5 \\
1 \\
2\end{array}$ \\
\hline $\begin{array}{l}\text { POLUIÇĀO AMBIENTAL } \\
\text { Poluição do Ar } \\
\text { Poluiçāo do Solo }\end{array}$ & $\begin{array}{l}1 \\
1\end{array}$ & 1 & $\begin{array}{l}2 \\
1\end{array}$ \\
\hline $\begin{array}{l}\text { SANEAMENTO } \\
\text { Águas Residuárias } \\
\text { Disposição de Águas Residuárias } \\
\text { Disposição de Residuos Sólidos } \\
\text { Saneamento Urbano } \\
\text { Tratamento de Águas Residuárias }\end{array}$ & $\begin{array}{l}2 \\
2 \\
2 \\
2 \\
4 \\
1\end{array}$ & $\begin{array}{l}- \\
\dot{.} \\
\dot{1} \\
-\end{array}$ & $\begin{array}{l}2 \\
2 \\
2 \\
3 \\
4 \\
1\end{array}$ \\
\hline SAÚDE OCUPACIONAL & 3 & 1 & 4 \\
\hline $\begin{array}{l}\text { SEGURANÇA DO TRABALHO } \\
\text { Acidentes do Trabalho } \\
\text { Exposiçāo Ocupacional } \\
\text { Riscos Ocupacionais }\end{array}$ & $\begin{array}{l}1 \\
2 \\
1\end{array}$ & $\begin{array}{l}1 \\
- \\
2\end{array}$ & $\begin{array}{l}2 \\
2 \\
3\end{array}$ \\
\hline TOTAL .... & 38 & 12 & 50 \\
\hline
\end{tabular}

e) SP-5 - "Epidemiologia e Estatística" (Quadro 6) - Os estudos epidemiológicos descrevem os agravos que ocorrem na população, apontando as causas e indicando os meios de controle e de profilaxia. A mensuração desses agravos é feita pela Estatística, cujos modelos, métodos e procedimentos visam a caracterizar e mensurar os problemas prioritários de saúde para futuro estabelecimento de programações de serviços de saúde. Esta área contou com maior número de trabalhos, tanto das dissertaçōes como das teses de doutorado. Do total desses estudos ( 79 mestrados e 23 doutorados), três mestrados e um doutorado abordam informações sobre "análises, métodos e procedimentos estatísticos"; os demais estão relacionados a trabalhos sobre levantamentos epidemiológicos, ou seja, à coleta de dados sobre saúde e doença de uma população, em áreas determinadas. 
QUADRO 6 - Assuntos das Dissertaçōes de Mestrado e Teses de Doutorado, da Categoria SP-5 - Epidemiologia e Estatistica (DeCS)

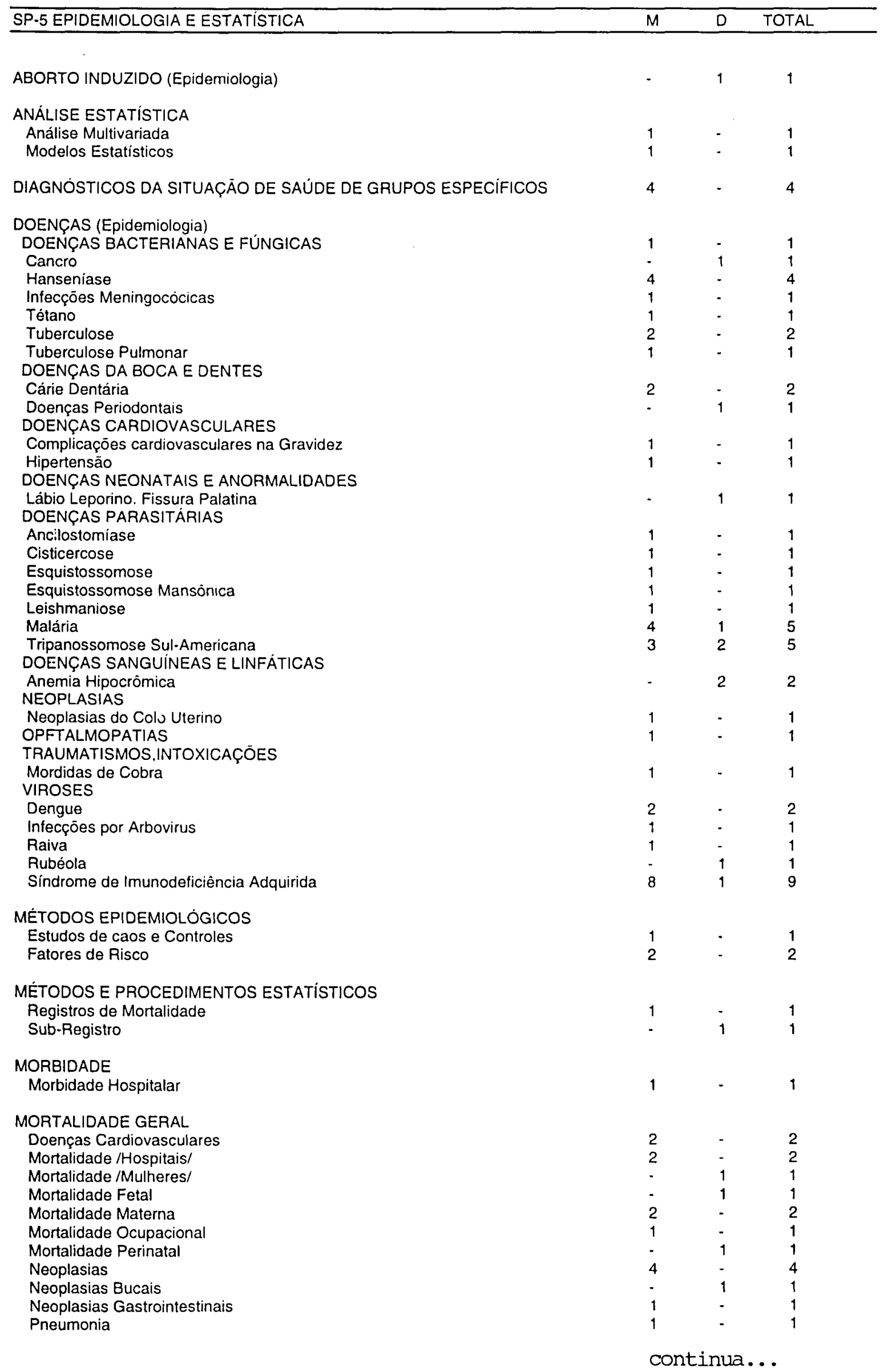


(continuação)

Síndrome de Imunodeficiência Adquirida Violência

MORTALIDADE INFANTIL

USOS DA EPIDEMIOLOGIA

VIGILÂNCIA EPIDEMIOLÓGICA

VIOLÊNCIA /ESCOLARES/

$$
\text { TOTAL }
$$

Os trabalhos classificados nesta sub-categoria (SP-5) dizem respeito a: usos da epidemiologia em Diagnósticos de Situação de Saúde em Grupos Específicos de população (crianças, trabalhadores, situação de garimpo, mineração) em 4 dissertações; Métodos Epidemiológicos relacionados a estudos de caso e controle, fatores de risco (três mestrados). A grande concentração dos trabalhos está nos estudos relativos aos aspectos epidemiológicos das doenças como ocorrência, formas de transmissão, medidas de prevenção e controle (41 mestrados e 10 doutorados). Nesse sentido foram desenvolvidos 15 trabalhos sobre doenças parasitárias (sobressaindo-se os temas malária e tripanossomiase sul-americana), 14 sobre doenças viróticas (onde se destaca o tema sobre AIDS desenvolvido em oito mestrados e um doutorado), 11 sobre doenças bacterianas (hanseniase e tuberculose os temas mais estudados) e outras doenças, com temas sobre neoplasias, doenças da boca e dos dentes, doenças sanguíneas e linfáticas entre outros. Os demais trabalhos nesta categoria, recaíram sobre "mortalidade" por causas especificas ou de grupos específicos de população, tema esse estudado em 22 mestrados $(27,8 \%)$ e 9 doutorados $(39,1 \%)$. O assunto "neoplasias" foi o mais estudado dentre os trabalhos sobre mortalidade geral por causa especifica. Destaque deve ser dado ao assunto "mortalidade infantil" que foi o mais representativo dos temas abordados (oito dissertaçōes e quatro teses). Merece destaque também os trabalhos que trataram dos aspectos epidemiológicos dos temas "aborto" e "violência" considerados como problemas de saúde pública em nosso meio. 
f) SP-6 - Nutrição (Quadro 7) - Inclui trabalhos que dizem respeito ao consumo de alimentos e serviços essenciais de complementação alimentar. Dos 23 trabalhos (17 mestrados e 6 doutorados) classificados nesta área, 10 ( oito mestrados e dois doutorados) referem-se a "Programas e Políticas de Nutrição e Alimentação" com aspectos voltados à vigilância nutricional, alimentação de escolares, suplementação de alimentos, etc. Destacam-se ainda outros aspectos da nutrição como: avaliação do Estado Nutricional infantil, de escolares e recém-nascidos (duas dissertaçōes e uma tese); Distúrbios Nutricionais (quatro mestrados e dois doutorados) de onde se destacam três trabalhos sobre desnutrição proteico-energética que, para a saúde pública, é um dos maiores problemas existentes nos países do 3. Mundo. Os demais trabalhos nesta categoria estão voltados a contaminação de alimentos, fome e hábitos alimentares.

QUADRO 7 - Assuntos das Dissertações de Mestrado e Teses de Doutorado da Categoria SP-6 -

\begin{tabular}{|c|c|c|c|}
\hline SP-6 NUTRIÇĀO & $M$ & $\mathrm{D}$ & TOTAL \\
\hline \multicolumn{4}{|l|}{ ALIMENTO } \\
\hline Contaminação de Alimentos & 1 & - & 1 \\
\hline Embalagens de Alimentos & 1 & - & 1 \\
\hline \multicolumn{4}{|l|}{ DIETA E DIETÉTICA } \\
\hline Hábitos Alimentares /Idosos/ & - & 1 & 1 \\
\hline \multicolumn{4}{|l|}{ DISTÚRBIOS NUTRICIONAIS } \\
\hline Deficiência de Vitamina A & - & 1 & 1 \\
\hline Desnutrição Proteico-Energética & 2 & 1 & 3 \\
\hline Transtornos Nutricionais & 2 & - & 2 \\
\hline \multicolumn{4}{|l|}{ ESTADO NUTRICIONAL } \\
\hline Baixo Peso ao Nascer & 1 & - & 1 \\
\hline Desenvolvimento Infantil & 1 & - & 1 \\
\hline Estado Nutricional /Escolares/ & $\cdot$ & 1 & 1 \\
\hline FOME & 1 & - & 1 \\
\hline PROGRAMAS E POLÍTICAS DE NUTRIÇÃO E ALIMENTAÇĀO & 1 & - & 1 \\
\hline Alimentação Escolar & 2 & - & 2 \\
\hline Avaliação Nutricional & 1 & - & 1 \\
\hline Inquéritos sobre Dietas & - & 1 & 1 \\
\hline Programas de Nutrição & 1 & 1 & 2 \\
\hline Recuperaçào Nutricional & 1 & - & 1 \\
\hline Suplementação Alimentar & 2 & - & 2 \\
\hline TOTAL & 17 & 6 & 23 \\
\hline
\end{tabular}

g) "Outras áreas" (Quadro 8) - Neste conjunto estão incluídos 41 diferentes descritores que definem os temas tratados em 31 dissertações e 16 doutorados. Como dito anteriormente, há uma diversificação muito grande de assuntos (1.1 documento por 
descritor) que envolvem outras categorias do DeCS. O maior número de trabalhos ( 7 mestrados) está concentrado em estudos sobre aspectos terapêuticos e diagnóstico de doenças específicas (hanseniase, cárie dentária, cisticercose, diabete mellitus, tuberculose) e doenças de animais; três mestrados e dois doutorados tratam de temas sobre classificação e análise de vetores (artrópodes/ dípteros); aspectos psicológicos e psiquiátricos que envolvem distúrbios mentais e comportamentais são tratados em sete mestrados e dois doutorados. O assunto "gravidez na adolescência" (dentro da categoria "reprodução"), foi aquele que teve um pouco mais de interesse entre os alunos de pós-graduação para elaboração de seus trabalhos de grau (duas dissertações e duas teses). Os demais assuntos foram tratados uma única vez tanto nos mestrados como doutorados.

QUADRO 8 - Assuntos das Dissertaçōes de Mestrado e Teses de Doutorado, das Demais Categorias DeCS

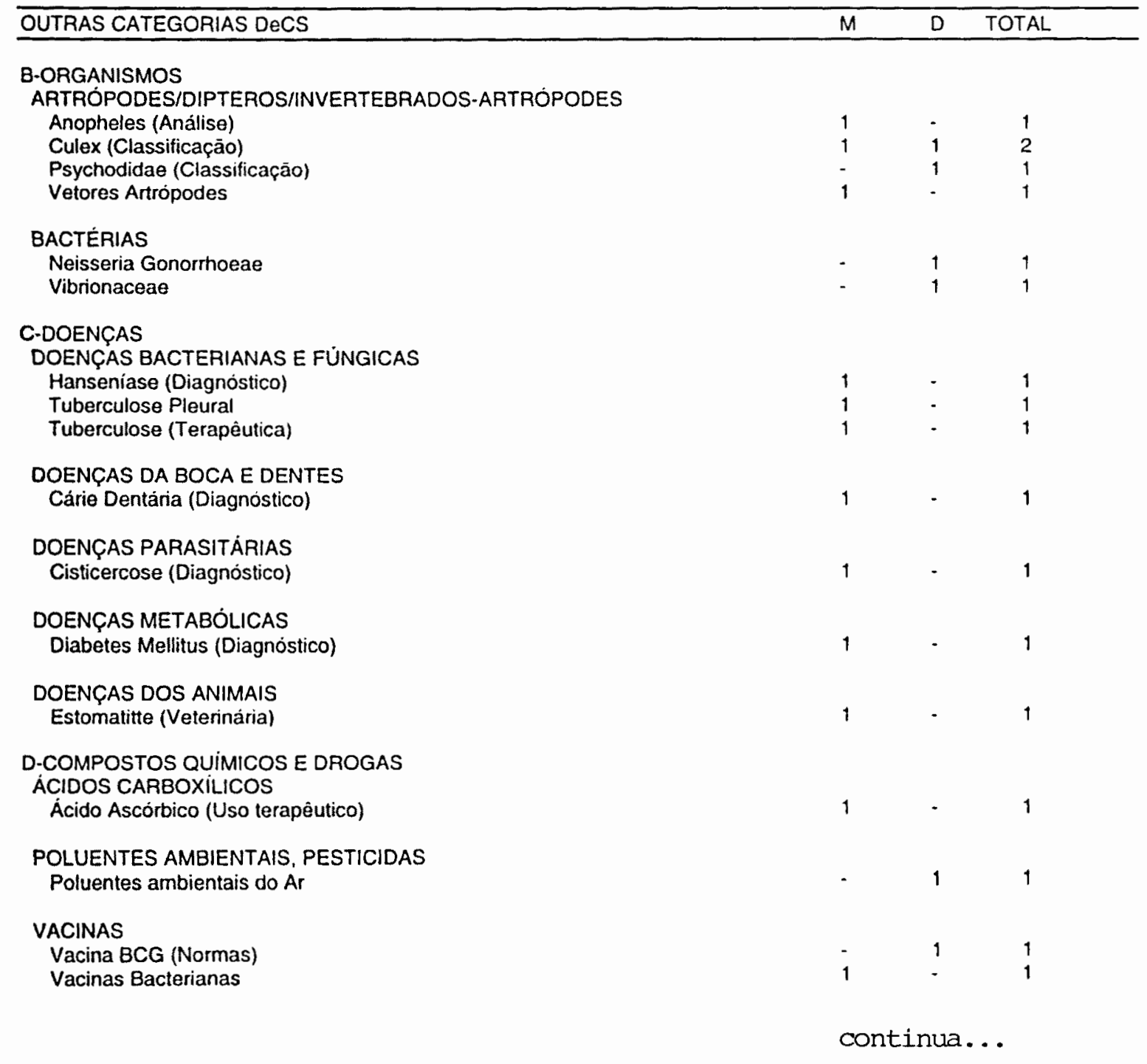




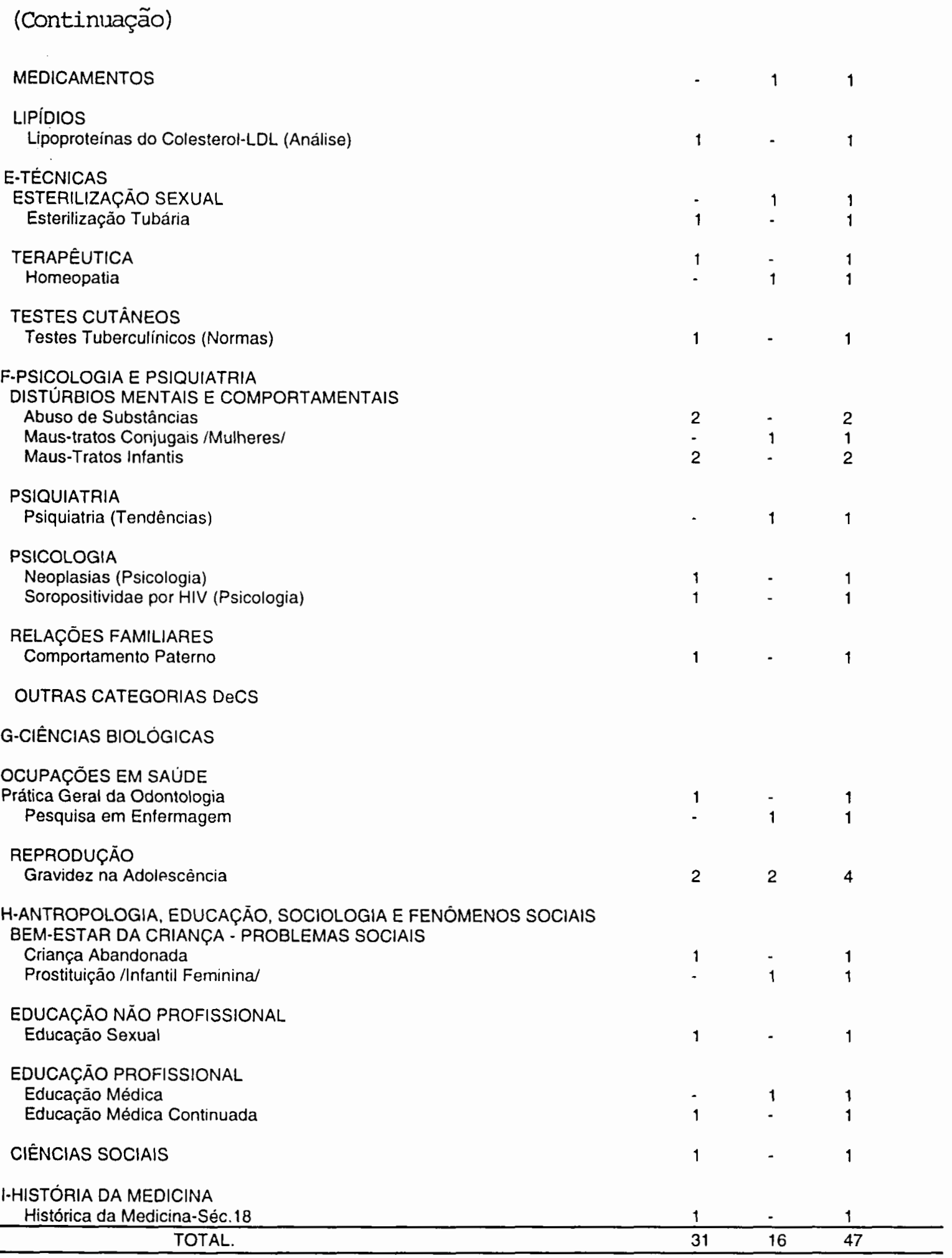

O resultado desta análise mostrou que a temática das dissertações/teses apresentou-se bastante diversificada, dentro das categorias DeCS, refletindo abordagens variadas sobre organização, política e economia da saúde, investigações epidemiológicas sobre saúde-doença na população (infantil, adulta, idosa); administração de serviços de saúde e de hospitais; recursos humanos para a saúde; 
estatísticas vitais (mortalidade, morbidade); caracteristicas do meio ambiente; ecologia e controle de vetores; poluição, saneamento; distúrbios nutricionais da população, serviços de nutrição, além de outros temas que fazem parte do complexo multidisciplinar da saúde pública, como ciências sociais, psicologia, psiquiatria, entre outros.

Para se verificar se houve ou não continuidade no desenvolvimento dos temas no periodo estudado, isto é, se o interesse dos alunos para o desenvolvimento de seus trabalhos de grau, nos cinco anos estudados, manteve-se estável, ou não, os descritores agrupados, nas respectivas sub-categorias, foram dispostos em Quadro (Anexo 4), indicando-se o quanto que foram tratados nos mestrados e doutorados. Por esse quadro, observa-se que mais da metade dos temas estudados $(54,1 \%)$ foram desenvolvidos em uma ou duas dissertações/teses,o que pode estar refletindo nesta dispersão (30 temas com uma única ocorrência para as 350 dissertações/teses) um interesse momentâneo por parte dos alunos no desenvolvimento desses assuntos.

Por outro lado, observa-se que alguns temas mantiveram-se estáveis, sem solução de continuidade no período, mostrando um interesse constante por parte desses alunos. Destacam-se trabalhos voltados ao estudo de doenças (bacterianas, parasitárias e viróticas), mortalidade geral por causas específicas e mortalidade infantil , saneamento e serviços de saúde. Dentre esses temas, tratados nos cinco anos deste estudo, os trabalhos sobre viroses vem ganhando mais espaço com o passar dos anos (de um trabalho realizado em 1990 a cinco em 1994)e, dentre eles, o assunto específico AIDS, é o que maior interesse vem despertando nos alunos dos cursos de pós-graduação em saúde pública no Brasil a partir de 1991, evidenciando fatores epidemiológicos e psicológicos dessa doença. Nos demais assuntos relacionados o caráter de descontinuidade temporal é francamente predominante. 
Essa característica de descontinuidade foi encontrada por $\operatorname{ANDRADE}^{6}$ (1992) na análise da temática dos artigos publicados na área da Epidemiologia onde alguns temas mantiveram-se estáveis sem acentuada solução de continuidade, e na área de Serviços de Saúde, onde o caráter descontínuo foi mais marcante.

A existência de poucos trabalhos que caracterizam os assuntos específicos da produção bibliográfica em saúde pública torna dificil que se trace com mais detalhe o perfil da temática que vem sendo estudada pela comunidade científica nesse campo. conhecimento das Linhas de Pesquisa desenvolvidas nas Instituições onde foram apresentadas as dissertações/teses, poderia dar maior clareza a estes resultados e, de certa forma, justificá-los com maior precisão.

NUNES $^{67}$ (1992) classificou a produção da literatura latino-americana em ciências sociais aplicadas à saúde, em quatro categorias temáticas: Medicina Tradicional; Serviços de Saúde; Processo Saúde-Doença; e Formação de Recursos Humanos. São trabalhos que, segundo o autor "com maior ou menor densidade teórica, procuram se acercar das questões de saúde, da medicina e das práticas em saúde sob a perspectiva das ciências sociais" (p.39). As temáticas "serviços de saúde"e "processo saúde-doença" destacaram-se como os de mais interesse dos pesquisadores. Em análise da produção biomédica da América Latina na década de 80, García, citado por NUNES $^{67}$ (1992, p.33) mostra que a maioria dos artigos publicados é sobre doenças (42\%) e não voltados à pesquisa básica. De certa forma, os resultados do presente trabalho são próximos a esses citados, dado que temas como "serviços de saúde" e "aspectos epidemiológicos de doenças" foram os mais desenvolvidos.

\subsection{DIVULGAÇÃO DAS DISSERTAÇŌES E TESES}

Mediante os dados coletados, a análise da divulgação das dissertações/teses dos cursos de pós-graduação em saúde pública, através da indexação em bases de 
dados bibliográficos automatizadas e do conhecimento dos veículos utilizados na divulgação desses documentos, em outros formato, mostrou o seguinte resultado:

\subsubsection{DIVULGAÇÃO EM BASES DE DADOS BIBLIOGRÁFICOS AUTOMATIZADAS}

Do total de 350 documentos analisados, foram indexados $291(83,1 \%)$ em bases de dados bibliográficos. Destes documentos, $219(82,3 \%)$ referem-se a dissertações de mestrado e $72(85,7 \%)$ às teses de doutorados (Tabela 6$)$.

Tabela 6 - Dissertações de Mestrado e Teses de Doutorado analisadas, Indexadas segundo as Bases de Dados Bibliográficos

\begin{tabular}{|c|c|c|c|c|c|c|c|c|c|c|c|}
\hline \multirow{2}{*}{ BASES DE DADOS Inst. } & \multicolumn{3}{|c|}{ ENSP } & \multicolumn{3}{|c|}{ FSP } & \multirow{2}{*}{ IMS } & \multicolumn{2}{|c|}{ TOTAL } & \multicolumn{2}{|c|}{$\begin{array}{l}\text { TOTAL } \\
\text { GERAL }\end{array}$} \\
\hline & $M$ & $\mathrm{D}$ & Total & $M$ & $\mathrm{D}$ & Total & & $M$ & $\bar{D}$ & № & $\%$ \\
\hline INDEXADAS EM 1 BASE: & & & & & & & & & & & \\
\hline AdSAÚDE & 10 & - & 10 & 3 & 1 & 4 & 12 & 25 & 1 & 26 & \\
\hline LILACS & 35 & 3 & 38 & 29 & 25 & 54 & - & 64 & 28 & 92 & \\
\hline TESES-IBICT & - & - & & - & - & & 1 & 1 & - & 1 & \\
\hline SUB-TOTAL & 45 & 3 & $\begin{array}{c}48 \\
45,3\end{array}$ & 32 & 26 & $\begin{array}{c}58 \\
33.7\end{array}$ & $\begin{array}{c}13 \\
100,0\end{array}$ & $\begin{array}{c}90 \\
(41,1)\end{array}$ & $\begin{array}{c}29 \\
(40,3)\end{array}$ & 119 & $(100,1$ \\
\hline INDEXADAS EM 2 BASES: & & & & & & & & & & & \\
\hline AdSAÚDE/LILACS & 45 & 4 & 49 & 18 & 11 & 29 & - & 63 & 15 & 78 & \\
\hline AdSAÜDE/TESES & - & . & - & 1 & - & 1 & . & 1 & - & 1 & \\
\hline LILACS/REPIDISCA & 3 & - & 3 & - & - & - & - & 3 & - & 3 & \\
\hline LILACS $/ T E S E S-I B I C T$ & - & - & . & 26 & 17 & 43 & . & 26 & 17 & 43 & \\
\hline SUB-TOTAL & 48 & 4 & $\begin{array}{c}52 \\
49,0\end{array}$ & 45 & 28 & $\begin{array}{c}73 \\
42.5\end{array}$ & - & $\begin{array}{c}93 \\
(42,5)\end{array}$ & $\begin{array}{c}32 \\
(44,4)\end{array}$ & 125 & $(100,6$ \\
\hline $\begin{array}{l}\text { INDEXADAS EM 3 BASES: } \\
\text { AdSAUDDELILACS/ } \\
\text { REPIDISCA }\end{array}$ & 4 & - & 4 & - & - & - & - & 4 & - & 4 & \\
\hline $\begin{array}{l}\text { AdSAUUDE/LILACS/ } \\
\text { TESES-IBICT }\end{array}$ & 1 & 1 & 2 & 29 & 10 & 39 & - & 30 & 11 & 41 & \\
\hline $\begin{array}{l}\text { LILACS/REPIDISCA } \\
\text { TESES-IBICT }\end{array}$ & - & - & - & 2 & - & 2 & - & 2 & - & 2 & \\
\hline SUB-TOTAL & 5 & 1 & $\begin{array}{c}6 \\
5,7\end{array}$ & 31 & 10 & $\begin{array}{c}41 \\
23.8\end{array}$ & - & $\begin{array}{c}36 \\
(16,4)\end{array}$ & $\begin{array}{c}11 \\
(15,3)\end{array}$ & 47 & $(100,6$ \\
\hline TOTAL INDEXADAS & $\begin{array}{c}98 \\
(87,5)\end{array}$ & $\begin{array}{c}8 \\
(72,7)\end{array}$ & $\begin{array}{c}106 \\
(86,2)\end{array}$ & $\begin{array}{c}108 \\
(88,5)\end{array}$ & $\begin{array}{c}64 \\
(88,5)\end{array}$ & $\begin{array}{c}172 \\
(88,2)\end{array}$ & $\begin{array}{c}13 \\
(40,6)\end{array}$ & $\begin{array}{c}219 \\
(82,3)\end{array}$ & $\begin{array}{c}72 \\
(85,7)\end{array}$ & 291 & 83,1 \\
\hline NĀO INDEXADAS & $\begin{array}{c}14 \\
(12,5)\end{array}$ & $\begin{array}{c}3 \\
(27,3)\end{array}$ & $\begin{array}{c}17 \\
(13,8)\end{array}$ & $\begin{array}{c}14 \\
(11.5)\end{array}$ & $\begin{array}{c}9 \\
(12.3)\end{array}$ & $\begin{array}{c}23 \\
(11,8)\end{array}$ & $\begin{array}{c}19 \\
(59.4)\end{array}$ & $\begin{array}{c}47 \\
(17.7)\end{array}$ & $\begin{array}{c}12 \\
(14,3)\end{array}$ & 59 & 16,9 \\
\hline TOTAL GERAL & $\begin{array}{c}112 \\
(100.0)\end{array}$ & $\begin{array}{c}11 \\
(100.0)\end{array}$ & $\begin{array}{c}123 \\
(100.0)\end{array}$ & $\begin{array}{c}122 \\
(100.0)\end{array}$ & $\begin{array}{c}73 \\
(100,0)\end{array}$ & $\begin{array}{c}195 \\
(100,0)\end{array}$ & $\begin{array}{c}32 \\
(100.0)\end{array}$ & $\begin{array}{c}266 \\
(100,0)\end{array}$ & $\begin{array}{c}84 \\
(100,0)\end{array}$ & 350 & 100.6 \\
\hline
\end{tabular}

Segundo a instituição de origem, verifica-se o alto percentual dos mestrados e dos doutorados defendidos na ENSP $(86,2 \%)$ e na FSP $(88,2 \%)$, constantes das fontes consultadas. No entanto, dos mestrados defendidos no IMS constam dessas bases apenas $40,6 \%$.

Os 219 mestrados e 72 doutorados foram indexados em até três fontes diferentes. Constam em uma única fonte: $48(45,3 \%)$ da ENSP, $58(33,7 \%)$ da FSP e $13(100,0 \%)$ do IMS; em duas fontes: $52(49,0 \%)$ da ENSP e $73(42,5 \%)$ da FSP; em 
três fontes: $6(5,7 \%)$ da ENSP e $41(23,8 \%)$ da FSP. Nenhuma dissertação ou tese aparece indexada em todas as quatro bases consultadas simultaneamente.

As 291 dissertações/teses foram indexadas num total de 510 vezes, nas bases consultadas. Este número significa que cada tese foi divulgada, em média, em quase duas fontes (média de 1,8 fonte/documento). Na Tabela 7 , esses documentos são distribuidos segundo as bases de dados bibliográficos onde encontram-se indexados.

Tabela 7 - Número de Indexações das Dissertações de Mestrado e Teses de Doutorado analisadas, segundo as Bases de Dados Bibliográfico.

\begin{tabular}{|c|c|c|c|c|c|c|c|c|c|c|c|}
\hline \multirow{2}{*}{ Bases de Dados Bibliográficos } & \multicolumn{3}{|c|}{ ENSP } & \multicolumn{3}{|c|}{ FSP } & \multirow{2}{*}{ IMS } & \multicolumn{2}{|c|}{ Total } & \multicolumn{2}{|c|}{ TOTAL GERAL } \\
\hline & $M$ & $D$ & TOT. & $M$ & $D$ & TOT. & & $M$ & $D$ & N. & $\%$ \\
\hline AdSAÚDE & 60 & 5 & 65 & 51 & 22 & 73 & 12 & 123 & 27 & 150 & 29,5 \\
\hline LILACS & 88 & 8 & 96 & 104 & 63 & 167 & - & 192 & 71 & 263 & $51,5^{\circ}$ \\
\hline REPIDISCA & 7 & - & 7 & 2 & - & 2 & - & 9 & - & 9 & 1,8 \\
\hline TESES/IBICT & 1 & 1 & 2 & 58 & 27 & 85 & 1 & 60 & 28 & 88 & 17,2 \\
\hline TOTAL & 156 & 14 & 170 & 215 & 112 & 327 & 13 & 384 & 126 & 510 & 100,0 \\
\hline
\end{tabular}

A base AD-SAÚDE, especializada em Administração de Serviços de Saúde, (com 150 documentos indexados) divulga 46,2\% dos mestrados (266) e 32,1\% dos doutorados (84) analisados. Da ENSP constam dessa base 53,6\% (60) dos mestrados (112) e 45,5\% (5) dos seus doutorados (11). Da FSP são indexados nessa base $41,8 \%(51)$ dos mestrados (122) e 30,1\% (22) dos doutorados (73). Esta é a única base em que o IMS mantém representados 12 dos seus 32 mestrados (40,6\%). Por ser uma base de especialidade mais limitada, a sua situação parece ser mais consistente do que as demais, isto considerando que todos os documentos (124) que abordaram temas dentro das áreas "administração e planejamento de saúde" e "cuidados de saúde" (Quadros 2 e 3), encontram-se indexadas nessa fonte, além de outros temas pertinentes de outras áreas.

A base LILACS abrange uma área temática mais ampla, o que explica 0 alto número de indexação das dissertações/teses. Indexou 263 documentos, ou seja, 
$75,1 \%$ do total estudado (350), o que corresponde a $72,2 \%$ das dissertações de mestrado e $84,5 \%$ das teses de doutorado estudadas. Quase a totalidade das dissertações/teses indexadas da ENSP $(90,6 \%)$ e da FSP $(97,1 \%)$ figuram nessa base, o que é um resultado bastante positivo. Do IMS não consta nenhum documento na base LILACS.

A indexação das dissertações/teses na base TESES, do IBICT, foi de $88(25,1 \%$ do total estudado) sendo que a grande maioria foi defendida na FSP $(96,6 \%$ das teses indexadas nessa base). No entanto, a representatividade dessa base para os documentos da FSP restringe-se a 58 mestrados $(21,8 \%)$ e 22 doutorados $(33,3 \%)$ da FSP. O registro de informação das dissertações/teses das demais Unidades para esta base é baixo $(7,7 \%$ do IMS e $1,2 \%$ da ENSP).

A base REPIDISCA foi a que menos número de documentos divulgou ( 9 mestrados, ou $2,5 \%$ do total dos documentos estudados). Esta é uma base voltada à área de Engenharia Sanitária e Saúde Ambiental, e por isso mais seletiva em termos de especializações. No entanto, ao se considerar que nesta área foram elaboradas 50 dissertações/teses (Quadro 5), pode-se considerar pouca a sua representação $(1,8 \%)$.

Ao se comparar as indexações das dissertações/teses segundo 0 ano de sua defesa (Tabela 8) verifica-se, do total das teses não indexadas (59) existe um resíduo de três $(51,0 \%)$ defendidas em 1990; $9(15,3 \%)$ em 1992; $12(20,3 \%)$ em 1993 e, 35 $(39,3 \%)$ em 1994. Apenas as defendidas em 1991 foram todas indexadas. Nota-se que existe uma certa consistência na manutenção das bases AD-SAÚDE e LILACS, durante os cinco anos analisados e uma queda na base REPIDISCA. Apenas para a base TESES do IBICT, ocorre uma parada em sua manutenção nos últimos dois anos (nenhuma indexada em 1993 e apenas duas em 1994). Segundo informações pessoais, a geração dessa base vem passando por um processo de re-avaliação ou re- 
estruturação nestes anos. Resta aguardar algum tempo para confirmar esta possibilidade.

Tabela 8 - Dissertações de Mestrado e Teses de Doutorado analisadas, segundo as Bases de Dados Bibliográficos (número de indexações) e o Ano de Defesa.

\begin{tabular}{l|ccccc|c}
\hline \multicolumn{1}{c|}{ Ano Defesa } & 1990 & 1991 & 1992 & 1993 & 1994 & TOTAL \\
$\begin{array}{l}\text { BASES DE DADOS } \\
\text { BIBLIOGRÁFICOS }\end{array}$ & & & & & & \\
\hline TOTAL INDEXADO & $43(93,5)$ & $75(100,0)$ & $58(86,6)$ & $59(83,1)$ & $56(61,5)$ & $291(83,1)$ \\
\hline $\begin{array}{l}\text { No de Indexações: } \\
\text { AdSAÚDE }\end{array}$ & 19 & 45 & 31 & 28 & 27 & 150 \\
LILACS & 39 & 73 & 52 & 56 & 43 & 263 \\
REPIDISCA & 2 & 4 & 1 & 1 & 1 & 9 \\
TESES-IBICT & 31 & 41 & 14 & - & 2 & 88 \\
\hline Total Indexações & 91 & 163 & 98 & 85 & 73 & 510 \\
\hline TOTAL NÄO INDEXADO & $\begin{array}{l}3(6,5) \\
(5,1 \%)\end{array}$ & - & $\begin{array}{c}9(13,4) \\
(15,3)\end{array}$ & $\begin{array}{c}12(16,9) \\
(20,3)\end{array}$ & $\begin{array}{c}35(38,5) \\
(59,3)\end{array}$ & $\begin{array}{c}59(16,9) \\
(100,0)\end{array}$ \\
\hline TOTAL GERAL & $46(100,0)$ & $75(100,0)$ & $67(100,0)$ & $71(100,0)$ & $91(100,0)$ & $350(100,0)$ \\
\hline
\end{tabular}

Estes resultados estão aquém do esperado, dado que todos os documentos analisados encontram-se disponíveis no acervo das bibliotecas há tempo suficiente, para sua indexação em fontes específicas. A alimentação dessas bases deveria ser feita quase que automaticamente quando do recebimento das dissertações/teses nas Bibliotecas, e sua divulgação em edições periódicas de CDs, não ultrapassar a um período de, no máximo, seis meses. No caso do presente trabalho, foram nove meses desde a última defesa (provavelmente em dezembro de 1994) o tempo considerado para que as bibliotecas tivessem todas as dissertações e teses disponiveis para os usuários, e indexadas nas bases em que participam.

As notificações dos documentos às bases LILACS, REPIDISCA e AD-SAÚDE são feitas, periodicamente, através de disquetes, pelo processo "on-line" e, também, mais recentemente, via Internet, conforme informações recebidas das Bibliotecas. Para 
a base TESES, do IBICT, a notificação é feita anualmente pela CAPES, o que pode justificar, em parte, o número reduzido de indexações das dissertações e teses nessa base, defendidas em 1994. Isto significa que a demora na indexação dos documentos seja causada mais provavelmente pelos responsáveis na manutenção das bases do que propriamente pelos serviços das bibliotecas. Por outro lado, o que aconteceu com as teses dos anos passados que não constam das bases? Não teriam sido notificadas ainda? De qualquer forma, existem pontos que entravam uma divulgação mais rápida das informações contidas nas dissertações/teses e medidas podem ser tomadas para melhorar este quadro, como por exemplo, entre outras, estabelecimento de prazos mínimos para a notificação às bases de dados, que, por sua vez, devem ser elaboradas e dispostas à consulta com periodicidade mais frequente. $E$ as novas tecnologias, vias eletrônicas, sem dúvida, contribuirāo para o sucesso dessas medidas. 


\subsubsection{DIVULGAÇÃO EM OUTROS FORMATOS}

Conforme já mencionado, foi feita pesquisa para se saber se as dissertações/teses foram publicadas posteriormente à sua aprovação. Para tanto, foram consultadas as bases de dados bibliográficos utilizadas na consulta da sua indexação. Além dessa consulta. foram computadas as informações prestadas pelos professores-orientadores $(61,0 \%$ deram resposta à solicitação feita) quanto ao seu conhecimento sobre as publicações das dissertações e teses dos alunos sob sua orientação, no periodo.

Desta forma, com os dados obtidos pelas pesquisas nas bases LILACS, REPIDISCA e AD-SAÚDE, e pelas informações dos professores-orientadores foram identificados $95(27,1 \%)$ documentos publicados (Tabela 9), sendo a maioria deles (68, ou $71,6 \%$ ) sob a forma de artigos de periodicos: $8(8,4 \%)$ editados como livros e 6 $(6,3 \%)$ como capitulos de livros. Além desses, 13 documentos $(13,7 \%)$ da categoria "outros" referem-se a comunicaçōes em eventos.

Segundo ainda informaçōes prestadas pelos professores-orientadores, encontravam-se no prelo ou em vias de publicaçāo como artigos, à época desta pesquisa, cinco documentos, sendo três originados de mestrados e dois de doutorados. Outros 13 documentos ( 9 mestrados e 4 doutorados) estão em fase de preparo para publicação (um livro e 12 artigos). Assim. se esses casos "pendentes" forem efetivados, pode-se contar com 113 dissertações/teses $(32,3 \%$ do total analisado) que foram divulgadas em outros formatos.

É importante assinalar que oito mestrados e cinco doutorados, ao serem publicados, deram origem a dois ou três artigos cada uma e propiciaram a apresentação de duas ou três comunicaçōes em eventos. Uma só tese de doutorado foi divulgada em forma de livro, de artigo e de comunicação em evento.

Ao se considerar o ano de defesa das dissertações/teses verifica-se que a maior parte publicada refere-se àquelas defendidas em 1993 (33,8\% das defendidas neste 
ano foram publicadas) e em 1991 (33,3\% publicadas). Apenas $16(17,6 \%)$ das defendidas em 1994 já foram publicadas; no entanto, 14 das defendidas nesse ano encontram-se em fase de preparo para publicação ou já no prelo, o que somaria a $33,0 \%$ (total semelhante aos dos anos 91 e 93). Merece destaque a informação recebida de que dois mestrados defendidos em 1993, se encontram em fase de preparação para publicação. Assim, não se pode deixar de considerar que ainda existe a possibilidade de trabalhos defendidos em anos anteriores virem a ser publicados. Pressupõe-se, nestes casos, que os autores mantiveram o desejo e a preocupação em divulgar os resultados de seus trabalhos independentemente do periodo de tempo passado.

O tempo dispendido neste preparo é bastante variado. O ideal seria que, no mínimo em seis meses, o trabalho, após a sua defesa. estivesse preparado para publicaçāo e em mais 12 meses já divulgado em periódico especializado (tempo médio indicado pela literatura para que um trabalho seja publicado após a sua confecção) ${ }^{38}$. HANSON ${ }^{45}$ (1975), em análise da disseminação de teses em Sociologia, verificou que o tempo dispendido entre a obtenção do grau de $\mathrm{PhD}$ e a disseminação dos resultados em comunicaçōes em eventos foi de 2 anos, e, para divulgação em forma de artigo em revistas especializadas da área, o periodo médio foi de 3.2 anos. EHIKHAMENOR ${ }^{27}$ (1990) estimou em 45 meses o tempo dispendido desde o início da pesquisa da tese até a publicação em artigo de periódico. Este periodo mais longo foi atribuido às dificuldades existentes na realização da pesquisa científica, próprias dos paises em desenvolvimento. Além disso, a diferença de tempo para divulgação como artigo está também relacionada ao fato do mesmo passar por processo de seleção pelos "referees", mais demorado que os processos adotados pelos demais veículos de divulgação. 
Tabela 9 - Dissertações de Mestrado e Teses de Doutorado Divulgadas em Diferentes Formatos, segundo os anos de Defesa (1990-1994).

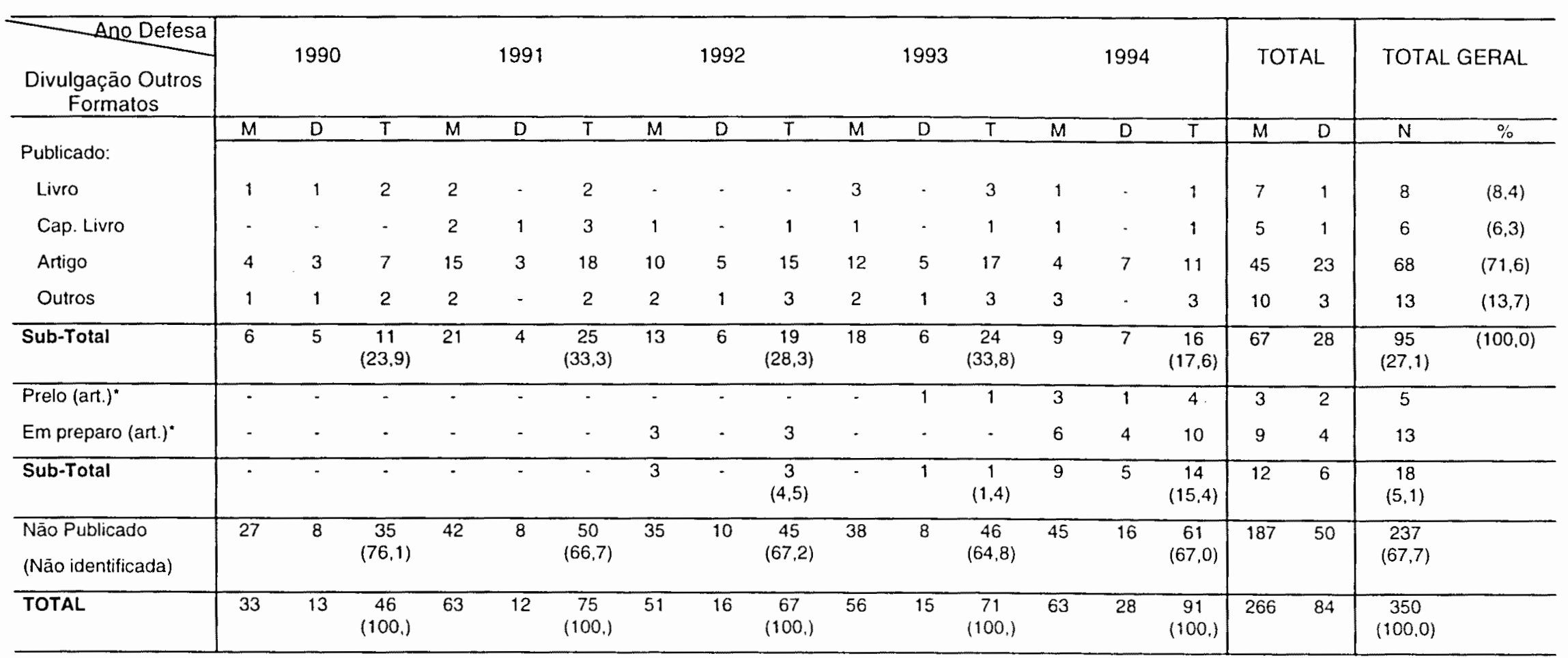

(*) Informação prestada pelos professores-orientadores 
Em estudos compilados por GARVEY $^{38}$ (1979) foi encontrado que, o preparo da tese para disseminação em formato de artigo leva de 6 a 8 meses. Se for considerado esse prazo e se contar com mais um ano até que o artigo seja publicado, pode-se considerar o período de 18 a 20 meses como o limite para a divulgação das dissertaçōes/teses em artigos de periódicos (GARVEY ${ }^{38}$, p.61).

Para a divulgaçāo das dissertações/teses em outros formatos, só cabe ao seu autor (ex-aluno de pós-graduação) a decisāo de seu preparo e encaminhamento para publicação. Muitas vezes os orientadores e os próprios elementos que compõem a banca de julgamento dos trabalhos, incentivam o aluno a tomar essa decisão, principalmente quando a informação contida nesses documentos for de reconhecido valor. Esta deve ser uma decisão a ser tomada logo a seguir à defesa da dissertação/tese, pois, vários fatores podem interferir na divulgação desses documentos em outros formatos.

Independentemente dos prazos, o que se verifica por parte dos mestres e doutores é que, se a adaptação do texto das dissertações/teses em forma de livros, capitulos, artigos e mesmo em comunicações em eventos não for feita de imediato, após a sua defesa, pressumivelmente a maioria deles nunca mais o será. A elaboração das dissertaçōes de mestrado e teses de doutorado e sua defesa, leva o aluno de pósgraduação a um ponto de saturação que ele nāo quer, durante muito tempo, siquer "pensar" em sua dissertação/tese. E quando retorna a ela, o interesse para refazê-la em outro formato, terá passado com o tempo. E com tudo isso, mais uma vez, informações que podem ser de importância têm limitados os caminhos para sua maior divulgação entre os pares. Urquhart e Armstrong, citados por SAYERS e WOOD ${ }^{85}$ (1991), apontam alguns motivos que os levam a não publicarem suas teses: a demora de tempo para elaboração do trabalho, necessidade de readaptaçāo do texto para publicação, mudanças de interesse, entre outros. Para esses autores a melhor forma 
para incentivar e assegurar que os alunos publiquem seus trabalhos é o auxilio do orientador que toma parte da responsabilidade na publicação $(88,0 \%$ das teses publicadas o foram em co-autoria com o orientador) ou mesmo de outros profissionais, como aponta Chew, citado por SILVA Jr e AUGUSTO ${ }^{89}$ (1989), que levanta uma questāo sobre a elaboraçāo de um mestrado que exigiu a participação de diversos especialistas nas diferentes análises no tema estudado: "seria justo a publicação deste estudio em nome de um único autor?" (p.91). VELHO ${ }^{97}$ (1986) verificou que cerca de $40 \%$ de artigos brasileiros publicados por pesquisadores da área agricola eram de coautoria com estudantes de pós-graduaçāo, o que, na verdade, segundo a autora, "a grande maioria desses artigos foi retirada de teses de mestrado ou de doutorado" (p.7).

A literatura registra alguns trabalhos, em diferentes áreas, que tratam da divulgaçāo de dissertações e teses, após a sua defesa, em outros formatos. HANSON $^{45}$ (1975) observou que 216 dissertaçōes em sociologia deram origem a 375 documentos entre artigos, livros, capítulos, comunicaçōes em eventos, entre outros. Em diversos estudos elaborados por GARVEY ${ }^{38}$ (1979) para o estabelecimento de padrões para a comunicação cientifica, foi estimado que $16-20 \%$ dos artigos científicos publicados nos principais periódicos em ciências médicas, biológicas e sociais foram baseados em dissertaçōes e teses. Em análise de dissertaçōes no campo da Ciência da Informação (defendidas de 1978 a 1987), SAYERS e WOOD ${ }^{85}$ (1991) encontraram o seguinte: $37,0 \%$ delas foram publicadas após a sua defesa e $27,0 \%$ divulgadas em outras formas (conferência, demonstração, cursos, seminários, etc.). Esta é considerada uma proporçāo alta quando comparada com o resultado da investigaçāo de Moore (1972), citado por esses autores, na qual $18,6 \%$ das teses de doutorado americanas foram publicadas.

Em estudo sobre o ciclo de publicação da produçāo científica nas universidades nigerianas, EHIKHAMENOR ${ }^{27}$ (1990) encontrou que $32,0 \%$ dos artigos publicados por cientistas desse pais, foram baseados em teses e dissertações. 
Esses resultados mostram que ainda nāo existe uma conscientização por parte dos alunos de pós-graduação da necessidade em divulgarem seus trabalhos acadềmicos em outros formatos, o que reflete uma tomada de consciência por parte dos pesquisadores em cumprir o ciclo da comunicação científica, trazendo os resultados de suas pesquisas com mais facilidade ao acesso dos interessados. 


\subsection{ANÁLISE DAS CITAÇÕES BIBLIOGRÁFICAS NAS DISSERTAÇÕES E TESES}

A análise das citações contidas nas dissertaçōes e teses estudadas no presente trabalho, mostra o seguinte resultado:

As 350 dissertações e teses defendidas de 1990 a 1994 nos cursos de pósgraduação em saúde pública da ENSP, FSP e IMS, contém um total de 35.505 citaçōes bibliográficas, o que equivale a uma média de 101.4 citações por documento (90.6 citaçōes por mestrado e 134.8 citações por doutorado). Este resultado é superior ao encontrado em estudos anteriores de análise de citações de trabalhos em saúde pública, onde $\operatorname{ANDRADE}^{\circ}$ (1984, p.34) encontrou uma média de 58,9 citações nos mestrados analisados e 83,8 citaçōes nos doutorado e. posteriormente, NORONHA ${ }^{65}$ (1987, p.64) detectou médias de 80,1 citações/mestrado e 97,4 citações/doutorado. Por estes trabalhos verifica-se uma certa tendência no aumento do número de citações nesses trabalhos acadêmicos.

A média de citações nas dissertações e teses não é muito diferenciada nas diferentes áreas, nem nos diferentes graus dos trabalhos acadêmicos embora exista uma certa tendência dos doutorados valerem-se de maior número de documentos para sua elaboração. Trabalhos em outras áreas mostram resultados próximos a esses mencionados. Assim, a média de citações nos doutorados em geociência estudados por WALCOTT $^{101}$ (1992) foi de 94.3 citações/teses; para as teses do campo da filosofia a média foi de 93.1 documento citado/tese (HERUBEL, 1991) ${ }^{48}$.

De qualquer forma, a média de citaçōes para esses documentos é superior, em quase 10 vezes, ao número médio de citações em artigos de periódicos que oscilam de 10 a 20 citações/artigo, segundo trabalhos realizados nas diferentes áreas: 16,9 citações/artigos em ciências biológicas (CARVALHO, 1976) ${ }^{15} ; 14,2$ citações/artigos na 
area agricola $\left(\right.$ VELHO, 1986) ${ }^{y \prime} ; 10,4$ citaçōes/artigos em cientometria (LIMA, 1984) ${ }^{55}$ 144; 19,9 citações/artigos em saúde públiuca (NORONHA, 1987, p.64) ${ }^{65}$.

Para uma análise mais profunda das citações e conforme consta no capitulo Material e Método, das 35.505 citações constantes das dissertações e teses foram selecionadas, por processo de amostragem, 6.019 citaçōes que constituíram a população amostrada para a presente análise.

O resultado encontrado na tabulação dos dados que caracterizaram as referências bibliográficas selecionadas na amostra, é mostrado a seguir:

\subsubsection{TIPOS DOS DOCUMENTOS CITADOS}

A Tabela 10 apresenta a relação dos diferentes tipos de documento citados nas dissertações e teses, segundo o grau e as instituçōes onde foram defendidas.

Do total de 6.019 citações, $46,7 \%$ são de artigos de periódicos, e mais encontrados dentre as citações dos doutorados $(50,0 \%)$. O percentual de livros citados foi de $30,4 \%$ com maior representatividade para as teses de doutorado $(31,9 \%$ dos documentos citados). As citações das dissertações/teses defendidas na ENSP apresentam um equilibrio entre artigos de periódicos $(37,0 \%)$ e livros $(36,2 \%)$; as da FSP um predominio de artigos $(55,6 \%)$ e para o IMS o número de citações de livros foi superior ao dos artigos $(44,2 \%$ e $32,0 \%$, respectivamente $)$

Os mestrandos utilizaram-se mais das dissertações e teses do que os doutorandos $(3,7 \%$ e $2,6 \%$, repectivamente). Os relatórios técnicos apresentaram baixa percentagem de uso, tanto nos mestrados $(2,1 \%)$ como nos doutorados $(1,5 \%)$. As comunicações em eventos técnico-cientificos foram mais utilizadas nos mestrados 
$(3,7 \%)$ do que nos doutorados $(2,6 \%)$. O uso de "outros tipos" de documentos (relacionados no Quadro 9). que não os mencionados, foi da ordem de $15,1 \%$ para os mestrados e $9,8 \%$ para os doutorados.

Os resultados obtidos na análise dos tipos de documentos citados nas dissertações/teses, comparados a outros alcançados em outras investigações realizadas, comportam algumas considerações expostas a seguir. Assim, com referência à citação de artigos de periódicos $(46,7 \%$ das citações são de artigos de periódicos) está mais próxıma aos achados por outros trabalhos sobre análise de citações em dissertaçōes/teses do que nas análises de citaçōes em artigos de periódicos científicos, nas diferentes áreas. Desta forma, $\operatorname{ANDRADE}^{5}(1984$, p.35) e NORONHA ${ }^{65}$ (1987, p.64) encontraram, respectivamente $62,0 \%$ e $60,1 \%$ de artigos citados nas teses e dissertações em saúde pública. Trabalhos em outras áreas mostram: $48.0 \%$ de artıgos citados em dissertaçōes no campo da Ciência da Informaçāo (RODRIGUES, 1982$)^{84} ; 28,7 \%$ em teses no campo da filosofia (HERUBEL, $1991)^{48} ; 43.0 \%$ em doutorados no campo da engenharia $(K R I Z, 1984)^{50}$. Com relação à análise de citações incluidas em artigos de periódicos, PRICE ${ }^{76}$ (1976) encontrou 80\% das citaçōes de artigos cientificos; CARVALHO ${ }^{15}$ (1976), 79\% das citações de artigos em ciências biológicas; NORONHA ${ }^{\hat{05}}$ (1987, p.64), 70.8\% das citaçōes em de artigos em saúde pública; FERREIRA e SOUZA ${ }^{28}$ (1987), 81,4\% das citações em artigos sobre física; LANCASTER e col. ${ }^{53}$ (1992), $79,3 \%$ das citações de artigos científicos; HAIQ1 ${ }^{44}$ (1995), de 61,0 a 67,0\% das citações de artigos em biblioteconomia médica; GODIN e col. $^{40}$ (1995), 70,8\% das citações em artigos científicos. Assim, os artigos de periódicos parecem ser mais utilizados na elaboração dos próprios artigos do que na elaboração das dissertaçōes/teses.

No entanto, esta tendência não é verificada em outros trabalhos realizados que demonstram situações diferentes. É o que foi obsevado por WALCOTT ${ }^{101}$ (1992) onde a citação de artigos de periódicos nas teses de instituições acadêmicas americanas no 
campo da geociência foi predominantemente maior do que outros tipos de documentos utilizados ( 75 a $86 \%$ das citações foram de artigos; 12 a $22 \%$ citações de livros).

O que ocorre, com algumas exceções, é que o predomínio de citação nas dissertações e teses é de artigos de periódicos, porém em menor escala quando comparados à proporção citada nos próprios artigos. 
Tabela 10 - Tipos de Documentos Citados nas Dissertaçōes de Mestrado e Teses de Doutorado analisadas.

\begin{tabular}{|c|c|c|c|c|c|c|c|c|c|c|c|c|c|c|c|c|}
\hline \multirow{3}{*}{$\begin{array}{c}\text { InSt. } \\
\text { TIPO DOCUMENTO } \\
\text { CITADO }\end{array}$} & \multicolumn{4}{|c|}{ ENSP } & \multicolumn{4}{|c|}{ FSP } & \multicolumn{2}{|c|}{ IMS } & \multicolumn{4}{|c|}{ TOTAL } & \multicolumn{2}{|c|}{ TOTAL GERAL } \\
\hline & \multirow[t]{2}{*}{$\bar{M}$} & \multirow[t]{2}{*}{$\mathrm{D}$} & \multicolumn{2}{|c|}{ TOTAL } & \multirow[t]{2}{*}{$\bar{M}$} & \multirow{2}{*}{$\mathrm{D}$} & \multicolumn{2}{|c|}{ TOTAL } & \multirow{2}{*}{$\begin{array}{l}M \\
N\end{array}$} & \multirow{2}{*}{$\begin{array}{l}\% \\
\%\end{array}$} & \multicolumn{2}{|c|}{$\bar{M}$} & \multicolumn{2}{|c|}{$\mathrm{D}$} & \multirow{2}{*}{$\bar{N}$} & \multirow{2}{*}{$\%$} \\
\hline & & & $^{\circ}$ & $\%$ & & & № & $\%$ & & & № & $\%$ & № & $\%$ & & \\
\hline Livro & 580 & 241 & 821 & 36,2 & 420 & 375 & 795 & 24,3 & 214 & 44,2 & 1214 & 29,7 & 616 & 31,9 & 1.830 & 30,4 \\
\hline Artigo de Periódico & 786 & 55 & 841 & 37.0 & 904 & 910 & 1814 & 55,6 & 155 & 32,0 & 1845 & 45,1 & 965 & 50,0 & 2.810 & 46,7 \\
\hline Dissertação/Tese & 59 & 2 & 61 & 2,7 & 73 & 49 & 122 & 3,7 & 19 & 3,9 & 151 & 3,7 & 51 & 2,6 & 202 & 3,4 \\
\hline Comunicaçāo em Evento & 80 & 10 & 90 & 4,0 & 83 & 70 & 153 & 4,7 & 12 & 2,5 & 175 & 4,3 & 80 & 4,2 & 255 & 4,2 \\
\hline RelatóriosTécnico & 41 & 5 & 46 & 2.0 & 36 & 23 & 59 & 1,8 & 9 & 1,9 & 86 & 2,1 & 28 & 1,5 & 114 & 1,9 \\
\hline “Outros” & 363 & 48 & 411 & 18,1 & 180 & 142 & 322 & 9,9 & 75 & 15,5 & 618 & 15,1 & 190 & 9,8 & 808 & 13,4 \\
\hline TOTAL & 1.909 & 361 & 2.270 & 100,0 & 1.696 & 1.569 & 3.265 & 100,0 & 484 & 100,0 & 4.089 & 100,0 & 1.930 & 100,0 & 6.019 & 100,0 \\
\hline
\end{tabular}


A diferença na tipologia dos documentos citados em trabalhos científicos, também se faz notar segundo as áreas de especialização. HEINZKILL ${ }^{47}$ (1980) apresenta um quadro onde são demonstradas as porcentagens de citações de artigos em vários trabalhos realizados nas diferentes áreas, onde o predomínio de citações de artigos de periódicos nas ciências puras e aplicadas é na ordem de $76,8 \%$ a $93,6 \%$, enquanto que nas humanas as porcentagens de citações de artigos variaram de $19,9 \%$ a 45,9\%. Para artigos no campo da literatura inglesa prevaleceu a citaçāo de livros (74,9\%) contra os $19,9 \%$ de citações de artigos. As Artes e Humanidades, embora disponham de muitas revistas, a principal fonte de informação utilizada são os livros (GARFIELD, 1980) $)^{37}$. WITTER e col. ${ }^{103}$ (1989) detectaram que todos os autores (100\%) de teses de psicologia clinica valeram-se de livros para seus trabalhos, $89 \%$ deles valeram-se de artigos e 55\% deles, de teses e dissertações.

O que se pode extrair dos dados encontrados na literatura é que os artigos de periódicos especializados constituem-se em fonte prioritária de uso tanto em artigos como em dissertaçōes/teses, com maior predominio nas áreas das ciências puras e aplicadas do que nas humanas.

A baixa porcentagem de uso de teses e dissertações $(3,4 \%)$, de comunicações em eventos $(4,2 \%)$ e de relatórios técnicos $(1,9 \%)$, pode estar relacionada ao fato dos mesmos constituirem o rol da chamada literatura cinzenta, cuja identificação e acesso são dificultados pela inexistência de fontes especificas de divulgação e pelo próprio desconhecimento de sua existência por parte dos pesquisadores. Nāo se deve deixar de considerar, a pouca quantidade produzida dessa literatura, em especial as dissertações/teses, cuja oferta é menor, quando comparada a outros tipos de documentos.

O uso de dissertações/teses na elaboração de outras dissertações/teses e mesmo de artigos de periódicos, não é marcante, conforme mostram os resultados de 
outros trabalhos sobre análise de citações: CARVALHO ${ }^{15}$ (1976) encontrou 1,75\% das citaçōes de teses em artigos em ciências biológicas; 0,7\% em artigos no campo da literatura inglesa (HEINZKILL. 1980) ${ }^{47} ; 1,6 \%$ das citações em mestrados de ciências da informaçāo (RODRIGUES, 1982) ${ }^{84}$; no campo da saúde pública ANDRADE $^{5}$ (1984, p.37) encontrou $4,5 \%$ das citações de teses e dissertações nos mestrados e doutorados analisados; $2,0 \%$ em trabalhos sobre o uso de literatura cinzenta na área da agricultura (AINA, 1987) ${ }^{1} ; 0.01 \%$ de citações em teses sobre filosofia foi achado por HERUBEL ${ }^{48}$ (1991); $1.7 \%$ das citações em artigos de periódicos na área da biblioteconomia médica referem-se a teses e relatórios técnicos (HAIQI, 1995) ${ }^{44}$.

Vale destacar, no entanto, que a pouca utilização de teses pode estar mascarada dado que as mesmas podem ter sido citadas mas em outro formato (dissertações e teses publicadas após a defesa) e este detalhe não foi detectado no presente estudo. Na verdade, as dissertações/teses, tidas como fontes de grande utilizaçāo e importância pelos pesquisadores, não são tão citadas quanto são ditas utilizadas. ANDRADE ${ }^{6}$ (1992, p.134) verificou que as teses foram consideradas com maior grau de consulta para $53,2 \%$ dos docentes dos cursos de pós-graduação em saúde pública da área de Epidemiologia e 66,7\% da área de Serviços de Saúde.

O Quadro 9 relaciona os vários tipos de documentos enquadrados na categoria "outros", e que dizem respeito a documentos convencionais (dicionários, enciclopédias, anuários estatísticos, documentos legislativos, manuais, etc.), e não-convencionais (cartas, oficios, circulares e outros documentos adminstrativos, trabalhos escolares, palestras, etc.), além de outras fontes.

Chama a atenção o percentual de $32,4 \%$ nesta categoria, representado por referências que se apresentaram de forma incompleta, com falta de elementos essenciais para a identificação do documento e apresentadas de tal forma que não foi possivel qualificar o tipo do documento citado. Assim, pela importância na identificação 
dos documentos que fundamentam todo o conteúdo das dissertações/teses, deveria haver por parte dos autores (alunos de pós-graduação) e de seus orientadores, maior cuidado na elaboração das referências bibliográficas dos documentos citados, seguindo as normas em curso (da ABNT ou adaptadas que sejam). Talvez o próprio desconhecimento por parte do aluno da existência e da necessidade dessa normalizaçāo, tenha contribuido para este resultado.

Dentre os documentos agregados no conjunto "outras publicações", destacam-se ainda, tanto para os mestrados como para os doutorados a presença de documentos legislativos, leis, decretos, acordãos, resoluções, bastante utilizados no campo da saúde pública, dado que muitos trabalhos são voltados a regulamentações de açōes governamentais, instituições públicas de serviços, que necessitam de docurnentação oficial para a comprovaçāo dos fatos. Publicações de dados estatísticos (anuários, censos, boletins estatisticos, tabelas) sāo também citados com bastante frequência, e consideradas fundamentais para o desenvolvimento de trabalhos no campo da saúde pública.

Embora a validade do uso de artigos de jornais noticiosos. populares, não possa ser comparada com aos publicados em revistas especializadas, foi grande o número de citaçōes desse tipo de documento. Tem-se verificado atualmente que este veículo de comunicação de massa vem dedicando cada vez mais um espaço para a ciência e a tecnologia. Segundo MELO ${ }^{60}$ (1987) a "presença acentuada do noticiário sobre a produção e a disseminação do conhecimento reflete o avanço da pesquisa brasileira e o interesse que o trabalho dos nossos cientistas desperta junto à sociedade" (p.13).

Alguns tipos de citaçōes nāo deveriam figurar entre as referências bibliográficas por não se tratar de informações extraidas de documentos gravados em papel ou outro formato de acesso público. $\dot{E}$ O caso de informações obtidas de "comunicações pessoais", "entrevistas", "depoimentos", que se recomenda sejam feitas em notas colocadas em rodapè da página onde constam, e não junto às referências bibliográficas 
dos demais documentos utilizados. O mesmo procedimento deve ser dado aos documentos internos administrativos, como atas de reuniōes, convênios, cartas, ofícios, memorandos, entre outros, que também mereciam ser destacados em notas de rodapé. Notas explicativas de como se pode obter esses documentos poderiam ser mostradas em substituição à sua menção em forma de referência bibliográfica.

QUADRO 9 - Relaçāo dos "Outros Tipos" de Documentos Citados nas Dissertações de Mestrado e Teses de Doutorado

\begin{tabular}{|c|c|c|c|}
\hline OUTROS TIPOS DE DOCUMENTOS & $M$ & $\mathrm{D}$ & TOTAL \\
\hline Citações incompletas, nāo identificadas & 196 & 66 & 262 \\
\hline Legislaçāo (leis. decretos, acordāos, resoluçōes, regimentos, estatutos, constituiçāo & 105 & 22 & 127 \\
\hline Dados estatisticos (anuarios. censos, boletins) & 89 & 21 & 110 \\
\hline $\begin{array}{l}\text { Obras de referència (dic..enciclop. diretorios.guias.almanaques, manuais classit.) } \\
\qquad 54\end{array}$ & & 37 & 17 \\
\hline Artigos de jornais diarios (populares) & 31 & 12 & 43 \\
\hline Documentos internos (adm..discussảo, aquivos,prontuários) & 37 & 8 & 45 \\
\hline Apostilas, materiai didático, anotaçōes aula ,programas de curso & 31 & 10 & 41 \\
\hline Projetos & 27 & 6 & 33 \\
\hline Folhetos, folders & 23 & 9 & 32 \\
\hline Fasciculos de periodicos no todo & 15 & 7 & 22 \\
\hline Comunicaçāo pessoal, entrevistas, depoimentos & 14 & 7 & 21 \\
\hline Publicaçào no prelo & 7 & 2 & 9 \\
\hline Audio-visual (video, programas de TV) & 4 & 2 & 6 \\
\hline Mapas e atlas & 2 & 1 & 3 \\
\hline TOTAL.. & 618 & 190 & 808 \\
\hline
\end{tabular}

A Tabela 11 mostra os dados da análise dos documentos citados segundo a natureza (Básica e Aplicada) das dissertaçōes/teses.

Os 79 trabalhos de natureza Básica foram fundamentados com 1.334 citaçōes $(22,2 \%)$ e os 271 de natureza Aplicada contaram com 4.685 documentos citados $(77,8 \%)$. 
Para os trabalhos categorizadas como pesquisa Básica prevaleceu a citação de livros $(48,1 \%$ das citaçōes) tanto para os mestrados $(42,8 \%)$ como para os doutorados, com uma diferença favorável a estes últimos $(58,2 \%$ das citações dos doutorados classificados como básicos referem-se a livros). Foi baixa a porcentagem de relatórios técnicos utilizados nas pesquisas básicas, tanto nos mestrados como doutorados.

Os trabalhos de natureza Aplicada valeram-se na sua maioria de artigos de periódicos $(51,1 \%)$ seguida de livros $(25,4 \%)$ das comunicações em eventos $(4,7 \%)$, de teses $(3,4 \%)$ e dos relatórios técnicos $(2,1 \%)$. Esta sequência é a mesma observada nas dissertações e nas teses. As "outras publicações" tiveram uso semelhante tanto para as pesquisas básicas $(13,3 \%)$ como para as aplicadas $(13,7 \%)$. 
Tabela 11 - Tipos de Documentos Citados nas Dissertaçōes de Mestrado e Teses de Doutorado, segundo as Categorias de Pesquisa.

\begin{tabular}{|c|c|c|c|c|c|c|c|c|c|c|c|c|c|c|}
\hline \multirow{3}{*}{$\begin{array}{l}\text { CAT. PESQUISA } \\
\text { TIPO DOCUMENTO CITADO } \\
\text { Livro }\end{array}$} & \multicolumn{4}{|c|}{ BÁSICA $(N=79)$} & \multicolumn{4}{|c|}{ APLICADA $(N=271)$} & \multicolumn{4}{|c|}{ TOTAL $(N=350)$} & \multicolumn{2}{|c|}{ TOTAL GERAL } \\
\hline & $\frac{M=63}{379}$ & $\frac{D=16}{262}$ & \multirow{2}{*}{$\begin{array}{c}T \\
641\end{array}$} & \multirow{2}{*}{$\frac{\%}{48.1}$} & \multirow{2}{*}{$\begin{array}{c}M=203 \\
835\end{array}$} & $\frac{\mathrm{D}=68}{354}$ & $\frac{T}{1.189}$ & $\begin{array}{c}\% \\
25.4\end{array}$ & \multicolumn{2}{|c|}{$M=266$} & \multicolumn{2}{|c|}{$D=84$} & $\frac{N}{1.830}$ & $\frac{\%}{30.4}$ \\
\hline & $\begin{array}{c}379 \\
(42.8)\end{array}$ & $\begin{array}{c}262 \\
(58.2)\end{array}$ & & & & $\begin{array}{c}354 \\
(23.9)\end{array}$ & 1.189 & 25.4 & 1214 & 29.7 & 616 & 31,9 & 1.830 & 30.4 \\
\hline Artigo Periódico & $\begin{array}{c}300 \\
(33.9)\end{array}$ & $\begin{array}{c}117 \\
(26.0)\end{array}$ & 417 & 31.3 & $\begin{array}{l}1545 \\
(48.2)\end{array}$ & $\begin{array}{c}848 \\
(57.3)\end{array}$ & 2393 & 51.9 & 1845 & 45.1 & 965 & 50,0 & 2.810 & 46.7 \\
\hline Dissertaçäo/Tese & $\begin{array}{c}34 \\
(3,9)\end{array}$ & $\begin{array}{c}8 \\
(1,8)\end{array}$ & 42 & 3,1 & $\begin{array}{l}117 \\
(3,6)\end{array}$ & $\begin{array}{c}43 \\
(2,9)\end{array}$ & 160 & 3.4 & 151 & 3.7 & 51 & 2.6 & 202 & 3,4 \\
\hline Comunicação em Evento & $\begin{array}{c}28 \\
(3.2)\end{array}$ & $\begin{array}{c}9 \\
(2,0)\end{array}$ & 37 & 2.8 & $\begin{array}{l}147 \\
(4,6)\end{array}$ & $\begin{array}{c}7.1 \\
(4,8)\end{array}$ & 218 & 4.7 & 175 & 4.3 & 80 & 4,2 & 255 & 4,2 \\
\hline Relatório Técnico & $\begin{array}{c}8 \\
(0.9)\end{array}$ & $\begin{array}{c}6 \\
(1,3)\end{array}$ & 14 & 1,0 & $\begin{array}{c}78 \\
(2,4)\end{array}$ & $\begin{array}{c}22 \\
(1,5)\end{array}$ & 100 & 2.1 & 86 & 2.1 & 28 & 1,5 & 114 & 1,9 \\
\hline "Outros" & $\begin{array}{c}135 \\
(15.3)\end{array}$ & $\begin{array}{c}48 \\
(10.7)\end{array}$ & 183 & 13,7 & $\begin{array}{c}483 \\
(15.1)\end{array}$ & $\begin{array}{r}142 \\
(9.6)\end{array}$ & 625 & 13.3 & 618 & 15.1 & 190 & 9.8 & 808 & 13.4 \\
\hline TOTAL & $\begin{array}{c}884 \\
(100,0)\end{array}$ & $\begin{array}{c}450 \\
(100,0)\end{array}$ & 1.334 & 100.0 & $\begin{array}{l}3.205 \\
(100,0)\end{array}$ & $\begin{array}{c}1.480 \\
(100,0)\end{array}$ & 4.685 & 100.0 & 4.089 & 100,0 & 1.930 & 100,0 & 6.019 & 100,0 \\
\hline
\end{tabular}




\subsubsection{TEMPORALIDADE DOS DOCUMENTOS CITADOS}

As citaçōes dos diferentes tipos de documentos foram agrupadas segundo sua temporalidade, em periodos de anos, e mostram o seguinte quadro:

A Tabela 12 mostra a temporalidade dos diferentes tipos de documentos citados, segundo o grau do trabalho analisado. Assim, verifica-se que a maior concentração dos documentos citados encontra-se nos conjuntos publicados entre 6 a 10 anos $(30,3 \%)$ e de 11 a 20 anos $(25,3 \%)$ da defesa da dissertação/tese

Assim, publicações de até 10 anos cobrem 60,2\% das citações dos Mestrados e $58,8 \%$ das citações dos Doutorados. Nesse mesmo sentido, $\operatorname{ANDRADE}^{5}$ (1984, p.42) verificou que cerca de $50 \%$ das citações em mestrados e doutorados em saúde pública, referem-se aos 10 anos mais recentes.

Ao se analisar a temporalidade relacionada ao tipo de documento citado, verificase que a moda para a citação de livros e artigos de periódicos se dá no período de tempo de 6 a 10 anos, com pouca diferença entre ambos $(31,1 \%$ dos livros e $30,9 \%$ dos artigos de periódicos citados).

Pela própria natureza dos periódicos, como veículo básico para atualização do conhecimento, esperava-se uma melhor representatividade de artigos mais recentes em comparação com os demais tipos de documentos. Para LANCASTER e col. ${ }^{53}$ (1992), espera-se que o melhor trabalho científico cite mais trabalhos recentes e, em média, contenham uma alta porcentagem de referência a artigos de periódicos. NORONHA ${ }^{65}$ (1987) refere-se ao fato de que o uso de periódicos mais recentes é maior para os empréstimos do que para as citações.

Este mesmo periodo de tempo é encontrado na maioria das dissertações e teses e dos relatórios técnicos citados. Para as comunicações em eventos a maioria das 
citações recaiu no grupo mais recente, de três a cinco anos, o mesmo acontecendo para os "outros tipos" de documentos.

Os doutorados apresentaram maior frequência de publicações mais recentes, dos últimos 2 anos, do que os mestrados (7,2 e 6,1\%, respectivamente). Por outro lado, detiveram mais publicações com 20 anos e mais $(14,3 \%)$ do que os mestrados $(11,8 \%)$. Este resultado pode estar refletindo uma maior experiência do doutorando em trabalhos de pesquisa, o que, de certa forma, o capacita a melhor identificar as diferentes fontes de consulta para identificação de documentos de interesse e conhecer os meios existentes na seleção e obtenção de informações atualizadas, publicadas mais recentemente, sem deixar de considerar a importância de obras consideradas clássicas, ou mesmo antigas, para o desenvolvimento de seu trabalho.

O maior número de publicações "sem data" recaiu sobre os "outros tipos" de publicações, o que era esperado, dada a grande variedade de fontes incluídas nesse grupo. Esta situação ocorreu mais nos mestrados.

Considerando-se ainda a temporalidade dos documentos, mas, desta feita voltada à natureza das pesquisas das dissertações e teses, nota-se pela Tabela 13, que a maioria dos trabalhos de natureza Básica cita publicaçōes de 6 a 10 anos e de 11 a 20 anos com 26,2\% das citações em cada um desses grupos. As dissertações/teses de natureza Aplicada apresentam 31,4\% das citações com idade de 6 a 10 anos e 25,1\% de 11 a 20 anos. Os demais grupos de temporalidade não mostram diferenças marcantes entre os trabalhos básicos e aplicados.

As pesquisas de natureza Básica envolveram 48,1\% de citações de livros, e, destes, a maior parte $(31,2 \%)$ com 11 a 20 anos de publicação. Para esta mesma categoria de pesquisa, os artigos de periódicos tiveram $31,3 \%$ das citações, sendo que aparecem em igual porcentagem (24,7\%) para ambos os grupos 6-10 e 11-20 anos; seguem ainda as teses citadas $(3,1 \%)$ com maior número no grupo de $6-10$ anos $(33,3 \%)$; comunicações em eventos $(2,8 \%)$ com igual porcentagem para os período $3-5$ 
anos e 6-10 anos (32,4\%); e relatórios técnicos (1,1\%) com 42,9\% no grupo 6-10 anos. Os "demais tipos"de documentos são da ordem de $13,7 \%$ das citações de trabalhos de natureza básica, com a maioria entre 3-5 anos $(29,0 \%)$. As pesquisas Básicas detiveram também maior número de trabalhos com mais de 20 anos do que as pesquisas Aplicadas.

Quanto aos documentos citados nos trabalhos de natureza Aplicada, existe uma inversão nessa ordem. Os artigos apresentam o maior número de citações $(51,1 \%)$, sendo a maior parte deles $(31.9 \%)$ de idade de $6-10$ anos; neste mesmo grupo de anos encontra-se a maioria dos livros $(33,0 \%)$ e dos relatórios técnicos $(39,0 \%)$ citados. Ao contrário das pesquisas Básicas, a maior parte das dissertações/teses citadas nos trabalhos de natureza Aplicada, é de idade entre 11-20 anos (29,4\%). As comunicações nos eventos apresentam igual porcentagem de citação para os períodos de 3-5 anos e $6-10$ anos $(32,4 \%)$.

Estes resultados confirmam a tendência das pesquisas aplicadas fundamentarem-se mais em informações extraídas de artigos de periódicos do que em outras categorias de documentos e com maior número de publicações no grupo dos 6 a 10 anos de idade $(31,4 \%)$, situaçāo inversa, se comparada às pesquisas básicas que se valeram mais de livros $(48.1 \%)$ e de publicações igualmente distribuídas nos períodos de $6-10$ anos $(26,2 \%)$ e $11-20$ anos $(26,2 \%)$ somando a $52,4 \%$. 
Tabela 12 - Tipos de Documentos Citados nas Dissertações de Mestrado e Teses de Doutorado, segundo Temporalidade de Publicação.

\begin{tabular}{|c|c|c|c|c|c|c|c|c|c|c|c|c|c|c|c|c|c|c|c|c|c|}
\hline \multirow{2}{*}{$\begin{array}{l}\text { TEMPORALIDADE } \\
\text { TIPO DOCUMENTO } \\
\text { CITADO }\end{array}$} & \multicolumn{3}{|c|}{ ATÉ 2 ANOS } & \multicolumn{3}{|c|}{ 3.5 ANOS } & \multicolumn{3}{|c|}{ 6-10 ANOS } & \multicolumn{3}{|c|}{ 11-20 ANOS } & \multicolumn{3}{|c|}{+20 ANOS } & \multicolumn{3}{|c|}{ SEM DATA } & \multicolumn{2}{|c|}{ TOTAL } & \multirow[t]{2}{*}{ TOTAL GERAL } \\
\hline & $M$ & $D$ & $T$ & $M$ & $D$ & $T$ & $M$ & $D$ & $T$ & $M$ & $D$ & $T$ & $M$ & $D$ & $T$ & $M$ & $D$ & $T$ & $M$ & $D$ & \\
\hline \multirow[t]{2}{*}{ Livro } & 59 & 38 & 97 & 20.1 & 118 & 381 & 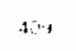 & 100 & $\sin$ & $\$ s t$ & 208 & 5,4 & 1.4 & is & 213 & 13 & ? & 25 & 1219 & 616 & 1830 \\
\hline & 4.9 & 62 & 15.31 & 217 & 192 & 1208 & $3.1:$ & 200 & (sil & $2: 8$ & 338 & 248 & is & $13 k$ & 116 & 15 & 11 & 114 & 1000 & 1000 & $(1000)$ \\
\hline \multirow[t]{2}{*}{ Artigo Periódico } & 78 & 54 & 132 & 432 & 181 & 613 & 530 & 337 & 867 & 499 & 220 & 719 & 289 & 171 & 460 & 17 & 2 & 19 & 1845 & 965 & 2810 \\
\hline & 4.2 & 5.6 & $(4,7)$ & 23.4 & 18.8 & (21.8) & 28.7 & 34,9 & (30.9) & 26.0 & 22.8 & $(25.6)$ & 15.7 & 17.7 & $(16.4)$ & 0.9 & 0.2 & $(0.7)$ & 100,0 & 100.0 & $(100.0)$ \\
\hline \multirow[t]{2}{*}{ Dissertaçāo/Tese } & 15 & 3 & 18 & 42 & 12 & 54 & 41 & 19 & 60 & 43 & 15 & 58 & 10 & 2 & 12 & $\cdot$ & & & 151 & 51 & 202 \\
\hline & 9.9 & 5.9 & $(8.9)$ & 27.8 & 23.5 & $(26.7)$ & 27.2 & 373 & (29.7) & 28.5 & 29.4 & $(28.7)$ & 6.6 & 3.9 & (5.9) & & & & 100,0 & 100.0 & $(100.0)$ \\
\hline \multirow{2}{*}{$\begin{array}{l}\text { Comunicação em } \\
\text { Eventos }\end{array}$} & 19 & 13 & 32 & 52 & 24 & 76 & 52 & 21 & 73 & 31 & 18 & 49 & 19 & 4 & 23 & 2 & & 2 & 175 & 80 & 255 \\
\hline & 10.9 & 16.3 & (12.5) & 29.7 & 30.0 & $(29.8)$ & 297 & 26.3 & (28.6) & 37.7 & 22.5 & $(192)$ & 109 & 5.0 & 19.01 & 1.1 & & 108 & 1000 & 1000 & $(1000)$ \\
\hline \multirow[t]{2}{*}{ Relatório Técnico } & 7 & 2 & 9 & 30 & 7 & 37 & 31 & 14 & 45 & 14 & 4 & 18 & 3 & 1 & 4 & 1 & & 1 & 86 & 28 & 114 \\
\hline & 8.1 & 7.1 & (7.9) & 349 & 25.0 & (32.5) & 360 & 500 & (39 5) & 163 & 143 & $(15.8\}$ & 3.5 & 36 & $3.5\}$ & 1.2 & & 1091 & 100.0 & 1000 & $\{100.0\}$ \\
\hline \multirow[t]{2}{*}{ "Outros" } & 71 & 28 & 99 & 187 & 66 & 253 & $: 72$ & 37 & 209 & 96 & 39 & 135 & 34 & 13 & 47 & 58 & 7 & 65 & 618 & 190 & 808 \\
\hline & 11.5 & 14.7 & (12.2) & 303 & 34.7 & (31.3) & 278 & 19.5 & (259) & 155 & 20.5 & $(167)$ & 55 & 6.8 & (5.8) & 9.4 & 3.7 & 180 & 1000 & 1000 & $(100.0)$ \\
\hline \multirow[t]{2}{*}{ TOTAL } & 249 & 138 & 387 & 1006 & 408 & 1.414 & 1235 & 588 & 1823 & 1020 & 504 & 1524 & 483 & 276 & 759 & 96 & 16 & 112 & 4089 & 1930 & 6019 \\
\hline & & & $6.4 \%$ & & & $235^{\circ \%}$ & & & $30 \%$ & & & $2533 \mathrm{r}$ & & & $126^{\circ}$ & & & $19 \sigma_{m}$ & & & $\left(100^{\infty} \%\right)$ \\
\hline
\end{tabular}


Tabela 13 - Tipos de Documentos Citados nas Dissertaçōes de Mestrado e Teses de Doutorado por Categorias de Pesquisa, segundo a Temporalidade de Publicação.

\begin{tabular}{|c|c|c|c|c|c|c|c|c|c|c|c|c|c|c|c|c|c|c|c|c|c|}
\hline \multirow{2}{*}{$\begin{array}{l}\text { TEMPORALIDADE } \\
\text { TIPO DOCUMENTO } \\
\text { CITADO }\end{array}$} & \multicolumn{3}{|c|}{ ATÉ 2 ANOS } & \multicolumn{3}{|c|}{ 3-5 ANOS } & \multicolumn{3}{|c|}{ 6-10 ANOS } & \multicolumn{3}{|c|}{ 11-20 ANOS } & \multicolumn{3}{|c|}{+20 ANOS } & \multicolumn{3}{|c|}{ SEM DATA } & \multicolumn{2}{|c|}{ TOTAL } & \multirow[t]{2}{*}{$\begin{array}{l}\text { TOTAL } \\
\text { GERAL }\end{array}$} \\
\hline & Bas. & Apl. & $\mathrm{T}$ & Bas. & Apl. & $T$ & Bas. & Apl. & $\mathrm{T}$ & Bas. & Apl. & $T$ & Bas. & Apl. & $\mathrm{T}$ & Bas. & Apl. & $\mathrm{T}$ & Bas. & Apl. & \\
\hline \multirow[t]{2}{*}{ Livros } & 36 & 61 & 97 & 130 & 251 & 381 & 176 & 393 & 569 & 200 & 345 & 545 & 91 & 122 & 213 & 8 & 17 & 25 & $\begin{array}{lll}641 & 481\end{array}$ & 118925.4 & 1.830 \\
\hline & 5.6 & 5.1 & (5.3) & 203 & 21.1 & 120.81 & 275 & 33.0 & $(311)$ & 31.2 & 29.0 & 2981 & 14.2 & 103 & $(116)$ & 1.2 & 1.4 & (1.4) & 100.0 & 100.0 & $(100.0)$ \\
\hline \multirow[t]{2}{*}{ Artigo Periódico } & 19 & 113 & 132 & 90 & 523 & 613 & 103 & 764 & 867 & 103 & 616 & 719 & 100 & 360 & 460 & 2 & 17 & 19 & $417 \quad 31.3$ & 239351.1 & 2.810 \\
\hline & 4.6 & 4.7 & $(4.7)$ & 21.6 & 21.9 & (21.8) & 24.7 & 31.9 & $(30.8)$ & 24.7 & 25.7 & (25.6) & 24.0 & 15.0 & (16.4) & 0.5 & 0.7 & $(0.7)$ & 100.0 & 100.0 & $(100.0)$ \\
\hline \multirow[t]{2}{*}{ Dissertação/Tese } & 7 & $n$ & 18 & 9 & 45 & 54 & 14 & 46 & 60 & 11 & 47 & 58 & 1 & 11 & 12 & - & . & - & $42 \quad 3.1$ & $160 \quad 3.4$ & 202 \\
\hline & 16.7 & 6.9 & (8.9) & 21.4 & 28,1 & $(26.7)$ & 33,3 & 28.8 & $(29.7)$ & 26.2 & 29.4 & $(28,7)$ & 2,4 & 6.9 & $(5,9)$ & & & & 100.0 & 100.0 & $(100.0)$ \\
\hline \multirow{2}{*}{$\begin{array}{l}\text { Comunicação em } \\
\text { Eventos }\end{array}$} & 5 & 27 & 32 & 12 & 64 & 76 & 12 & 61 & 73 & 3 & 46 & 49 & 5 & 18 & 23 & . & 2 & 2 & $37 \quad 2.8$ & 218 & 255 \\
\hline & 13.5 & 12.4 & $(12,6)$ & 32,4 & 29.4 & (29.8) & 32,4 & 28.0 & $(28,6)$ & 8.1 & 21.1 & $(19.2)$ & 13.5 & 8.3 & $(9.0)$ & & 0.8 & $(0.8)$ & 100.0 & 100.0 & $(100.0)$ \\
\hline \multirow[t]{2}{*}{ Relatório Técnico } & 1 & 8 & 9 & 5 & 32 & 37 & 6 & 39 & 45 & 1 & 17 & 18 & 1 & 3 & 4 & - & 1 & 1 & $14 \quad 1.1$ & 100 & 114 \\
\hline & 7.1 & 8.0 & $(7,9)$ & 35.7 & 32.0 & (32.4) & 42.9 & 39.0 & $(39,5)$ & 7.1 & 17.0 & $(15.8)$ & 7.1 & 3.0 & (3.5) & & 1.0 & (0.9) & 100.0 & 100.0 & $(100,0)$ \\
\hline \multirow[t]{2}{*}{ "Outros" } & 25 & 74 & 99 & 53 & 200 & 253 & 39 & 170 & 209 & 32 & 103 & 135 & 21 & 26 & 47 & 13 & 52 & 65 & $\begin{array}{ll}183 & 13.7\end{array}$ & $625 \quad 13.3$ & 808 \\
\hline & 13.6 & 11.8 & $(12.3)$ & 29.0 & 32,0 & (31.3) & 21.3 & 27.2 & (25.9) & 17.5 & 16.5 & $(16.7)$ & 11.5 & 4.2 & $(5.8)$ & 7.1 & 8.3 & $(8.0)$ & 100.0 & 100.0 & $(100,0)$ \\
\hline \multirow[t]{2}{*}{ TOTAL } & 93 & 294 & 387 & 299 & 1.115 & 1.414 & 350 & 1.473 & 1823 & 350 & 1.174 & 1.524 & 219 & 540 & 759 & 23 & 89 & 112 & 1334100 & $4.685 \quad 100.0$ & 6.019 \\
\hline & 6.9 & 6,3 & $(6,4)$ & 22,4 & 23.8 & (23.5) & 26.2 & 31,4 & $(30.3)$ & 26,2 & 25.1 & $(25.3)$ & 16,4 & 11.5 & $(12,6)$ & 1,7 & 1.9 & (1.9) & 100,0 & 100,0 & $(100,0)$ \\
\hline
\end{tabular}


Com relação à temporalidade das teses citadas verifica-se que as pesquisas básicas valeram-se de teses mais recentes $(16,7 \%$ das teses citadas são dos últimos 2 anos e $21,4 \%$ de $3-5$ anos) enquanto que para esses mesmos períodos, respectivamente, as pesquisas aplicadas detiveram $6,9 \%$ e $28,1 \%$ das teses citadas. As pesquisas básicas mostram também uma tendência de uso de comunicações em eventos de datas mais recentes quando comparadas às pesquisas aplicadas. Ao se considerar as publicações dos últimos 2 anos nota-se uma semelhança muito estreita entre essas duas categorias de pesquisas com uma ligeira vantagem para as básicas $(6,9 \%$ contra $6,3 \%)$.

Alguns trabalhos que tratam da idade média das citaçōes mostram que ela é variável quanto à área e o tipo de documento citado. $\operatorname{ANDRADE}^{5}$ (1984), em análise de citações de dissertações e teses em Epidemiologia, encontrou a idade média de 11,1 anos para os periódicos e de 10,4 anos para os livros citados(p.47). No campo da geologia este periodo de 10 anos foi coberto por $53,7 \%$ das citações e na paleontologia por 38,2\% das citações (WALCOTT, 1992) ${ }^{101}$. RODRIGUES ${ }^{84}$ (1982) aponta em seu trabalho alguns resultados alcançados na detecção da vida média da citação de artigos de periódicos especializados em matemática (10,5 anos), geologia (11,8 anos), botânica (10 anos) e da citação de material efêmero especializado em física (4,6 anos) e engenharia química (4,8 anos), entre outros. Para essa citada autora, a vida média da literatura estudada (dissertações no campo da ciência da informação) está entre quatro e cinco anos. LANCASTER e col. $^{53}$ (1992) encontraram uma média de 8,8 anos de idade nas fontes citadas em artigos da comunidade cientifica de paises do leste europeu. HEINZKILL ${ }^{47}$ (1980), analisando as citações em artigos sobre literatura inglesa, encontrou $40 \%$ dos artigos citados publicados nos últimos 10 anos e $71 \%$ dos livros citados, publicados nos últimos 30 anos. 
Como coloca VERGUEIRO ${ }^{99}(1995$, p.23), a atualidade da informação como componente no estabelecimento de critérios para seleção do acervo das bibliotecas varia de acordo com a área do conhecimento em que a biblioteca atua e. assim sendo, "nas ciências humanas, obras "antigas" costumam ser muito valorizadas pelos pesquisadores por constituirem uma contribuição já reconhecida e incorporada ao conhecimento humano" (p.23). Como consequência dessa valorização, as citações em trabalhos na área de humanas tendem a ser mais antigas (HERUBEL, 1991) ${ }^{48}$. E isto parece também ser uma característica das citações nas dissertações e teses quando comparadas às citações nos artigos, conforme comenta VELHO ${ }^{97}$ (1986) ao analisar os relatórios de pós-graduação apresentados ao CNPq (1980-82) onde verificou que os pesquisadores agrícolas brasileiros utilizam-se mais de literatura científica antiga. Segundo explicação dada por um dos pesquisadores da área "quando um estudante está fazendo sua dissertação, ele é aconselhado a fazer uma revisão extensiva da literatura relativa ao seu tópico, retroativa a pelo menos quinze ou vinte anos. Obviamente, quando esse estudante escreve sua pesquisa, toda essa literatura antiga será utilizada" (p.7).

Os resultados alcançados no presente trabalho, na análise da temporalidade dos documentos citados mostram que, independentemente do tipo de documento citado, do grau do documento analisado e da natureza da pesquisa, o predomínio, na maioria das situações, é do periodo de 6-10 anos para as citações analisadas.

\subsubsection{IDIOMA DOS DOCUMENTOS CITADOS}

A distribuição dos documentos citados nas dissertações e teses segundo o idioma de publicação pode ser visualizado na Tabela 14. Verifica-se, no total geral, a predominância do idioma português $(49,3 \%)$ e do inglês $(39,6 \%)$. Esta sequência coincide nas citações encontradas nos mestrados, porém, nas teses de doutorado 0 
idioma inglês $(46,0 \%)$ é um pouco superior ao português $(40,4 \%)$. Assim, é marcante o predomínio dos idiomas português e inglês, para os mestrados $(90,2 \%)$ e doutorados $(86,4 \%)$.

É importante considerar que o número de publicações em "português" inclui obras traduzidas, principalmente no que se refere a livros e alguns documentos caracterizados em "outros". Considerando-se que o inglês é a língua franca da ciência e que a maior produção em saúde pública é escrita nesse idioma, era de se esperar o grande número de textos em inglês. Tudo isso traz, como consequência, uma contribuição não significativa dos demais idiomas (o francês, italiano, alemão e "outros" marcaram mais presença nos doutorados). Neste conjunto inclui-se o espanhol que aparece em apenas $7,6 \%$ dos documentos citados.

Ao se considerar o tipo de publicaçāo, verifica-se o predomínio do idioma português para os diferentes tipos de documentos, com exceção dos artigos de periódicos cuja predominância foi o idioma inglês. Assim, a maioria dos livros utilizados nos mestrados e doutorados é em idioma português $(60,7 \%)$, com predominância nos mestrados. A maioria dos artigos de periódicos utilizados é do idioma inglês $(63,4 \%)$ com predominância para os doutorados. As teses citadas, com predomínio do idioma português $(89,1 \%)$, aparecem também em inglês $(6,9 \%)$, espanhol $(3,0 \%)$ e outros idiomas $(1,0 \%)$. Quanto às comunicaçōes em eventos $66,7 \%$ são de idoma português. Esse idioma aparece na metade $(50.0 \%)$ dos relatórios técnicos e em $82,2 \%$ das citações caracterizadas como "outros tipos" de documentos. No grupo de "outros idiomas" $(0,1 \%)$ estão incluidas publicações em original russo, japonês e holandês.

Pela Tabela 15 os idiomas das publicações citadas são agrupadas segundo a natureza (Básica e Aplicada) do documento analisado. Assim, os documentos utilizados nas dissertações e teses categorizadas de natureza Básica, são predominantemente de língua portuguêsa $(58,4 \%)$ seguido do inglês $(23,5 \%)$. Os documentos citados nas 
dissertações/teses de natureza Aplicada seguem também esta sequência (português, $46,7 \%$ e inglês $44,2 \%$, com baixa percentagem para o restante dos idiomas. Mesmo com pouca utilização, as publicações em francês, italiano e alemão aparecem com mais frequência nos trabalhos de natureza Básica. O idioma espanhol é pouco utilizado tanto nas pesquisas básicas $(7,8 \%)$ como nas aplicadas $(7,5 \%)$.

Tanto nas pesquisas básicas como aplicadas a predominância para os livros citados é o idioma português $(61,6 \%$ e $60,2 \%$ respectivamente); para os artigos de periódicos predominou o idioma inglês em ambos os tipos de pesquisas. 
Tabela 14 - Tipos de Documentos Citados nas Dissertações de Mestrado e Teses de Doutorado, segundo Idioma de Publicação.

\begin{tabular}{|c|c|c|c|c|c|c|c|c|c|c|c|c|c|c|c|c|c|c|c|c|c|c|c|c|}
\hline \multirow[t]{2}{*}{$\begin{array}{l}\text { IDIOMA } \\
\text { TIPO DOC. } \\
\text { CITADO }\end{array}$} & \multicolumn{3}{|c|}{ PORTUGUÊS } & \multicolumn{3}{|c|}{ INGLÊS } & \multicolumn{3}{|c|}{ ESPANHOL } & \multicolumn{3}{|c|}{ FRANCÊS } & \multicolumn{3}{|c|}{ ITALIANO } & \multicolumn{3}{|c|}{ ALEMÃO } & \multicolumn{3}{|c|}{$\begin{array}{l}\text { OUTROS } \\
\text { IDIOMAS }\end{array}$} & \multicolumn{2}{|c|}{ TOTAL } & \multirow[t]{2}{*}{$\begin{array}{r}\text { TOTAL } \\
\text { GERAL }\end{array}$} \\
\hline & $M$ & $\mathrm{D}$ & $\mathrm{T}$ & $\bar{M}$ & $\mathrm{D}$ & $T$ & $M$ & $D$ & $T$ & $\bar{M}$ & $D$ & $I$ & $M$ & $D$ & $T$ & $M$ & $D$ & $\mathrm{~T}$ & $M$ & $\mathrm{D}$ & $T$ & $M$ & D & \\
\hline \multirow[t]{2}{*}{ Livro } & 804 & 307 & 1.111 & 254 & 162 & 416 & 113 & 65 & 178 & 4.1 & 42 & 83 & 1 & 33 & 34 & 1 & 5 & 6 & - & 2 & 2 & 1.214 & 616 & 1.830 \\
\hline & 66,2 & 49.8 & $(60.7)$ & 20.9 & 26.3 & (22.7) & 9.3 & 10.6 & (9.7) & 3.4 & 6.8 & (4.5) & 0.1 & 5,4 & $(1.9)$ & 0.1 & 0,8 & $(0.3)$ & & 0,3 & $(0,1)$ & 100,0 & 100.0 & $(100,0)$ \\
\hline \multirow[t]{2}{*}{ Artigo Periódico } & 591 & 196 & 787 & 1.106 & 676 & 1.782 & 119 & 53 & 172 & 21 & 28 & 49 & 3 & 6 & 9 & 4 & 4 & 8 & 1 & 2 & 3 & 1.845 & 965 & 2.810 \\
\hline & 32,0 & 20,3 & $(28,0)$ & 60,0 & 70,0 & $(63,4)$ & 6.4 & 5.5 & $(6,1)$ & 1,1 & 2.9 & $(1,7)$ & 0.2 & 0.6 & $(0,4)$ & 0.2 & 0.4 & $(0,3)$ & 0.1 & 0,2 & $(0,1)$ & 100.0 & 100,0 & $(100.0)$ \\
\hline \multirow{2}{*}{$\begin{array}{l}\text { Dissertaçāol } \\
\text { Tese }\end{array}$} & 135 & 45 & 180 & 10 & 4 & 14 & 5 & 1 & 6 & 1 & - & 1 & - & 1 & 1 & - & - & . & - & - & - & 151 & 51 & 202 \\
\hline & 89,4 & 88.2 & $(89.1)$ & 6.6 & 7,8 & $(6,9)$ & 3,3 & 2.0 & $(2,8)$ & 0,7 & & $(0,5)$ & & 2.0 & $(0.5)$ & & & & & & & 100,0 & 100,0 & $(100,0)$ \\
\hline \multirow{2}{*}{$\begin{array}{l}\text { Comunicąāo } \\
\text { em Evento }\end{array}$} & 111 & 59 & 170 & 39 & 13 & 52 & 24 & 7 & 31 & 1 & 1 & 2 & - & - & . & . & - & - & . & - & . & 175 & 80 & 255 \\
\hline & 63,4 & 73.8 & $(66.7)$ & 22.3 & 16,2 & $(20,4)$ & 13.7 & 8.7 & $(12,1)$ & 0,6 & 1.3 & $(0,8)$ & & & & & & & & & & 100.0) & 100.0 & $(100.0)$ \\
\hline \multirow{2}{*}{$\begin{array}{l}\text { Relatório } \\
\text { Técnico }\end{array}$} & 38 & 19 & 57 & 36 & 6 & 42 & 12 & 3 & 15 & - & - & . & $\cdot$ & - & - & - & . & $\cdot$ & - & . & . & 86 & 28 & 114 \\
\hline & 44,2 & 67,9 & $(50,0)$ & 41.9 & 21,4 & $(36.8)$ & 13.9 & 10.7 & $(13.2)$ & & & & & & & & & & & & & 100.0 & 100.0 & $(100,0)$ \\
\hline \multirow[t]{2}{*}{ "Outros" } & 511 & 153 & 664 & 50 & 26 & 76 & 46 & 7 & 53 & 9 & 3 & 12 & 1 & 1 & 2 & . & . & . & 1 & . & 1 & 618 & 190 & 808 \\
\hline & 82.7 & 80.5 & $(82.2)$ & 8.1 & 13,7 & $(9,4)$ & 7,4 & 3.7 & $(6.6)$ & 1.4 & 1.6 & $(1,5)$ & 0.2 & 0.5 & (0.2) & & & & 0.2 & & $(0.1)$ & 100,0 & 100,0 & $(100.0)$ \\
\hline TOTAL & 2.190 & 779 & $\begin{array}{l}2.969 \\
(49.3)\end{array}$ & 1.495 & 887 & $\begin{array}{l}2.382 \\
(39.6)\end{array}$ & 319 & 136 & $\begin{array}{l}455 \\
(7.6)\end{array}$ & 73 & 74 & $\begin{array}{l}147 \\
(2.4)\end{array}$ & 5 & 41 & $\begin{array}{l}46 \\
(0.8)\end{array}$ & 5 & 9 & $(0,2)$ & 2 & 4 & $(0,1)$ & 4.089 & 1.930 & 6019 \\
\hline
\end{tabular}


Tabela 15 - Tipos de Documentos Citados nas Dissertações de Mestrado e Teses de Doutorado por Categorias de Pesquisa, segundo Idioma de Publicação.

\begin{tabular}{|c|c|c|c|c|c|c|c|c|c|c|c|c|c|c|c|c|c|c|c|c|c|c|c|c|}
\hline \multirow{2}{*}{$\begin{array}{l}\text { IDIOMA } \\
\text { TIPO DOC. } \\
\text { CITADO } \\
\end{array}$} & \multicolumn{3}{|c|}{ PORTUGUÊS } & \multicolumn{3}{|c|}{ INGLÊS } & \multicolumn{3}{|c|}{ ESPANHOL } & \multicolumn{3}{|c|}{ FRANCÊS } & \multicolumn{3}{|c|}{ ITALIANO } & \multicolumn{3}{|c|}{ ALEMĀO } & \multicolumn{3}{|c|}{$\begin{array}{l}\text { OUTROS } \\
\text { IDIOMAS }\end{array}$} & \multicolumn{2}{|c|}{ TOTAL } & \multirow{2}{*}{$\begin{array}{l}\text { TOTAL } \\
\text { GERAL }\end{array}$} \\
\hline & Bas. & Apl. & $T$ & Bas. & Anl. & $T$ & Bas. & Apl. & $T$ & Bas. & Apl & $T$ & Bas. & Apl & $T$ & Bas & Apl. & $T$ & Bas & Apl & $T$ & Bas. & Anl. & \\
\hline Livro & $\begin{array}{l}345 \\
61.6\end{array}$ & $\begin{array}{r}716 \\
601.2\end{array}$ & $\begin{array}{l}1.111 \\
(6(1) .7)\end{array}$ & $\begin{array}{l}81 \\
12.6\end{array}$ & $\begin{array}{l}335 \\
28.2\end{array}$ & $\begin{array}{r}416 \\
(40.5)\end{array}$ & $\begin{array}{l}59 \\
9.2\end{array}$ & $\begin{array}{l}119 \\
10,01\end{array}$ & $\begin{array}{r}178 \\
(9.7)\end{array}$ & $\begin{array}{l}66 \\
10.3\end{array}$ & $\begin{array}{l}17 \\
1.4\end{array}$ & $\begin{array}{c}83 \\
(4.5)\end{array}$ & $\begin{array}{l}33 \\
5.2\end{array}$ & $\begin{array}{c}1 \\
0.1\end{array}$ & $\begin{array}{c}34 \\
(1.9)\end{array}$ & $\begin{array}{c}5 \\
0.8\end{array}$ & $\begin{array}{l}1 \\
0.1\end{array}$ & $\stackrel{6}{(0,3)}$ & $\stackrel{2}{0,3}$ & - & $\stackrel{2}{2}$ & $\begin{array}{l}(4) \\
(10), 0\end{array}$ & $\begin{array}{l}1.189 \\
1(x) .0\end{array}$ & $\begin{array}{l}\begin{array}{l}1.830) \\
(1(x) .0)\end{array}\end{array}$ \\
\hline Arigu Periódico & $\begin{array}{l}159 \\
38.1\end{array}$ & $\begin{array}{l}628 \\
26.2\end{array}$ & $\begin{array}{l}787 \\
(28.1)\end{array}$ & $\begin{array}{l}2019 \\
50.1\end{array}$ & $\begin{array}{l}1.573 \\
65.7\end{array}$ & $\begin{array}{l}1.782 \\
(63.4)\end{array}$ & $\begin{array}{l}29 \\
7,1\end{array}$ & $\begin{array}{l}143 \\
6.0\end{array}$ & $\begin{array}{c}172 \\
(6.1)\end{array}$ & $\begin{array}{r}17 \\
4.1\end{array}$ & $\begin{array}{l}32 \\
1.3\end{array}$ & $\begin{array}{r}49 \\
(1.7)\end{array}$ & - & $\begin{array}{c}y \\
0.4\end{array}$ & $\begin{array}{c}9 \\
0.3\end{array}$ & $\begin{array}{c}2 \\
0.5\end{array}$ & 6.3 & $\begin{array}{c}8 \\
(1,3)\end{array}$ & $\begin{array}{c}1 \\
0.2\end{array}$ & $\begin{array}{c}2 \\
0.1\end{array}$ & $\stackrel{3}{(0,1)}$ & $\begin{array}{l}417 \\
100,0\end{array}$ & $\begin{array}{l}2.393 \\
1(0,0), 0\end{array}$ & $\begin{array}{r}2.810) \\
(1(x), 1)\end{array}$ \\
\hline $\begin{array}{l}\text { Disscriaçäly } \\
\text { Tese }\end{array}$ & $\begin{array}{c}39 \\
92,8\end{array}$ & $\begin{array}{l}141 \\
88.1\end{array}$ & $\begin{array}{c}180 \\
(89.1)\end{array}$ & & $\begin{array}{l}14 \\
8.8\end{array}$ & $\begin{array}{c}14 \\
(6.9)\end{array}$ & $\begin{array}{c}2 \\
4.8\end{array}$ & $\begin{array}{c}4 \\
2.5\end{array}$ & $\begin{array}{c}6 \\
(3.4)\end{array}$ & 2.4 & & $\begin{array}{l}1 \\
(0.5)\end{array}$ & - & ${ }_{0.6}^{1}$ & $\begin{array}{c}1 \\
(0.5)\end{array}$ & & & & - & - & - & $\begin{array}{c}42 \\
(10), 0\end{array}$ & $\begin{array}{c}1(x) \\
1(x), 01\end{array}$ & $\begin{array}{c}202 \\
(100), 0)\end{array}$ \\
\hline $\begin{array}{l}\text { Comunicaçà̄ } \\
\mathrm{cm} \text { Evenuı }\end{array}$ & $\begin{array}{c}27 \\
73.0\end{array}$ & $\begin{array}{l}143 \\
65.6\end{array}$ & $\begin{array}{r}170 \\
(66.7)\end{array}$ & $\begin{array}{c}4 \\
10.8\end{array}$ & $\begin{array}{l}48 \\
22.0\end{array}$ & $\begin{array}{c}52 \\
(20.4)\end{array}$ & $\begin{array}{c}5 \\
13.5\end{array}$ & $\begin{array}{c}2 k \\
11.9\end{array}$ & $\begin{array}{c}31 \\
12,1\end{array}$ & $\begin{array}{r}1 \\
2,7\end{array}$ & $\begin{array}{c}1 \\
0.5\end{array}$ & $\begin{array}{c}2 \\
0.8\end{array}$ & - & & - & & . & - & - & . & . & $\begin{array}{c}37 \\
101,0\end{array}$ & $\begin{array}{c}218 \\
1(10.0)\end{array}$ & $\begin{array}{c}255 \\
(1600,0)\end{array}$ \\
\hline $\begin{array}{l}\text { Relatírio } \\
\text { Técnicus }\end{array}$ & $\begin{array}{r}12 \\
85.7\end{array}$ & $\begin{array}{c}45 \\
45.0\end{array}$ & $\begin{array}{c}57 \\
(50,0)\end{array}$ & $\begin{array}{l}1 \\
7.1\end{array}$ & $\begin{array}{l}41 \\
41.0\end{array}$ & $\begin{array}{c}42 \\
(36.8)\end{array}$ & $\begin{array}{l}1 \\
7.1\end{array}$ & $\begin{array}{c}14 \\
14.0\end{array}$ & $\begin{array}{c}15 \\
(13.2)\end{array}$ & - & & - & - & - & - & . & - & - & - & . & & $\begin{array}{c}14 \\
1000.0\end{array}$ & $\begin{array}{c}100 \\
(10 x), 0\end{array}$ & $\begin{array}{c}114 \\
(1(x), 0)\end{array}$ \\
\hline "'Outrus"'" & $\begin{array}{r}147 \\
80.3\end{array}$ & $\begin{array}{l}517 \\
82,7\end{array}$ & $\begin{array}{c}664 \\
(82.2)\end{array}$ & $\begin{array}{l}18 \\
9.8\end{array}$ & $\begin{array}{l}58 \\
9.3\end{array}$ & $\begin{array}{c}76 \\
(9.4)\end{array}$ & $\begin{array}{c}8 \\
4.4\end{array}$ & $\begin{array}{l}45 \\
7.2\end{array}$ & $\begin{array}{c}53 \\
(6.6)\end{array}$ & $\begin{array}{l}8 \\
4.4\end{array}$ & $\begin{array}{c}4 \\
0.6\end{array}$ & $\begin{array}{c}12 \\
(1.5)\end{array}$ & $\begin{array}{c}1 \\
0.6\end{array}$ & $\begin{array}{c}1 \\
0.2\end{array}$ & $\stackrel{2}{2}$ & & - & - & $\begin{array}{l}1 \\
0.5\end{array}$ & - & $\begin{array}{c}1 \\
(0,1)\end{array}$ & $\begin{array}{c}183 \\
100,0\end{array}$ & $\begin{array}{c}6.25 \\
1(x), 0\end{array}$ & $\begin{array}{c}808 \\
(1(0), 0)\end{array}$ \\
\hline TOTAL & $\begin{array}{l}779 \\
58.4\end{array}$ & $\begin{array}{l}2.1901 \\
46,7\end{array}$ & $\begin{array}{l}2.969 \\
(49.3)\end{array}$ & $\begin{array}{l}313 \\
23.5\end{array}$ & $\begin{array}{l}2.0699 \\
44.2\end{array}$ & $\begin{array}{r}2.382 \\
(39.6)\end{array}$ & $\begin{array}{l}114 \\
7.8\end{array}$ & $\begin{array}{l}351 \\
7.5\end{array}$ & $\begin{array}{l}455 \\
(7,6)\end{array}$ & $\begin{array}{l}9,3 \\
7.0\end{array}$ & $\begin{array}{l}54 \\
1.2\end{array}$ & $\begin{array}{l}1.47 \\
(2.4)\end{array}$ & 2.5 & $\begin{array}{l}12 \\
0.3\end{array}$ & $\begin{array}{l}46 \\
(0,8)\end{array}$ & $\begin{array}{c}7 \\
0.5\end{array}$ & $\begin{array}{c}7 \\
0,1\end{array}$ & $\begin{array}{c}14 \\
(1,2)\end{array}$ & 4 & $\stackrel{2}{0.0}$ & 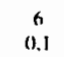 & $\begin{array}{l}1.334 \\
(0 x) .0\end{array}$ & $\begin{array}{l}4.685 \\
1(x), 0\end{array}$ & $\begin{array}{l}6.019 \\
(100,0), 0)\end{array}$ \\
\hline
\end{tabular}




\subsubsection{PROCEDÊNCIA GEOGRÁFICA DOS DOCUMENTOS CITADOS}

Com relação à origem geográfica ou procedência dos documentos citados, pela Tabela 16 pode-se verificar que, em primeiro lugar, aparecem as publicaçōes brasileiras $(49,0 \%)$, seguidas das norte americanas $(26,3 \%)$, da Inglaterra $(8,2 \%)$, dos países da América Latina $(4,0 \%)$, França $(2,3 \%)$, Itália $(1,0 \%)$, Alemanha $(0,6 \%)$. De "outros paises" foram citados 426 documentos $(7,1 \%)$. A não identificação do local de publicação para 89 documentos $(1,5 \%)$ deveu-se à citação incorreta ou incompleta das referências bibliográficas. Algumas citações não apresentavam o local de publicação, e outras pela forma de apresentação (como a abreviatura do título de periódicos) não foi possivel conhecer a sua procedência, como já mencionado.

Com exceção dos artigos de periódicos, cuja maior procedência foi dos Estados Unidos $(42, \%)$, os demais tipos de documentos são de procedência brasileira. Observando a produção dentro de cada país/região, o Brasil teve sua maior contribuição com livros (37,1\%); as publicações da América Latina foram mais representativas para os artigos de periódicos $(45,2 \%)$ o mesmo ocorrendo para publicações dos Estados Unidos $(74,4 \%)$,da Inglaterra $(83,7 \%)$, e Alemanha $(67,6 \%)$. França e Itália foram mais representados pelos livros $(60,4 \%$ e $63,8 \%$, respectivamente).

Segundo LANCASTER e col. ${ }^{53}$ (1992), o pais de publicação de uma fonte citada está fortemente relacionado com o pais da publicaçāo citante. No entanto, no presente trabalho esta relação não foi detectada tão intensamente, dado que quase a metade das citações analisadas é de origem brasileira $(49,0 \%)$. Este fato, além de confirmar a dependência dos paises do Terceiro Mundo, como o Brasil, de informações geradas nos grandes centros, pode ser reflexo do número limitado de publicações brasileiras especializadas, da proliferaçāo de revistas feitas sem critérios adequados de qualidade (irregularidade na publicação e distribuição, além da falta de corpo editorial e "referees") ou mesmo da própria qualidade da informação prestada nas fontes nacionais, que não seja de interesse para as pesquisas em saúde pública. A valorização dada às 
publicações internacionais, em especial americanas, pode também estar refletindo nos resultados encontrados.

Além disso, deve ser considerada também a preferência de pesquisadores de países menos desenvolvidos em divulgar os resultados de suas investigações em fontes estrangeiras, o que pode ter contribuido para este resultado. Esta situação é verificada na América Latina onde 3.000 manuscritos por ano, são publicados em revistas estrangeiras (Alonso citado por EHIKHMENOR, 1990) ${ }^{27}$; "cientistas brasileiros publicam anualmente cerca de 2.000 trabalhos em revistas internacionais" (MENEGHINI ${ }^{61}, 1992$, p.464) De qualquer forma, é inegável a contribuição que a literatura produzida nos Estados Unidos presta à ciência mundial. 
Tabela 16 - Tipos de Documentos Citados nas Dissertações de Mestrado e Teses de Doutorado segundo a Procedência Geográfica

\begin{tabular}{|c|c|c|c|c|c|c|c|c|c|c|c|c|c|c|c|c|c|c|c|c|}
\hline \multirow{2}{*}{$\begin{array}{l}\text { PROC. GEOG. } \\
\text { TIPOS DOC. } \\
\text { CITADO }\end{array}$} & \multicolumn{2}{|c|}{ BRASIL } & \multicolumn{2}{|c|}{ EUA } & \multicolumn{2}{|c|}{$\begin{array}{l}\text { AMERICA } \\
\text { LATINA }\end{array}$} & \multicolumn{2}{|c|}{ INGLATERRA } & \multicolumn{2}{|c|}{ FRANÇA } & \multicolumn{2}{|c|}{ ITALIA } & \multicolumn{2}{|c|}{ ALEMANHA } & \multicolumn{2}{|c|}{$\begin{array}{l}\text { OUTRAS } \\
\text { PROCED. }\end{array}$} & \multicolumn{2}{|c|}{$\begin{array}{l}\text { PROCED. } \\
\text { NÄO IDENT. }\end{array}$} & \multicolumn{2}{|c|}{ TOTAL } \\
\hline & N. & $\%$ & $N$ & $\%$ & $\mathrm{~N}$ & $\%$ & N. & $\%$ & $N$ & $\%$ & $\mathrm{~N}$. & $\%$ & $N$ & $\%$ & $N$ & $\%$ & $\mathrm{~N}$. & $\%$ & $\bar{N}$ & $\%$ \\
\hline Livro & 1.093 & 37.1 & 327 & 20,6 & 82 & 34.3 & 62 & 12,5 & 84 & 60,4 & 37 & 63,8 & 9 & 24,3 & 125 & 29,3 & 11 & 12,4 & 1.830 & 30,4 \\
\hline Artigo Periódico & 789 & 26.7 & 1.180 & 74,4 & 108 & 45,2 & 415 & 83.7 & 41 & 29,5 & 15 & 25,9 & 25 & 67,6 & 214 & 50.2 & 23 & 25,8 & 2.810 & 36,4 \\
\hline $\begin{array}{l}\text { Dissertaçāo/ } \\
\text { Tese }\end{array}$ & 180 & 6.1 & 3 & 0,2 & 6 & 2,5 & 8 & 1,6 & 2 & 1.4 & $\cdot$ & - & - & - & 3 & 0,7 & $\cdot$ & - & 202 & 3,4 \\
\hline $\begin{array}{l}\text { Comunicaçāo em } \\
\text { Evento }\end{array}$ & 177 & 6.0 & 22 & 1.4 & 19 & 7,9 & 7 & 1,4 & 3 & 2,2 & 2 & 3,4 & 2 & 5,4 & 21 & 4,9 & 2 & 2,2 & 255 & 4,2 \\
\hline Relatório Técnico & 54 & 1.8 & 14 & 0,9 & 4 & 1,7 & 1 & 0,2 & - & - & - & & $\cdot$ & - & 38 & 8,9 & 3 & 3,4 & 114 & 1,9 \\
\hline "Outros" & 657 & 22.3 & 39 & 2,5 & 20 & 8,4 & 3 & 0,6 & 9 & 6.5 & 4 & 6,9 & 1 & 2,7 & 25 & 5,9 & 50 & 56,2 & 808 & 13,4 \\
\hline Total & $\begin{array}{l}2.950 \\
(49,0) \\
\end{array}$ & 100.0 & $\begin{array}{l}1.585 \\
(26,3)\end{array}$ & 100,0 & $\begin{array}{c}239 \\
(4,0) \\
\end{array}$ & 100,0 & $\begin{array}{c}496 \\
(8,2) \\
\end{array}$ & 100,0 & $\begin{array}{r}139 \\
(2.3) \\
\end{array}$ & 100,0 & $\begin{array}{c}58 \\
(1,0) \\
\end{array}$ & 100,0 & $\begin{array}{c}37 \\
(0.6) \\
\end{array}$ & 100,0 & $\begin{array}{c}426 \\
(7,1)\end{array}$ & 100,0 & $\begin{array}{c}89 \\
(1,5)\end{array}$ & 100,0 & 6.019 & 100,0 \\
\hline
\end{tabular}


Comparando-se o idioma dos documentos citados e a sua procedência geográfica (pais de origem), pela Tabela 17, nota-se, para todos os países, com exceção da Alemanha, o predomínio absoluto, do idioma pátrio. Assim, das publicações brasileiras (2.950), quase a totalidade (2.916) é publicada em português, 26 em inglês, 7 em espanhol, e uma em francês.

O idioma inglês foi o único a figurar entre as publicações dos diferentes países de origem. Do total de publicações em inglês (2.382), 60,9\% são de origem americana e $20,6 \%$ de origem inglesa., o que mostra maior influência dos EUA. O Brasil contribuiu com $1,1 \%$ do total de publicações nesse idioma, superior à contribuição da América Latina $(0,2 \%)$, França $(0,6 \%)$ e Alemanha $(0,9 \%)$.

Este resultado mostra que, embora exista uma tendência para os periódicos brasileiros editarem seus artigos em inglês para uma maior divulgação internacional, poucos documentos usados foram publicados nesse idioma no Brasil $(1,1 \%)$, que pode estar refletindo que são poucas as publicações na área da saúde pública editadas no Brasil em inglês ou que essas publicações são preteridas pelos alunos pelo não domínio do idioma. 
TABELA 17 - Documentos Citados nas Dissertaçōes de Mestrado e Teses de Doutorado, segundo sua Procedência Geográfica e Idioma de Publicaçāo.

\begin{tabular}{|c|c|c|c|c|c|c|c|c|c|c|c|c|c|c|c|c|}
\hline \multirow{2}{*}{$\begin{array}{l}\text { IDIOMA } \\
\text { PROCEDÉNCIA } \\
\text { GEOGRÁFICA }\end{array}$} & \multicolumn{2}{|c|}{ PORTUGUÉS } & \multicolumn{2}{|c|}{ INGLEES } & \multicolumn{2}{|c|}{ ESPANHOL } & \multicolumn{2}{|c|}{ FRANCES } & \multicolumn{2}{|c|}{ ITALIANO } & \multicolumn{2}{|c|}{ ALEMÄO } & \multicolumn{2}{|c|}{ "OUTROS" } & \multicolumn{2}{|c|}{ TOTAL } \\
\hline & $\mathrm{N}^{0}$ & $\%$ & $\mathrm{~N}^{0}$ & $\%$ & $\mathrm{~N}^{\mathrm{O}}$ & $\%$ & $\mathrm{~N}^{\circ}$ & $\%$ & No & $\%$ & NNo & $\%$ & $\mathrm{~N}^{\circ}$ & $\%$ & $\mathrm{~N}$. & $\%$ \\
\hline BRASIL & $\begin{array}{l}2.916 \\
(98,8)\end{array}$ & 98,2 & $\begin{array}{c}26 \\
(0.9)\end{array}$ & 1,1 & $\begin{array}{c}7 \\
(0,2)\end{array}$ & 1,5 & $\begin{array}{c}1 \\
(0.0)\end{array}$ & 0,7 & - & - & - & - & - & - & $\begin{array}{c}2.950 \\
(100,0)\end{array}$ & 49,0 \\
\hline $\begin{array}{l}\text { AMÉRICA } \\
\text { LATINA }\end{array}$ & - & - & $\begin{array}{c}5 \\
(2.1)\end{array}$ & 0,2 & $\begin{array}{c}234 \\
(97.9)\end{array}$ & 51,4 & - & & - & $\cdot$ & . & - & - & - & $\begin{array}{c}239 \\
(100,0)\end{array}$ & 4,0 \\
\hline EUA & $\begin{array}{c}17 \\
(1,1)\end{array}$ & 0,6 & $\begin{array}{l}1.450 \\
(91,5)\end{array}$ & 60,9 & $\begin{array}{c}116 \\
(7,3)\end{array}$ & 25,5 & $\begin{array}{c}1 \\
(0,1)\end{array}$ & 0.7 & - & - & $\begin{array}{c}1 \\
(0.1)\end{array}$ & 7,1 & - & $\cdot$ & $\begin{array}{c}1.585 \\
(100,0)\end{array}$ & 26,3 \\
\hline INGLATERRA & - & - & $\begin{array}{c}492 \\
(99,2)\end{array}$ & 20,6 & $\begin{array}{c}2 \\
(0,4)\end{array}$ & 0,4 & $\begin{array}{c}2 \\
(0,4)\end{array}$ & 1.4 & - & $\cdot$ & . & $\cdot$ & - & - & $\begin{array}{c}496 \\
(100,0)\end{array}$ & 8.2 \\
\hline FRANÇA & $\begin{array}{c}2 \\
(1,4)\end{array}$ & 0,1 & $\begin{array}{c}14 \\
(10,1)\end{array}$ & 0,6 & $\begin{array}{c}2 \\
(1,4)\end{array}$ & 0,4 & $\begin{array}{c}120 \\
(86,3)\end{array}$ & 81,6 & $\begin{array}{c}1 \\
(0,7)\end{array}$ & 2.2 & . & . & $\cdot$ & . & $\begin{array}{c}139 \\
(100,0)\end{array}$ & 2,3 \\
\hline ITÁLIA & $\cdot$ & - & $\begin{array}{c}12 \\
(20,7)\end{array}$ & 0,5 & $\begin{array}{c}1 \\
(1,7)\end{array}$ & 0.2 & . & - & $\begin{array}{c}45 \\
(77,6)\end{array}$ & 97,8 & . & - & - & - & $\begin{array}{c}58 \\
(100,0)\end{array}$ & 1,0 \\
\hline ALEMANHA & $\begin{array}{c}1 \\
(2,7)\end{array}$ & 0,0 & $\begin{array}{c}22 \\
(59,5)\end{array}$ & 0,9 & - & - & $\begin{array}{c}2 \\
(5.4)\end{array}$ & 1,4 & - & & $\begin{array}{c}12 \\
(32.4)\end{array}$ & 85,7 & - & $\cdot$ & $\begin{array}{c}37 \\
(100,0)\end{array}$ & 0,6 \\
\hline $\begin{array}{l}\text { OUTRAS } \\
\text { PROCED. }\end{array}$ & $\begin{array}{c}22 \\
(5.1)\end{array}$ & 0,7 & $\begin{array}{c}310 \\
(72,8)\end{array}$ & 13,0 & $\begin{array}{c}68 \\
(16,0)\end{array}$ & 15,0 & $\begin{array}{c}19 \\
(4,5)\end{array}$ & 12,9 & - & & $\begin{array}{c}1 \\
(0.2)\end{array}$ & 7,1 & $\begin{array}{c}6 \\
(1,4)\end{array}$ & 100,0 & $\begin{array}{c}426 \\
(100,0)\end{array}$ & 7,1 \\
\hline $\begin{array}{l}\text { PROCED. NĀO } \\
\text { IDENTIFICADA }\end{array}$ & $\begin{array}{c}11 \\
(12,4)\end{array}$ & 0,4 & $\begin{array}{c}51 \\
(57,3)\end{array}$ & 2.1 & $\begin{array}{c}25 \\
(28,1)\end{array}$ & 5.5 & $\begin{array}{c}2 \\
(2,2)\end{array}$ & 1.4 & - & & - & - & - & - & $\begin{array}{c}89 \\
(100,0)\end{array}$ & 1,5 \\
\hline TOTAL & $\begin{array}{l}2.969 \\
(49,3)\end{array}$ & 100,0 & $\begin{array}{l}2.382 \\
(39,6)\end{array}$ & 100,0 & $\begin{array}{c}455 \\
(7,6)\end{array}$ & 100,0 & $\begin{array}{c}147 \\
(2,4)\end{array}$ & 100,0 & $\begin{array}{c}46 \\
(0,8)\end{array}$ & 100,0 & $\begin{array}{c}14 \\
(0,2)\end{array}$ & 100,0 & $\begin{array}{c}6 \\
(0,1)\end{array}$ & 100,0 & $\begin{array}{c}6.019 \\
(100,0)\end{array}$ & 100,0 \\
\hline
\end{tabular}


As publicações de idioma francês e editadas na França somam a $120(86,3 \%)$, sendo $13,7 \%$ editadas fora desse país. Da Alemanha foram citados 37 documentos sendo destes, a maioria em idioma inglês (59,5\%) - apenas $32,4 \%$ escritas em alemão, sugerindo que, a exemplo de outros países que sofrem o problema da barreira linguistica no meio científico pelo pouco dominio do idioma pátrio fora de suas fronteiras, a Alemanha vale-se muito do inglês para maior divulgação de suas publicações.

Os 17 documentos escritos em português e os $116 \mathrm{em}$ espanhol, editados nos Estados Unidos, possivelmente sejam produtos de trabalhos elaborados pela Organização Panamericana da Saúde (OPAS), que é um escritório regional da Organização Mundial da Saúde (OMS), sediada em Washington, DC, EUA, voltada às Américas e Caribe, que edita vários tipos de documentos monográficos e publicações seriadas, além de manter por vários anos a publicação de um periódico corrente (Boletin de la Oficina Sanitaria Panamericana/Bulletin of the Pan American Organization). São publicações editadas em inglês, espanhol e português, destinadas a divulgar resultados de investigações no campo da saúde pública, elaboradas por profissionais ou equipes de profissionais, e que refletem os interesses da região

Além da OPAS, a OMS, sediada em Genebra, é representada em outros países, com sedes regionais, que também são responsáveis pela elaboração de publicaçōes editadas em outras línguas (com predomínio do inglês) além da oficial do país. Isto pode estar refletindo no fato de a maioria das publicações editadas em "outros locais" ser em língua inglesa $(72,8 \%)$.

Segundo WALCOTT ${ }^{101}$ (1992), publicações em inglês de outros países estão competindo fortemente contra a indústria de publicaçōes dos Estados Unidos. Em trabalho realizado, encontrou nas citações em doutorados de geociências de instituições americanas, $96 \%$ das publicações em língua inglesa, porém, delas, 36\% não são 
publicadas nos Estados Unidos. Outros exemplos confirmam os achados desse autor, como cientistas de paises do leste europeu que citaram em seus trabalhos mais publicaçōes em inglês do que da própria língua, embora as origens das publicações fossem próprias $(74,1 \%$ dos documentos citados em inglês e, destes, 39,0\% de origem americana) (LANCASTER e col., 1992) ${ }^{53}$. CARVALHO ${ }^{15}$ (1976) em análise de citação de artigos publicados por docentes de ciencias biológicas de uma universidade brasileira detectou que $69 \%$ das citações publicadas em inglês, $44 \%$ são americanas e $16 \%$ inglesas.

A preferência de uso de publicações brasileiras e escritas em português, por parte dos alunos de pós-graduação na elaboração de suas pesquisas, pode ser reflexo da temática desenvolvida, voltada a problemas de saúde locais ou nacional e de interesse da clientela específica brasileira. $E$ isto sem se considerar o problema da barreira linguistica existente no meio acadêmico.

\subsubsection{CARACTERIZAÇÃO DA AUTORIA DAS CITAÇÕES BIBLIOGRÁFICAS}

Com relação ao estudo dos autores dos documentos citados nas dissertações e teses em saúde pública, os mesmos foram agrupados na Tabela 18 conforme o tipo de autoria em: autoria única (trabalhos de um único autor/pessoa física); autoria múltipla (trabalhos de mais de um autor); e autoria institucional (quando uma instituição responsável pelo conteúdo do documento). Quando não identificado, na referência bibliográfica, nenhum desses tipos, o documento foi classificado na categoria "sem autoria". 
Tabela 18 - Documentos Citados nas Dissertaçōes de Mestrado e Teses de Doutorado, segundo

\begin{tabular}{|c|c|c|c|c|c|c|c|c|c|c|}
\hline \multirow{3}{*}{$\begin{array}{l}\text { TIPOS AUTORIA } \\
\text { TIPOS } \\
\text { DOCUMENTO } \\
\text { CITADO }\end{array}$} & \multirow{2}{*}{\multicolumn{2}{|c|}{ UNNICA }} & \multirow{2}{*}{\multicolumn{2}{|c|}{ MÚLTIPLA }} & \multirow{2}{*}{\multicolumn{2}{|c|}{ INSTITUCIONAL }} & \multirow{2}{*}{\multicolumn{2}{|c|}{ SEM AUTORIA }} & \multirow{2}{*}{\multicolumn{2}{|c|}{ TOTAL }} \\
\hline & & & & & & & & & & \\
\hline & N. & $\%$ & N. & $\%$ & N. & $\%$ & N. & $\%$ & N. & $\%$ \\
\hline LIVRO & $\begin{array}{l}1.236 \\
(67,5)\end{array}$ & 43.9 & $\begin{array}{c}446 \\
(24,4)\end{array}$ & 19.1 & $\begin{array}{c}129 \\
(7,1)\end{array}$ & 22,8 & $\begin{array}{c}19 \\
(1,0)\end{array}$ & 6,3 & $\begin{array}{c}1.830 \\
(100,0)\end{array}$ & 30.4 \\
\hline $\begin{array}{l}\text { ARTIGO } \\
\text { PERIÓDICO }\end{array}$ & $\begin{array}{l}1.023 \\
(36,4)\end{array}$ & 36.3 & $\begin{array}{l}1.696 \\
(60.4)\end{array}$ & 72,6 & $\begin{array}{c}40 \\
(1.4)\end{array}$ & 7,1 & $\begin{array}{c}51 \\
(1,8)\end{array}$ & 17,1 & $\begin{array}{c}2.810 \\
(100,0)\end{array}$ & 46,4 \\
\hline DISSERT./TESE & $\begin{array}{c}202 \\
(100,0)\end{array}$ & 7.2 & - & - & - & - & - & - & $\begin{array}{c}202 \\
(100,0)\end{array}$ & 3.4 \\
\hline $\begin{array}{l}\text { COMUNICAÇĀO EM } \\
\text { EVENTO }\end{array}$ & $\begin{array}{c}108 \\
(42,4)\end{array}$ & 3.8 & $\begin{array}{c}88 \\
((34,5)\end{array}$ & 3,8 & $\begin{array}{c}30 \\
(11.7)\end{array}$ & 5,3 & $\begin{array}{c}29 \\
(11,4)\end{array}$ & 9.7 & $\begin{array}{c}255 \\
(100,0)\end{array}$ & 4,2 \\
\hline $\begin{array}{l}\text { RELATÓRIO } \\
\text { TÉCNICO }\end{array}$ & $\begin{array}{c}13 \\
(11,4)\end{array}$ & 0.5 & $\begin{array}{c}20 \\
(17,5)\end{array}$ & 0,8 & $\begin{array}{c}66 \\
(57.9)\end{array}$ & 11,7 & $\begin{array}{c}15 \\
(13,2)\end{array}$ & 5,0 & $\begin{array}{c}114 \\
(100,0)\end{array}$ & 1,9 \\
\hline "OUTROS" & $\begin{array}{c}236 \\
(29,2) \\
\end{array}$ & 8.3 & $\begin{array}{c}86 \\
(10,6) \\
\end{array}$ & 3.7 & $\begin{array}{r}301 \\
(37,3) \\
\end{array}$ & 53,2 & $\begin{array}{r}185 \\
(22,9) \\
\end{array}$ & 61,9 & $\begin{array}{r}808 \\
(100,0) \\
\end{array}$ & 13.5 \\
\hline TOTAL & $\begin{array}{l}2.818 \\
(46,8)\end{array}$ & 100.0 & $\begin{array}{l}2.336 \\
(38,8)\end{array}$ & 100,0 & $\begin{array}{c}566 \\
(9.4)\end{array}$ & 100,0 & $\begin{array}{l}299 \\
(5.0)\end{array}$ & 100,0 & $\begin{array}{c}6.019 \\
(100,0)\end{array}$ & 100,0 \\
\hline
\end{tabular}

A autoria única, de pessoa física, prevaleceu em $46,8 \%$ das citações, seguida da múltipla $(38,8 \%)$ e da institucional $(9,4 \%)$. Foram encontrados $5,0 \%$ dos documentos citados, "sem autoria" identificada.

Segundo o tipo de documento, a autoria única, prevaleceu para os livros $(67,5 \%)$, e para as comunicações em eventos $(42,4 \%)$. Os artigos de periódicos foram representados em $36,4 \%$ pela autoria única.

A autoria múltipla de pessoa física, inversamente prevalece para os artigos de periódicos com $60,4 \%$ das citações. A seguir, as comunicações em eventos com $34,5 \%$; livros $(24,4 \%)$, relatórios técnicos $17,5 \%$ e, "outros tipos de documentos"com 10,6\%.

A autoria institucional prevaleceu para os relatórios técnicos, com $57,9 \%$ das citações; $37,3 \%$ recaiu para os "outros tipos" de documentos citados (maior representatividade para essa categoria de documento). O maior número de trabalhos "sem autoria" recaiu no grupo "outros tipos de documentos" $(61,9 \%)$, seguido dos artigos de periódicos $(17,1 \%)$. 
Com a acentuada interação interdisciplinar na ciência, tem-se verificado, atualmente, uma tendência progressiva na elaboração de trabalhos científicos por equipes de profissionais. Nesses trabalhos cada participante deve mostrar a sua contribuição, assumindo publicamente o seu conteúdo. Segundo $\operatorname{PRICE}^{76}(1976$, p.55) houve uma aceleração continua de autoria múltipla a partir do início deste século, com moderada diferenciação nos diferentes campos científicos (segundo esse autor, até então, $80 \%$ da produção de artigos sobre quimica eram de autoria única e os demais de autoria dupla). Em análise de autoria em trabaihos experimentais e clínicos na medicina, SILVA Jr.e col. ${ }^{90}$ (1990) verificaram que a proporção de artigos de trabalhos experimentais, com autoria múltipla, passou de 67,3\% em 1940 para 98,25\% em 1988,e os clínicos, de $67,4 \%$ para $92,7 \%$. Esses autores comentam que esse aumento de autoria múltipla ocorreu simultaneamente ao progresso vertiginoso da medicina, de onde inferem que "os dois processos estão, possivelmente, correlacionados como um fenômeno de causa/efeito".

Este quadro vem se firmando, com pequenas tendências nas diferentes áreas e nos diferentes tipos de documentos, conforme demonstram estudos feitos. Existem também discussões em torno de que os artigos com mais de um autor são de melhor qualidade e mais confiáveis do que aqueles escritos por um só autor. Os padrões de autoria diferem dessa forma, nas ciências e nas artes. Nas ciências o predomínio é da autoria coletiva, com tendência a se intensificar; nas ciências sociais a autoria múltipla é menos acentuada e nas artes quase não se verifica (NUNES, 1990) ${ }^{66}$.

ANDRADE $^{6}$ (1992, p.218), encontrou em artigos de pesquisa publicados por docentes de pós-graduação em saúde pública, $89,5 \%$ de autoria múltipla. Em artigos na área de ciências biológicas, o resultado encontrado por CARVALHO ${ }^{15}$ (1976) foi de $56 \%$ para artigos de autoria múltipla e $44 \%$ para autoria única. Os artigos publicados por cientistas no campo da física, prevalecem em $80,8 \%$ os elaborados em colaboração (com dois ou mais autores) (ROBINSON, 1989) ${ }^{81}$. Essa autora reforça outras opiniões de que "a ciência é hoje um trabalho desenvolvido mais em equipe e menos 
individualmente como costumava ser". Algumas exceções ocorrem nesse sentido, como o verificado por OLIVEIRA ${ }^{68}(1992$, p.60) na área da enfermagem obstétrica, cujo quadro não foi o mesmo, uma vez que houve o predomínio de artigos de autoria única $(65,5 \%)$ nos artigos de periódicos dessa especialidade. PUERARI e PEREIRA ${ }^{77}$ (1992), em estudo sobre padrões de autoria na produção brasileira na área da economia, identificaram $55 \%$ dos autores que adotaram a prática da produção acadêmica em trabalho de equipe, e apontam como padrão geral que aqueles que escrevem individualmente escrevem menos, e, os que o fazem em colaboração com outros colegas, tendem a produzir mais. Outro padrão indicado por GARFIELD ${ }^{37}$ (1980) é que, os autores que trabalham sozinhos dispendem maior período de tempo do que quando trabalhando em equipe para terminar o trabalho e consequente publicação. $E$ isto ocorre mais com trabalhos básicos em humanidade que são, na maioria, feitos por um só autor, e que devem exigir mais tempo de gestação e elaboração das idéias. GODIN e col. ${ }^{40}$ (1995) identificaram a autoria múltipla predominando nos trabalhos realizados por pesquisadores de Quebec (publicados de 1980 a 1990) tanto para aqueles ligados ao setor acadêmico $(85,6 \%)$, como ligados a hospitais $(88,0 \%)$, governo $(85,1 \%)$ e indústria $(78,2 \%)$. Dentro da autoria múltipla, prevalece a autoria dupla nos setores acadêmico e industrial e as com mais de 4 autores em trabalhos realizados por equipes de hospitais e governos.

A autoria única predominou nos documentos citados $(46,8 \%)$ nas dissertações/teses analisadas, resultado este que vem de encontro à tendência predominante da autoria múltipla no campo da saúde.

\subsubsection{ORIGEM INSTITUCIONAL E GRAU DAS TESES CITADAS}

Do total de 202 teses citadas nos mestrados e doutorados analisados, 66 $(32,7 \%)$ foram apresentadas na FSP, $22(10,9 \%)$ na ENSP, $6(3.0 \%)$ no IMS, 90 $(44,5 \%)$ em outras instituiçōes nacionais e $18(8,9 \%)$ em instituições do exterior (Tabela 19). 
Tabela 19 - Teses Citadas nas Dissertações de Mestrado e Teses de Doutorado analisadas. segundo o Grau e Instituição de Origem.

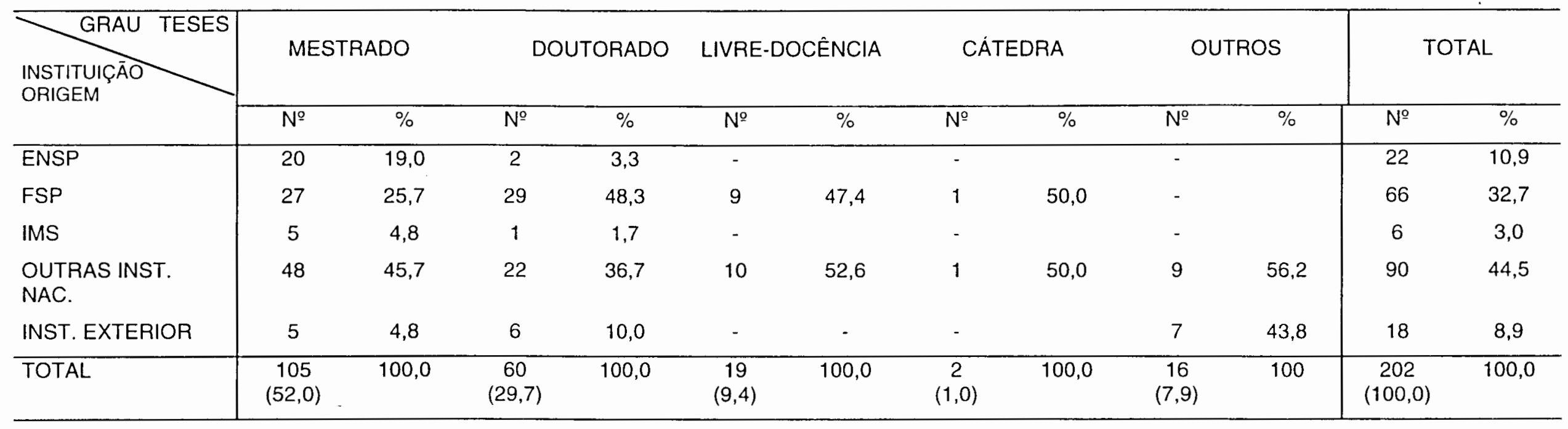


Quando se analisa essa população de teses pelo seu grau. verifica-se que a maioria desses documentos citados refere-se às dissertações de mestrado $(52,0 \%)$ seguidas das teses de doutorado $(29,7 \%)$, de livre-docência $(9,4 \%)$ e das antigas teses de cátedra $(1,0 \%)$. Os 16 documentos caracterizados como "outros"graus referem-se a citaçōes que não apresentaram a especificação do grau junto à instituição onde foram defendidas (destas, 9 são de instituições nacionais e 7 de instituições estrangeiras).

O maior número dos mestrados citados provém de "outras instituições nacionais" (45,7\%) que não a FSP, ENSP e IMS. Dos 105 mestrados citados 27 são da FSP, 20 da ENSP, 5 do IMS e 5 do exterior.

Quanto aos doutorados a situação é um pouco diferente, pois, das 60 teses citadas, $29(48,3 \%)$ são da FSP, $22(36,7 \%)$ de "outras instituições nacionais", 2 da ENSP, 6 do exterior e uma do IMS (única defendida no periodo e nāo computada no presente estudo).

Foram 19 as teses de livre-docência citadas, sendo 9 apresentadas na FSP e 10 em "outras instituições nacionais" e, duas as teses de cátedra (uma da FSP e outra de "outras instituições nacionais").

Este resultado mostra que a maioria das dissertações/teses citadas $(53,4 \%)$ foi defendida em outras instituições, especializadas ou não em saúde pública, o que revela serem de maior interesse ou de mais fácil acesso para os alunos de pósgraduação das instituições estudadas.

No entanto, ao se considerar a informação de Christovão, citada por OLIVEIRA e ARAGÃO'69 (1995) "a não significação de uma fonte para um pesquisador/professor é decorrente do desconhecimento sobre a mesma ou dificuldade extrema de acesso" (p.99), este resultado viria confirmar a precariedade 
dos serviços existentes de divulgação e de acesso aos documentos ou, mais especificamente, às teses e dissertaçōes. Além disso, não se pode deixar de considerar também que este resultado seja reflexo da diversificação dos temas desenvolvidos nas dissertaçōes/teses possivelmente pela dispersão das linhas de pesquisas em desenvolvimento nas Unidades de ensino.

Para complementar as informações sobre as dissertações e teses citadas (180, com 202 citações), foi feita a sua distribuição de frequência de citação, através da qual constatou-se que duas teses foram citadas três vezes, 18 teses foram citadas duas vezes e o restante das teses (160) foi citada uma única vez.

Finalmente, do conjunto das 350 dissertações/teses defendidas de 1990 a 1994 e analisadas no presente trabalho, constam das referências bibliográficas 17 delas (4,9\%), sendo: 8 mestrados defendidos na ENSP (três em 1990, quatro em 1991 e um em 1993); 8 defendidas na FSP (2 mestrados defendidos em 1991 e 1992, e 6 doutorados sendo dois defendidos em 1990 e quatro em 1992); e um mestrado defendido em 1992 no IMS. Pelo restante das dissertações/teses não citadas, pergunta-se se terá sido pela diversificação de interesse devido à dispersão temática?: pelo desconhecimento de sua existência devido à falta de uma divulgação mais agressiva?

\subsubsection{NÚCLEO DOS TITULOS DE PERIÓDICOS CITADOS}

Tendo como meta identificar os títulos de periódicos de maior uso pelos alunos dos cursos de pós-graduação em saúde pública, na elaboração de suas dissertações ou teses, foram selecionadas as 2.810 citações de artigos de periódicos dos documentos analisados. Assim, foi constatado o uso de 968 diferentes títulos de periódicos que cobriram esse volume de citações.

Para a determinação do núcleo dos mais citados, os títulos de periódicos foram distribuidos segundo a frequência de citações (Quadro 10) e, em seguida 
traçado um gráfico, segundo modelo de BRADFORD ${ }^{11}$, através do qual foram identificadas três zonas de produtividade.

Quadro 10 - Distribuiçāo de Freqüência das Citaçōes de Periódicos nas Dissertações de Mestrado e Teses de Doutorado.

\begin{tabular}{|c|c|c|c|c|c|c|}
\hline & $T$ & C & $\sum T$ & T.C & $\sum(T . C)$ & $\begin{array}{c}\text { \% acumulada } \\
\text { de citações }\end{array}$ \\
\hline & 1 & 133 & 1 & 133 & 133 & 4,7 \\
\hline & 1 & 65 & 2 & 65 & 198 & 7,0 \\
\hline & 1 & 44 & 3 & 44 & 242 & 8,6 \\
\hline & 1 & 41 & 4 & 41 & 283 & 10,1 \\
\hline & 2 & 40 & 6 & 80 & 363 & 12,9 \\
\hline & 1 & 38 & 7 & 38 & 401 & 14,3 \\
\hline & 2 & 35 & 9 & 70 & 471 & 16,8 \\
\hline & 1 & 34 & 10 & 34 & 505 & 18,0 \\
\hline & 1 & 31 & 11 & 31 & 536 & 19,1 \\
\hline & 2 & 29 & 13 & 58 & 594 & 21,1 \\
\hline \multirow[t]{17}{*}{$Z-1$} & 1 & 28 & 14 & 28 & 622 & 22,1 \\
\hline & 1 & 27 & 15 & 27 & 649 & 23,1 \\
\hline & 1 & 25 & 16 & 25 & 674 & 24,0 \\
\hline & 1 & 24 & 17 & 24 & 698 & 24,8 \\
\hline & 2 & 22 & 19 & 44 & 742 & 26,4 \\
\hline & 1 & 21 & 20 & 21 & 763 & 27,1 \\
\hline & 1 & 19 & 21 & 19 & 782 & 27,8 \\
\hline & 3 & 17 & 24 & 51 & 833 & 29,6 \\
\hline & 2 & 16 & 26 & 32 & 865 & 30,8 \\
\hline & 3 & 15 & 29 & 45 & 910 & 32,4 \\
\hline & 6 & 14 & 35 & 84 & 994 & 35,4 \\
\hline & 3 & 13 & 38 & 39 & 1.033 & 36,8 \\
\hline & 4 & 12 & 42 & 48 & 1.081 & 38,5 \\
\hline & 2 & 11 & 44 & 22 & 1.103 & 39,2 \\
\hline & 5 & 10 & 49 & 50 & 1.153 & 41,0 \\
\hline & 7 & 9 & 56 & 63 & 1.216 & 43,3 \\
\hline & 4 & 8 & 60 & 32 & 1.248 & 44,4 \\
\hline \multirow[t]{5}{*}{ Z-2 } & 16 & 7 & 76 & 112 & 1.360 & 48,4 \\
\hline & 20 & 6 & 96 & 120 & 1.480 & 52,7 \\
\hline & 25 & 5 & 121 & 125 & 1.605 & 57,1 \\
\hline & 35 & 4 & 156 & 140 & 1.745 & 62,1 \\
\hline & 67 & 3 & 223 & 201 & 1.946 & 69,2 \\
\hline Z-3 & 119 & 2 & 342 & 238 & 2.184 & 77,7 \\
\hline & 626 & 1 & 968 & 626 & 2.810 & 100,0 \\
\hline
\end{tabular}

$\mathrm{T}=$ Número de Títulos de Periódicos

$\mathrm{C}=$ Número de Citações

$\sum T=$ Somatória dos Títulos

T.C. $=$ Títulos $\times$ Citações

$\Sigma(T . C)=$ Somatória das Citações

Por esse modelo, os valores da coluna da somatória dos títulos de periódicos $\left(\sum T\right)$ e somatória das citações por títulos $(\Sigma(T . C))$ determinaram a curva no Gráfico e, posteriormente, foi traçada uma reta que procurou conter ou aproximar-se do maior número de pontos. A partir do primeiro ponto que coincidiu com a reta traçada foi determinado o número de títulos na abscissa e o número de citações na 
ordenada, identificando-se, desta forma, os títulos componentes da primeira zona (núcleo) de produtividade. As demais zonas foram determinadas dobrando-se 0 número de citações encontradas no núcleo e traçando-se a ordenada até a reta e. pela abscissa, encontrando o número de títulos dessas zonas.

Assim, com o traçado do Gráfico (Anexo 5), foi identificada a primeira zona ou o núcleo, representado por 38 títulos de periódicos mais citados $(3,9 \%$ do total de títulos citados) que detiveram um total de 1.033 citações $(36.8 \%$ do total de citações de artigos de periódicos), com, no mínimo, até 13 citações cada um. Só um único título $(0,1 \%)$ foi responsável por 133 citaçōes $(4,7 \%)$.

A média de citações dos periódicos componentes do núcleo foi de 27,2 citações/titulo. Este resultado está bem próximo aos encontrados em outros trabalhos sobre análise de periódicos no campo da saúde pública ( NORONHA ${ }^{65}$ (1987, p.71), com 3,1\% dos titulos cobrindo $30,1 \%$ das citaçōes; ANDRADE $^{5}$ (1984, p.47) $3.0 \%$ dos títulos $31,5 \%$ das citaçōes; $\mathrm{ASH}^{7}$ (1974), $31 \%$ dos títulos $/ 73,4 \%$ citações)

A zona 2 (citação moderada) está constituida por 185 títulos de periódicos $(19,1 \%)$ que detiveram de 12 a 3 citações cada titulo. Nesta segunda zona pode-se verificar que, $50 \%$ das citações de artigos originaram-se de $8,7 \%$ dos títulos de periódicos citados (84 títulos cobriram 1.405 citaçōes). Este conjunto foi responsável por 913 citações, com uma média de 4.9 citações/título.

A zona 3, de menor produtividade, é composta por 745 títulos que foram citados de 2 a uma única vez. Assim é que dos 745 títulos que compõem essa zona, $626(64,7 \%$ do total de títulos analisados) foram citados uma única vez. Este resultado está próximo aos achados de $\operatorname{ANDRADE}^{5}\left(1984\right.$, p.47) e NORONHA ${ }^{65}$ (1987, p.77) em análise de citaçōes de teses em saúde pública quando encontraram, respectivamente, $50,9 \%$ e $50,8 \%$ dos títulos com uma única citação.

Os títulos de periódicos que compõem a primeira zona, ou núcleo dos periódicos mais citados, estão indicados no Quadro 11. 
Quadro 11 - Relação dos Títulos Componentes do Núcleo dos Periódicos Citados, em Ordem Descrescente de Citação.

\begin{tabular}{lc}
\hline \multicolumn{1}{c}{ Títulos } & № de Citacões \\
\hline 1. Revista de Saúde Pública & 133 \\
2. American Journal of Epidemiology & 65 \\
3. American Journal of Public Health & 44 \\
4. Boletin de la Oficina Sanitaria Panamericana & 41 \\
5. International Journal of Epidemiology & 40 \\
6. Lancet & 40 \\
7. Cadernos de Saúde Pública & 38 \\
8. American Journal of Clinical Nutrition & 35 \\
9. Saúde em Debate & 35 \\
10. New England Journal of Medicine & 34 \\
11. Social Science and Medicine & 31 \\
12. American Review of Respiratory Diseases & 29 \\
13. Memórias do Instituto Oswaldo Cruz & 29 \\
14. Journal of the American Medical Association & 28 \\
15. American Journal of Tropical Medicine and Hygiene & 27 \\
16. Revista do Instituto de Medicina Tropical de Săo Paulo & 25 \\
17. British Medical Journal & 24 \\
18. Bulletin of the World Health Organization & 22 \\
19. Revista da Sociedade Brasileira de Medicina Tropical São Paulo & 22 \\
20. Journal of Occupational Medicine & 21 \\
21. International Journal of Leprosy & 19 \\
22. British Journal of Industrial Medicine & 17 \\
23. P.eviews of Infectious Diseases & 17 \\
24. Revista Brasileira de Saúde Ocupacional & 17 \\
25. Medical Care & 16 \\
26. Transaction of the Royal Society of Tropical Medicine Hygiene & 16 \\
27. Applied of Environmental Microbiology & 15 \\
28. Journal of Pediatrics & 15 \\
29. Pediatrics & 15 \\
30. Ciencia e Cultura & 14 \\
31. Educacion Medica y Salud & 14 \\
32. International Journal of Health Services & 14 \\
33. Journal of the American Dietetic Association & 14 \\
34. Journal of Chronic Diseases & 14 \\
35. Revista de Administração Püblica & 14 \\
36. Archives of Environmental Health & 13 \\
37. Revista da Fundação SESP & 13 \\
38. Salud Pública de México & 13 \\
\hline
\end{tabular}

A listagem dos titulos de periódicos componentes do núcleo é encabeçada pela "Revista de Saúde Pública", que, mais uma vez, vem se firmando como um importante veículo nacional na divulgação da informação entre os pares no campo da saúde pública. Este título recebeu 133 citações, que correspondem a 4,7\% do total, ou $12,9 \%$ das citações componentes do núcleo (1.033). A "Revista de Saúde Pública" figura entre os mais utilizados em trabalhos no campo da saúde pública conforme resultados de investigaçōes realizadas por $\operatorname{ANDRADE}^{5}$ (1984, p.50), NORONHA e col. ${ }^{64}$ (1978), COSTA LIMA e col. ${ }^{24}$ (1985), NORONHA ${ }^{65}$ (1987, 
p.76), ocupando, atualmente, o "honroso $4^{0}$ lugar dentre os dez periódicos mais usados no Brasil" (Rossetti (1995), citado por FORATTINI ${ }^{30}, 1996$, p.5).

Destaque-se que, dos 38 títulos que compõem o núcleo, $10(26,3 \%)$ são de revistas brasileiras. Assim, além da "Revista de Saúde Pública", figuram entre os mais citados: "Cadernos de Saúde Pública", "Saúde em Debate", "Memórias do Instituto Oswaldo Cruz", "Revista do Instituto de Medicina Tropical de São Paulo", "Revista da Sociedade Brasileira de Medicina Tropical", "Revista Brasileira de Saúde Ocupacional", "Ciência de Cultura", "Revista de Administração Pública" e "Revista da Fundação SESP". Destes títulos, cinco, constam do núcleo de periódicos considerados prioritários em estudo da FAPESP (KRZYZANOWSKI e col., 1991) na avaliação de títulos de periódicos científicos brasileiros. Quatro desses títulos figuram entre os mais usados pelos professores orientadores dos cursos de pósgraduação, para publicação de seus artigos (ANDRADE, 1992, p.204) ${ }^{6}$.

Dos 28 títulos estrangeiros componentes do núcleo, 25 são editados no idioma inglês, firmando mais uma vez a primazia desse idioma nas citações de artigos de periódicos.

A maioria dos títulos componentes do núcleo é constituída por títulos dedicados especificamente ao campo da saúde pública; outros são títulos de áreas dedicadas à nutrição, administração pública, pediatria, henseníase, entre outras. A presença de títulos de assuntos médicos em geral também se faz marcante como o caso das revistas "Lancet", "New England Journal of Medicine", "Journal of the American Medical Association (JAMA)", "British Medical Journal", que se configuram como básicas para as pesquisas em saúde pública.

A persistência de alguns títulos entre aqueles mais citados é um fator preponderante na tomada de decisões administrativas para a manutenção do acervo de periódicos em bibliotecas das escolas de saúde pública. Ao mesmo tempo que 
esses títulos merecem ser considerados como prioritários nos serviços de seleção e aquisição, é importante repensar na manutenção daqueles que não tiveram uma utilização representativa por parte dos usuários. São os considerados títulos "periféricos"que podem e devem ser suprimidos da coleção das bibliotecas por motivos de contenção de despesas, problemas com armazenamento, entre outros.

Não se deve deixar de considerar, no entanto, a informação veiculada por eles que deverá ser acessivel ao usuário. O que se propõe é que as bibliotecas invistam menos no acervo e cada vez mais em serviços que visam, desde a maximização do uso de suas coleções, a, principalmente, propiciar condições à recuperação da informação e acesso ao documento. A participação em redes e sistemas é essencial para essa meta. 


\section{CONSIDERAÇÕES FINAIS}

Antes de serem apresentadas as conclusões do presente trabalho merece destaque a apresentação de algumas considerações, que, mesmo não sendo parte dos objetivos propostos, complementam a discussão dos resultados obtidos nas análises realizadas.

Este trabalho originou-se de questionamentos feitos ao longo de uma trajetória de vida profissional junto à comunidade acadêmica de uma instituição de ensino e pesquisa em saúde pública: o que acontece com as dissertações e teses apresentadas pelos alunos de pós-graduação? Será que seu destino é ficar implacavelmente nas prateleiras das bibliotecas à espera de serem "descobertas"? São guardadas apenas para preservação da "memória" da instituição onde foi defendida? O que elas divulgam visa contribuir para o bem estar da população? Com que intensidade podem se tornar conhecidas da comunidade científica? Enfim, se elas são baseadas em outras informações já existentes como podem contribuir para o aumento do conhecimento? Como se caracteriza a literatura utilizada na sua elaboração?

Não há dúvidas quanto ao valor desse tipo de documento, e isto não se considerando apenas o seu conteúdo científico, mas sim, e talvez principalmente, pela oportunidade que oferece aos alunos de desenvolver sua capacidade criativa e

obter sua capacitação necessária ao exercício autônomo da atividade científica. É imperioso reconhecer também o quanto a subjetividade marca a obra humana $e$, sendo assim, a dissertação/tese, reflete, de certa forma, os limites de capacidade do aluno no processo da investigação.

A avaliação da produção científica, medida através dos produtos dos cursos de pós-graduação (dissertações de mestrado e teses de doutorado), pode servir 
como um instrumento para responder a essas questões, apresentando um diagnóstico de sua situação nas universidades brasileiras, como um alerta para tomada de decisões.

Além disso, avaliações dessa natureza contribuem para o estabelecimento de indicadores necessários à avaliação da produtividade científica brasileira, que irão refletir a realidade da pesquisa como produto dos cursos de pós-graduação em saúde pública. Esses conhecimentos são necessários a todos envolvidos na realização das dissertações e teses, como os próprios alunos orientandos, os professores-orientadores, organizadores dos cursos, especialistas e professores de metodologia científica, e profissionais da informação.

Assim, tentando dar respostas a vários questionamentos e, considerando as limitações inerentes à sua realização, o presente trabalho se propôs a levantar e analisar urn fragmento da produção dos cursos de pós-graduação em saúde pública, através de suas dissertaçōes de mestrado e teses de doutorado, segundo alguns critérios de avaliação selecionados. Além das análises propostas obtidas dos dados levantados, alguns comentários merecem ser destacados antes da apresentação das conclusões.

\section{- Análise da natureza da pesquisa e temática dos trabalhos} selecionados.

Esta foi a parte do trabalho onde maior dificuldade foi encontrada para sua efetivação. $E$ isto deveu-se principalmente pelo fato das informações serem extraídas dos resumos dos documentos analisados. Para algumas dissertações/teses a confecção do resumo deixou margem de dúvida para a categorização da natureza da pesquisa realizada, pois os seus objetivos, mesclando-se ao objeto de estudo do trabalho, não permitiu, com facilidade, identificar se o trabalho era de natureza Aplicada ou Básica. As dúvidas, nestes 
casos, foram sanadas com consultas a profissionais especialistas na área. De qualquer forma, mesmo em se considerando uma margem de erros nessa classificação, acredita-se não ter havido grande interferência nos resultados finais.

Confirmou-se, por este tipo de análise, que os trabalhos considerados de natureza Aplicada foram os de preferência tanto para os mestrandos como para os doutorandos. Este era um resultado esperado dada a caracteristica marcante da saúde pública, voltada a ações para solução de problemas de saúde da população, em nivel local e nacional.

Para a classificação dos assuntos, o destaque que chama a atenção é a grande diversificação dos temas estudados, o que deve ser considerado em futuras avaliações da categoria SP-Saúde Pública, do sistema adotado para a classificação temática das dissertaçōes/teses (Vocabulário DeCS). Pela análise temática verificou-se que os assuntos tratados foram, em grande parte, relacionados à epidemiologia e cuidados de saúde. Alguns temas especificos dessas áreas predominaram durante o período estudado, como pesquisas sobre mortalidade $1 \mathrm{e}$ serviços de saúde. "Novos" e "antigos" problemas de saúde da população, como AIDS e mortalidade infantil, foram o destaque da temática desenvolvida.

\section{- Análise da divulgação das dissertações/teses.}

O sistema de divulgação das dissertações/teses ainda não se encontra em um estágio de plena satisfação. Embora já existam melhores recursos para tal, com as novas tecnologias, com os sistemas de recuperação por redes, abrindo-se maiores perspectivas de divulgação desse material, o que se verifica é que ainda falta por parte dos elementos envolvidos nesse processo, uma maior conscientização do seu valor. Há necessidade de serem abertas fronteiras para que as informações nelas contidas possam ser de fácil acesso à comunidade científica. Como destaca FORATTINI ${ }^{29}$ (1995) a comunidade científica deve ter 
como norma de conduta, a "divulgação da informação e dos conhecimentos adquiridos" (p.81), com a realização de suas pesquisas.

É oportuno salientar neste aspecto, que as próprias instituições de onde se originam as dissertações e teses, deveriam propiciar condiçōes para maior divulgaçào desses documentos na comunidade acadêmica e científica. Assim, em principio, caberia às bibliotecas das unidades a criação e/ou colaboração na manutenção de bases de dados bibliográficos, com todos os esforços voltados para a sua atualização corrente e dispor dos meios necessários a obtenção desses produtos, além de adotar medidas para o incentivo do uso dessas bases. como serviços de alerta, treinamento ao usuário, entre outras. Aos serviços/departamentos de pós-graduação caberia agilizar 0 processo de disposição do exemplar da Unidade encaminhando-o à Biblioteca tão logo da sua defesa e aprovação. E para as instituições de onde se originam, caberia propiciar condições para editarem a produção de teses em outras publicações científicas, ou em formato de livros editados pelas editoras das próprias universidades ou incentivando a publicação de artigos em revistas especializadas de suas unidades. Propiciar eventos como palestras, cursos, dentro das instituições onde o "recémmestre" ou o "recém-doutor" possa expor seu trabalho, agora não mais sob a pressão de um julgamento, também é uma forma, embora restrita, de divulgar os achados das pesquisas das dissertações/teses. Os programas de pós-graduação deveriam ter como meta que, cada tese defendida e aprovada perante uma banca examinadora desse origem, pelo menos, a uma outra publicação. Para a própria CAPES, como coordenadora desses cursos, e para as agências de fomento que financiam grande parte desses estudos, é importante que tenham um retorno daquilo que foi aplicado, como um incentivo à melhoria e ampliação desses investimentos. Como destaca BORGES ${ }^{10}(1994)$ não são raros os casos em que os pós-graduandos, mesmo tendo terminado a tese, adiam a sua defesa para continuar 
recebendo sua bolsa de estudo até o final do prazo determinado pelas agências financiadoras. Não seria oportuno então a "cobrança" de pesquisas realizadas durante o período do curso medida através de trabalhos publicados?

\section{- Análise dos documentos citados nas dissertações/teses -}

A análise da literatura citada evidenciou várias características que podem servir como indicadores para avaliar a produçāo bibliográfica científica no campo da saúde pública. Primeiramente, com a identificação das diferentes categorias dos documentos citados, com sua temporalidade, idioma de publicação e procedência geográfica, tem-se um perfil do material utilizado mostrando a influência da literatura publicada de interesse aos alunos dos cursos de pós-graduação. Este tipo de análise pode também servir como subsídio para tomada de decisões por parte de bibliotecas especializadas na política de manutenção de seus acervos e principalmente na criação de serviços cooperativos para maximizar o uso da informação.

Fora todos esses aspectos, a análise de citaçōes realizada permite detectar alguns pontos, que, embora não sejam todos objeto de estudo deste trabalho, merecem ser destacados e discutidos para a atenção de todos aqueles que estão envolvidos nos trabalhos dos cursos de pós-graduação. Tratam-se dos aspectos relacionados à estrutura normativa das dissertações e teses.

Assim, a exemplo de qualquer outro tipo de veiculo utilizado na divulgação da pesquisa científica, é necessário que as dissertações/teses sejam elaboradas com um discurso organizado em uma sequência lógica e compreensivel às pessoas que delas se utilizam (WITTER e col., 1989) ${ }^{102}$ e que mantenha uma padronização na sua estrutura formal. Montar uma tese de forma adequada e uniforme conforme a natureza da área e tipo de estudo, é objeto de destaque em manuais de metodologia que divulgam regras para a organização de trabalhos escritos (REY ${ }^{79}$, 
1972; CASTRO $^{16}$, 1976; FRANÇA e col. ${ }^{31}$, 1990; GOLDEMBERG e col. ${ }^{41}, 1994$; $\mathrm{ECO}^{26} .1$ 1995; entre inúmeros outros). Os cursos de pós-graduação procuram orientar seus alunos a apresentar suas teses dentro de normas indicadas em manuais próprios, ou através de orientação prestada em disciplinas de Metodologia da Pesquisa ou de Orientação Bibliográfica, contando, em geral, com a colaboração do pessoal técnico especializado das Bibliotecas. Essa orientação abrange desde 0 roteiro para o levantamentos bibliográfico, processo de obtenção do documento até a montagem da tese. No entanto, verifica-se que, mesmo com toda orientação prestada e exigências dos cursos de pós-graduação, muitos documentos têm apresentado deficiências quanto à sua forma estrutural (montagem, resumos, referências bibliográficas fora das normas convencionadas), prejudicando sua própria imagem e mesmo sua divulgação. As dissertações e teses representam um início de atividades acadêmica e científica de seus autores e, portanto, esses trabalhos devem ser realizados com o rigor científico exigido para trabalho de pesquisa. As referências bibliográficas são parte integrante de qualquer trabalho científico e, portanto, a elas também se aplica esse rigor, tanto na sua forma como na sua adequada utilização. No entanto, preocupar-se com a normalização dos trabalhos, da apresentação das referências bibliográficas dos documentos utilizados, é tido por muitos estudiosos como uma "perda de tempo". Na verdade, o pesquisador nāo precisa ele próprio dispender seu tempo com esses "detalhes". Outros podem fazer por ele... O que vale é que esse pesquisador tenha a consciência da importância e necessidade de apresentar o discurso de seu trabalho de forma clara e que os documentos utilizados e que fundamentam todo o conteúdo do trabalho, sejam "todos" referenciados de forma completa e normalizada. As citações das referências bibliográficas bem elaboradas permitem que a documentação das informações contidas no texto do trabalho possam ser efetivamente comprovadas, quando necessário. Sua função é dar autoridade e credibilidade para os fatos citados no texto, além de permitir a outros 
pesquisadores a oportunidade de conhecer outros trabalhos que tratam do tema de seu interesse. É também válida a preocupação em se apresentar as referências normalizadas, para que, em trabalhos de análises de citações que frequentemente são elaboradas em estudos da produtividade científica, os resultados não sejam distorcidos em função de sua apresentação incompleta ou distorcida (na presente análise foram 262 citações consideradas "incompletas" ou "incorretas").

$\mathrm{Na}$ leitura das referências bibliográficas do presente trabalho foram detectados alguns pontos que merecem ser destacados. Assim, vale chamar a atençāo para alguns cuidados que devem ser tomados na montagem das referências bibliográficas quanto: a) títulos de periódicos - nas citações de artigos, os títulos são indicados de forma abreviada, o que é uma tradição na área. No entanto a abreviatura foi apresentada, em alguns casos, de maneira incompreensivel. A indicação do título por extenso ou do local de publicação junto ao título abreviado dos periódicos, como norma, ajudaria na identificação completa desses títulos. b) autores-colaboradores - a maioria das citações se valeu da expressão latina "et alii" ou "et al." para substituir os nomes dos autorescolaboradores. Esta forma de citação, embora preconizada nas normas, inviabiliza uma análise mais completa e detalhada das autorias dos documentos citados, como por exemplo, a identificação da elite dos autores mais citados, o impacto da produtividade científica de diferentes autores, entre outras. Pelas próprias normas existe a possibilidade de que todos os autores (independentemente do número de colaboradores) sejam citados nas referências e, quando o documento for mencionado no texto, figurar apenas o primeiro autor acompanhado de "e col..", "e colab." ou "e colaboradores". Esta é a sugestão apresentada. c) Nome dos autores - outro ponto que impede uma identificação precisa dos autores dos documentos citados é o fato dos pré-nomes dos mesmos serem apresentados de forma abreviada após os sobrenomes (o que também é tradição na área). O nome 
dos autores deveriam figurar nas referências de forma completa, na maneira como aparecem no documento citado. Aqui vale ressaltar o cuidado que os autores devem ter ào usar o seu nome de uma única forma, nos trabalhos que escrevem, pois, só assim estarão assegurando uma melhor precisão quando for medido o impacto de suas publicaçōes na comunidade científica. Outro ponto refere-se à mudança de sobrenomes de autoras ao passarem para a condição de casadas ou descasadas, o que também pode contribuir para uma identificação errônea de autorias de trabalho, escapando ao controle de análises desta natureza. Aqui fica a sugestão para as autoras adotarem sempre o mesmo sobrenome de identidade científica. A simplificação elou diversificação na grafia do nomes dos autores dificulta, também, quando da identificação de grupos de elite dos autores mais citados. d) tipos de autoria - vale destacar, mais uma vez, o predomínio de trabalhos citados de autoria única, o que vem de encontro à tendência atual de realização de trabalhos cientificos em equipe.

Resta saber agora se o quadro revelado neste estudo, com as diferentes análises realizadas, è fixo ou produto de um momento? As características identificadas teriam sido as mesmas em trabalhos de anos atrás? Ou permanecerão as mesmas nas próximas dissertações/teses a serem realizadas? Somente outros trabalhos realizados nesse sentido, poderão dar respostas a estas questōes. E o presente estudo atingirá sua meta, quando, junto aos demais dessa natureza, contribuir com informações para o estabelecimento de padrões próprios para o real conhecimento da produtividade científica brasileira no campo da saúde pública. Por outro lado, pode servir como alerta para determinação de critérios que possam melhorar as condições das dissertações/teses, enquanto fontes de informação. 


\section{CONCLUSÕES}

Diferentes enfoques podem ser dados aos estudos de Dissertaçōes de Mestrado e Teses de Doutorado, que poderão enriquecer o perfil da pós-graduação em saúde pública no Brasil.

Os resultados do presente trabalho, através da análise de dissertações e teses de alunos de cursos de pós-graduação em saúde pública, mostram várias possibilidades de contribuiçōes para o estabelecimento de indicadores para avaliação do desempenho da produtividade científica no campo da saúde pública. Embora alguns dados encontrados venham ao encontro de indicadores já firmados, ainda são necessários outros trabalhos, desta natureza, para a definição de um quadro que melhor situe a pesquisa brasileira no campo da saúde pública.

As dissertaçōes e teses foram abordadas no que diz respeito à natureza da pesquisa, à temática, à divulgação e análise dos documentos citados. Os resultados obtidos nessas análises permitem as seguintes conclusōes.

A primeira abordagem feita refere-se à caracterização das dissertaçōes/teses quanto à natureza da pesquisa e temática:

- A categorização segundo a natureza da pesquisa mostrou tendências diferenciadas de acordo com os niveis Mestrado e Doutorado, mas com predomínio das pesquisas Aplicadas (76,3\% na produção dos Mestrados e $80,6 \%$ nos Doutorados). Existe certa tendência no crescimento do número de pesquisas Básicas, principalmente nas teses de Doutorado.

- Constatou-se uma grande diversificação de assuntos, pela própria multidisciplinaridade da saúde pública, sendo mais frequentes temas voltados aos aspectos epidemiológicos das doenças e cuidados de saúde. 
- Dentro do sistema de classificação temática adotado (DeCS), a categoria dedicada ao campo da saúde pública (SP) não contempla todo o caráter multi e interdisciplinar da saúde pública $(13,4 \%$ das dissertações/teses analisadas referem-se a temas classificadas em outras categorias).

- A distribuição cronológica dos temas abordados nas dissertações/teses permitiu detectar aspectos de descontinuidade temporal o que sugere uma diversificação de interesses no campo da saúde pública ou de temas de interesse momentâneo, por parte dos alunos dos cursos estudados.

Com referência à análise da divulgação das dissertações/teses:

- A divulgação das dissertações de Mestrado e teses de Doutorado, em sua forma original, nas bases de dados bibliográficos especializadas, é satisfatória, embora não plenamente, dado que restava, ainda, no período, um resíduo de $16,9 \%$ delas (algumas defendidas em anos passados) para serem indexadas nas bases de dados selecionadas. Foram indexados $82,3 \%$ dos Mestrados e $85,7 \%$ dos Doutorados).

- Das bases de dados consultadas, a LILACS e a AD-SAÚDE mostraram ser as mais abrangentes e representativas na divulgação das dissertações/teses estudadas. A base LILACS contou com 263 documentos, sendo $72,2 \%$ dos Mestrados e $84,5 \%$ dos Doutorados e a base AD-SAÚDE, especializada em administração de serviços de saúde, contou com 150 documentos, sendo 46,2\% dos Mestrados e $32,1 \%$ dos Doutorados.

- A divulgação das dissertações/teses em outros formatos (livros, artigos de periódicos, etc.), após a sua defesa, ainda é incipiente. Foram publicadas, em outros formatos, $27,1 \%$ das dissertações/teses (95), firmando-se a preferência nos artigos de periódicos (71,6\% dos publicados). Este resultado leva a se 
considerar que ainda não existe, por parte dos alunos de pós-graduação em saúde pública, uma conscientização na necessidade em divulgar o conteúdo de suas dissertaçōes/teses em outros veículos de comunicação, tornando assim os resultados de sua pesquisa de mais fácil acesso aos demais pesquisadores da área.

Finalmente, das abordagens feitas na análise das citações destacam-se alguns pontos que podem contribuir para o estabelecimento de um perfil da literatura utilizada nas dissertações/teses no campo da saúde pública:

- Os Doutorados valem-se de maior número de documentos para fundamentação de seus achados do que os Mestrados (média de 134,8 citações/tese e 90,6 citações/dissertação).

- Quanto aos tipos de documentos citados, os artigos de periódicos constituem-se no principal veículo de utilização na elaboração das dissertações/teses $(46,7 \%$ das citações), e são proporcionalmente mais utilizados nos Doutorados $(50,0 \%)$ e nas pesquisas de natureza Aplicada $(51,1 \%)$. Os livros aparecem em maior número na dissertações/teses de natureza Básica $(48,1 \%)$.

- Não existe muita diferença na temporalidade da literatura utilizada nos Mestrados e Doutorados. A maior concentração dos documentos citados encontra-se nos conjuntos publicados em até 10 anos da defesa da dissertação/tese $(60,9 \%$ das citações nos Mestrados e $58,8 \%$ das citações nos Doutorados). O período de 6-10 anos foi o mais representativo nas citações nas dissertações/teses $(30,3 \%)$, e onde se encontra o maior número dos documentos usados nas pesquisas de natureza Aplicada (31,4\%). As de natureza Básica a maioria dos documentos citados refere-se aos publicados nos dois grupos de idade: de 6-10 anos (26,2\%) e 11-20 (26,2\%). 
- O idioma português predomina nos diferentes tipos de documentos citados (principalmente nas citações de livros com 60,7\%) com exceção dos artigos de periódicos onde prevalece o idioma inglës (63,4\% das citações dos artigos). Os alunos de pós-graduação em saúde pública, mesmo desenvolvendo trabalhos de pesquisa de interesse local ou nacional, não podem prescindir do domínio do idioma inglês, cujas publicações, em especial os artigos de periódicos, são de fundamental importância no desenvolvimento de suas pesquisas.

- A literatura brasileira, com $49,0 \%$ das citações, não é suficiente para cobrir a demanda de informação dos alunos dos cursos de pós-graduação em saúde pública que continuam na dependência da produção de outros países para o desenvolvimento de suas pesquisas.

- Comparando-se o idioma dos documentos citados e a sua procedência geográfica (pais/região de origem) existe o predomínio do idioma pátrio nas citações (quase a totalidade das publicações brasileiras citadas é editada em português; as publicaçōes em inglês têm procedência maior dos EUA e da Inglaterra). Apenas para as publicações da Alemanha predomina o idioma inglês (59,5\%). A América Latina contribuiu apenas com 4,0\% das citações, influindo na pouca utilizaçāo de obras em idioma espanhol $(7,6 \%)$.

- Com relação ao tipo de autoria dos documentos citados, não se confirma o padrão de autoria múltipla. Embora exista uma tendência progressiva na elaboração de trabalhos por equipes de pesquisadores, encontrou-se um quadro inverso, onde a autoria única (pessoa física) correponde a $46,8 \%$ das citações e a múltipla (com dois ou mais autores pessoa/física) em 38,8\%. A prevalência da autoria múltipla nas citações deu-se apenas para os artigos de periódicos $(60,4 \%)$ 
- Com referência ao núcleo dos títulos de periódicos mais citados nas dissertações/teses verificou-se que poucos títulos cobriram grande parte da demanda, isto é, $3,9 \%$ do total de títulos citados detiveram 1.033 citações (ou $36,8 \%$ do total de citaçōes dos artigos de periódicos). São 38 títulos (sendo 10 de origem brasileira) que podem ser considerados fundamentais no desenvolvimento dos estudos dos cursos de pós-graduação em saúde pública.

- O uso de teses: os alunos de pós-graduação mostraram mais interesse mas dissertaçōes/teses de outras instituições $(53,4 \%$ - nacionais e do exterior) do que naquelas defendidas nas escolas estudadas $(46,6 \%)$, podendo-se supor ser consequência da diversificação de interesses nos temas desenvolvidos.

- Finalmente, observando se as dissertações e teses estudadas no presente trabalho serviram de embasamento para a realização das mesmas, conclui-se que esse tipo de fonte é pouco utilizado pelos próprios alunos de pós-graduação. Das 350 dissertações de Mestrado e teses de Doutorado analisadas, 17 (4,9\%) foram citadas, uma única vez cada, por esses autores, o que parece estar relacionado mais à diversificação de interesse nos temas estudados e, principalmente, ao próprio desconhecimento de sua existência por parte desses alunos, do que pela sua importância como fonte de informação.

- As dissertações de Mestrado e teses de Doutorado não devem ser consideradas apenas como mais um trabalho de ascensão acadêmica. Mas, para isso, precisam ser conhecidas para sem reconhecidas. 


\section{REFERÊNCIAS BIBLIOGRÁFICAS}

1. AINA, L.O. Grey literature and agricultural research in Nigeria. Quarterly Bulletin of the International Association of Agricultural Librarians and Documentalists, 32 (1): 47-50, 1987. [Resumo na Base LISA/CD-ROM]

2. ALENCAR, Maria de Cléofas Faggion; MARTINS, Adriana Rinaldi; FERNANDES, Luzia Sigoli; RUZZA, Regina Célia Pisanelli de; PEGORARO, Silvelene. Referências bibliográficas nos planos de curso de pós-graduação em biblioteconomia da PUCCAMP (1978/1987). Trans-in-formação, 1 (2): 219-31, maio/ago. 1989.

3. ALVES, Alda Judith. A "revisão da bibliografia" em teses e dissertações: meus tipos inesqueciveis. Cadernos de Pesquisa, (81): 53-60, maio, 1992.

4. ANDERLA, Georges. A informação em 1985: estudo prospectivo de necessidades e recursos de informação. Rio de Janeiro, CNPq/IBICT, 1979.

5. ANDRADE, Maria Teresinha Dias de. Literatura citada em dissertações e teses no campo da Epidemiologia, apresentadas à Faculdade de Saúde Pública da Universidade de São Paulo, no periodo de 1979-1982. São Paulo, 1984. [Dissertação de Mestrado Faculdade de Saúde Pública da USP]

6. ANDRADE, Maria Teresinha Dias de. Pesquisa cientifica em saúde pública: produtividade da comunidade acadêmica brasileira 1983-1989. São Paulo, 1992. [Tese de Doutorado - Escola de Comunicações e Artes da USP]

7. ASH, Joan. Library use of public health materials: description and analysis. Bulletin of the Medical Library Association, 62 (2): 95-104, Apr. 1974.

8. ASSOCIAÇÃO BRASILEIRA DE NORMAS TÉCNICAS (ABNT). Apresentação de dissertações e teses. Procedimento. 1. projeto de norma. São Paulo, out. 1984. /Projeto 14:02.02-002/

9. ASSOCIAÇÃO BRASILEIRA DE PÓS-GRADUAÇÃO EM SAÚdE COLETIVA (ABRASCO). Catálogo de pós-graduação em saúde coletiva: Brasil-1993. Rio de Janeiro, 1992.

10. BORGES, D.R. Consideraçōes sobre a pós-graduaçào na área médica. Revista da Associação Médica Brasileira, 40 (4): 271-5, 1994.

11. BRADFORD, S.C. Documentação. Rio de Janeiro, Fundo de Cultura, 1961. p.196-216: O caos documentário.

12. BRAGA, Gilda M. Informação, ciência, política científica: o pensamento de Derek de Solla Price. Ciência da Informação, 3 (2): 155-77, 1974.

13. BREIMER, Lars H.; BREIMER, Downe D. A computer-based international "thesis-line"? Trends in Biochemical Science, 20 (5): 175-6, May, 1995.

14. CAMPELLO, Maria Bernadete Santos. Materiais não convencionais em bibliotecas especializadas: relatórios técnicos, teses e dissertações, normas técnicas e patentes. Revista da Escola de Biblioteconomia da UFMG, 11 (1): p.38-52, mar. 1982. 
15. CARVALHO, Maria de Lourdes Borges de. Estudo de citações da literatura produzida pelos professores do Instituto de Ciências Biológicas da UFMG. Ciência da Informação, $\mathbf{5}$ (1/2): $27-42,1976$.

16. CASTRO, Claudio de Moura. Estrutura e apresentação de publicações científicas. São Paulo, MacGraw-Hill do Brasil, 1976.

17. CASTRO, Claudio de Moura. Há produção científica no Brasil? Ciência e Cultura, 37 (7 supl.): $165-87,1985$.

18. CASTRO, Claudio de Moura. As babás dos cientistas. Folha de S. Paulo, São Paulo, 10 ago. 1994. p.1-3.

19. CHASTINET, Yone. O Prossiga na Internet: informação e comunicação para a pesquisa (http://www.prossiga.Incc.br). Jornal da Ciência Hoje, (n.especial 343), 3 de maio de $1996 ?$

20. CONFERÉNCIA NACIONAL DE SAÚDE, 8., Brasilia, 1986. Anais. Brasília, Ministério da Saúde, 1986.

21. CONSTITUIÇÃO da República Federativa do Brasil: 1988. Brasília, Ministério da Educaçāo, 1988.

22. COORDENAÇȦO DE APERFEIÇOAMENTO DE PESSOAL DE NIVEL SUPERIOR (CAPES). Avaliação da pós-graduação: sintese dos resultados/CAPES. Brasilia, 1993.

23. CORDEIRO, Hesio (coord.); MARQUES, Marilia Bernardes; POSSAS, Cristina; BUSS, Paulo. Prioridades nacionais, pesquisa essencial e desenvolvimento em saúde. Rio de Janeiro, FIOCRUZ, 1990. (Série Política de Saúde, 10)

24. COSTA LIMA, João A.; ROSA, Celina M. Schimitt; PIEGAS, Maria H.; PEIXINHO, Albaneide; SCHMIDT. André; BRIQUET DE LEMOS, Antonio A.; SOUZA, Carlos A. Marcilio de. Análisis de la información científica publicada en el Brasil en cinco años sobre la enfermedad de Chagas, esquistossomiasis, malaria, leishmaniasis y filariasis. Educacion Médica y Salud, 19 (2): 209-26, 1985.

25. DIAMOND, Jared. Publique ou pereça. Novaciência, 2 (6): 47-50, 1990.

26. ECO, Umberto. Como se faz uma tese. 12. ed. Sāo Paulo, Ed. Perspectiva, 1995.

27. EHIKHAMENOR, Fabian A. Aspects of the publication cycle of physical scientists in some Nigerian universities. Journal of Information Science, 16: 257-63, 1990.

28. FERREIRA, Delia Valerio: SOUZA, Rosali Fernandez de. Características da informação bibliográfica relevante para um grupo de pesquisa obtidas através de sua produção científica publicada: um estudo de caso. Ciência da Informação, 16 (1): 45-52, jan./jun. 1987.

29. FORATTINI, Oswaido Paulo. Pesquisa em saúde pública. Revista de Saúde Pública, S.Paulo, 29 (2): 81-7, abr. 1995.

30. FORATTINI, Oswaldo Paulo. A triade da publicação científica. Revista de Saúde Pública, S.Paulo, 30 (1): 3-12, fev. 1996. 
31. FRANÇA, Júnia Lessa; VASCONCELLOS, Ana Cristina de; BORGES, Stella Maris; MAGALHĀES, Maria Helena de Andrade. Manual para normalização de publicaçōes técnico-científicas. Belo Horizonte, Ed. UFMG, 1990.

32. FRENK, Julio; BOBADILHA, José Luis; SEPÚLVEDA, Jorge Rosenthal; RUELAS, Enrique. Un modelo conceptual para la investigación en salud publica. Boletin de la Oficina Sanitaria Panamericana, 101 (5): 477-92, nov. 1986.

33. FRICK, Silvia Teresa Ferreira. Produção cientifica dos principais centros de ensino e pesquisa em economia no Brasil. São Paulo, 1991. [Tese de Doutorado-Escola de Comunicações e Artes da USP]

34. FUNDAÇÃO OSWALDO CRUZ (FIOCRUZ). Escola Nacional de Saúde Pública. Catálogo de teses e dissertações: 1980-1994. 2.ed. Rio de Janeiro, 1994.

35. FUNDAÇĀO OSWALDO CRUZ (FIOCRUZ). Escola Nacional de Saúde Pública. Pósgraduação "strictu sensu": mestrado e doutorado na ENSP-1993-1994. Rio de Janeiro, 1994.

36. FUNDAÇÃO OSWALDO CRUZ (FIOCRUZ). Escola Nacional de Saúde Pública. Regimento interno dos cursos de pós-graduação "strictu sensu" em saúde pública. Rio de Janeiro, 1996. [folders]

37. GARFIELD, Eugene. Is information retrieval in the arts and humanities inherently different from that in science? The effect that ISI's citation index for the arts and humanities is expected to have on future scholarship. Library Quarterly, 50 (1): 40-57, Jan. 1980.

38. GARVEY, William G. Communication: the essence of science. Oxford. Pergamon Press, 1979.

39. GIL, Antonio Carlos. Métodos e técnicas de pesquisa social. 2.ed. São Paulo, Ed. Atlas, 1989.

40. GODIN, B.; BARKER, R.S.: LANDRY, M. Besides academic publications: which sectors compete, or are there competitors? Scientometrics, 33 (1): 3-12, 1995.

41. GOLDENBERG, Saul (coord.); POBLACIÓN, Dinah Aguiar; TONINI, Karla Conceição; CASTIGLIONE. Tânia Pereira Moraes. Manual: orientação normativa para elaboração de tese, normas e instruções. São Paulo [Escola Paulista de Medicina], 1994.

42. GRANJA, Elza Corrêa. Produção cientifica: dissertaçōes e teses do IPUSP (1980/1989). São Paulo, 1995. [Tese de Doutorado - Instituto de Psicologia da USP]

43. GRANOVSKY, YU.V.; LUIBIMOVA, T.N.; MURASHOVA, T.I.; MYATLEV, V.D. Informationbased evaluation of the quality of doctoral theses. Scientometrics, 23 (3): 361-76, 1992.

44. HAIQI, Zhang. A bibliometric study on articles of medical librarianship. Information Processing \& Management, 31 (4): 499-510, 1995.

45. HANSON, David J. The dissemination of Ph.D. results: further findings. American Sociologist, 10:237-8, Nov. 1975.

46. HARROD's librarians' glossary of terms used in librarianship, documentation and the book crafts. 5. ed. Aldershot, Gower, 1984. 
47. HEINZKILL, Richard. Characteristics of references in selected scholarly English literary journals. Library Quarterly, 50 (3): 352-65, July, 1980.

48. HERUBEL, Jean-Pierre V.M. Philosophy dissertation bibliographies and citations in serials evaluation. The Serials Librarian, 20 (2/3): 65-73, 1991.

49. KALTON, G. Introduction to survey sampling. Beverly Hills, Sage Publ., 1983. (Sage University Paper. Series 07-035)

50. KRIZ, H.M. Library management implications of journal citation patterns in engineering doctoral dissertations. 1984. (Publ. n.: ED243481). [Resumo na base LISA/CD-ROM]

51. KRZYZANOWSKI, Rosaly Favero; KRIEGER, Eduardo Moacyr; DUARTE, Francisco A. de Moura. Programa de apoio às revistas científicas para a FAPESP. Ciência da Informação, 20 (2): 137-50, jul./dez. 1991.

52. KUNSCH, Margarida Maria Krohling. Universidade e comunicação na edificação da sociedade. São Paulo, Ed. Loyola, 1992.

53. LANCASTER, F.W.; BURGER, R.H.; RAUCHFUSS, B.M. Use of literature by East European scientists: what influences place of publication of sources cited? Scientometrics, 24 (3): 419-39, 1992.

54. LIMA, Maria Fátima Bezerra Ferreira. Produção científica: revisão parcial da literatura brasileira com ênfase na área agrícola. Ciência da Informação, 22 (3): 233-6, set./dez. 1993.

55. LIMA, Regina Célia Montenegro de. Estudo bibliométrico: análise de citaçōes no periódico "Scientometrics". Ciência da Informação, 15 (1): 57-66, jan./jun. 1984.

56. LIMA, Regina Celia Montenegro de; FIGUEIREDO, Nice Menezes de. Seleção e aquisição: da visão clássica à moderna aplicação de técnicas bibliométricas. Ciência da Informação, 13 (2): 137-50, jul./dez. 1984.

57. LIMA, Regina Celia Montenegro de. Bibliometria: análise quantitativa da literatura como instrumento de administração em sistemas de informação. Ciência da Informação, 15 (2): $127-33,1986$.

58. LONDON School of Hygiene \& Tropical Medicine. London, 1992. p.42. [Catálogo de Cursos]

59. MARTINS, Geraldo M.; QUEIROZ, Rubens. O perfil do pesquisador brasileiro. Revista Brasileira de Tecnologia, 18 (6): 38-46, set. 1987.

60. MELO, José Marques de. Informação científica na imprensa brasileira: origem, fonte e autoria. Ciência da Informação, 16 (1): 13-9, jan./jun. 1987.

61. MENEGHINI, Rogerio. Brazilian production in biochemistry international versus domestic publication. In: Conferénce Internationale sur les Indicateurs de Sciences dans les Pays en Développement, Paris, 1990. Actes. Paris, Ed. ORSTOM, 1992. p.457-65.

62. MINAYO, Maria Cecilia de Souza. O desafio do conhecimento: pesquisa qualitativa em saúde. São Paulo, Hucitec/ABRASCO, 1992. 
63. MORALES, Melvyn. Informetrics and its importance. International Forum Information ana Documentation, 10 (2): 15-21, Apr. 1985.

64. NORONHA, Daisy Pires; FIGUEIREDO, Maria Cecilia Ferreira; ROCHA, Maria Isabel Viveiros da. Análise bibliométrica da dispersão de artigos sobre saúde pública em periódicos brasileiros. Revista da Escola de Biblioteconomia da UFMG. 7 (1): 69-89, 1978.

65. NORONHA, Daisy Pires. Utilização de periódicos por docentes e alunos de pós-graduação de uma instituição de ensino e pesquisa em saúde pública. São Paulo, 1987. [Dissertação de Mestrado - Faculdade de Saúde Pública da USP]

66. NUNES, Claudio Omar lahnke. Autoria múltipla como fator constitutivo da comunidade cientifica em Medicina Tropical, no Brasil. Belo Horizonte, 1990. [Dissertação de Mestrado - Escola de Biblioteconomia da UFMG]

67. NUNES, Everardo Duarte. As ciências sociais em saúde no Brasil e na América Latina. In: Spinola, Aracy Witt de Pinho (coord.) et al. Pesquisa social em saúde. São Paulo, Cortez, 1992. p.25-44.

68. OlIVEIRA, Anna de Lucca. Produção cientifica brasileira da área de enfermagem obstétrica 1956-1986. São Paulo, 1992. [Tese de Doutorado - Escola Paulista de Medicina]

69. OLIVEIRA, Margarida Pinto; ARAGÃO, Esmeralda Maria de. Padrões de comunicação científica dos professores/pesquisadores da Faculdade de Medicina/UFBA. Trans-informação, 7 (1/3): 85-110, jan./dez. 1995.

70. PELLEGRINI FILHO, Alberto. Analisis comparativo. In: Organización Panamericana de la Salud. La investigación en salud en America Latina: estudio de paises seleccionados. Washington, DC, 1992. p.137-63. (OPAS - Publicación Cientifica, 543).

71. PINTO, Paulo Silva. Pós-graduação: doutorado nota A cai de $73 \%$ para $66 \%$. Folha de S.Paulo, S.Paulo, 22 abr. 1995. p.3-3.

72. POBLACIÓN, Dinah Aguiar. Análise quantitativa da produção científica do corpo docente da área de saúde da USP - campus de São Paulo, 1980-1983. São Paulo, 1986. [Tese de Doutorado - Escola de Comunicações e Artes da USP]

73. POBLACIÓN, Dinah Aguiar; DUARTE, Jurandir Godoy. Comunicação da informação científica entre pesquisadores. Intercom, (61): 47-61, 1989.

74. POBLACIÓN, Dinah Aguiar. Literatura cinzenta ou não convencional: um desafio a ser enfrentado. Ciência da Informação, 21 (3): 243-6, set./dez. 1992.

75. POBLACIÓN, Dinah Aguiar; NORONHA, Daisy Pires. Autores permanentes e transientes de literatura cinzenta: comparação com a produção de literatura branca. [Apresentado na 48a. Reunião Anual da SBPC, São Paulo, 7-12 julho 1996]

76. PRICE, Derek J. de Solla. O desenvolvimento da ciência: análise histórica, filosófica, sociológica e econômica. Rio de Janeiro, Livros Técnicos e Científicos Ed., 1976. 
77. PUERARI, Dely Bezerra de Miranda; PEREIRA, Maria de Nazaré Freitas. Measurement of the scientific production in Brazil: the case of economics. In: Conference Internationale sur les Indicateurs de Science dans les Pays en Développement, Paris, 1990. Actes. Paris, Ed. ORSTOM, 1992. p.497- 507.

78.REJOWSKI. Mirian. Pesquisa acadêmica em turismo no Brasil (1975 a 1992): configuração e sistematização documental. São Paulo, 1993. [Tese de Doutorado - Escola de Comunicaçōes e Artes da USP]

79. REY, Luis. Como redigir trabalhos cientificos: para publicação em revistas médicas e biológicas. São Paulo, Ed. Edgard Blucher, 1972.

80. RIBEIRO, Sérgio Costa. Ensino e/ou pesquisa: a teoria na prática é outra. Ciência Hoje, 4 (22): 24-33, jan./fev. 1986.

81. ROBINSON, Lilian C. Análise numérica da produção técnico-científica do CBPF publicada em periódicos brasileiros e estrangeiros no periodo de 1981 a 1985. Ciência e Cultura, 41 (3): 259-63, mar. 1989.

82. ROCHE, Marcel. A pesquisa científica sempre pode ser aplicada? Interciencia, 13 (3): 114, maio/jun. 1988.

83. ROCHE, Marcel. Ha de desaparecer la revista cientifica? Interciencia, 19 (1): 5. jan./feb. 1994.

84. RODRIGUES, Maria da Paz Lins. Citaçōes nas dissertações de mestrado em ciência da informação. Ciencia da Informação, 11 (1): 35-59, 1982.

85. SAYERS, M.K.; WOOD, F.E. The use and value of MSc Information studies dissertations. Journal of Information Sciences, 17 (5): 307-14, 1991.

86. SCHWARTZMAN, Simon; CASTRO, Claudio de Moura, org. Pesquisa universitária em questão. Campinas, Ed. UNICAMP, 1986.

87. SEVERINO, Antonio Joaquim. Metodologia do trabalho cientifico. 18.ed. São Paulo, Cortez Ed. 1992.

88. SIGULEM, Daniel. Informática médica. São Paulo, BIREME, 1992. /Apresentado ao I Congresso Regional de Informação em Ciências da Saúde, São Paulo, 1992/

89. SILVA Jr, Orlando de Castro e; AUGUSTO, Cesar. Co-autoria: acaso ou necessidade? Acta Cirúrgica Brasileira, 4 (3): 89-91, jul./dez. 1989.

90. SILVA Jr, Orlando de Castro e; GOMES, Uilho Antonio; OLIVEIRA, Wagner de. Aumento da co-autoria em artigos publicados: um fenômeno clínico e experimental. Acta Cirúrgica Brasileira, 5 (3): 85-7, jul./ set. 1990.

91. SOUZA, Luiz Antonio de. Padrões de comunicação em saúde coletiva: análise de citações das dissertações apresentadas ao IMS-UERJ, 1997/1992. Rio de Janeiro, 1995. /Dissertação de Mestrado - IBICT/UFRJ/ Apud CAVALCANTI, IIce Gonçalves Milet; BARRETO, Aldo de Albuquerque; SOUZA, Rosali Fernandez de. Acompanhamento das dissertações/teses apresentadas/defendidas no Programa de Pós-Graduação do CNPq/IBICT-UFRJ/ECO, no periodo de 1972 a 1995. Ciência da Informação, 24 (1): 148-58, jan./abr. 1995. 
92. TERADA, E. Uso da informação e adequação da coleção de periódicos: estudo aplicado ao Instituto de Pesquisas Energéticas e Nucleares. São Paulo, 1984. [Dissertação de Mestrado - Instituto Brasileiro de Informação em Ciência da Informação da UFRJ]

93. UNIVERSIDADE DO ESTADO DO RIO DE JANEIRO. Instituto de Medicina Social. Programa de pós-graduação em saúde coletiva: mestrado e doutorado. Rio de Janeiro, 1996.

94. UNIVERSIDADE DE SÃO PAULO. Faculdade de Saúde Pública. Informações gerais. São Paulo, 1989. (Catálogo FSP. Série, 1)

95. UNIVERSIDADE DE SÃO PAULO. Faculdade de Saúde Pública. Cursos de pósgraduação. Sāo Paulo, 1990. (Catálogo FSP. Série, 3)

96. UNIVERSIDADE DE SÃO PAULO. Faculdade de Saúde Pública. Serviço de Biblioteca e Documentação. Saúde pública: teses 1989-1992. São Paulo, 1993.

97. VELHO, Léa Maria L.S. A contemporaneidade da pesquisa agrícola brasileira como reflexo da distribuição da idade das citações. Ciência da Informação, 15 (1): 3-9, jan./jun. 1986.

98. VELHO, Léa. Avaliação acadêmica. A hora e a vez do "baixo clero". Ciência e Cultura, 41 (10): 957-68, out. 1989.

99. VERGUEIRO, Waldomiro. Seleção de materiais de informação: principios e técnicas. Brasília, DF, Briquet de Lemos/Livros, 1995.

100. VIACAVA, Francisco (coord.); FERREIRA PACHECO, Maura; PORTO, Silvia Marta; FERREIRA BRITO, IVo; BARRIOS T., Julio; TOBAR, Federico. Perfil e tendências da produção científica em saúde no Brasil. Washington, DC, Organización Panamericana de la Salud, 1991. (DRC/RG/BRA/89047).

101. WALCOTT, Rosalind. Characteristics of citations in geoscience doctoral dissertations accepted at United States academic institutions 1981-1985. Science \& Technology Libraries, 12 (2): 5-16, Win. 1992.

102. WITTER, Geraldina Porto; TERZIS, Antonio I.; GUZZO, Raquel Souza; MONTE SERRAT, Saulo; AMARAL, Vera Lucia Adami Raposo do. Dissertações de mestrado em psicologia clínica (PUCCAMP 1975/1987): análise da estrutura geral do discurso. Trans-in-formação, 1 (1): 65-79, jan./abr. 1989.

103. WITTER, Geraldina Porto; TÉRZIS, Antônio I.; GUZZO, Raquel Souza Lobo; AMARAL, Vera Lucia Raposo Adami do. As referências bibliográficas nas dissertações de mestrado em psicologia clínica da PUCCAMP (1972-1987). Tran-in-formação, 1 (2): 205-17, maio/ago. 1989.

104. WITTER, Geraldina Porto (coord.); OLIVEIRA, Silas Marques de; POBLACIÓN, Dinah Aguiar; VERGUEIRO, Waldomiro. Dissertaçōes/teses produzidas nos cursos de pósgraduação em biblioteconomia e ciência da informação no Brasil (1970/1992). Campinas, Dept.Pós-Graduação em Biblioteconomia. Faculdade de Biblioteconomia PUCCAMP, 1992. [Projeto de pesquisa] 
ANEXOS 


\section{ANEXO 1 - RELAÇÃO DAS DISSERTAÇÕES DE MESTRADO E TESES DE DOUTORADO DEFENDIDAS NOS CURSOS DE PÓS-GRADUAÇÄO DA ENSPIFIOCRUZ, FSPIUSP E IMS/UERJ (1990-1994).}

\section{DISSERTAÇŌES DE MESTRADO E TESES DE DOUTORADO DA ENSP/FIOCRUZ}

\section{DEFENDIDAS EM 1990}

ANDRADE, Vera Lúcia Gomes de. Caracteristicas epidemiológicas da hanseníase em área urbana: municipio de São Gonçalo-Rio de Janeiro.

/Dissertação de Mestrado/

BRETAS, Gustavo dos Santos. Determinação da malária no frccesso de ocupação da fronteira agricola. /Dissertação de Mestrado/

CALDERÓN DE FIGUEROA, Rutilia. Los procesos de desnutrición-infección en niños institucionalizados de las guarderias de la Fundación Estatal de Educación al Menor (FEEM) en Rio de Janeiro.

/Dissertação de Mestrado/

CARVALHO, Marilia Sá. Avaliaçào da prática de vigilância epidemiológica nos serviços públicos de saúde no Brasil.

/Dissertação de Mestrado/

FISZON, Judith Tiomny. A politica nacional de saneamento de 1968 a 1984: o caso do PLANASA.

/Dissertação de Mestrado/

POST, Cora Luiza Araujo. Fatores prognósticos de letalidade hospitalar por diarréia ou pneumonia: um estudo de casos e controle.

/Dissertação de Mestrado/

ROSA, Maria Luiza Garcia. Assistência e prática médica em Duque de Caxias, 1980-1987.

/Dissertação de Mestrado/

SCHNEIDER, Maria Cristina. Estudo de avaliação sobre área de risco para a raiva no Brasil.

/Dissertação de Mestrado/

SOSA ESTANI, Sergio Alejandro. Prevalencia y morbilidad de la infección chagásica en una población rural de la Provincia de Santiago del Estero, República Argentina.

/Dissertação de Mestrado/

URIBE MERINO, José Fernando. La racionalidad de la cura: mito y simbolo en la terapeutica modema. /Dissertação de Mestrado/

\section{DEFENDIDAS EM 1991}

ANDREAZZI, Maria de Fátima Siliansky de. O seguro saúde privado no Brasil.

/Dissertação de Mestrado/

ARRUDA, Mercia Eliane. A malária em populaçōes indigenas na Amazônia brasileira: possiveis interrelaçōes entre as malárias humana e simiana.

TTese de Doutorado/

ASSIS, Simone Gonçalves de. Quando crescer é um desafio social: estudo sócio-epidemiológico sobre violência em escolares de Duque de Caxias, RJ.

/Dissertação de Mestrado/ 
BAHIA, Ligia. Oferta e produção de serviços de saúde no Brasil na década de 80: um estudo exploratório.

/Dissertação de Mestrado/

BOSCHI-PINTO, Cynthia. Mcrtalidade por câncer de trato digestivo no Estado do Rio de Janeiro: uma apreciação por estratificação.

IDissertação de Mestrado/

BRAGA NETO, Francisco Campos. Examinando altomativas para a administração dos hospitais: os modelos de gestão descentralizados e por linhas de produção.

/Dissertação de Mestrado/

CAMPOS, Carlos Eduardo Aguilera. A desordem da demanda: os inquéritos de morbidade, demanda e utilização sob a perspectiva do planejamento em saúde - um estudo de caso.

/Dissertação de Mestrado/

CARVALHO. Marcus Renato de. Modelos assistenciais de unidades básicas de saúde e integralidade. Estudo de caso: a área de planejamento 3.1 (RJ/RJ) contribuição para sua distritalização.

/Dissertação de Mestrado/

COUTO, Rosa Carmina de Sena. Buscando ouro, perdendo saúde: um estudo sobre as condições de saúde no garimpo de Cumaru-Pará.

/Dissertação de Mestrado/

DA ROS, Marco Aurélio. Um drama estratégico: o movimento sanitário e sua expressão num município de Santa Catarina.

/Dissertação de Mestrado/

DUARTE, Cristina Maria Rabelais. Políticas públicas e indicadores de saúde: o caso da mortalidade infantil no Estado do Rio de Janeiro.

/Dissertação de Mestrado/

DUARTE, Maria Jalma Rodrigues Santana. Internação institucional do idoso: assistência à saúde em geriatria no setor público.

rTese de Doutorado/

DUCHIADE, Milena Piraccini. Mortalidade infantil por pneumonias na região metropolitana do Rio de Janeiro: 1976 a 1986.

/Dissertação de Mestrado/

FELIPE, José Saraiva. A municipalização como estratégia da descentralização dos serviços de saúde no Brasil.

(Dissertação de Mestrado/

FERNANDES, Tania Maria Dias. A produção da vacina antivariólica no Brasil da monarquia a 1920: a ciência, a técnica e o "poder dos homens".

/Dissertação de Mestrado/

GALLO, Edmundo. Razão e planejamento: algumas indicaçōes críticas para uma práxis emancipadora. /Dissertação de Mestrado/

KOPF, Aguida Wichrowski. A reformulação do setor saúde no municipio de ljui (RS), no periodo de 1983 a 1989.

/Dissertação de Mestrado/

LUCCHESI, Geraldo. Dependência e autonomia no setor farmacêutico: um estudo da CEME.

/Dissertação de Mestrado/

MACHADO. Jorge Mesquita Huet. Violência no trabatho e na cidade: epidemiologia da mortalidade po acidente de trabalho registrada no municipio do Rio de Janeiro em 1987 e 1988.

/Dissertação de Mestrado/ 
MARTINS, José Francisco Pedra. Mortalidade por câncer em trabalhadores da indústria do petróleo: Brasil, 1970 a 1985.

/Dissertação de Mestrado/

MARTINS, Mônica Silva. A mortalidade hospitalar: novas abordagens metodológicas.

/Dissertação de Mestrado/

MORAES, llara Hammerli Sozzi de. Sistemas de informações em saúde: reflexōes sobre sua prática fragmentada.

/Dissertação de Mestrado/

PEREZ, Maurício de Andrade. A esquistossomose em Brasilia de Minas, Minas Gerais: um estudo ecológico sobre a prevalência após três anos de atuação da SUCAM.

/Dissertação de Mestrado/

RIBEIRO, José Mendes. Arranjos neocorporativos e defesa de interesses dos médicos.

/Dissertação de Mestrado/

RIBEIRO, Patricia Tavares. A instituição do campo científico da saúde coletiva no Brasil: 1975-1978.

/Dissertação de Mestrado/

SOUZA, Edinilsa Ramos de. Violência velada e revelada: estudo epidemiológico da mortalidade por causas externas em Duque de Caxias, RJ.

/Dissertação de Mestrado/

STOTZ, Eduardo Navarro. Necessidades de saúde: mediações de um conceito (contribuição das Ciências Sociais para a fundamentação teórico-metodológica de conceitos operacionais da área de planejamento em saúde)

TTese de Doutorado/

URIBE RIVERA, Francisco Javier. O agir comunicativo e a planificação estratégica no setor sorial (e sanitário): um contraponto teórico.

rTese de Doutoradol

VALLINOTO, Tereza Christina. A construção da solidariedade: um estudo sobre a reposta coltiva : AIDS.

/Dissertação de Mestrado/

VERANI, José Femando de Souza. A vigilância epidemiológica na erradicação de doenças: $a$ caso $/$ variola e da poliomielite.

/Dissertação de Mestrado/

VIANNA, Maria Sylvia Ripper. Salubridade domiciliar: uma discussão sobre saneamento básico na favelas do municipio do Rio de Janeiro.

/Dissertação de Mestrado/

VICENTIN, Genésio. Saúde e mineração na Amazônia: o caso da Mineração Rio do Norte.

/Dissertação de Mestrado/

VILLA-FORTE, Denise Nabuco. O processo orçamentário em instituições públicas de saúde no Estar do Rio de Janeiro: um estudo de caso.

/Dissertação de Mestrado/

\section{DEFENDIDAS EM 1992}

AGUIAR, Adriana Cavalcanti de. Assistência integral à saúde da mulher no Distrito Sanitário do Cent Sul: a ótica dos profissionais de saúde.

/Dissertação de Mestrado/ 
BARROS, Eugênio Oliveira Martins de. Estudo do sistema de mortalidade de Campo Grande, MS, em 1991, considerando óbitos de mulheres em idade fértil.

/Dissertação de Mestrado/

CARNEIRO, Mauro Brandão. O controle de endemias no Sistema Único de Saúde (SUS): o caso do dengue no município do Rio de Janeiro.

/Dissertação de Mestrado/

GOULART, Flávio A. de Andrade. Políticas e instituições de saúde: o vivido, o percebido e o representado.

/Dissertação de Mestrado/

LEITE, Heliana Nunes Feijó. Avaliação do planejamento em saúde 10 municipio de Manaus no periodo de 1976 a 1988.

/Dissertação de Mestrado/

MAGALHÃES, Rosana. A fome no pensamento de Josué de Castro: uria interpretação.

/Dissertação de Mestrado/

MAGLUTA, Cynthia. Identificação de mortes evitáveis em um hospita! materno-infantil.

IDissertação de Mestrado/

MARASCIULO, Antonio Cartos Estima. Dinâmica da infecção por ancilostomídeos em região semi-árida do nordeste brasileiro.

/Dissertação de Mestrado/

MENDONÇA, Maria Helena Magalhães de. Reorientação do sistema de saúde no contexto de mudança social.

/Dissertação de Mestrado/

MONTENEGRO, Maria Martha. Morbilidad de los menores en circunstancias especialmente dificiles, Managua, Nicaragua.

/Dissertação de Mestrado/

SEVALHO, Gil. Permanências culturais e o uso do medicamento alopático modemo.

/Dissertaçä̃o de Mestrado/

SILV.A, Rosângela Alves Pereira Rodrigues da. Nutrição-má-nuttrição e condições de vida em Cárceres-MT, 1986.

/Dissertação de Mestrado/

SIQUEIRA, Sandra Aparecida Venâncio de. Práticas educativas em saúde: uma discussão sobre a contracepção - um estudo de caso.

/Dissertação de Mestrado/

WARTH, Samuel. Assistencialismo médico: o controle sindical do desgaste operário. Um estudo do caso do Sindicato dos Metalúrgicos do Rio de Janeiro 1987-1991.

/Dissertação de Mestrado/

\section{DEFENDIDAS EM 1993}

ALCANTARA, Luciene Burlandy C. Saúde coletiva: uma trajetória em questão refletindo sobre a produção científica no campo das politicas de saúde (1979-1991).

/Dissertação de Mestrado/

ALFONSO BERRIO, Lázara. Evaluación del sistema de vigilancia para la esquistosomisais de Cuba. /Dissertação de Mestrado/

ARTMANN. Elizabeth. O planejamento estratégico situacional: a trilogia matusiana e uma proposta para o nivel local de saúde (uma abordagem comunicativa)

/Dissertação de Mestrado/ 
BARBOSA, Regina Helena Simões. AIDS e gênero: as mulheres de uma comunidade favelada.

/Dissertação de Mestrado/

BRONFMAN P., Mario N. Multimortalidad y estructura familar: un estudio cualitativo de las muertes infantiles entre las familias.

TTese de Doutoradol

CARVALHO, Márcia Lazaro de. Mortalidade neonatal e aspectos da qualidade da atenção à saúde na região metropolitana do Rio de Janeiro em 1986/87.

/Dissertação de Mestrado/

CLARO, Lenita Barreto Lorena. Hanseniase: representações sobre a doença. Estudo em população de pacientes ambulatoriais no Rio de Janeiro.

/Dissertação de Mestrado/

COHEN. Simone Cynamon. Reabilitação de favela: até que ponto a tecnologia empregada é apropriada?

/Dissertação de Mestrado/

DESLANDES, Suely Ferreira. Maus-tratos na infância: um desafio para o sistema público de saúde. Análise da atuação CRAMI-Campinas.

/Dissertação de Mestrado/

GOMES, Maria Aparecida Teixeira. Potencial de transmissão da tripanossomíase americana nas localidades do Sítio do Mocó e Borda, município de São Raimundo Nonato, Sudeste do Piauí.

/Dissertação de Mestradol

KALE, Pauline Lorena. Distribuição espaço-temporal da mortalidade infantil por diarréia no município do Rio de Janeiro 1979-1988.

/Dissertação de Mestrado/

LIMA, Lúcia Abelha. O estigma do abandono: estudo epidemiológico de uma população de crianças e adolescentes internados na colônia Juliano Moreira vindos diretamente da FUNABEM.

/Dissertação de Mestrado/

LOVISI. Giovanni Marcos. Suporte social e distúrbios psiquiátricos em mulheres soro-positivas pelo HIV: uma associaçāo evanescente?

/Dissertação de Mestrado/

MATTOS, Inês Echenique. Mortalidade por câncer em trabalhadores de companhia geradora de eletricidade em São Paulo.

/Dissertação de Mestrado/

MEDRONHO, Roberto de Andrade. A geografia do dengue no municipio do Rio de Janeiro: uma análise por geoprocessamento.

/Dissertação de Mestrado/

NOGUEIRA, Maria Inês. Assistência pré-natal em Duque de Caxias: um caso de violência institucional. /Dissertação de Mestrado/

NORONHA, Claudio Pompeiano. Avaliação da eficácia da vacina anti-meningocócica BC no Rio de Janeiro: um estudo caso-controle.

/Dissertação de Mestrado/

OLIVEIRA, Rosely Magalhães de. A distribuiçào desigual dos serviços de água e esgoto no municipio do Rio de Janeiro: o caso da regiâo de Leopoldina.

/Dissertação de Mestrado/

PEREIRA, Gilza Sandre. O profissional de saúde e a educação em saúde: representaçōes de uma prática. 


\section{/Dissertação de Mestrado/}

POSE. Silvana Blanco. Avaliação das condiçōes de saúde bucal dos indios Xavante do Brasil Central. Dissertação de Mestradol

PRADO. Shirley Donizete. Autonomia: tentadora e reificada. Estudo sobre nutricionistas dos centros municipais de saúde do Rio de Janeiro.

Dissertaçảo de Mestrado/

REVELLO SANCHEZ, Waldo Alfredo. El proceso de privatización en Venezuela: la experiencia reciente en el sector salud.

/Dissertação de Mestrado/

SÁ, Marilene de Castilho. Planejamento estratégico em saúde: problemas conceituais e metodológicos. /Dissertação de Mestrado/

SANTOS, Maria Ruth dos. Do boticário ao bioquímico: as transformações ocorridas com a profissão farmacèutica no Brasil.

/Dissertação de Mestrado/

SANTOS NETO. Pedro Miguel dos. O processo da profissionalização médica em Pernambuco: um estudo sobre a categoria médica pernambucana, sua organização, seus interesses.

/Dissertação de Mestrado/

SCHRAMM. Fermin Roland. A terceira margem da saúde: a ética natural. Complexidade, crise e responsabilidade no saber-fazer sanitário.

rTese de Doutorado/

SCHRAMM, Joyce Mendes de Andrade. Tétano neonatal: repensando a proposta de eliminação. Uma discussão sobre os problemas presentes na proposta de controle.

/Dissertação de Mestrado/

SILVA, Luiza de Paiva. Erradicação do sarampo: uma possibilidade real? Revisão crítica da teoria e das estratégias de eliminação.

/Dissertaçāo de Mestrado/

SZWARCWALD, Cèlia Landman. Estimativas da mortalidade infantil como função da distribuição etária dos óbitos registrados: proposta de um procedimento.

Trese de Doutorado/

VALIM, Clarissa. Transmissão da Leishmania (Viannia) braziliensis no Ceará: caracteristicas da transmissão $\mathrm{em}$ diferentes formaçōes paisagisticas com particular referència ao loçai de transmissão para o homem.

/Dissertação de Mestrado/

WAISSMAN, William. O trabalho na gênese das doenças isquêmicas do coraçà̀.

/Dissertação de Mestrado/

\section{DEFENDIDAS EM 1994}

ALBUQUeRQUe, Paulette Cavalcanti de. Planejamento e participação popular em saúde: o caso de Duque de Caxias.

/Dissertação de Mestrado/

AMARANTE, Paulo Duarte de Carvalho. O homem e a serpente: outras histórias para a loucura e a psiquiatria.

ITese de Doutorado/ 
BORGES, Sherrine Maria Njaine. Metamorfoses do corpo, uma pedagogia freudiana.

ITese de Doutoradol

BRAGA, Carlos Alberto Valle. Hanseniase no Estado do Amazonas: estudo das caracteristicas epidemiológicas da hanseniase no municipio de Lábrea.

/Dissertação de Mestrado/

CARVALHO, Antonio Ivo de. Conselhos de saúde no Brasil.

IDissertação de Mestrado/

CASTRO, Inês Rugani Ribeiro de. O Sistema de Vigilância Alimentar e Nutricional na rede pública de assistência à saúde: limitaçōes e interfaces com a vigilância epidemiológica e os programas de atenção integral.

/Dissertação de Mestrado/

CAVALCANTI, Maria de Lourdes Tavares. Concepçōes de identidade feminina entre mulheres esterilizadas e não esterilizadas em Angra dos Reis.

/Dissertação de Mestrado/

COSTA. André Monteiro. Análise histórica do saneamento no Brasil.

/Dissertação de Mestrado/

COSTA, Júlio Fernando Leite da. O comportamento sexual na África Subsahariana: seu significado e influência sobre a transmissão e propagação da AIDS - contribuição para uma política de saúde.

/Dissertação de Mestrado/

CUNHA, Fátima Teresinha Scarparo. Estudo da evolução dos centro de saúde no tempo e no espaço na cidade do Rio de Janeiro (1920-1950).

/Dissertaçāo de Mestrado/

DELGADO, Antonio Pedro da Costa. Politicas de saúde em Cabo Verde na década de 1980-1990: uma experiência de construção de um sistema nacional de saúde.

/Dissertação de Mestrado/

ESCOBAR, Ana Lúcia. Malária no sudoeste da Amazônia: uma meta-análise.

/Dissertação de Mestrado/

FERREIRA, Heloisa Pacheco. O perigo silencioso: um estudo da intoxicação de trabalhadores por vapor de mercúrio em uma indústria de cloro/soda. Rio de Janeiro.

/Dissertação de Mestrado/

FREITAS, Nilton Benedito Branco. Controle social do risco e da saúde Jos trabalhadores: o caso da indústria de cloro-soda.

/Dissertação de Mestrado/

GOMES, Romeu. O corpo na rua e o corpo da rua: a prostituição iniantil feminina em questão.

Trese de Doutorado/

LOTUFO, Márcia. Utilização da epidemiologia no processo de planejamento: uma articulação no momento explicativo.

Dissertação de Mestrado/

MARTINS, Maria Inès Carsalade. As organizaçōes de saúde no contexto do SUS: uma realidade em construção.

Missertação de Mestrado/

MENDONÇA, Eduardo Alves. Representações sociais sobre AIDS: um estudo etnográfico sobre travestis em atividades de prostituição.

/Dissertação de Mestrado/ 
NIOBEY, Flávia Maria Leal. A análise da mortalidade infantil pós-neonatal sob a perspectiva das causas múltiplas: Rio de Janeiro 1986/1987.

/Dissertação de Mestrado/

OLIVEIRA, Eliane dos Santos de. A questão alimentar nutricional na "Nova República": discurso e prática.

/Dissertação de Mestrado/

OLIVEIRA, Luiz Sérgio Brandão de. A intervenção do Estado nos ambientes de trabalho: origens, evolução no Brasil e análise critica da prática da Delegacia Regional do Trabalho do Rio de Janeire na década de 1980.

/Dissertação de Mestrado/

OLIVEIRA, Rosália Maria de. Estudo da contaminação do solo e pasto causada pcr hexaclorociclohexanos $(\mathrm{HCH})$ na Cidade dos Meninos em Duque de Caxias, RJ.

Dissertação de Mestrado/

PALMEIRA, Guido Antonio E.S. A medida da psique: uma apreciação das variáveis utilizadas na investigação dos aspectos psicológicos relacionados ao câncer.

Dissertaçāo de Mestrado/

PETERSON, Christopher Robert. Risco sob risco: prostituição e AIDS.

/Dissertação de Mestrado/

RIBEIRO. Fátima Sueli Neto. Da identidade do pesquisado à identidade da pesquisa: os trabalhadores brasileiros na Pesquisa Nacional sobre Saúde e Nutrição.

/Dissertaçảo de Mestrado/

SALLES, Maria José. Indicadores das condições de saneamento do ambiente.

/Dissertação de Mestrado/

SILVA, Claudia Osório da. Curar adoecendo: um estudo do processo de trabalho hospitalar em busca da saúde, da inventividade e da vida.

/Dissertação de Mestrado/

SILVA, Roseli Monteiro da. A teoria organizacional do planejamento estratégico situacional e a gestão no setor saúde: uma análise da experiència da Santa Casa de Misericórdia do Pará.

/Dissertação de Mestrado/

SOTERO, Jorge Adriano Moreira Feitoza. O dito e o feito: o uso dos recursos federais na área de salide e os compromissos da "Nova República" com o setor (1985/1990).

/Dissertação de Mestrado/

TEIXEIRA, Mary Jane de Oliveira. A vigilância epidemiológica e o controle público em tempos de SUS: a fala dos profissionais e usuários organizados da região da Leopoldina.

/Dissertação de Mestrado/

TOSCHI, Wálria Dias Machado. A evolução da mortalidade por doença isquêmica do coraçāo e doenças cérebro-vasculares no municipio do Rio de Janeiro na década de 80.

/Dissertação de Mestrado/

TURCl. Silvana Rubano Barretto. Avaliação toxicológica, clínica, laboratorial e citogenética de soldadores da indústria naval.

/Dissertação de Mestrado/

WALADARES, Jorge de Campos. Espaço ambiente e situação do sujeito.

TTese de Doutoradol

VASCONCELLOS. Luiz Carlos Fadel de. Os caminhos do caminho: a municipalização como estratégia de consolidação da saúde do trabalhador no setor saúde.

/Dissertação de Mestrado/ 
VIEL. Rômulo Fernando. Estudo do funcionamento da estação de tratamento de esgotos do campus da Fundação Oswaldo Cruz.

/Dissertação de Mestrado/

\section{DISSERTAÇÕES DE MESTRADO E TESES DE DOUTORADO DA FSPIUSP}

\section{DEFENDIDAS EM 1990}

ALMEIDA. Margarida Maria Mattos Brito de. Vigilância epidemiológica da tuberculose no Município de São Paulo: uso de dados de mortalidade.

ITese de Doutorado/

AMIGO CARTAGENA. Hugo Francisco. A mortalidade urbana na infância: um estudo de caso-controle na cidade de Recife.

Trese de Doutorado/

BERTOLAMI, Marcelo Chiara. Comparação da fórmula de Friedewald com a ultracentrifugação analítica durante o tratamento das dislipidemias.

/Dissertaçào de Mestrado/

CARDOSO, Maria Regina Alves. Comparação entre três métodos de amostragem que visam à estimaçāo da cobertura vacinal.

/Dissertação de Mestrado/

CESAR, Amarilys de Toledo. O uso do ácido ascórbico no controle da deficiência de ferro, utilizando a estrutura do programa de merenda escolar.

/Dissertação de Mestrado/

FERREIRA, Carios Eugênio de Carvalho. Mortalidade infantil e desigualdade social em São Paulo.

TTese de Doutorado/

GALATI, Eunice Aparecida Bianchi. Sistemática dos Phlebotominae (Diptera, Psychodidae) das Américas.

Trese de Doutorado/

GAMBARDELLA, Ana Maria Dianezi. O programa de alimentação do trabalhador frente as recomendaçōes nutricionais para esse segmento específico da população: área netropolitana de São Paulo.

/Dissertação de Mestrado/

IBAÑEZ, Nelson. Sistema local de saúde de Cotia: estudo de caso.

TTese de Doutoradol

KOTAIT, Ivanete. Estudo epizootiológico da estomatite vesicular no Vale do Paraiba, SP.

/Dissertação de Mestrado/

LEFEVRE, Fernando. O medicamento como problema de saúde pública: contribuição para o estudo de uma mercadoria simbólica.

ITese de Doutoradol

LOFFREDO, Leonor de Castro Monteiro. Fissuras lábio-palatais: estudo de caso-controle de fatores de risco.

Trese de Doutorado/ 
LUI NETTO, Adamo. Alterações oculares relacionadas com hipertensão, diabetes e desnutrição no idoso.

/Dissertação de Mestrado/

MARTINS, Cleide Lavieri. O modo de ser da Habilitação em Enfermagem de Saúde Pública na Faculdade de Saúde Pública/USP 1980 a 1987.

/Dissertação de Mestrado/

MATOS, Isaura Maria de Souza. Transmissão materno-infantil da doença de Chagas, em filhos de pacientes chagásicas.

/Dissertação de Mestrado/

MORAES, Suzana Alves de. Reprodutibilidade e valor diagnóstico de testes quantitativos no diabetes mellitus.

/Dissertação de Mestrado/

MORAES, Thelma Aparecida Bombonatti Prado Pinto de. Contribuição ao estudo da grávida portadora de cardiopatia chagásica: estudo retrospectivo.

/Dissertação de Mestrado/

OLIVER, Fátima Correa. A atenção à saúde da pessoa portadora de deficiência no sistema de saúde no municipio de São Paulo: uma questão de cidadania.

/Dissertação de Mestrado/

PANZA, Ana Maria Marchetti. Padrões de enfermagem em centro cirúrgico e instrumentos para sua operacionalização: proposta e ajuizamento.

TTese de Doutorado/

PEDRAZZANI, Elisete Silva. O ensino e a prática do enfermeiro em hanseníase.

TTese de Doutoradol

PHILIPPI, Sonia Tucunduva. Estudo e aplicação do enfoque de risco nutricional em crianças de zero a cinco anos de idade em uma comunidade de São Paulo.

Trese de Doutorado/

PINHEIRO, Fernando Emilio Vernier. O emprego de reatores anaeróbicos no tratamento de despejos liquidos de indústrias de celulose e papel.

/Dissertação de Mestrado/

RANCEVAS, Sergio. Riscos ambientais decorrentes da utilizaçāo de energias alternativas: o controle da poluição do ar na regiāo metropolitana de São Paulo e avaliaçōes através de estudos de associações entre dados de concentraçōes ambientais de dióxido de enxofre com indicadores de saúde relativos a doenças respiratórias.

/Dissertação de Mestrado/

ROCHA, Marly Theoto. Decodificação de um texto sobre hanseniase por estudantes, docentes e pessoal de enfermagem.

/Tese de Doutorado/

RODRIGUES, João Roberto. Critérios ambientais para a classificação de atividades poluidoras corr vistas ao ordenamento territorial.

/Dissertação de Mestrado/

ROMANO, Nicolina Silvana. O uso do teste imunoenzimático na vigilância epidemiológica dı arboviroses.

/Dissertação de Mestrado/

SANTOS. Helena dos. A recuperação nutricional como atividade do programa de assistência integral : saúde da criança: avaliação dos aspectos operacionais e do impacto nutricional em uma unidade dı saúde da Secretaria de Estado da Saúde de São Paulo.

/Dissertação de Mestrado/ 
SILVA, Francisca Maria de Carvalho Gonzaga e. Avaliação da cobertura de vacinação em Teresina, Piaui, Brasil.

/Dissertação de Mestrado/

SILVA, Izete Soares da. Hipertensão: conhecimentos e práticas do paciente.

/Dissertação de Mestrado/

SILVA, Marcelo Gurgel Carlos da. Técnicas para definir prioridades em saúde: análise da mortalidade por causas evitáveis em Fortaleza em 1981-83.

TTese de Doutorado/

VIANNA, Lucila Amaral Cameiro. Características da mortalidade das mulheres (10 anos e mais) residentes em Diadema, SP - 1985-1986.

ITese de Doutorado/

\section{DEFENDIDAS EM 1991}

ALGRANTI, Eduardo. Doenças respiratórias associadas à mineração de carvão: estudo de coorte de 5 anos.

TTese de Doutorado/

BAEZ GARCIA, Miguel Angelo. Sub-notificação de acidentes do trabalho em pacientes atendidos no Hospital Universitário Antonio Pedro, Niterói-RJ.

/Dissertação de Mestrado/

BERTAGNON, José Ricardo Dias. Recém-nascido pequeno para idade gestacional: algumas caracteristicas epidemiológicas.

/Dissertação de Mestrado/

BERTOLOZZI, Maria Rita. Pacientes com tuberculose pulmonar no municipio de Taboão da Serra: perfil e representaçōes sobre a assistência prestada nas unidades básicas de saúde.

/Dissertação de Mestrado/

CARVALHO, Regina Ribeiro Parizi. Participaçāo do Hospital do Servidor Público Estadual "Francisco Morato de Oliveira", no Programa de Controle da Tuberculose, durante o período de 1982 a 1986.

/Dissertaçäo de Mestrado/

CORDEIRO, Rogério Guimarães Frota. Cunhecimento e opinião sobre a AIDS dos estudantes do 1. ano das faculdades de Farmácia e Bioquimica do Estado do Paraná.

/Dissertação de Mestrado/

CORNETTA, Vitória Kedy. Comparação da força de trabalho em serviços de saúde.

TTese de Doutorado/

CORVINO, Marcos Paulo Fonseca. A educação continuada de médicos nos serviços públicos de atenção primária à saúde.

/Dissertação de Mestrado/

FEITOZA, Dalmo Herrera. Contribuição para a avaliação dos serviços de saúde em Sorocaba, SP. 1986-1987: variáveis organizacionais e epidemiológicas.

/Dissertação de Mestrado/

FELICE, Sebastião André de. Planejamento de assistência a pacientes pediátricos asmáticos na cidade de São Paulo.

ITese de Doutorado/

FIGUEIREDO, Túlio Alberto Martins de. Perfil de adolescentes de uma escola pública e suas opiniões em relação à orientação sexual na escola.

/Dissertação de Mestrado/ 
FONSECA, Luiz Augusto Marcondes de. Estudo de um coorte de pacientes soropositivos para o virus da imunodeficiència humana: uma contribuição ao conhecimento da história natural da sindrome de imunodeficiència adquirida.

/Dissertação de Mestrado/

GALLO, Paulo Rogério. Fatores associados à desnutrição proteico-energética em crianças menores de cinco anos usuárias da rede estadual de saúde do municipio de Guarulhos, 1987. /Dissertação de Mestrado/

GASI. Tânia Mara Tavares. Remoção de microrganismos em reatores anaeróbicos de fluxo ascendente e manto de lodo operando com esgotos domésticos.

/Dissertação de Mestrado/

HOFMEISTER, Vera Anna. Efeitos da poluição do ar sobre a função pulmonar: um estudo de coorte en crianças de Cubatão.

/Tese de Doutorado/

JACOMO, Yumiko Asada. Fatores de satisfação e insatisfação que interferem na prática do pessoal di enfermagem em assistência primária de saúde: estudo realizado no municipio de Cotia.

/Dissertação de Mestrado/

LEITÃO, Glória da Conceição Mesquita. Crenças argumentais de mulheres que sofreram agressão d seus maridos ou companheiros: estudo comparativo no campo da análise transacional, realizado con populaçōes atendidas na 2a. Delegacia de Polícia de Defesa da Mulher, e no Centro de Saúde Ruben Monteiro Amuda, São Paulo (SP), 1988.

Trese de Doutorado/

LOPES, Abilio Rodrigues. Política de saúde da mulher: 1982-1987.

/Dissertação de Mestrado/

LÓPEZ ALEGRIA. Fanny Viviana. Esterilização não-cirúrgica: estudo do perfil reprodutivo e dos efeito colaterais de mulheres que recorreram a este método.

Trese de Doutorado/

MALUCELLI, Maria Ivette Carboni. O método polarográfico na determinaçāo da viabilidade da vacin BCG liofilizada.

Trese de Doutorado/

MONCAU, José Eduardo Cajado. Análise estratificada em estudos caso-controle.

/Dissertação de Mestrado/

MONTEIRO, Iraci da Silva Leme. Estudo sobre a utilização de bactérias fotossintéticas no tratamento c residuos orgânicos.

/Dissertação de Mestrado/

MONTERO D'ÓLEO, Rafael de Jesus. Utilização dos leitos hospitalares na região de Ribeirào Pret 1988.

/Dissertação de Mestrado/

MOURA, José Valdez de Castro. Gravidez na adolescência: estudo retrospectivo nos anos de 197 1982 e 1987 na Santa Casa de Misericórdia de Pindamonhangaba/SP.

/Dissertaçāo de Mestrado/

MURAI, Hogla Cardozo. Participação da enfermagem na prevenção de incapacidades físicas । hanseniase.

/Dissertação de Mestrado/

NAKAGaWA, Tereza Mizue. Politicas de saneamento básico e mortalidade infantil no Municipio Osasco. 1970 a 1985.

/Dissertação de Mestrado/ 
OLIVEIRA, Carios Augusto Fernandes de. Estudo da ocorrência de enteroparasitas em hortaliças comercializadas na região metropolitana de São Paulo, SP, Brasil.

/Dissertação de Mestrado/

OLIVEIRA, Denize Cristina de. O desenvolvimento infantil e suas representações: dimensões do saber técnico-profissional e do senso comum.

/Dissertaçäo de Mestrado/

RATTNER, Daphne. Subsidios para a avaliação da qualidade do processo de assistência ao parto.

/Dissertação de Mestradol

RIBEIRO, Lindioneza Adriano. Estudo epidemiológico de acidentes por serpentes peçohentas no Estado de São Paulo, atendidos no Hospital Vital Brazil, 1988.

/Dissertação de Mestrado/

SALLUM. Maria Anice Mureb. Estudo taxonômico do cibário na secção Spissipes de Culex (Melanoconion) (Diptera; Culicidae).

/Dissertação de Mestrado/

SANTOS, José Araújo de Oliveira. Soluções de baixo custo para problemas de saneamento ambiental. /Dissertação de Mestrado/

SANTOS, Ozinaldo Oliveira dos. Conhecimento atual sobre técnicas de determinação do hábito alimentar de artrópodes vetores.

/Dissertação de Mestrado/

SANTOS FILHO, Eládio. Avaliação operacional das atividades de recuperaçào nutricional em suas unidades básicas de saúde do municipio de Santos, SP.

/Dissertação de Mestrado/

SILVA, Marina Vieira da. Contribuição do Programa de Merenda Escolar - ciclo básico - para as recomendaçōes nutricionais de escolares da cidade de Piracicaba, Estado de São Paulo.

/Dissertação de Mestrado/

SOUSA, Maria da Luz Rosário de. Determinação do risco de cárie em escolares de 11 a 13 anos e sua aplicação na clinica odontológica.

/Dissertação de Mestrado/

STEVENS, David Paul. Saúde pública: inclusão cưmo variável ambiental na implantação de reservatórios.

/Dissertação de Mestrado/

TEIXEIRA, Sylvia Maria Tolomei. Diagnóstico precoce da hanseniase: avaliação da histopatologia, imunoperoxidase anti-BCG e imunofluorescència direta na hanseniase indeterminada.

/Dissertação de Mestrado/

VALADĀO, Marina Marcos. Estudo do uso e conhecimento dos métodos anticoncepcionais pelas professoras da rede pública de ensino num municipio do Alto Vale do Paraiba, Estado de São Paulo.

/Dissertação de Mestrado/

WALDMAN, Eliseu Alves. Vigilância epidemiológica como prática de saúde pública.

TTese de Doutorado/

\section{DEFENDIDAS EM 1992}

ABBUD NETO, Scandar. Caracteristicas epidemiológicas da hanseníase indeterminada, casos detectados no Estado de São Paulo no periodo de 1959 a 1973 e de 1977 a 1984.

/Dissertação de Mestrado/ 
ADORNO, Rubens de Camargo Ferreira. A trajetória do movimento e da participação: a conduta dos atores sociais da saúde.

ITese de Doutorado/

AMARAL, Luiz Augusto do. Influência da precipitação pluviométrica nas caracteristicas bacteriológicas,físicas e quimicas da água de diferentes mananciais de abastecimento da cidade de Jaboticabal, SP.

/Tese de Doutorado/

BÓGUS. Cláudia Maria. A reforma sanitária e a educação continuada: a importância do investimentc nos recursos humanos dos serviços locais de saúde.

/Disertação de Mestrado/

BORN. Rubens Harry. Aspectos conceituais, ambientais e de saúde pública do aproveitamento (re-uso) de águas residuárias no solo como instrumento de administração da qualidade ambiental.

/Dissertação de Mestrado/

CASTRO, Cláudio Gastão Junqueira de. O estudo da demanda do serviço de pronto atendimento de urr hospital como subsidio ao modelo assistencial do Sistema Nacional de Saúde.

/Dissertação de Mestrado/

CHAMMÉ. Sebastiāo Jorge. Poliqueixoso: metáfora ou realidade?

ITese de Doutorado/

DOUGLAS. Joyce Lenora. Contribuição para a caracterização da enfermagem que atua na assistênci: à saúde do trabalhador na América Latina.

/Dissertação de Mestrado/

FREITAS FILHO, João Paulo Aché de. Parâmetros entomológicos e ambientais relativos : epidemiologia da malária com vistas a Estudos de Impacto Ambiental (EIA) e Relatórios de Impacto di Meio Ambiente (RIMA).

/Dissertação de Mestrado/

GIAZZI, João Flávio. Contribuição para o estudo dos protozoários bucais em 700 indivíduos di populaçăo de Araraquara. Estado de São Paulo.

TTese de Doutorado/

GIMENES, Aparccida Silvia Mellin. Avaliação da capacidade resolutiva do Centro de Saúde Integraçãı e do Centro de Saúde do Jardim Florence em Campinas, São Paulo.

/Dissertação de Mestrado/

GONZALEZ, Amélia Beatriz Camacho. Análise e avaliação de riscos do Gás Liquefeito de Petróle (GLP) visando o seu gerenciamento.

/Dissertação de Mestrado/

GONZÁLEZ PĖREZ DE MORELL, María Graciela. Estudo da mortalidade intra-uterina em São Paulo. TTese de Doutoradol

HERNANDEZ, Nira Lidia Alves Ribeiro. Discussão de alguns aspectos da padronização técnica do test de Mitsuda em relaçào ao teste tuberculínico.

/Dissertação de Mestrado/

KAKITANI, Iná. Observações preliminares sobre a paridade de Anopheles (Kerteszia) cruzii. /Dissertação de Mestradol

KOTAKA. Filomena. Avaliaçào da organização espacial, quanto aos fluxos das circulações, de ur hospital geral.

/Dissertação de Mestrado/

LATORRE. Maria do Rosário Dias de Oliveira. Mortalidade como preditor da morbidade.

(Dissertação de Mestrado/ 
LIEBER, Renato Rocha. Trabalho em turnos e riscos quimicos: o horário de trabalho como fator interveniente no efeito tóxico.

/Dissertação de Mestrado/

MAGALHÃES, Lilia Bueno de. A prática dos enfermeiros em postos de saúde municipais no Estado do Paraná e sua relação com a formação profissional e a organização dos serviços.

TTese de Doutoradol

MANCUSO, Pedro Caetano Sanches. O reuso da água e sua possibilidade na região metropolitana de São Paulo.

TTese de Doutorado/

MARTILDES, Mario Lúcio Ramalho. Avaliação do impacto de programas incrementais de atendimento odontológico sobre as condiçōes de saúde bucal de escolares aos 12 anos de idade em São José dos Campos, SP, 1991.

/Dissertação de Mestrado/

MARUCCI, Maria de Fátima Nunes. Aspectos nutricionais e hábilos alimentares de idosos, matriculados em ambulatório geriátrico.

Trese de Doutoradol

NEMES FILHO, Alexanare. Os médicos sanitaristas e a politica de saúde do Estado de São Paulo no periodo de 1976 a 1988.

/Dissertação de Mestrado/

NOZAWA, Marcia Regina. Ação educativa participante com gestantes: a análise do uiscurso como instrumento de avaliação.

/Dissertação de Mestrado/

PASTORELO, Edmur Flávio. Políticas de saúde, caracteristicas do atendimento e mortalidade por câncer: estudo de caso no Município de São Paulo.

TTese de Doutorado/

PÉREZ CARRIÓN, José Esteban. Indices de qualidade ambiental para estudos de AlA (Avaliação de Impactos Ambientais).

/Dissertaçāo de Mestrado/

PIALARISSI, Carmen Silvia de Melo. Utilização do teste de eritroimunoadsorção por captura no imunodiagnóstico da neurocisticercose.

/Dissertação de Mestrado/

PINTO, Vitor Gomes. A questão epidemiológica e a capacidade de resposta dos serviços de saúde bucal no Brasil.

Trese de Doutorado/

RODRIGUEZ JUNIOR, Ney. Distribuição do leite em pó pela Secretaria Municipal da Saúde de São Paulo: uma contribuição para a reestruturação desta atividade.

/Dissertação de Mestradol

RUIZ, Emily Anr a Catapano. Cultura institucional e a viabilizaçào do Sistema ínico de Saúde (SUS): papel dos gerentes de hospital.

TTese de Doutorado/

SALGADO NETTO, João. Mortalidade materna: estudo em 3 municipios do Estado de São Paulo: Bauru, Marilia e Presidente Prudente, período 1989/1990.

/Dissertação de Mestrado/

SANTOS, Antonio Cardozo dos. Efeitos renais crônicos em trabalhadores expostos ao chumbo e suas relações com a pressão arterial.

TTese de Doutoradol 
SANTOS, Carlos Lopes dos. Tecnologias de reuso aplicadas ao abastecimento de água potável e industrial da Baixada Santista.

Tese de Doutorado/

SILVA, Raimundo Antonio da. O lugar do biólogo e do social da morbimortalidade perinatal: estudo de caso em amostra de parturientes e recém-nascidos atendidos em hospitais de São Luiz do Maranhão.

TTese de Doutorado/

SILVA, Rebeca de Souza e. Aborto provocado: sua incidência e características. Um estudo com mulheres de idade fértil (15 a 49 anos), residentes no sub-distrito de Vilit Madalena.

Trese de Doutorado/

SOUZA Regina Kazue Tanno de. Mortalidade infantil e sub-registro de nascidos vivos no município de Maringá. PR, em 1989.

IDissertação de Mestrado/

VIEIRA, Carlos Alberto Lisboa. A descentralização no setor de saüde no Estado de São Paulo: aspectos de seu impacto na organizaçào e funcionamento do ERSA - Escritório Regional de Saúde-12, Itapecerica da Serra/São Paulo.

/Dissertação de Mestrado/

VILAR ESTEVES, Maria Josefa. A utilizaçào dos custos hospitalares em hospitais paulistas: um estudo preliminar.

/Dissertação de Mestrado/

VOLOCHKO. Anna. Mortalidade de mulheres, mortatidade matema: SUS-4/1988.

/Dissertação de Mestrado/

WÜNSCH FILHO, Victor. Riscos ocupacionais e cảncer de pulmão.

TTese de Doutorado/

\section{DEFENDIDAS EM 1993}

ASSUNÇÃO, João Vicente de. Viabilidade e importância da rędução da emissão de clorofluorcarbonos (CFCs) por reciclagem e controle no uso.

Trese de Doutorado/

BUCHALLA, Cassia Maria. A sindrome da imunodeficiência ac'quiricía e a mortalidade masculina, de 20 a 49 anos, no municipio de São Paulo, 1983 a 1986.

TTese de Doutorado/

BUSCHINELLI, José Tarcisio Penteado. Epidemiologia das doenças profissionais registradas no Brasil na década de 80.

/Dissertação de Mestrado/

CHAVES, André Preissler Loureiro. Temática ambiental: instituiçōes envolvidas e a imprensa na cidade de São Paulo.

/Dissertação de Mestrado/

CHIARAVALLOTI NETO, Francisco. Aedes aegypti na região de São José do Rio Preto, Estado de São Paulo.

/Dissertação de Mestrado/

CORTES, Fernando Sabino. Sistema viário de acesso ao litoral norte de São Paulo: planejamento integrado e incorporação da variável ambiental.

/Dissertação de Mestrado/ 
CUNHA, Valdenice Fernandes da. O sub-registro de nascimento e os fatores que contribuem para a omissão de registro.

ITese de Doutorado/

DINI, Ercilia Leal. Condições periodontais: associações com indicadores de risco e proposta de programas de prevenção/tratamento para trabalhadores de usinas de açúcar e álcool de Araraquara, SP. TTese de Doutorado/

D'ORO, Ana Carolina Darelli de Oliveira. Adolescência e gravidez: estudo de adolescentes atendidas em serviços de saúde da cidade de São Carlos. Estado de São Psulo.

/Dissertação de Mestrado/

ESPIRITO SANTO, Antonio Carlos Gomes do. Avaliação formal e informal dos serviços de saúde: um estudo de caso.

TTese de Doutorado/

GIMENO, Suely Godoy Agostinno. Análises estatísticas estratificada e multivariada: comparaçãc em estudo caso-controle.

/Dissertação de Mestrado/

KNOPLICH, José. Modelo de crenças em saúde: aplicado a funcionários públicos com dores na coluna vertebral.

Trese de Doutorado/

LOPES FILHO, José Divino. Dieta consumida por pré-escolares em centros infantis: avaliação em dois $\mathrm{Cl}$ 's da Prefeitura do Municipio de Campinas, SP - 1982.

/Dissertação de Mestrado/

LOTUFO, Paulo Andrade. As doenças cardiovaculares no Brasil: estudo de caso da tendência da mortalidade no Estado de São Paulo, 1970-89.

/Dissertação de Mestrado/

MORENO, Cláudia Roberta de Castro. Critérios cronobiológicos na adaptação ao trabalho em turnos alternantes: validação de um instrumento de medida.

/Dissertação de Mestrado/

MUCCl, José Luiz Negrão. A influência da decomposição da vegetação na qualidade da água de reservatórios.

Trese de Doutorado/

NAKAO, Neusa. A suscetibilidade à rubéola da gestantes - Bauru, 1987.

TTese de Doutorado/

NARVAI, Paulo Capel. Prática odontológica no Brasil: propostas e açōes no peri.jdo 1952-92. /Dissertação de Mestrado/

PEREIRA, Antonio Carlos. Estudo comparativo de diferentes métodos de exame, utilizados em odontologia, para o diagnóstico da cárie dentária.

/Dissertação de Mestrado/

REIS, Alberto Olavo Advíncula. O discurso da saúde pública sobre a adolescente grávida: avatares.

तTese de Doutorado/

RISSO, Wanda Maria de. Gerenciamento de resíduos de serviços de saúde: a caracterização como instrumento básico para abordagem do problema.

/Dissertação de Mestrado/

SANNAZZARO, Carlos Adalberto de Camargo. Contribuição para o estudo dos custos unitários de análises bioquimicas quantitativas realizadas pelo processo manual e pelo processo automático no laboratório de análises clínicas do Hospital Universitário da Universidade de São Paulo, em 1989.

Trese de Doutorado/ 
SANTOS JÚNIOR, Manuel Fernando Queiroz dos. Aspectos do cancro mole no Município de Sảo Paulo. TTese de Doutoradol

SILVA. Olga Maria Panhoca da. Dimensionamento do serviço odontológico da unidade de emergencia do Hospital Municipal Prof. Waldomiro de Paula.

Dissertaçāo de Mestrado/

SOUSA, Lázaro D'Assunção Batista de. A mortalidade de crianças menores de 5 anos em São Tomé e Principe, no periodo de 1981-1990.

/Dissertação de Mestrado/

SOUZA, Marcelo Pereira de. Metodologia de cobrança sobre os usos da águia e sua aplicação como instrumento de gestão.

TTese de Doutorado/

SUAREZ ARANDA, Francisco. Cisticercose suina: um estudo em áreas endèmicas no Perú.

/Dissertação de Mestrado/

TALERO MONROY, Guillermo. Avaliação de impacto na população menor de um ano de idade e do processo de trabalho de enfermeira comunitária no projeto Atenção Integral Matemo Infantil para o Desenvolvimento Comunitário - AIMIDEC - da Universidade Nacional da Colômbia.

/Dissertação de Mestrado/

TRUFELLI, Ana Maria. Acessibilidade funcional dos serviços de saúde e sua relação com a mortalidade de crianças e perdas fetais intermediärias e tardias: distrito de saúde de Campo Limpo-São Paulo.

Dissertação de Mestrado/

VALENTE. Maria Gomes. Utilização dos serviços de saúde por alunos das escolas públicas do subdistrito de Santana, municipio de São Paulo.

/Dissertaçāo de Mestrado/

WATANABE. Helena Akemi Wada. O processo de controle do câncer cérvico-uterino no sistema regionalizado e hierarquizado de saúde: projeto Cotia, 1987-1989.

/Dissertação de Mestrado/

\section{DEFENDIDAS EM 1994}

ANDRADE. Ana Lúcia Sampaio Sganbatti ce. Avaliação de possiveis fatores de risco para a infeç̧üo pelo Trypanosoma cruzi em crianças: t'studo caso-controle em área rural do Estado de Goiás.

iTese de Doutorado/

ANDRE. Lúcia Márcia. Heróis da lama: sobrecarga emocional e estratégias defensivas no trabalho de limpeza pública.

/Dissertaçäo de Mestrado/

BARBOSA, Jonyse de Paiva. Erupção dos primeiros molares permanentes e surgimento da cárie em crianças de 5 a 6 anos de idade.

/Dissertação de Mestrado/

BARCIOTTE. Maria Lúcia. Coleta seletiva e minimização de residuos sólidos urbanos: uma abordagem integradora.

TTese de Doutorado/

BELCULFINÉ. Douglas Carlyle. Contribuição ao estudo da tuberculose pleural.

/Dissertação de Mestrado/ 
BELINATI, Waldmir. Avaliação crítica do aumento da capacidade operativa dos serviços de saúde ao nivel primário: Londrina, 1986-1992.

Trese de Doutorado/

CALEFFI, Sueli. A represa de Guarapiranga: estudo da comunidade zooplanctônica e aspectos da eutrofização.

/Dissertação de Mestrado/

CASTRO, Virginia Maria Ferraz de. Visão sistêmica da embalagem de alimentos no processo da comunicação: um estudo exploratório sobre a visão empresarial e a do consumidor.

/Dissertaçāo de Mestrado/

CHIESA, Anna Maria. O uso de estratégias participativas para o conhecimento das representações sociais de mulheres da regiāo de Pirituba/Perus com resultado classe III de Papanicolau.

/Dissertação de Mestrado/

CONSOLINO, Luiz Vitório Bissoli. Assistência pré-natal: a evolução na abordagem ambulatorial da moléstia hipertensiva especifica da gravidez, em adolescentes.

/Dissertação de Mestrado/

CORDEIRO, Rogério Guimarães Frota. Conhecimentos, crenças, opiniōes e conduta em relação à AIDS de estudantes do segundo grau de escolas estaduais do municipio de São Paulo, 1993.

Trese de Doutorado/

CORRÊA FILHO, Heleno Rodrigues. Percepção de riscos na ocupação precedendo lesões do trabalho: um estudo no municipio de Campinas, São Paulo, 1992-1993.

Trese deDoutorado/

COSTA, Carmen Beatriz Taipe Lagos da. Caracterização epidemiológica da malária no Projeto de Colonizaçāo Agricola Pedro Peixoto Gomide, Estado do Acre, Brasil.

Dissertação de Mestrado/

EL-KHATIB, Umaia. As dificuldades das pessoas portadoras de deficiência física: quais são e onde estāo.

/Dissertação de Mestrado/

FEDERMANN, Miriam. Conhecimentos e práticas alimentares de individuos diabéticos não insulinodependentes.

/Dissertação de Mestrado/

FORTES, Paulo Antonio de Carvalho. A responsabilidade médica nos tribunais.

ITese de Doutorado/

FUJIMORI, Elizabeth. Gravidez na adolescência: estado nutricional referente ao ferro.

TTese de Doutorado/

GOMES, Jaime de Oliveira. Mortalidade infantil em Presidente Prudente-SP, 1990 a 1992.

/Dissertação de Mestrado/

GOMES, Keila Rejane Oliveira. Contribuição ao estudo do uso de medicamentos durante a gravidez.

Dissertação de Mestrado/

GRECO, Rosangela Maria. Cargas de trabalho dos técnicos operacionais da Escola de Enfermagem da Universidade de São Paulo.

/Dissertação de Mestrado/

JOSEPH, Nava Erlich. Transformação dos serviços da Secretaria Municipal de Saúde de São Bernardo do Campo de 1984 a 1989.

/Dissertação de Mestrado/ 
KEMP, Brigina. Aspectos spidemiológicos e diagnóstico laboratorial da doença meningocócica no municipio de Campinas/SP no período de 1988 a 1993.

/Dissertação de Mestrado/

LEI, DoriasLucia Martini. Retardo do crescimento na idade pré-escolar: fatores sócio-econômicos, associação com o estado nutricional na idade escolar e prognóstico do aproveitamento discente no municipio de Osasco (área metropolitana de São Paulo).

Trese de Doutoradol

LERNER, Barbara Regina. A alimentação e a anemia carencial em adolescentes.

Trese de Doutoradol

LIMA, Valéria Vernaschi. Mortalidade precoce e por causas evitáveis, municipios de Lins e Penápolis, Estado de São Paulo, 1979-81 e 1990-92.

/Dissertação de Mestrado/

MACIEL, Alexandrina Aparecida. Ser/estar pai: uma figura de identidade.

/Dissertação de Mestrado/

MACIEL, Sandra Mara. Saúde bucal infantil: a participação da mãe.

TTese de Doutoradol

MARQUES, Cristiano Corrêa de Azevedo. Modelos matemáticos aplicados ao estudo da epidemiolcgia das doenças transmitidas por vetores.

/Dissertação de Mestrado/

MARQUES, Gisela Rita Alvarenga Monteiro. Comportamento antropofilico de culicídeos da região do Vale do Paraíba, Estado de São Paulo, com especial referência "Aedes albopictus" (SKUSE).

/Dissertação de Mestrado/

MATHIAS, Thais Aidar de Freitas. Morbidade hospitalar no municipio de Maringá-PR, em 1992. /Dissertação de Mestrado/

MATTÉ, Glavur Rogerio. Isolamento de víbrios potencialmente patogênicos em moluscos bivalves. Trese de Doutoradol

MEDINA, Maria Célia Guerra. Condição previdenciária, saúde e incapacidade de idosos residentes no Município de São Paulo.

Trese de Doutoradol

MENDICELLI, Vera Lúcia de Sá Leitão. Homeopatia: percepção e conduta de clientela de postos de saúde: São Paulo, S.P., 1994.

Trese de Doutoradol

MESQUITA, Agnes Soares de. Residuos tóxicos industriais organoclorados em Samaritá: um problema de saúde pública.

/Dissertação de Mestrado/

NEVES, Lúcia Helena de Moura. Câncer daeboca: mortalidade entre os residentes no Estado de São Paulo no período de março de 1979 a fevereiro de 1982.

TTese de Doutorado/

OLIVEIRA, Carlos Augusto Fernandes de. Aflatoxina M1 em leite em pó distribuido pelo Programa de Alimentação Escolara no Municipio de São Paulo, SP-Brasil: utilização do ensino por enzimas imunoadsorvidas (ELISA).

Trese de Doutorado/

RICALDE PAREJA, Anamaria Elena. Contribuição para o estudo do perimetro braquial na avaliação do estado nutricional da gestante.

/Dissertação de Mestrado/ 
ROSSETINI, Stela Maria Ouvinhas. O Modelo de Crenças de Saúde (MCS) na prevencão do câncer cérvico-uterino: estudo em mulheres que frequentam serviços de saúde em São José dos Campos, SP. 1989.

Trese de Doutorado/

SALLUM, Maria Anice Mureb. Revisão de Seção Spissipes de Culex (Melanoconion) (Diptera: Culicidae).

rTese de Doutorado/

SANTOS, Naila Janilde Seabra. As mulheres e a AIDS.

/Dissertação de Mestrado/

SCHUMACHER, Lourdes Cunha de Pontes. Análise dos atendimentos realizados pelo serviço médico de uma empresa siderírgica da região Sudeste do Brasil, no periodo de abril/1986 a dezembro/1990.

/Dissertação de Mestradol

SILVA, Silvio Rocha Corrẻa da. Características dos cirurgiões-dentistas com vinculo empregatício em empresas públicas e/ou privadas no municipio de Araraquara-SP.

/Dissertação de Mestrado/

SILVEIRA, Ghisleine Trigo. O ensino em saúde no sistema estadual de ensino: do discurso legal à prática.

/Dissertação de Mestrado/

SIQUEIRA, Luiz Femando de Góes. Aspectos fenotipicos e epidemiológicos de cepas de Neisseria gonomhoeae produtora de penicilinase (NGPP) isoladas na cidade de São Paulo.

TTese de Doutorado/

SOUZA, Sônia Buongermino de. Anemia e alimentação no primeiro ano de vida.

rTese de Doutorado/

SPERANDIO, Ana Maria Girotti. Assistência à saúde ocular de crianças nos serviços de saúde pública do municipio de Campinas: 1992-1994.

/Dissertação de Mestrado/

STRUFFALDI, Maria Cristina Blanco. Reabilitação profissional: caracteristicas, conhecimentos e opiniōes de trabalhadores acidentados: São Paulo, S.P., 1994.

Trese de Doutorado/

TRIGO, Martene. Metodologia de inquérito dietético: estudo do método recordatório de 24 horas.

Trese de Doutorado/

UCHIMURA, Taqueco Teruya. Anemia e desnutrição em escolares ingressantes nas escolas estaduais de Maringá-PR.

/Dissertação de Mestrado/

VELASQUEZ MELENDEZ, Jorge Gustavo. Estado nutricional relativo à vitamina $A$ em crianças com infeç̧ōes respiratórias agudas e doenças diarréicas.

Trese de Doutorado/

WANDERLEY, Dalva Marli Valério. Perspectivas de controle da doença de Chagas no Estado de São Paulo.

Trese de Doutorado/

ZAVARIS, Cecilia. Avaliação da utilização industrial de mercúrio metálico no Estado de São Paulo e aplicação de metodologia de intervenção nas condiçōes de trabalho.

IDissertação de Mestrado/

ZIONI, Fabíola. Pesquisa participante: relato e avaliação de uma experiência.

Trese de Doutoradol 


\section{DISSERTAÇŌES DE MESTRADO DO IMS/UERJ}

\section{DEFENDIDAS EM 1990}

BARBOSA, Regina Maria. Mulher e contracepção: entre o técnico e o político. /Dissertaçäo de Mestrado/

CAMARGO JUNIOR, Kenneth Rochel de. (Ir)racionalidade médica: os paradoxos da clínica. /Dissertação de Mestrado/

GAMEIRO, Flávio Sá. Sexo doença e cuidado médico: um estudo sobre as diferenças por sexo na morbidade e utilização dos serviços de saúde nos servidores da Universidade do Estado do Rio de Janeiro.

/Dissertação de Mestrado/

GERALDES, Paulo Cesar. Co-gestão: um modelo de administração de serviços públicos de saúde. A experiência da regionalização e hierarquização da assistência psiquiátrica no município do Rio de Janeiro.

/Dissertação de Mestrado/

LOPES. Claudia de Souza. Morbidade psiquiátrica e tentativas de suicídio em usuários de drogas.

/Dissertação de Mestrado/

DEFENDIDAS EM 1991

ANDREAZZI, Marco Antonio Ratzsch de. Impactos das hidrelétricas na Amazônia para a saúde da população: uma proposta de abordagem metodológica.

/Dissertaçäo de Mestrado/

MENDONÇA, Gulnar Azevedo e Silva. Mortalidade por câncer no Estado do Rio de Janeiro: 1979/1986. /Dissertaçăo de Mestrado/

\section{DEFENDIDAS EM 1992}

ALLAM, Vera Lucia Chiara. Politica social de alimentação e nutrição e participação popular: o caso do programa de suplementação alimentar no municipio do Rio de Janeiro (1985-1987).

/Dissertação de Mestrado/

ALMEIDA, José Luiz Telles de. A qualificaçăo do atendente no processo de profssionalização da enfermagem.

/Dissertação de Mestrado/

ANDRADE, Márcia Schmidt de. Democratizaçåo no hospital psiquiátrico: um estudo da colônia Juliano Moreira nos anos oitenta.

/Dissertação de Mestrado/

ASSIS, Mônica de. Da hipertensão à vida: por uma práxis comunicativa na educação e saúde.

/Dissertação de Mestrado/

CORREAA, Marilena Cordeiro Dias Villela. Medicalização e individualismo: o caso da AIDS.

/Dissertação de Mestrado/

LEMME, Antonio Cesar. Saúde, educação e cidadania na década de 30: "o municipio do bem-estar socialn.

/Dissertaçào de Mestrado/

LIMA, Elson da Silva. Drogas na escola: quem consome o que?

/Dissertação de Mestrado/ 
NASCIMENTO, Dilene Raimundo do. Tuberculose: de questão pública a questão de estado: a Liga Brasileira contra a Tuberculose.

/Dissertação de Mestrado/

ROCHA, Ruth Mylius. Enfermagem psiquiátrica: que papel é esse?

/Dissertação de Mestrado/

TEIXEIRA, Maria Teresa Bustamante. Mortalidade por câncer no Estado do Rio de Janeiro 1979/1981: um estudo da distribuição geográfica.

/Dissertação de Mestrado/

VIEIRA, Ana Luiza Stiebler. O atendente de enfermagem no Estado do Rio de Janeiro: classificação da demanda para a profissionalização.

/Dissertação de Mestrado/

VIEIRA, Manoel Martins. Reflexōes sobre raciorıalidades médicas: dilemas de um clínico.

/Dissertação de Mestrado/

WERNECK, Guilherme Loureiro. Fatores de risco para queimaduras severas na infância.

/Dissertação de Mestrado/

\section{DEFENDIDAS EM 1993}

BRAGA, José Ueleres. Meta-análise dos fatores de risco para infecções respiratórias agudas. /Dissertação de Mestrado/

CALDAS, Célia Pereira. Memórias de velhos trabalhadores.

/Dissertação de Mestrado/

CHAVES, Regina Rodrigues. Identidade de gênero feminino frente ao poder institucional. /Dissertação de Mestrado/

ELIAS, Mauricio Vieira. Proposta de um sistema de vigilância epidemiológica em saúde ocupacional. /Dissertação de Mestrado/

FERRAZ, Regina Coeli Franco. A aritmética da saúde na Encyclopédie de Diderot e d'Alembert.. /Dissertaçäo de Mestrado/

GOMES, Maria Paula Cerqueira. A emergência psiquiátrica em Angra dos Reis: um estudo de caso. /Dissertação de Mestrado/

LEÃO, Teresa Cristina Caruso. Violência contra crianças e adolescentes: estudo do processo de vitimizaçāo.

/Dissertação de Mestrado/

REGO, Marisa Palacios da Cunha e Melo de Almeida. Trabalho hospitalar e saúde mental: o caso de um hospital geral e público no municipio do Rio de Janeiro.

/Dissertação de Mestrado/

RIBEIRO, Sonia Natal. Abandono do tratamento da tuberculose: aspectos do tratamento mal conduzido. Discussão de possiveis fatores como causa do abandono do tratamento especifico da tuberculose e a situação bacteriológica após o abandono.

/Dissertaçäo de Mestrado/ 


\section{DEFENDIDAS EM 1994}

AZEVEDO, Creusa da Silva. Gerência hospitalar ì visão dos diretores de hospitais públicos do municipio do Rio de Janeiro.

/Dissertação de Mestrado/

FARIA, Lina Rodrigues de. A fase pioneira da reforrna sanitária no Brasil: a atuação da Fundação Rockfeller (1915/1930).

/Dissertação de Mestrado/

RODRIGUES, Heliana de Barros Conde. As subjetiviaıdes em revolta: institucionalismo francês e novas análises.

/Dissertação de Mestrado/ 
ANEXO 2 - Lista Hierárquica das Categorias Principais dos Descritores em Saúde (DeCS) ${ }^{1}$

CATEGORIAS PRINCIPAIS-DECS

A

- TERMOS ANATÓMICOS

A1 - REGIÖES DO CORPO

A2 - SISTEMA MUSCULOSQUELÉTICO

A3 - SISTEMA DIGESTIVO

A4 - SISTEMA REPIRATÓRIO

A5 - SISTEMA UROGENITAI

A6 - SISTEMA ENDÓCRINO

A7 - SISTEMA CARDIOVASCULAR

A8 - SISTEMA NERVOSO

A9 - ÓRGÃOS DOS SENTIDOS

A10 - TIPOS DE TECIDOS

A11 - CÉLULAS

A12 - LIQQUIDOS E SECREÇÕES

A13 - TERMOS ANATÓMICOS ANIMAIS

A14 - SISTEMA ESTOMATOGNÁTICO

A15 - SISTEMAS SANGUINNEO E IMUNE

A16 - ESTRUTURAS EMBRIONÁRIAS

B - ORGANISMOS
B1 - INVERTEBRADOS
B2 - VERTEBRADOS
B3 - BACTÉRIAS
B4 - VÍRUS
B5 - ALGASE FUNGOS
B6 - PLANTAS

C - DOENÇAS
C1 DOENÇAS BACTERIANAS E FÚNGICAS
C2 - VIROSES
C3 - DOENÇAS PARASITÁRIAS
C4 - NEOPLASIAS
C5 - DOENÇAS MUSCOLOSQUELÉTICAS
C6 - DOENÇAS DO SISTEMA DIGESTIVO
C7 - DOENÇAS DA BOCA E DENTES
C8 - DOENÇAS RESPIRATÓRIAS
C9 - OTORRINOLARINGOPATIAS
C10 - DOENÇAS DO SISTEMA NERVOSO
C11 - OFTALMOPATIAS
C12 - DOENÇAS UROLÓGICAS E DOS GENITAIS MASCULINOS
C13 - DOENÇAS DOS GENITAIS FEMININOS E COMPLICAÇÕES NA GRAVIDEZ
C14 - DOENÇAS CARDIOVASCULARES
C15 - DOENÇAS SANGUINEAS E LINFÁTICAS
C16 - DOENÇAS NEONATAIS E ANORMALIDADES
C17 - DERMATOPATIAS
C18 - DOENÇAS NUTRICIONAIS E METABÓLICAS
C19 - ENDOCRINOPATIAS
C20 - DOENÇAS IMUNOLÓGICAS
C21 - TRAUMATISMOS, DOENÇAS OCUPACIONAIS E INTOXICAÇĀO
C22 - DOENÇAS DOS ANIMAIS
C23 - PATOLOGIA GERAL E SINTOMAS

\footnotetext{
'Extraida de: BIREME. Descritores cm Cièncias da Saúde (DeCS): Lista hicrárquica. 2a.ed.rev. São Paulo. 1992.
} 
D - COMPOSTOS QUIMICOS E DROGAS

$\begin{array}{ll}\text { D1 } & \text { - COMPOSTOS INORGÂNICOS } \\ \text { D2 } & \text { - COMPOSTOS ORGÂNICOS } \\ \text { D3 } & \text { - COMPOSTOS HETEROCICLICOS } \\ \text { D4 } & \text { - HIDROCARBONETOS POLICICLICOS } \\ \text { D5 } & \text { - POLUENTES AMBIENTAIS, PESTICIDAS } \\ \text { D6 } & \text { - HORMONIOS, SUBSTITUTOS, ANTAGONISTAS } \\ \text { D7 } & \text { - AGENTES PARA CONTROLE DE REPRODUÇÃO } \\ \text { D8 } & \text { - ENZIMAS, COENZIMAS, INIBIDORES DE ENZIMAS } \\ \text { D9 } & \text { - CARBOHIDRATOS E AGENTES HIPOGLICEMICCS } \\ \text { D10 } & \text { - LIPIDIOS E AGENTES ANTILIPEMICOS } \\ \text { D11 } & \text { - SUBSTANCIAS DE CRESCIMENTO, PIGMENTOS, VITAMINAS } \\ \text { D12 } & \text { - AMINOÁCIDOS, PEPTIDIOS E PROTEINAS } \\ \text { D13 } & \text { - NUCLEOSIDIOSE NUCLEOTIDIOS } \\ \text { D14 } & \text { - DEPRESSORES DO SISTEMA NERVOSO CENTRAL } \\ \text { D15 } & \text { - AGENTES DE AÇÄO NO SISTEMA NERVOSO CENTRAL } \\ \text { D16 } & \text { - AGENTES DE AÇÃO NO SISTEMA NERVOSO AUTONOMO } \\ \text { D17 } & \text { - AGENTES NEUROMUSCULARES } \\ \text { D18 } & \text { - AGENTES DO SISTEMA CARDIOVASCULAR } \\ \text { D19 } & \text { - AGENTES HEMATOLOGICOS, GÁSTRICOSE RENAIS } \\ \text { D20 } & \text { - ANTIINFECCIOSOS } \\ \text { D21 } & \text { - ANTIPARASITARIOS } \\ \text { D22 } & \text { - ANTINEOPLASSICOS, IMUNOSSUPRESSORES } \\ \text { D23 } & \text { - BLOQUEADORES NEURORREGULARES } \\ \text { D24 } & \text { - FATORES IMUNOLÓGICOS E BIOLÓGICOS } \\ \text { D25 } & \text { - MATERIAIS BIOMÉDICO E ODONTOLOGICO } \\ \text { D26 } & \text { - DROGAS E AGENTES VARIADOS }\end{array}$

- TÉCNICAS

E1 - DIAGNÓSTICO

E2 - TERAPEUUTICA

E3 - ANESTESIA E ANALGESIA

E4 - TECNICAS OPERATÓRIAS

E5 - TÉCNICAS VARIADAS

E6 - ODONTOLOGIA

E7 - EQUIPAMENTOS E PROVISÕES

\section{- PSICOLOGIA E PSIQUIATRIA}

F1 - COMPORTAMENTO E MECANISMOS COMPORTAMENTAIS

F2 - PROCESSOS E PRINCIPIOS PSICOLÓGICOS

F3 - DISTÚRBIOS MENTAIS E COMPORTAMENTAIS

F4 - DISCIPLINAS, TESTES, TERAPIA, SERVIÇOS

G - CIĖNCIAS BIOLÓGICAS

G1 - CIENCIAS BIOLÓGICAS

G2 - OCUPACŌES EM SAUUDE

G3 - AMBIENTE E SAÚDE PÚBLICA

G4 FENÔMENOS BIOLÓGICOS, FISIOLOGIA CELULAR, IMUNIDADE

G5 - GENÉTICA

G6 - FENÔMENOS BIOQUIMIICOS, METABOLISMO E NUTRIÇÃO

G7 - FISIOLOGIA GERAL

G8 - REPRODUÇĀO, FISIOLOGIA UROGENITAL

G9 - FISIOLOGIA RESPIRATÓRIA E CIRCULATÓRIA

G10 - FISIOLOGIA DIGESTIVA, ORAL E DE PELE

G11 - FISIOLOGIA MUSCULOESQUELĖTICA, NEURAL E O OLHO

G12 - FENÔMENOS QUIMICOS E FARMACOLÓGICOS

H - CIÊNCIAS FISICAS

H1 - CIEENCIAS FISICAS 
HP - HOMEOPATIA

HP1 - HOMEOPATIA EM GERAL

HP2 - CLÍNICA HOMEOPÁTICA

HP3 - TERAPEUUTICA HOMEOPÁTICA

HP4 - MATÉRIA MÉDICA

HP5 - REPERTÓRIO

HP6 - SEMIOLOGIA HOMEOPÁTICA

HP7 - FARMÁCIA HOMEOPÁTICA

I - ANTROPOLOGIA, EDUCAÇÃO, SOCIOLOGIA E FENÔMENOS SOCIAIS

I1 - CIÉNCIAS SOCIAIS

12 - EDUCAÇĀO

13 - ATIVIDADES HUMANAS

J - TECNOLOGIA, INDÚSTRIA, AGRICULTURA E ALIMENTOS

J1 - TECNOLOGIA, INDÚSTRIA, AGRICULTURA

K - HUMANIDADES

K1 - HUMANIDADES

L - CIÊNCIAS DA INFORMAÇÃO

L1 - CIENNCIA DA INFORMAÇÃO

M - DENOMINAÇÃO DE GRUPOS

M1 - DENOMINAÇĀO DE GRUPOS

SP - SAÜDE PÜBLICA

SP1 - ADMINISTRAÇÃO E PLANEJAMENTO EM SAÚDE

SP2 - CUIDADOS DE SAÚDE

SP3 - DEMOGRAFIA

SP4 - SAÚDE AMBIENTAL

SP5 - EPIDEMIOLOGIA E BIOESTATISTICA

SP6 - NUTRIÇÃO

Z -GEOGRÁFICOS

Z1 - GEOGRÁFICOS 
ANEXO 3 - Modelo de planilhas para o registro dos dados das dissertaçōes de Mestrado e teses de Doutorado analisadas

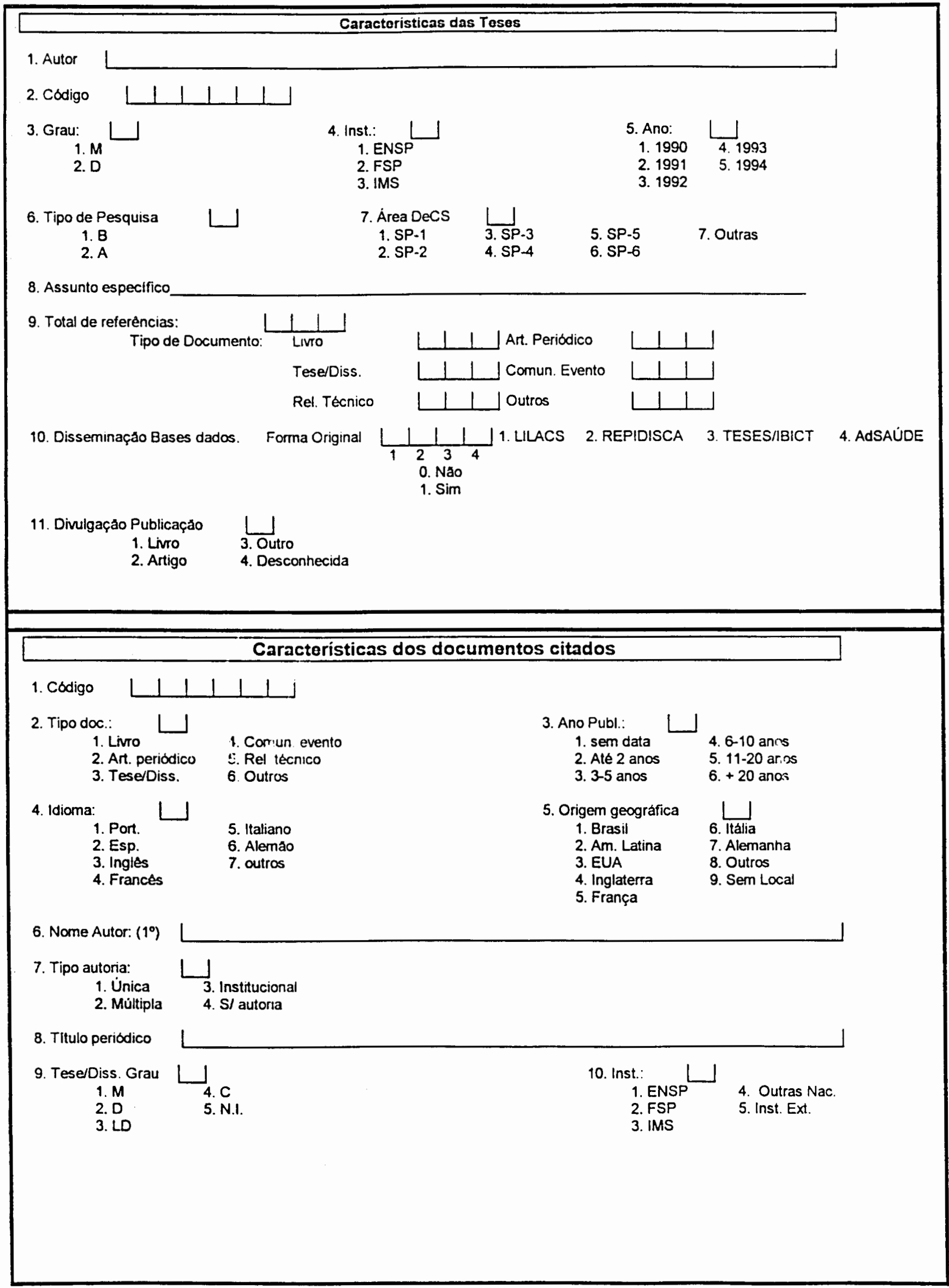


QUADRo - Evolução Tenporal dos Assuntos das Dissertações de Mestrado e Teses de Doutorado (1990-1994)

\begin{tabular}{|c|c|c|c|c|c|}
\hline AsSUNTOS & 1990 & 1991 & 1992 & 1993 & 1934 \\
\hline ABASTECIMENTO DE ÁGUA & & & & & \\
\hline ABORTO INDUZIDO & & & - & & \\
\hline ÁCIDOS CARBOXILICOS /ÁCIDO ASCORBICO/ & & & & & \\
\hline ADMINISTRAÇÃO CUIDADOS DO PACIENTE / VACINAÇÃO/ & & & & & \\
\hline ALMINISTRAÇĀO EARMACEUUTICA /USO MEDICAMENTO/ & & & & & \\
\hline ADMINISTRAÇÃO EINANCEIPA DE HOSEITAIS & & & & & \\
\hline ADMINISTRAÇÃO DE SERVIÇOS DE SAÚDE & & 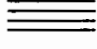 & & & \\
\hline AL IMENTOS & & & & & \\
\hline ANÁLISE ESTATISTICA & & & & & \\
\hline ARTRÓPODES /DfPTEROS/ & & & & & \\
\hline BACTERIAS & & & & & $=$ \\
\hline BEM-ESTAR DA CRIANÇA-FPOBLEMAS SOC. & & & & & \\
\hline CIÊNCIAS SOCIAIS & & & & & \\
\hline CONDIÇDES CE TRABALHO & & & & & \\
\hline CUIDADOS DE ENFERMAGEM & & & & & \\
\hline CUIDADOS DE SAÚDE & & & & & \\
\hline $\begin{array}{l}\text { DIAGNOSTICO SITUAÇAO DE SAUDE (Criança, Garimpo, } \\
\text { Mineraçăo, Trabalhadores) }\end{array}$ & & & & & \\
\hline DIETA E DIETÉTICA & & & & & \\
\hline DIREITOS HUMANOS /SAUDE/ & & & & & \\
\hline UISTÚRBIOS MENTAIS E COMPORTAMENTAIS & & & & & \\
\hline DISTÚRBIOS NUTRICIONAIS & & & & & \\
\hline DOENÇAS DE ANIMAIS & & & & & \\
\hline LOENÇAS BACTERIANAS E FUNGICAS & & & & & \\
\hline EOENÇAS DA BOCA E DENTES & & & & & \\
\hline DOENÇAS CARDIOVASCULARES & & & & & \\
\hline DOENÇAS METABÓLICAS & & & & & \\
\hline DOENÇAS NEONATAIS E ANORMALIDADES & & & & & 2 \\
\hline DOENÇAS PARASITÁRIAS & & & & & \\
\hline DOENÇAS SANGUINEAS E LINFÁTICAS & & & & & $=$ \\
\hline EDUCAÇAO NAO PROEISSIONAL /SEXUAL, & & & & & \\
\hline EDUCAÇĀO PROEISSIONAL /MÉOICA/ & & & & & \\
\hline ESTADO NUTRICIONAL & & & & & \\
\hline ESTERILIZAÇAO SEXUAL /TUBÁRIA/ & & & & & \\
\hline FOME & & & & & Conti \\
\hline
\end{tabular}




\section{ASSUNTOS (COnt...) \\ FORCAS DE TPABALHO}

HISTÓRIA DA MEDICINA

LIPÍDIOS /COLESTEROL/

MEDICAMENTOS

MEDICINA OCUPACIONAL

MEIO AMBIENTE

MÉTODOS EEIDEMIOLÓGICOS

MÉTODOS E RROCEDTMENTOS ESTATASTICOS

MORBIDADE /HOSPITAIS/

MORTAIIDADE GERAL

MORTALIDADE INEANTIL

NEOPLASTAS (Epidemiologia)

OCUPAÇOEES EM SAÚDE

OETALMOPATIAS

PIANEJAMENTO FAMILIAR

PLANETAMENTO EM SAUDE

POLUENTES AMBIENTAIS, PESTICIDAS

POLUIÇÃO AMBIENTAL

POLfTICAS DE SAÚdE

PRÁTICA PROEISSIONAL (ÉTICA)

PROGRAMAS POLITICAS DE NUTRIÇÃO E ALIMENTAÇÃO

PSICOLOGIA (NEOPLASIAS, SOROPOSITIVIDADE, HIV) PSIQUTATRIA TTendèncias:

RECURSOS HUMANOS EY SAÚDE

RECURSOS EM SAUUDE. INSTITUIÇŌES

REFORMA SANITARIA

RELACÕES FAMILIARES /COMPORTAMENTO PATERNO/

RELAÇŌES TRABALHISTAS /SINDICATOS/

REPRODUÇÃO /GRAVIDEZ ADOLESCENNCIA/

SANEAMENTO

SAUUDE OCUPACIONAL

SAÚDE PÚBLICA

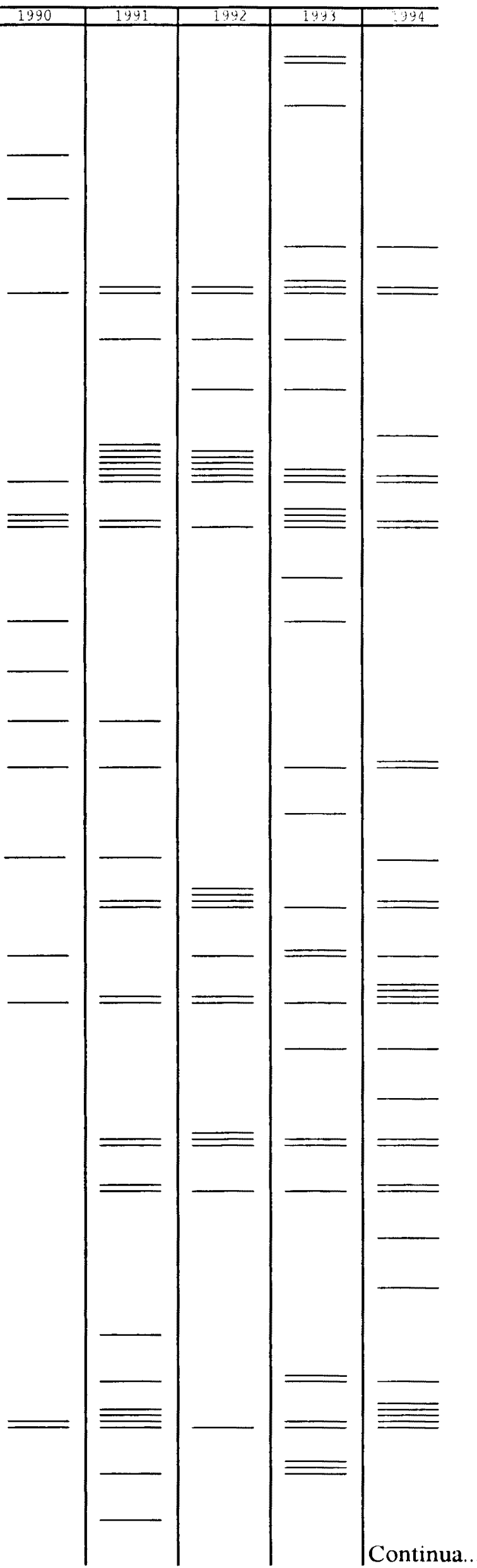




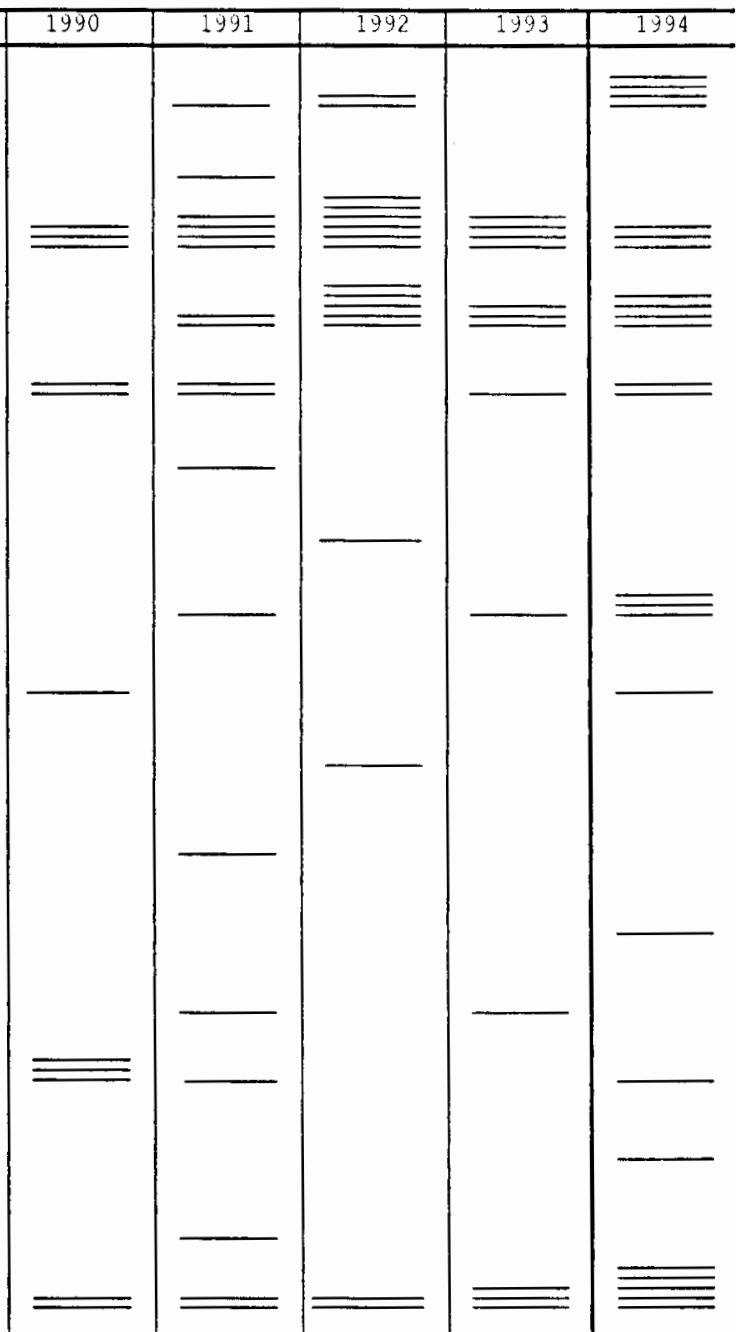


ANEXO 5

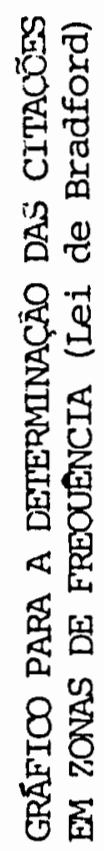

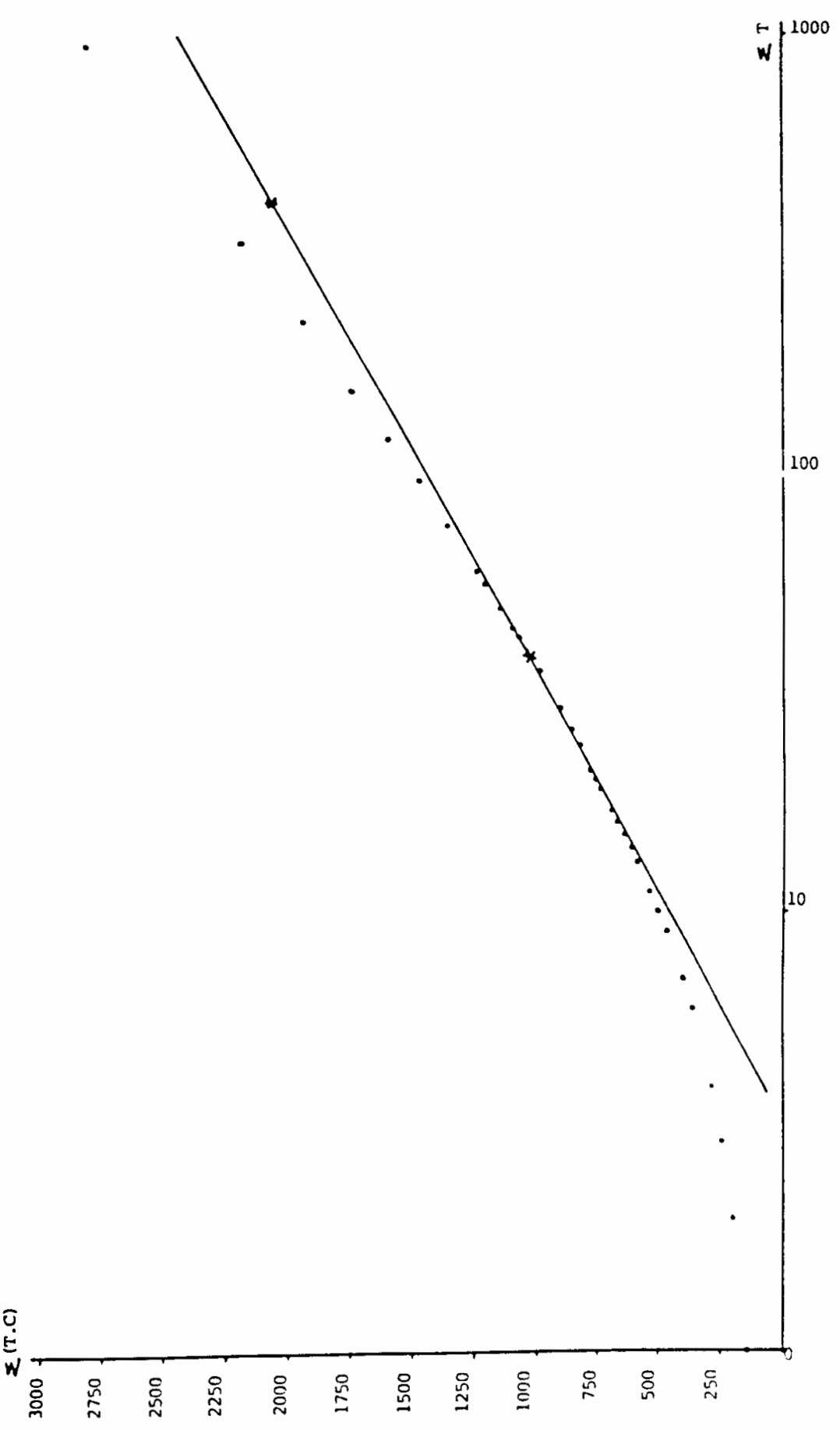




\section{ANEXO 6}

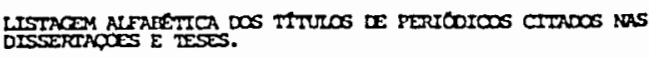

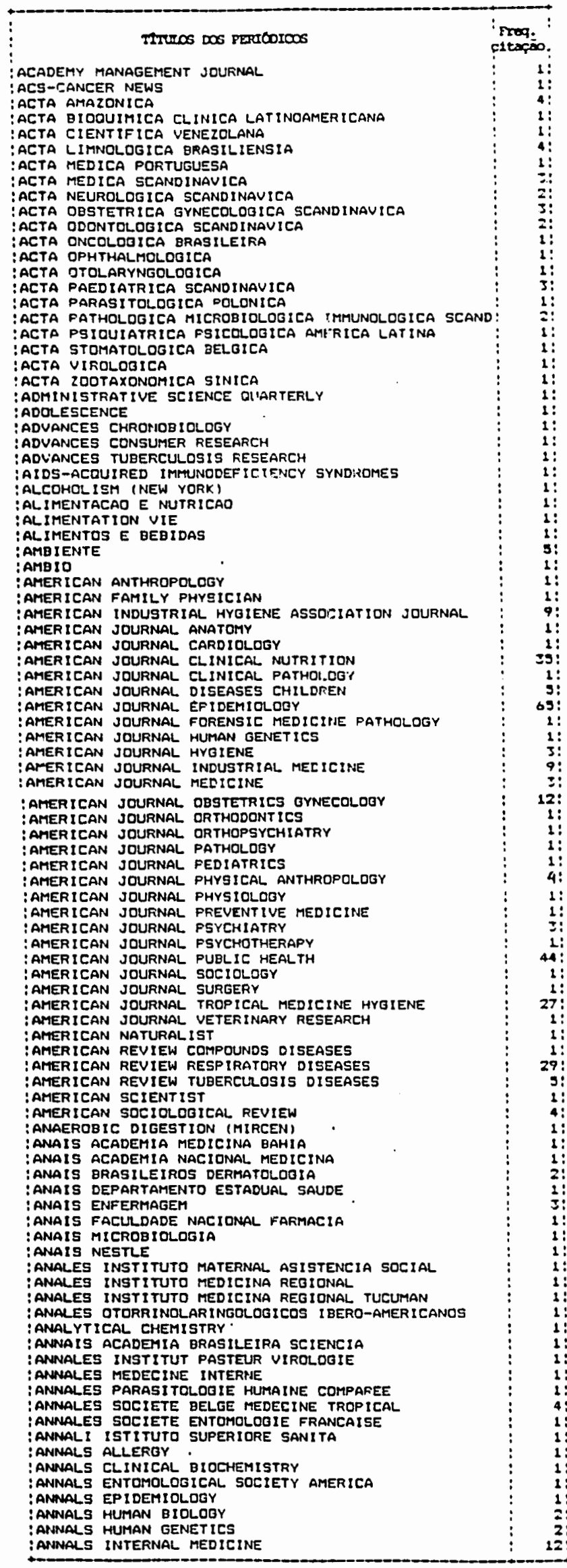


Listagem Alfabética dos Títulos de Periódicos Citados nas Dissertacões de Mestrado e Teses de Doutorado (continuação)

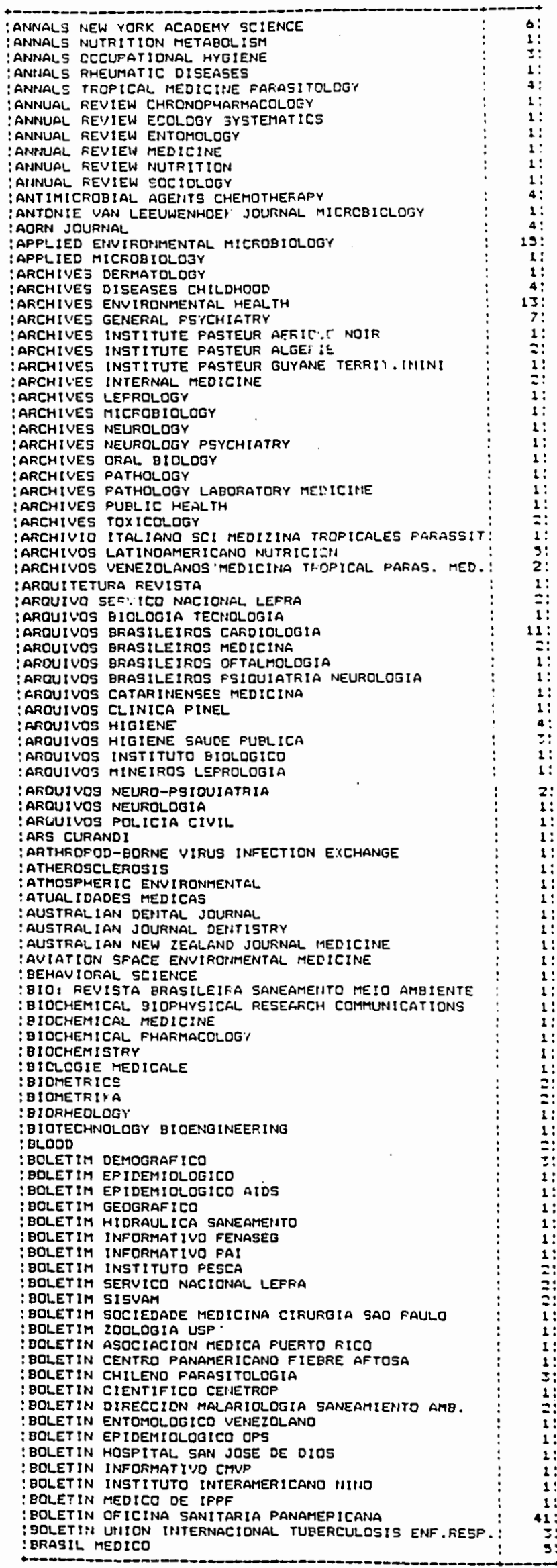


Listagem Alfabētica dos Títulos de Periödicos Citados nas Dissertações de Mestrado e Teses de Doutorado (continuação)

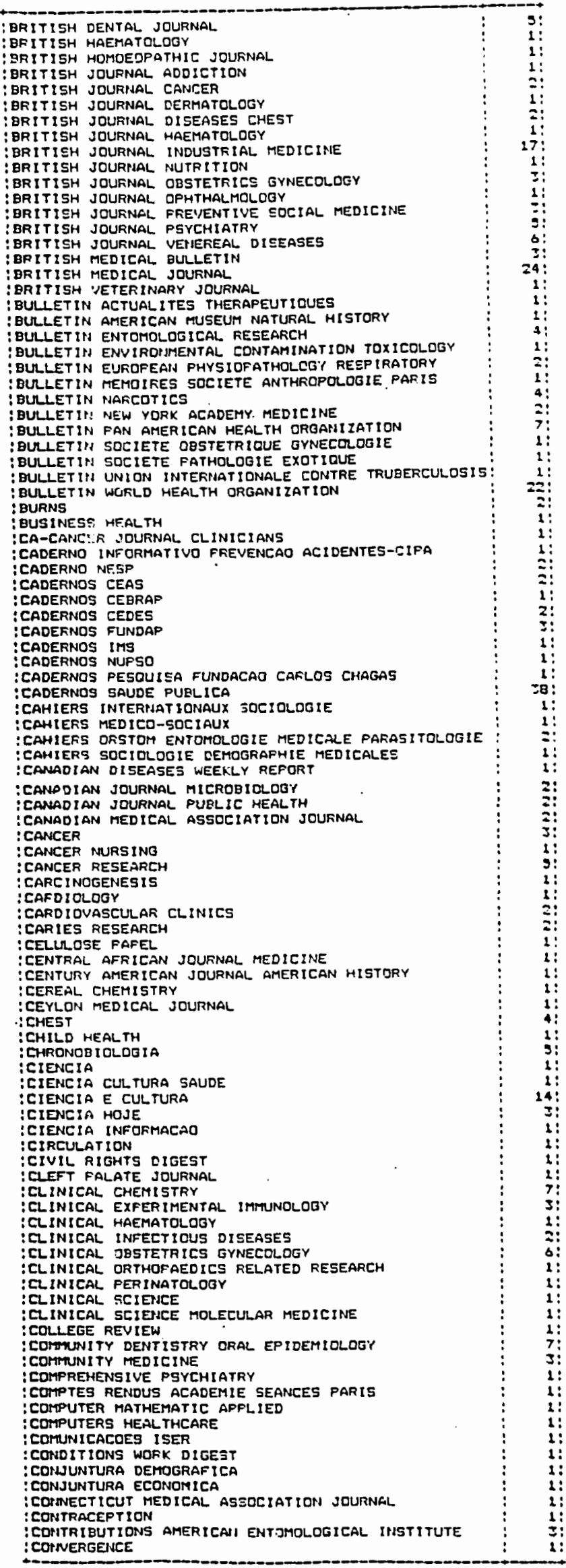


Listagem Alfabética dos Títulos de Periōdicos Citados nas
Dissertações de Mestrado e Teses de Doutorado (continuaçăo)

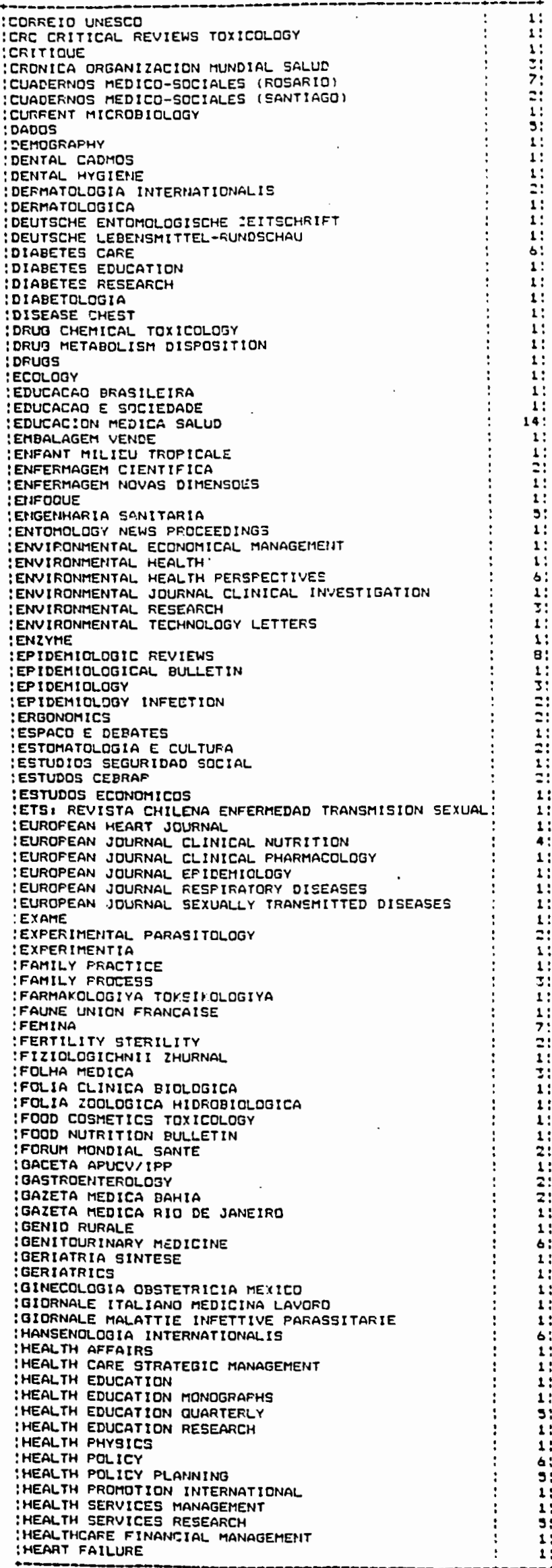


Listagem Alfabética dos Títulos de Periōdicos Citados nas Dissertarōes de Mestrado e Teses de Doutorado (continuação)

\begin{tabular}{|c|c|c|}
\hline 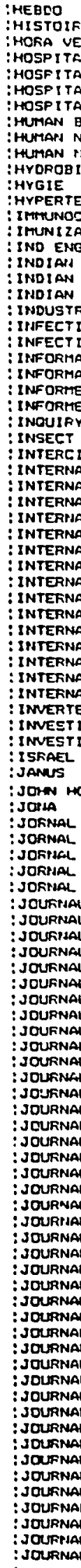 & 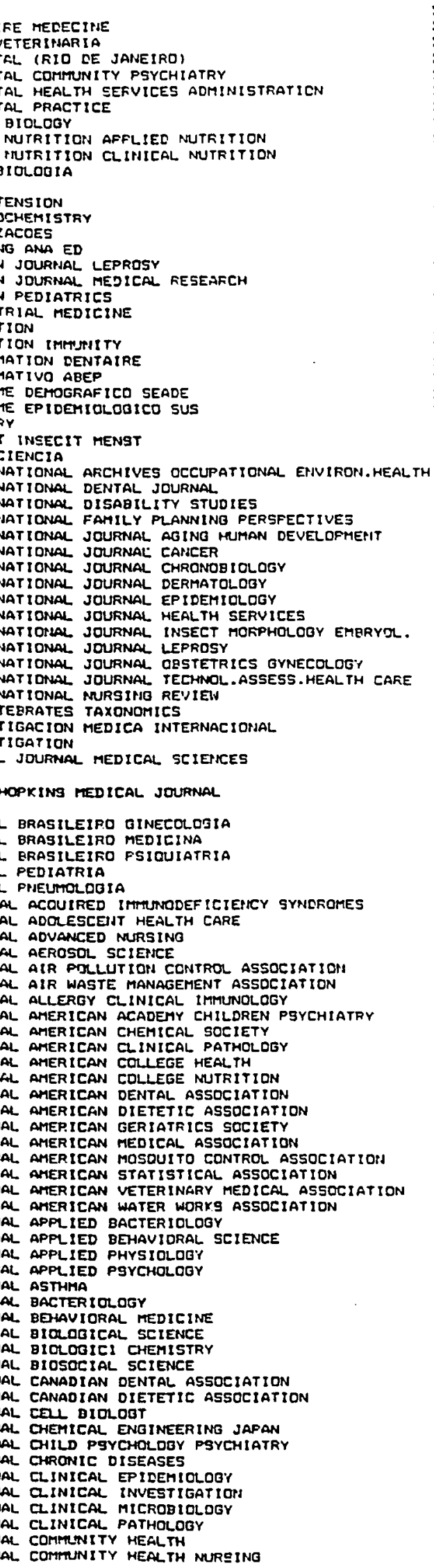 & 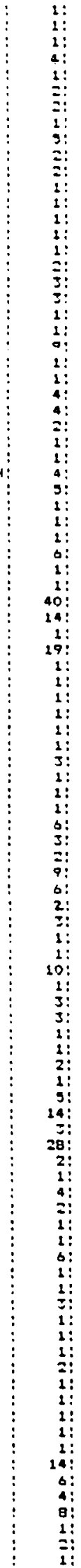 \\
\hline
\end{tabular}


Listagem Alfabética dos Títulos de Periödicos Citados nas Dissertaçōes de Mestrado e Teses de Doutorado (continuação)

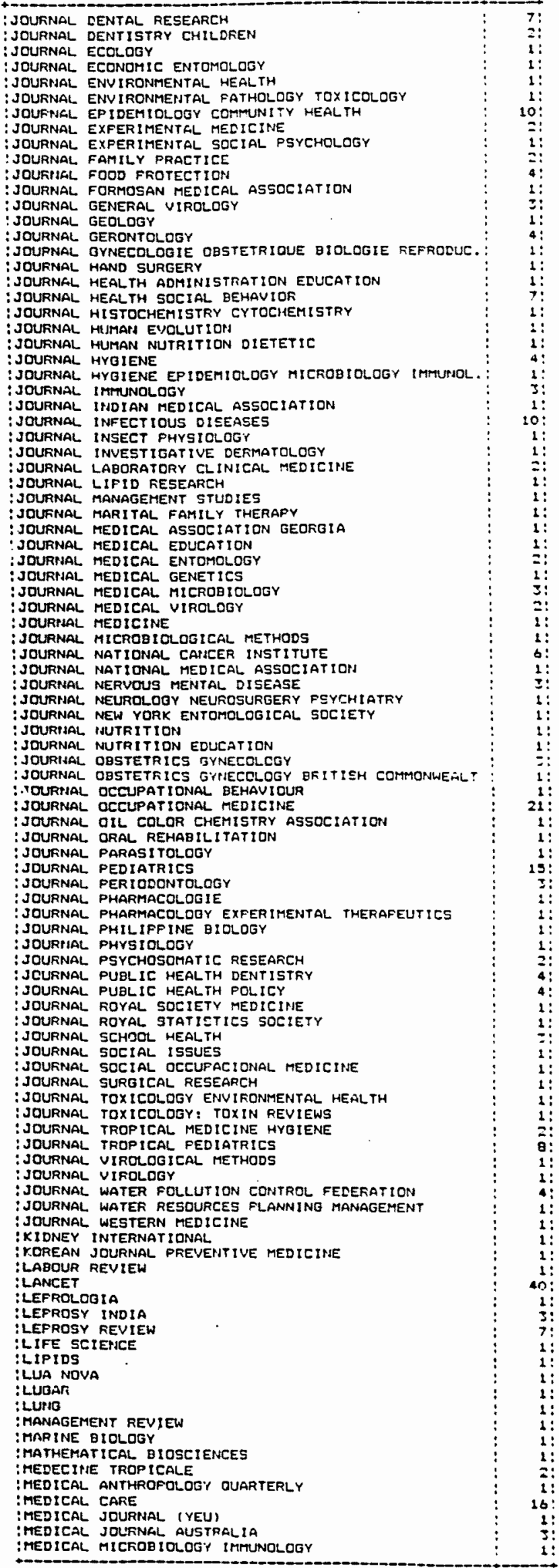


Listagē Alfabética dos Títulos de Periódicos Citados nas
Dissertações de Mestrado e Teses de Doutorado (continuação)

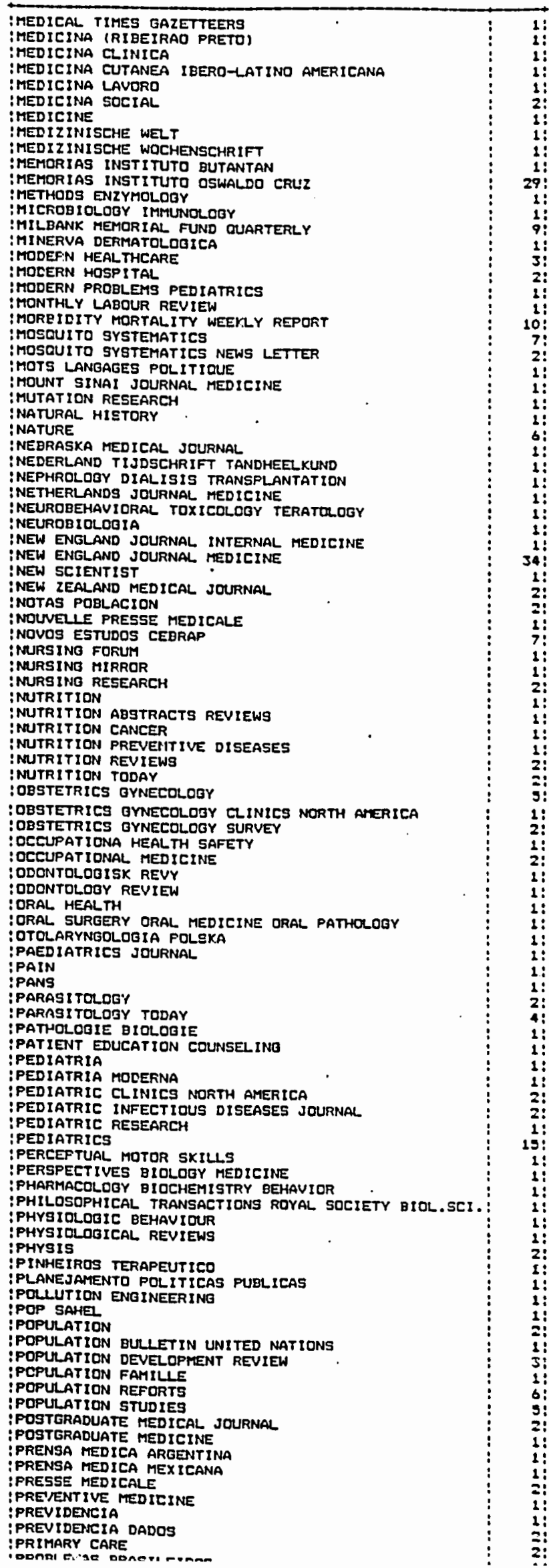


Listagem Allfabētica dos Títulos de Periödicos Citados nas
Dissertações de Mestrado e Teses de Doutorado (continuação)

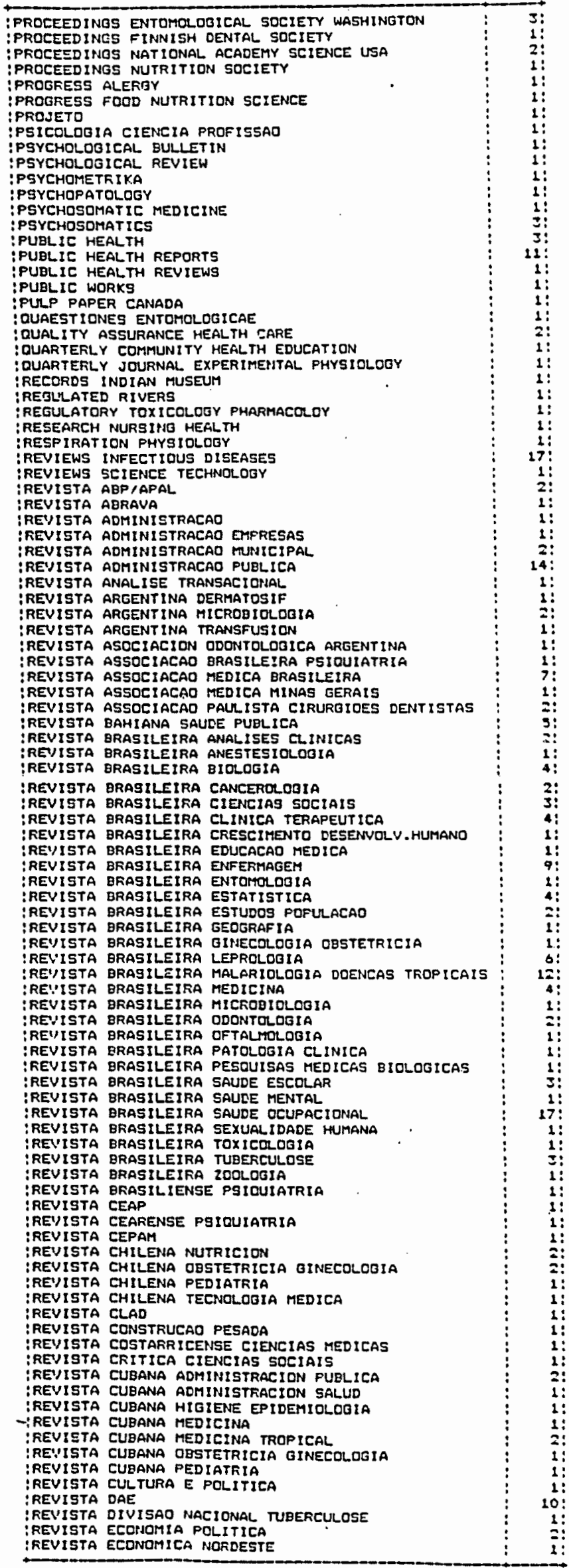


Listagem Alfabética dos Títulos de Periódicos Citados nas Dissertações de Mestrado e Teses de Doutorado (continuação)

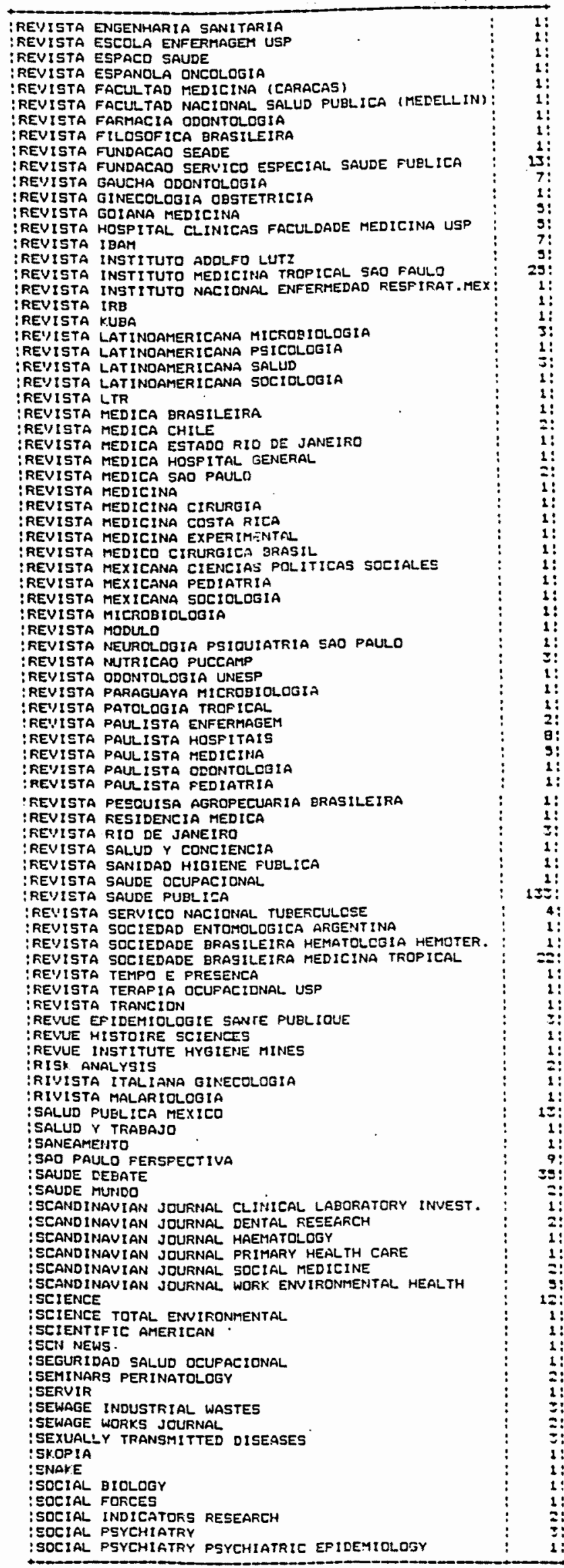


Iistagen Alfabética dos Titulos de Periódicos Citados nas Dissertações de Mestrado e Teses de Doutorado (continuação)

\begin{tabular}{|c|c|}
\hline 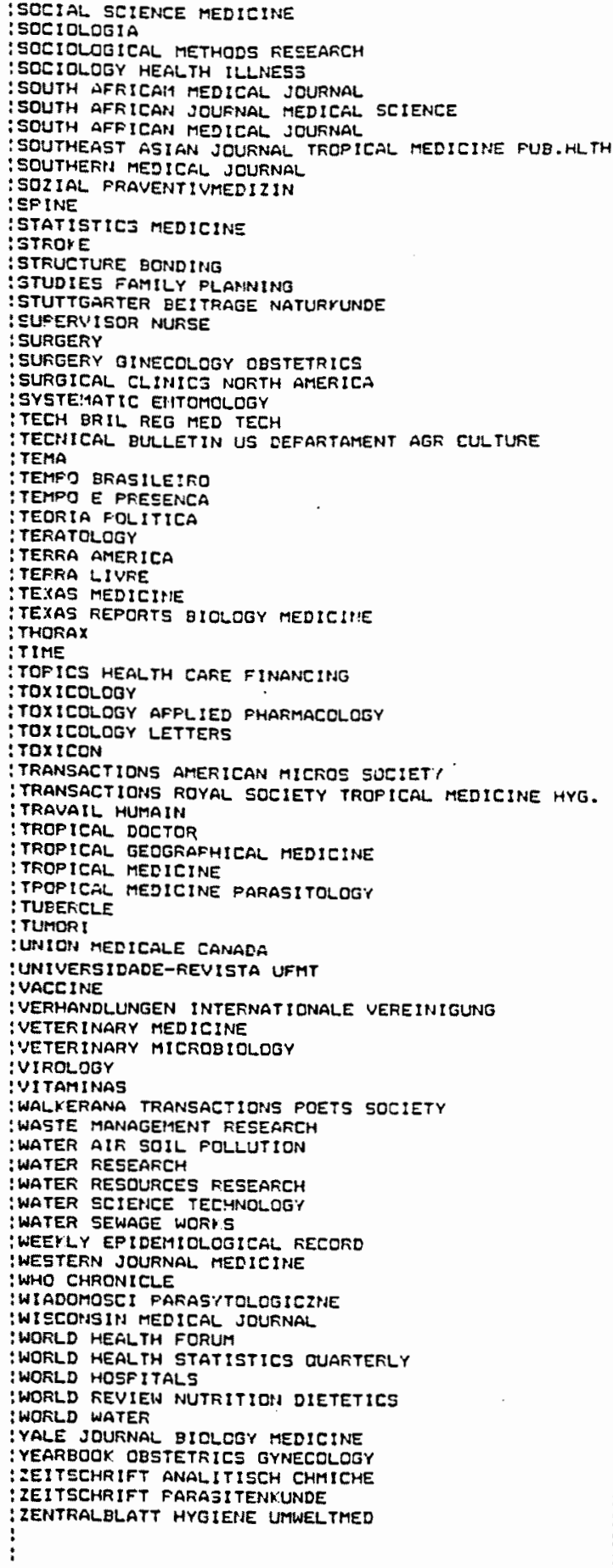 & 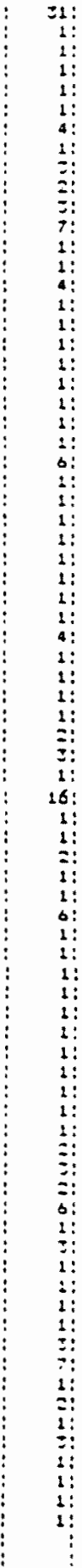 \\
\hline
\end{tabular}

